\title{
Respiratory Tract and Mediastinum
}

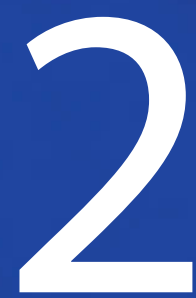

Respiratory Tract, FNAB and Exfoliative Cytology: Introduction, Normal and Abnormal Cells, Non-cellular Components, Respiratory Infections ......... 107

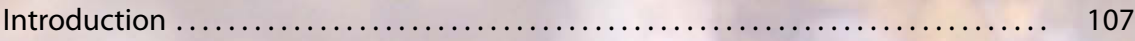
Cell Lining of the Respiratory System and Cell Function................. 109 Normal Cytology and Benign Cellular Components...................... 110 Abnormal and Atypical Epithelial Cells ............................ 112 Endogenous and Exogenous Noncellular Elements and Nonhuman Cellular Components......................................... 115 Infectious Diseases ............................................ 116 Further Reading.

2.2 Respiratory Tract, FNAB and Exfoliative Cytology: Tumor-like Lesions,

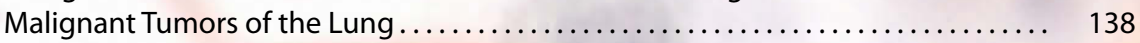

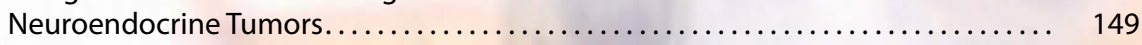

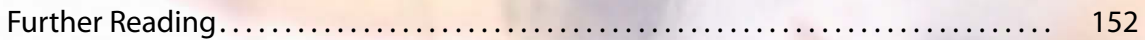

Respiratory Tract: Bronchoalveolar Lavage .................... 176

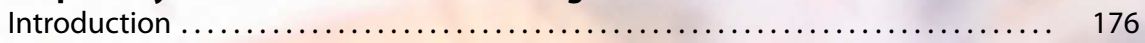

Laboratory Procedures, Technical Aspects, Reporting.................. 176

Normal Cytology in BAL Specimens ................................ 178

Diagnostic Findings in BAL Specimens . . . . . . . . . . . . . . . . . . . . . 178

Infectious Diseases .......................................... 187

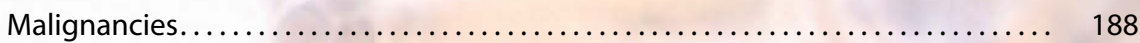

Other Pulmonary Disorders with Particular BAL Cytology .................. 189

Bronchoalveolar Lavage in Lung Transplant Recipients .................. 190

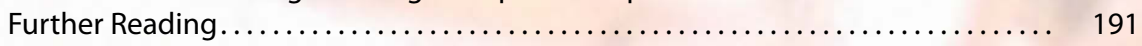


2.4 Mediastinum: Introduction, Non-tumorous and Neoplastic Disorders,

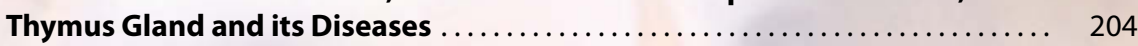

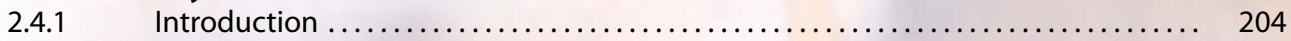

2.4.2 Cytology of Nontumorous Mediastinal Disorders ..................... 206

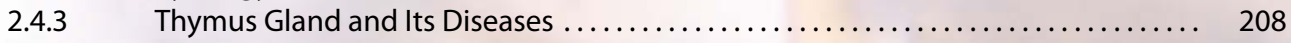

2.4.4 Neurogenic Tumors and Mesenchymal Tumors....................... 216

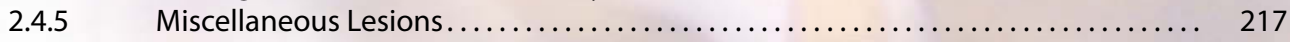

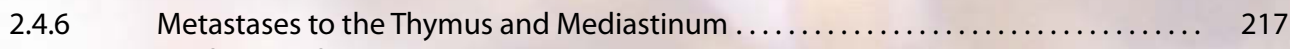

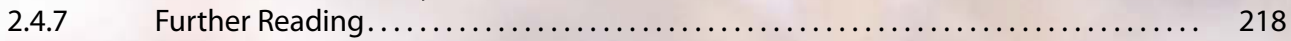

\section{Synopsis and Algorithms}

2.1 Respiratory Tract, FNAB and Exfoliative Cytology: Normal and Abnormal

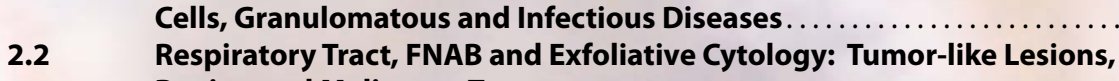

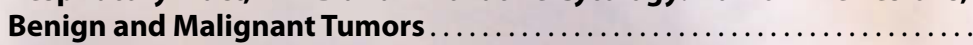

2.4 Mediastinum: Non-tumorous Lesions, Thymus Gland and its Diseases,

Lymphoid Disorders 


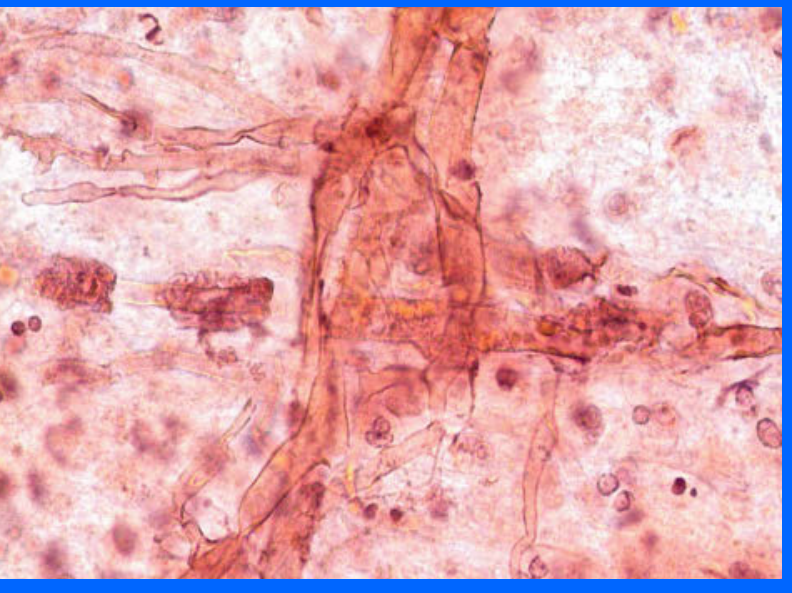

\title{
Section 2.1 \\ Respiratory Tract: \\ FNAB and Exfoliative Cytology
}

\author{
Introduction
}

Normal and Abnormal Cells

Noncellular Components

Respiratory Infections

\subsubsection{Introduction}

\section{General Comments}

- During the past few decades, the investigation of cytologic samples from the lower respiratory tract has been established in major hospitals, pulmonary clinics, and together with chest physicians' offices throughout the world.

- It has become a common tool in diagnostic evaluation of any patient with suspected lung cancer, particular infectious diseases, and interstitial lung disorders. Furthermore, in recent years fine-needle aspiration biopsy (FNAB) has greatly enhanced the impact of cytology on primary lung cancer diagnosis and tumor staging.

- This section covers:

(1) The important technical aspects of pulmonary cytology.

(2) The cytology of exfoliative bronchial and alveolar samples.

(3) Transthoracic, transbronchial, transesophageal FNAB for diagnosing primary and metastatic lung tumors, and mediastinal lesions.

(4) Cytologically relevant primary mediastinal pathologic conditions.

- Numerous reviews, monographs, and textbooks are available covering all aspects pertaining to pulmonary cytology.

\subsubsection{Cytopreparatory Methods}

\subsection{Paraffin Embedding}

Paraffin embedding of sputum [110] for histologic work-up was abandoned many years ago. However, the method known as the cell-block technique is still in use for cell material sampled by FNAB and, sporadically, for tissue fragments or clots from exfoliative specimens as well.

\subsection{Cell-Freeing Techniques}

Techniques for cell freeing and tumor cell concentrating by mucolysis are valuable methods, but they appear to be too laborious and time-consuming in daily practice $[11,53]$.

\subsection{Major Techniques}

The major techniques include: the wet-film preparation, the pick-and-smear technique from fresh or prefixed respiratory exfoliative material, the Saccomanno blender technique, and the membrane filtration techniques [14, 23, 94]. These four methods may be used for spontaneously produced or induced sputum, bronchial washings and brushings, bronchoalveolar lavage, and fine-needle aspirates.

Pick-and-smear from fresh unfixed respiratory material. This technique generally yields sufficient diagnostic material along with excellent preservation and staining of the cells. The method is highly appreciated at our institution. Fresh early-morning deep-cough specimen of sputum is collected and submitted in a wide-mouthed jar. In the laboratory the specimen is poured into a Petri dish and dispersed for inspection. The mass is examined for grey-white smooth strings of mucus and blood-tinged areas that have been found to most 
likely harbor tumor cells. Samples are picked from the selected areas and gently crush-smeared between two glass slides. The smears are immediately placed in $95 \%$ ethyl alcohol or Delauney's solution for 15-30 min.

\section{Caution}

The selection of blood-tinged and/or gray-white mucus strings is critical in correct processing of fresh deepcough sputum specimens

Pick-and-smear from prefixed respiratory material. Prefixed sputum may be obtained in situations where it is not possible to transmit fresh, unfixed material to the laboratory. The patient expectorates into a jar partially filled with $70 \%$ ethyl alcohol. The disadvantage of this procedure is insufficient preservation and poor staining quality of the cells trapped in masses of mucus that is penetrated by the fixative and dye with difficulty.

Saccomanno blender technique. This technique for homogenization and cell concentration is used for sputum specimens collected in Saccomanno fixative [81]. While in Europe the technique is less accepted, it has gained wide popularity particularly in the United States and on other continents. The method produces artifacts on tumor cells that may impair diagnostic accuracy compared to slide preparations from unfixed sputum samples [73].

\subsection{Special Techniques}

The bronchial brush direct smear preparation. The mucusrich material adherent to a brush is smeared by rolling the brush over one or more glass slides followed by immediate fixation. This method should only be used by skilled bronchoscopists or an attendant cytotechnologist.

Cytocentrifugation is particularly applied to process lavage fluids.

Liquid-based cytology is increasingly used for the processing of FNAB material [103]. The advantages and interpretative cautions concerning the liquid-based preparation are reported in the literature [75] and in various chapters of this work (e.g., Sect. 10.1.2.2, p. 634).

\subsection{Staining}

The Papanicolaou (Pap) method is the most widely accepted staining method for cytologic preparations of respiratory specimens.

\subsubsection{Sampling Modalities}

The accuracy of the different modalities as to cancer diagnosis has recently been summarized from published data by Schreiber and McCrory [84].

Sputum has been the most frequently examined sample from the respiratory tract for many decades. Since the intro- duction of fiberoptic bronchoscopy and the wide use of FNAB, sputum cytology has diminished [58]. Pulmonologists and institutions specialized in lung diseases prefer primary investigation using invasive and more directed methods based upon imaging results and supported by auxiliary device.

\subsection{Sputum: Spontaneous and Induced, and Postbronchoscopy Sputum}

Sputum specimens are prepared as described. In patients who cannot produce sputum by deep coughing, a sputum sample may be induced by inhalation of an aerosolized solution $[72,80]$. The vapor stimulates mucus production and may enhance the coughing stimulus. Another useful physical technique for provoked expectoration is the external percussion and vibration of the chest wall [96]. Postbronchoscopy sputum is an approach used to increase diagnostic accuracy. However, from our experience, a high percentage of postbronchoscopy samples are extremely sanguineous and difficult to evaluate.

\section{Caution}

Deep-cough specimens and their immediate transfer to the cytology laboratory after collecting are of utmost importance for reliable diagnostic results.

\subsection{Bronchial Aspirates, Washings, and Brushing}

The development of the flexible fiberoptic bronchoscope has enabled the operator to reach much smaller bronchi compared to those formerly attained by the rigid bronchoscope.

Specimens are obtained from the periphery of the bronchial tree by:

- Aspiration of localized secretions.

- Instilling a few milliliters of a saline solution through the bronchoscope and re-aspiration of the fluid together with the exfoliated cells.

- Brushing a conspicuous lesion with a brush inserted through the endoscope.

Laboratory procedures and technical aspects concerning bronchoalveolar lavage (BAL) are discussed in Sect. 2.3.2, p. 176.

Aspirates and washings, and brush samples rinsed in an appropriate solution (balanced salt solution or cell medium) are to be centrifuged. Subsequently, smears are prepared from the cell button. The different preparation techniques including bronchial brush direct smear preparation have been described above.

Presence of blood in aspirates and brushings is frequent and found most particularly in patients with primary lung cancer involving the bronchial system. Vigorous brushing may provide large tissue fragments from the bronchial wall composed of connective tissue and smooth muscle bundles (Fig. 2.1). 


\section{Caution}

It frequently occurs that cancer cells are included in thick masses of erythrocytes; accordingly target cells become obscured. A careful evaluation of such cytologic specimens is important. Complete absence of tumor cells in extremely sanguineous bronchial material from cancer patients is possible, such that additional cytologic specimens should be prepared from selected areas containing less blood.

\subsection{Fine-Needle Aspiration Biopsy Methods}

FNAB has led to a revolutionary input to the cytology of the lung. The evolution of sophisticated radiologic and sonographic imaging techniques and improved endoscopic instruments made this progress possible [6].

A variety of techniques exist to visualize and aspirate intrapulmonary lesions, mediastinally located masses, and lymph nodes:

- Transthoracic FNAB: A lung mass can be visualized by radiography, computed tomography, or transcutaneous ultrasound. A fine needle attached to a syringe (best attached in a pistol-type holder) is passed through the chest wall into the lesion $[28,34,87]$.

- Transbronchial FNAB: Modern fiberoptic equipment enables the operator to visualize peripherally located intrabronchial lesions and enlarged peribronchial nodules. The needle is passed through the fiberendoscope and precisely inserted through the bronchial or tracheal wall into the primary pulmonary lesion or peribronchial, hilar, and paratracheal lymph nodes [37, 78].

- Endoscopic ultrasound-guided FNAB (EUS-FNAB): In these days, fiberendoscopes can be equipped with highly sophisticated, tiny ultrasound transducers attached to the tip of the instrument. Transbronchial and transtracheal endoscopic ultrasound allows the operator to visualize intramural/submucosal lesions and lesions in adjacent mediastinal compartments that are not detected and not accessible by other techniques, due to their location or their size [78]. Most of these lesions can reliably be evaluated by EUS-FNAB.

The same technique is applied for transesophageal ultrasound-based minimally invasive morphologic investigation of disorders located adjacent to the esophagus, in the dorsal mediastinal space, and in dorsal regions and the upper lobes of the lung [22, 99, 109].

Transbronchial, transtracheal and transesophageal EUSFNAB has become an important tool for staging lung cancer at the time of diagnosis and for assessing diagnosis on otherwise undiagnosed pulmonary and mediastinal masses. [2, 35, 47, 54, 65, 101]. With this procedure, numerous invasive surgical interventions (mediastinoscopy, thoracotomy, thoracoscopy) can be avoided [115].

\subsubsection{Cell Lining of the Respiratory System and Cell Function}

\subsubsection{Ciliated Epithelium}

Major portions of the upper and lower respiratory tract are lined by a pseudostratified cuboidal and columnar ciliated epithelium. The function of these cells is the proximal transport of the mucus stream. For this reason, each cell carries approximately 300 cilia (average length $6 \mu \mathrm{m}$ ) anchored in an apical terminal plate.

\subsubsection{Nonkeratinizing Squamous Epithelium}

Nonkeratinizing squamous epithelium predominantly makes up the lining of the oral cavity, throat, and voice box, which represent the main compartments of the upper respiratory tract.

\subsubsection{Mucus-Producing Goblet Cells}

Mucus-producing goblet cells are found between ciliated bronchial lining cells; their mucoid glycoprotein is discharged apically. Goblet cells are more numerous proximally in the bronchial tract and increase in number when irritations or certain bronchial disorders occur.

\subsubsection{Basal or Reserve Cells}

Adjacent to the basement membrane are small round to polygonal-shaped cells with dark nuclei and scant cytoplasm. These cells are basal or reserve cells and are precursors of the two types of bronchial lining epithelial cells.

\subsubsection{Kulchitsky Cells}

Kulchitsky cells are considered part of the diffuse neuroendocrine system. The cells are basally located, occur singly or in groups, and contain cytoplasmic granules.

\subsubsection{Clara Cells}

Clara cells are nonmucous and nonciliated secretory, domeshaped cells found in the bronchioles of the lungs (bronchioles represent the transition from the conducting portion to the respiratory portion of the lung system) and account for the majority of nonciliated bronchiolar cells. They protect the bronchiolar epithelium secreting mucoid and nonmucinous products and contribute to surfactant production. They can also multiply and differentiate into ciliated cells. 


\subsubsection{Alveolar Pneumocytes}

Alveolar pneumocytes line the alveoli in the periphery of the lung. The alveolar epithelium comprises two cell types with completely different functions [105]:

- Type 1 alveolar pneumocytes are very large, flat cells that cover more than $90 \%$ of the alveolar surface performing efficient gas exchange. Type 1 pneumocytes are incapable of replication.

- Type 2 alveolar pneumocytes are small cuboidal to columnar cells comprising about $10 \%$ of the alveolar cell lining, ultrastructurally they show prominent microvilli. The cells are responsible for the production and secretion of surfactant that reduces tension of alveolar fluids and maintain alveolar stability (see also Sect. 2.3.4.10, p. 186). Type 2 pneumocytes can replicate and may replace damaged type 1 pneumocytes as well.

\subsubsection{Normal Cytology and Benign Cellular Components}

\subsubsection{Normal Epithelial Cells (Fig. 2.2)}

The normal epithelial components of sputum consist of squamous epithelial cells, usually ciliated columnar cells, bronchiolar cells, and alveolar pneumocytes. The morphology of benign cellular components of respiratory material has repeatedly been described in the literature. References are indicated in the textbook by Johnston and Frable [40] and elsewhere.

\subsection{Squamous Cells}

These cells exfoliate mainly from the oral cavity and the pharyngeal area. They are generally numerous in sputum but less common in bronchial specimens and are absent in the majority of BALs and FNABs.

O Intermediate squamous cells are characterized by round to oval monomorphic nuclei with smooth membrane and fine loose chromatin. They have a low N/C ratio. The cytoplasm is transparent and cyanophilic.

O Superficial squames have small pyknotic nuclei and broad orangeophilic cytoplasm.

\subsection{Columnar Cells}

Ciliated columnar cells exfoliate most frequently from the tracheobronchial tree, less frequently from the upper respiratory tract (nasal cavity, sinuses, larynx). Nonciliated cuboidal to columnar cells mainly originate from the bronchioles. Ciliated columnar cells are constantly present in exfoliative respiratory samples. They occur numerously in specimens of induced sputum, in postbronchoscopy sputum, in bronchial aspirates and brushings. They are uncommon in BAL and FNAB specimens.
O The bronchial epithelial cell is characterized by a columnar shape, which at one end tapers off to terminate in a tail-like process. At the opposite or luminal end of the cell, there is a flat terminal plate, anchoring the cilia. The nucleus is located toward the cytoplasmic tail exhibiting a round to oval shape, smooth outline, conspicuous membrane, loose chromatin, and one or multiple small nucleoli.

\subsection{Ciliocytophthoria (Fig. 2.3)}

Ciliocytophthoria is a specific form of degeneration of ciliated columnar epithelium of the respiratory tract. It was first described by Papanicolaou in 1956 [71]. The cellular alteration has been regarded as a common finding in viral infection.

O Cellular changes include detached ciliary tufts (remnants of ciliated epithelium) and degenerating cytoplasmic fragments with a pyknotic nucleus. Additional round eosinophilic cytoplasmic inclusions may be present. Look-alikes may be seen in body fluids, especially of peritoneal origin and in washings of the pouch of Douglas. They can cause confusion with ciliated protozoa.

\subsection{Goblet Cells}

Cells of the bronchial lining with extreme mucus production are called goblet cells. They increase in number when irritants interact, and in patients with chronic tracheobronchial disease.

O The nuclei are molded or flattened and displaced to the periphery of the cells. Cytoplasmic mucoid inclusions stain light pink and are translucent in the Papanicolaou staining procedure.

\subsection{Parabasal and Basal Cells, Reserve Cell Hyperplasia (Fig. 2.4)}

Basal cells (reserve cells) are adherent to the basement membrane of bronchi and bronchioli and are generally covered by the overlying respiratory epithelium. They do not spontaneously exfoliate unless damage occurs to the bronchial lining epithelium. Reserve cells are hardly ever encountered in sputum probes, but they are frequently present in aspirates, bronchial lavages, and particularly in brush specimens. Brushing uncovers deep cell layers enabling an active sampling of the basal cells.

O Basal cells are extremely small (smaller than a small lymphocyte) and round to polygonal. The cytoplasm appears as a scant, densely structured rim and often has a polygonal shape, similar to bronchial metaplastic squamous cells. The nuclei are tiny, darkly stained, and homogeneously structured.

O Reserve cell hyperplasia: Hyperplastic basal cells are mostly grouped in cohesive sheets of variable size. The small cell size and the arrangement in regular sheets exclude a small-cell carcinoma (Fig. 2.4). 


\section{Caution}

Densely clustered basal cells with their deeply stained nuclei may simulate small-cell carcinoma. This is particularly true for bronchial specimens where the cells are entrapped in thick blood masses. However, small cellular and nuclear size together with orderly arrangement are not compatible with any malignant neoplasia.

\subsubsection{Cells of Nonepithelial Origin}

\subsection{Pulmonary Alveolar Macrophages}

(Fig. 2.2)

Alveolar macrophages (AM) are derived from precursor cells called monocytes that first develop in the bone marrow [100]. Monocytes travel throughout the body in the circulatory system of blood. When needed, circulatory monocytes move into tissue, where they become macrophages. Another mechanism of accumulation of alveolar macrophages is hypothesized by increased local proliferation [90]. Alveolar macrophages serve as the front line of cellular defense against respiratory pathogens, clearing the air spaces of infectious, toxic, or allergic particles and ingesting carbon and other inhaled substances [88].

An alveolar macrophage is a mononuclear cell with a high phagocytic capacity on the epithelial surface of lung alveoli. The presence of this cell type in sputum indicates adequacy of the specimen submitted for microscopic evaluation.

O Apart from squamous cells, AMs are the second largest normal cells occurring in bronchial material. Their nuclei are eccentrically positioned, typically bean-shaped, showing a pale thinly dispersed chromatin. One or more small but distinct nucleoli are common. The cytoplasm is abundant and foamy, and includes various types of phagocytized material. Bi- and multinucleation (giant cells) are frequent.

Phagocytized material in the cytoplasm of AMs: The most common material is carbon. In cases of lipid pneumonia, however, AMs exhibit large sharply outlined vacuoles containing fat [50]. The startling cell size and cytoplasmic structure of fat-laden macrophages may overlap with cytologic features of clear cell adenocarcinoma or liposarcoma. However, the AM nuclei are bland and mucus cannot be identified either. Immunocytochemical studies can confirm the cell type in cases with ambiguous cytomorphology (CD68 positivity versus negativity for cytokeratins and other epithelial markers). Phagocytosis of hemosiderin is a sign of previous blood discharge into the alveolar space. Hemosiderin pigments appear as large roundish or square aggregates that are refractile and greenish or rusty colored. For greater detail on hemosiderin pigment, see Sect. 2.3.4.8, "Alveolar Hemorrhage Syndrome," p. 184.

Other noncellular elements are discussed in Sect. 2.1.5, p.

\section{Caution}

The presence of hemosiderin should be confirmed in any critical situation using a special stain for iron.

\subsection{Granuloma Cells and Sarcoidosis}

Granulomatous diseases of various etiologies may be associated with the presence of characteristic histiocytoid cells in respiratory samples submitted for cytologic testing [79]. Common histiocytes, foam cells, macrophages, leukocytes, small tissue fragments, and detritus may be present in variable amounts.

O Histiocytic giant cells of the foreign-body type show multiple nuclei irregularly distributed within the cytoplasm.

O Nuclei of Langhans-type giant cells are crowded at the periphery, frequently in a horseshoe-like arrangement; the cytoplasm may contain asteroid bodies (Figs. 2.5 and $2.89 \mathrm{~B}$ ).

○ Epithelioid cells are elongated mononucleated histiocytoid cells of variable size. The nuclei of Langhanstype cells and epithelioid cells have a bland chromatin structure and a typically elongated nucleus with one end broader than the other. Nucleoli depend on the cellular activity (Fig. 2.6).

Sarcoidosis. Langhans-type giant cells together with densely crowded activated epithelioid cells and benign small lymphocytes are highly suggestive of sarcoidosis. Activated epithelioid cells are characterized by enlargement and a more spherical configuration, nucleoli are obvious. Necrosis is absent with few exceptions. More information on sarcoidosis is provided in the Sects. 2.3.4.1, p. 179 and 15.2.5.6, p. 933. Characteristic cellular components of sarcoidosis are rarely encountered in respiratory exfoliative samples. Yet induced sputum, as a noninvasive technique, may be of diagnostic help in pulmonary sarcoidosis regarding the lymphocyte counts $[19,66]$. In contrast, EUS-FNAB has been shown to be an extremely accurate method for diagnosing sarcoidosis in patients affected by mediastinal disease [55, 111].

Mycobacterial granulomatosis is discussed in Sect. 2.1.6.1, p. 116.

\subsubsection{Neutrophilic Granulocytes}

Neutrophils are omnipresent in exfoliative cytologic specimens from the bronchial tree. Abundant polymorphonuclear leukocytes suggest infectious disease. Organisms may be recognized in conventionally stained cytologic specimens, but they are detected with higher accuracy using special stains such as Gram, Ziehl-Neelsen, periodic acid-Schiff reaction (PAS), and silver stains. 


\section{Caution}

Purulent exudates are likely to accompany a mycotic infection. Fungi may be obscured by the inflammatory background and are solely detected using PAS reaction or methenamine silver stain.

\subsection{Eosinophilic Granulocytes (Fig. 2.73)}

The presence of eosinophilic granulocytes in pulmonary material is often an indicator of a disorder with an allergic component and is most frequently associated with bronchial asthma (see also Sect. 2.1.5, "Charcot-Leyden Crystals," p. 115). A wide variety of etiologies may be responsible for allergic reactions, including inhaled particles, vapor, gases, ingested food, drugs, infectious agents (fungi, parasites), and endogenous processes (intrinsic asthma).

$\bigcirc$ A characteristic feature of the eosinophilic granulocyte is the bilobed nucleus. This attribute is a diagnostic key feature because the cytoplasmic granules may be faintly visible in Papanicolaou-stained specimens.

\subsection{Lymphocytes}

These cells are associated with chronic inflammatory processes, granulomatous disease, or acute viral infections. $\mathrm{Nu}$ merous lymphocytes in a circumscribed area in a smear preparation of sputum and other bronchial material most likely originate from a ruptured lymphoid infiltrate/lymph node located in the bronchial mucosa. Transformed lymphoid cells and starry-sky cells may occasionally be encountered, which makes it easy to exclude small-cell malignant lymphoma (chronic lymphocytic leukemia) and small-cell carcinoma.

O Benign lymphocytes are smaller than cells from a lymphoid or epithelial neoplasia. Nuclear texture of benign lymphocytes is bland, and nucleoli are rare and inconspicuous.

\subsubsection{Abnormal and Atypical Epithelial Cells}

\subsubsection{Etiology}

Numerous environmental irritants, various microbiological agents, drugs, chronic lung disorders, embolism [9], bronchial tumors, destructive granulomatous lesions, injuries due to instrumentation, and infarction [41] may induce hyperplastic processes including reactive (atypical) cell changes in the epithelium of the respiratory tract [40].

\subsubsection{Squamous Metaplasia and Abnormal Squamous Cells}

\section{Caution}

Squamous cells that exhibit atypical or frankly malignant features may originate from a regenerative, dysplastic, or neoplastic lesion in the oral/pharyngeal/laryngeal area. In general, only a small number of such cells will be present in exfoliative respiratory specimens [52].

\subsection{Squamous Metaplasia (Fig. 2.7)}

Squamous metaplasia in reference to the tracheobronchial system means replacement of the ciliated epithelium with a stratified epithelium that resembles immature squamous epithelium. Squamous metaplasia occurs as an abnormal repair response to irritations and to a multitude of environmental toxic agents and organisms [98]. Cigarette smoking is one of the most frequently cited causes responsible for the development of squamous metaplasia [4].

O Metaplastic squamous cells may appear discrete, but typically in small and larger cell groups. The monomorphic cells are arranged in monolayered sheets, whereas the polygonal cell shape gives the sheets a cobblestone-like appearance.

O The cytoplasm is dense and cyanophilic with a smooth outline. Maturing squamous cells become larger with incipient cytoplasmic keratinization (Fig. 2.7).

O Most of the nuclei are dense and patternless with smooth membrane and exhibit a light-blue or gray color with Pap staining. Perinuclear cytoplasmic clearing and karyopyknosis are frequently encountered.

\subsection{Atypical Squamous Metaplasia}

(Figs. 2.8 and 2.9)

Metaplastic squames may undergo changes that should classify them as atypical cells.

O The cells show an increased N/C ratio. The nuclei are slightly irregular in outline and exhibit granular chromatin, hyperchromasia, and nucleoli.

These cellular changes can be associated with prolonged nonneoplastic abnormal conditions of the bronchi and lung, or with carcinoma. It is virtually impossible to differentiate between different grades of atypia and to exclude premalignant epithelial lesions (dysplasia) by light microscopy [12] (Fig. 2.31).

\subsection{Abnormal Squamous Cells}

Abnormal squamous cells may exfoliate from the oral mucosa. Various diseases such as inflammation, ulceration, infection, chronic mucosal irritation, and others may be responsible for atypical squames, particularly in sputum probes. Cytologic features of the most common disorders of the oral mucosa and adjuvant diagnostic procedures that 
could help clarify equivocal cell changes are detailed in Sects. 8.4-8.6, pp. 565.

\section{Additional Analyses}

Ploidy analysis can be applied to atypical nuclei of mature and immature squamous cells in order to assess their malignant potential more reliably. DNA aneuploidy is a strong indicator for cellular malignancy and its precursors $[5,62,69]$. DNA cytometry on atypical squames is discussed in several chapters of this book, e.g., Sect. 8.4 "DNA Image Cytometry," p. 565.

Computerized cell imaging analyzing morphometric markers may also be helpful for the evaluation of preneoplastic lesions [31].

\section{Caution}

- Atypical squamous metaplasia is frequently encountered in respiratory samples from patients with lung cancer. Therefore, repeated exfoliative cytology and advanced imaging studies are necessary in patients without an apparent lung lesion [7].

- Image cytometric DNA ploidy assessment can distinguish between reactive atypia and atypical squamous cells with preneoplastic potential. The latter provide DNA aneuploidy, which requires further investigations; a diploid DNA histogram indicates reactive atypia, which should result in monitoring the patient by repeated cytology over a long period.

- Both the progression rate and the regression rate of dysplastic lesions of various morphologic grades should not be disregarded [12]. Both severe cytologic atypia and DNA aneuploidy do not necessarily imply progression to invasive growth.

\subsubsection{Abnormalities in Cells of Bronchial, Terminal Bronchiolar, and Alveolar Epithelium}

\subsection{3.1 Abnormalities in Bronchial Lining Cells}

Reactive forms of bronchial epithelial cells cover a wide spectrum ranging from mild cellular changes with inconspicuous nuclear atypias and attached cilia to marked cellular/ nuclear alterations that simulate adenocarcinoma [27, 49, $60]$.

\section{Multinucleation}

This is a common alteration, most frequently encountered following instrumentation. The cellular shape, terminal plate, and cilia are well preserved, whereas cellular size varies depending on the number of nuclei. The N/C ratio and nuclear features are bland.
Mild Reactive Cell Changes (Fig. 2.10A).

Mild irritation of the bronchial epithelium may occur in a number of chronic lung diseases including bronchial asthma, chronic bronchitis, bronchiectasis [43, 64, 82] and tuberculosis. In the majority of cases, the exfoliated single cells and hyperplastic mucosa fragments with mild atypias are accurately recognized as benign, if the cytologic features as indicated below are taken into consideration.

O Mild reactive hyperplasia of the bronchial epithelium is characterized by cohesive cell clusters composed of regularly arranged cells.

O Nuclear structure (pale and reticular) and nuclear shape (slight irregularities but smooth outlines) reveal minor changes. Nucleoli are enlarged but uniform and round.

O Focal preservation of ciliated respiratory cells on the surface of the cell clusters is the most important key as to their benignity.

O Small clusters of tightly grouped cells exhibit some molding of the cytoplasm and occasionally of the nuclei as well.

○ Large three-dimensional clusters, the so-called Creola bodies, are papilliform and composed of tightly packed cells. Nuclear details are obscured in large areas and should be carefully evaluated using cells that are not superimposed.

○ Highly vacuolated and mucus-producing cells are frequently present in such cell clusters.

Severe Reactive Cell Changes (Figs. 2.10B, 2.11-2.13)

Severe atypias due to irritation and proliferation of the bronchial epithelium are easily mistaken for adenocarcinoma. Based on our experience, such changes are mainly caused by viral infections, pulmonary infarction, chronic lung disease with recurrent infections (e.g., bronchiectasis), instrumentation, and toxic chemical agents (e.g., oxygen inhalation) [17, 42]. They may also be observed after radiation therapy [108] and chemotherapy $[15,97]$.

O The cell clusters may be loose or tight; irregular cellular arrangement, loss of nuclear polarity, and cellular/ nuclear overlapping are pronounced.

O Isolated atypical cells may be numerous or completely absent.

O Three-dimensional acinar cell groups as in adenocarcinomas are often encountered. They are characterized by central nuclear clustering and clear vacuolated cytoplasm protruding to the periphery, resembling hobnails. The contour of the clusters may be sharply delineated or knobby.

O All atypical cells are enlarged. The N/C ratio may be normal or slightly increased compared to normal epithelial cells.

O The nuclear outline tends to be smooth but molding and cleaving are possible. The chromatin structure varies from loose or finely granular to coarsely granular and clumping. 
O The nucleoplasm may be pale or deep blue in color. The nucleoli occur alone or in groups; they are significantly enlarged and may show pleomorphism.

o Terminal plates and cilia are hardly ever observed together with severe reactive cell atypias.

O The cytoplasm ranges from normal-sized (finely vacuolized) to enlarged (due to large vacuoles).

O Atypical squamous metaplastic cells may appear concomitantly with glandular cell hyperplasia.

\subsection{Hyperplasia of Terminal Bronchiolar} and Alveolar Epithelium (Figs. 2.72 and 2.84)

- Hyperplastic epithelial components from the terminal bronchioles and alveoli are infrequently encountered, both in sputum and bronchial samples. However, if such cells and cell clusters are present they often pose a major diagnostic challenge as to bronchioloalveolar carcinoma, particularly in bronchoalveolar lavage $[8,32,91]$.

- Reactive and proliferative changes of terminal bronchiolar epithelial cells and type II pneumocytes occur with respiratory disorders such as interstitial pneumopathy, organizing pulmonary fibrosis, pulmonary embolism [9], pulmonary infarction, infections particularly of viral origin, and others. Furthermore, radiation and chemotherapy may irritate not only tracheobronchial epithelial cells, but also alveolar epithelium and cells lining the terminal bronchioli.

\section{Microscopic Features and Differential Diagnosis}

A large spectrum of cellular changes from small cells to pronounced hyperplastic large cells may be seen, frequently mimicking adenocarcinoma. Cell changes share many features with those described for hyperplastic bronchial epithelial cells (Sect. 2.1.4.3.1, p. 113).

Large hyperplastic type II pneumocytes can usually be separated from cells of adenocarcinoma by:

O A transient mode with respect to a varying cell amount in subsequent specimens.

O Diverse cytomorphologic manifestations in the same preparation, e.g., wide ranges in the $\mathrm{N} / \mathrm{C}$ ratio, pale versus hyperchromatic nucleoplasm.

O Their sparse number.

O Their degenerative features.

Epithelial hyperplasia composed of abnormal large cells appearing singly and in atypical cell groups may strongly mimic adenocarcinoma. Furthermore, predominance of atypical single cells may pose difficulties distinguishing benign epithelial proliferation from both malignant lymphoma of the large cell type and malignant melanoma.Stanley and coauthors [91] and numerous related reports deal with the cytologic features of reactive type II pneumocytes and differential diagnostic considerations.

Small atypical cells: Small-cell type atypical proliferation resembles bronchioloalveolar carcinoma.
The cells occur individually, or may be grouped in small papilliform or alveolar tissue fragments.

$\mathrm{O}$ The $\mathrm{N} / \mathrm{C}$ ratio varies widely but is often high.

The nuclei exhibit membrane irregularities and prominent nucleoli.

Other than that, the cytologic features are identical, as described for proliferating bronchial lining cells.

\section{Caution}

- Diagnosis of adenocarcinoma in respiratory exfoliative cytology must be based on large numbers of atypical cells and cell clusters that exhibit unequivocal features of malignancy, in order to avoid falsepositive diagnoses. Sparse solitary cells with severe atypias more likely suggest a reactive disorder.

- Bronchoalveolar lavage may contain numerous clusters with severe regenerative cell changes indistinguishable from adenocarcinoma and bronchioloalveolar carcinoma, respectively.

- Clinical information, laboratory results, and image findings are invaluable in order to prevent a falsepositive or false-negative cytologic diagnosis [16, 91]. Reactive atypical proliferation appears transient and should disappear within a few days to a few weeks. Thus, repeated cytological tests may be a prudent approach in equivocal situations.

- Adenomatous atypical hyperplasia is believed to have a potential to progress to peripheral lung adenocarcinoma (see Sect. 2.2.2.1, "Preinvasive Lesions," p. 138).

\subsection{Peculiar Cellular Response to Irradiation and Chemotherapy (Figs. 2.13 and 2.72)}

Reactive cell changes induced by irradiation and chemotherapy can be easily recognized by experienced microscopists.

\section{Microscopic Features}

O The atypical cells are markedly enlarged, many of them show multinucleation.

$\mathrm{O}$ The N/C ratio is preserved; cytoplasmic vacuoles are numerous and prominent.

O The nuclei are pleomorphic; they frequently show indentations and grooves. Occasional nuclear vacuolization.

O The chromatin texture is characterized by fine and coarse granules; and chromatin strands outlining nuclear areas give the nucleus a peculiar empty look.

O Macronucleoli.

\section{Caution}

Carcinoma cells and benign epithelial cells showing strong degenerative changes induced by ionizing radiation are difficult to distinguish from each other. 


\section{Additional Analyses}

Immunocytochemistry

Guzman and coworkers showed that proliferative type II pneumocytes share many antigens with epithelial tumor cells, including keratins and TTF-1. Thus, immunocytochemical tests are of little help to differentiate between reactive pneumocytes and malignant cells [33].

DNA Ploidy

Several reports suggest DNA analysis on cytologic respiratory samples to be a reliable tool for the detection of early lung cancer and of high-risk patients with cellular atypias [5, $70,95,112]$. Automated DNA quantitation by image cytometry on cells in sputum and bronchial washings appears to be a sensitive method for the detection of malignancy and therefore also seems suited for screening procedures $[44,51]$; DNA aneuploidy serves as a marker for malignancy [113].

DNA flow cytometry has also been applied to various respiratory cytology specimens as an adjunct in cancer diagnosis; diagnostic accuracy is expected to increase [116].

\section{Caution}

As stated earlier, carcinoma cells are difficult to separate from benign epithelial cells showing marked ionizing radiation-induced degenerative changes. Since radiotherapy can cause major quantitative and structural alterations to the nuclear chromatin, DNA quantification will also be of little help in this setting and may contribute to enhanced confusion in assessing malignancy.

Cytomorphometric Analysis

A few reports discuss the significance of morphometric criteria distinguishing between benign reactive epithelial proliferations and bronchioloalveolar carcinoma [24, 117].

Molecular Genetics

Recent studies indicate that different genetic analyses using PCR and fluorescence in situ hybridization (FISH) assay yield valuable results for the detection of precancerous lesions and early-stage cancer [36, 45, 48, 89]. On that score, we recently contributed to a bi-institutional study that showed that a commercially available multitarget FISH assay (LA Vysion; Abbott/Vysis; Downers Grove, IL, USA) simultaneously analyzing chromosome 6 and the $5 \mathrm{p} 15,7 \mathrm{p} 12$ (EGFR gene), and 8q24 (MYC gene) loci, is very helpful in elucidating equivocal lung cytology, differentiating between regenerative-benign and neoplastic cell changes [83].

\subsubsection{Endogenous and Exogenous Noncellular Elements and Nonhuman Cellular Components}

Numerous noncellular structures may be present in cytologic samples from the respiratory tract. Some of them may indicate a specific pulmonary disorder, some are derived from the patient, some may have been inhaled, and some are contaminants from the environment to the cytologic specimen. Some of these elements may be confusing and may lead the less experienced cytologist to incorrect diagnoses.

Curschmann spirals are casts of mucus showing varying degrees of inspissation. They are frequently associated with bronchial asthma and heavy smoking, but the common cause is bronchial obstruction [102].

Mucus spheres with a pseudo-organoid appearance or with deep staining should not be misinterpreted as cells or nuclei.

Alveolar proteinosis may deliver amorphous masses into bronchial canaliculi. Their morphologic characteristics are discussed in Sect. 2.3.4.10, "Alveolar Proteinosis," p. 186 (Figs. 2.78 and 2.79).

Charcot-Leyden crystals may be found together with eosinophils in people who suffer from any form of allergic disease; however, in respiratory material they constitute a distinct sign of bronchial asthma. The crystals are derived from disintegrated eosinophils. Charcot-Leyden crystals vary in size and reach a length up to $50 \mu \mathrm{m}$. They are composed of two slender pyramids joining at their bases and tapering into pointed ends, they stain purplish-red with the Papanicolaou method (Fig. 2.14).

Corpora amylacea are rounded, hyaline bodies presenting with striations and concentric rings; they are condensates of glycoproteins. Corpora amylacea are formed in the bronchial tubes and in the alveolar spaces. Association with chronic lung disorders is well known.

Calcospherites (synonym: psammoma body) appear like corpora amylacea but they contain various anorganic compounds and are calcified. Calcospherites are related to lithiasis of the lung and to primary and secondary adenomatous cancers.

Ferruginous bodies (Figs. 2.15 and 2.75) result from inhalation of diverse mineral fibers that become coated with varying substances; ferroprotein is the fraction that yields the typical golden-brown color in Papanicolaou-stained specimens and the positive reaction with iron stains (e.g., Prussian Blue).

A high percentage of ferruginous bodies are seen together with one or more stimulated macrophages, which interact in the forming of these structures and try to ingest the foreign particles [20].

The encrustation of the fibers is extremely irregular, giving them the characteristic beaded bamboo shape segmentation of the shaft and blebs and buds on the branching and bulbous protrusions at both ends. Beaded slender rods with a smooth surface of the protrusions at both ends are most likely associated with asbestos bodies. Asbestos fibers, in interaction with other toxic elements, are responsible for asbestosis (and pulmonary fibrosis) of the lung, lung cancer, and mesothelioma. See also Sect. 2.3.4.9, "Pneumoconioses,." p. 184. 
Plant cells (Fig. 2.16) disclose a typical morphology and a characteristic layering; in general they are much larger than human cells. Experienced examiners will not mistake these cells for malignancy.

Microspores of pollen (Fig. 2.17) show indentations and a thick outer membrane. They should not be confused with yeast cells, vermicular eggs, or even atypical/malignant cells.

\subsubsection{Infectious Diseases}

\subsubsection{Mycobacterial Infection [63, 79]}

Components of granulomatous tubercles may be encountered both in exfoliated bronchial material and in FNAB. The occurrence of Langhans-type giant cells and epithelioid cells, together with caseous detritus and neutrophils, is highly suggestive of pulmonary tuberculosis. Atypical mycobacterial disease may present identical cytologic features but is caused by different type species of acid-fast bacilli and has completely different epidemiologic implications.

\section{Microscopic Features}

$\bigcirc$ The cytomorphology of Langhans-type giant cells and epithelioid cells is described in Sect. 2.1.3.2.2, "Granuloma Cells and Sarcoidosis," p. 111.

O Hallmarks: Compared to epithelioid cells in sarcoidosis, epithelioid cells in mycobacterial infection are more elongated and more slender, disclosing thinly elongated nuclei that are frequently pyknotic. Caseous necrosis consists of finely granular material in an opaque background (Fig. 2.18A).

O Epithelioid cells and detritus are frequently enmeshed in mucoid strands.

Searching for acid-fast bacilli in cytologic material by means of Ziehl-Neelsen stain is rarely effective (Fig. 2.18B). Bacteriologic procedures in a specialized laboratory are recommended for an accurate diagnosis including mycobacterial typing.

\section{Differential Diagnosis}

- As a rare exception, sarcoid granulomas may include caseation.

- Epithelioid granulomatosis is also encountered in other types of chronic inflammatory processes of the lung and may occur adjacent to malignant lesions [79].

- Caseous necrosis should not be misinterpreted as tumor necrosis.

- Elongated and somewhat pleomorphic epithelioid cells including dense cytoplasm and deeply stained pyknotic nuclei may mimic malignant squamous cells.

\section{Caution}

- Beware of cancer diagnosis in exfoliated bronchial material containing great amounts of degenerating epithelioid cells and coarse-type caseous detritus!

- Tuberculoid granulomas may occur in the immediate proximity of lung cancers as a nonspecific reactive process; on the other hand, lung cancer may also coincide with tuberculosis [56].

\subsubsection{Viral Infections}

Bronchial epithelial cells seem to be primarily affected in viral lung disorders; various types of cell changes are encountered in response to viral respiratory tract infections $[25$, 59].

\subsection{Nonspecific Virus-Induced Cell Changes}

(Fig. 2.19)

These alterations are particularly observed in patients with parainfluenza and adenovirus infections:

O Atypias are that of regeneration and repair of the respiratory epithelium. The enlarged cells show hyperchromatic nuclei and prominent nucleoli. Occasional multinucleation, pale nucleoplasm, and nuclear inclusions may occur. The chromatin texture is bland. Nuclear irregularities are variable and the $\mathrm{N} / \mathrm{C}$ ratio is normal compared with benign bronchial epithelial cells (see also Sect. 2.1.4.3, p. 113). False-positive diagnosis of adenocarcinoma is possible.

O A common finding in viral infections, especially induced by the adenovirus, is the degenerative cell change termed ciliocytophthoria. The morphologic description is given in Sect. 2.1.3.1.3, p. 110.

\subsection{Specific Virus-Induced Cell Changes}

The cytomorphologic recognition of certain viral infections with their specific cellular alterations has a practical significance not only in samples derived from the respiratory tract, but also from many other organs of the human the body, e.g., in cervical smears, cerebrospinal fluid, and esophageal and skin brushes.

Herpes Simplex Virus [29, 61] (Fig. 2.20)

Cellular changes induced by herpes simplex virus are distinctive:

O Bronchial epithelial cells are enlarged and rounded showing mono- or multinucleation and a distinct narrow cytoplasmic rim. The nuclei exhibit characteristic ground-glass texture, cyanophilic or eosinophilic inclusions, and granular condensation of the chromatin to the nuclear periphery. Nuclear molding frequently occurs. 
Cytomegalovirus $[1,39,106]$ (Fig. 2.83)

This is a virus of the herpesvirus group. Infection with cytomegalovirus is found in all geographic locations and can be life-threatening for patients who are immunocompromised (e.g., AIDS patients, organ-transplant recipients):

O Cytomegalic inclusion disease is characterized by striking enlargement of the affected cells, which contain a huge nucleus. Only a few cells may show multinucleation.

O The nuclei include a single deeply basophilic inclusion with inhomogeneous areas. The sharply demarcated inclusion is surrounded by a clear halo separating it from the nuclear membrane, resulting in an owl eye appearance (Fig. 2.83).

O The condensed chromatin is compressed against the inner surface of the nuclear membrane. A pearl necklacelike configuration may be observed.

O Intracytoplasmic, orangeophilic inclusions may be present, in addition to the classical intranuclear inclusion.

\section{Caution}

- Particularly cytomegalic cell changes, but also other phenotypes of cell alteration caused by viral infestation could mislead the inexperienced cytologist to an erroneous diagnosis of carcinoma.

- A careful search for individual cells with signs of cytomegalovirus infection is essential in any cytologic sample from immunocompromised patients.

- Cytomegalic inclusion disease is occasionally combined with other infectious diseases, particularly with protozoa (e.g., Pneumocystis jirovecii infection) [104] and mycoses.

Respiratory Syncytial Virus [59] (Fig. 2.21)

$O$ This infection is characterized by formation of enormous syncytial cell aggregates. The cytoplasm contains darkly stained inclusions with clear halos.

\section{Measles}

$\bigcirc$ Large multinucleated giant cells show small cytoplasmic and nuclear inclusion bodies, as indicated by Naib [59].

\subsubsection{Pulmonary Mycoses}

Mycotic infections have significantly increased:

- Since the implementation of chemotherapeutic and immunosuppressive drugs in therapeutic regimes.

- Because of the obvious increase in malignancies and longer patient survival.

- Because of higher incidence of immunocompromising viral infections.
- The majority of mycotic organisms can be identified in cytologic preparations from the respiratory tract. Routine cytological stains are usually adequate for identification. Special staining procedures are helpful in samples containing only a few fungi and in samples with concomitant acute florid inflammatory infiltrates that obscure the organisms. Grocott-Gomori methenamine-silver stain is the best stain to use, but periodic acid-Schiff may also be effective.

\subsection{Primary Pathogenic Fungi}

(Figs. 2.81 and 2.82)

The primary pathogenic fungi constitute a large group of variable organisms. The most common organisms of importance in routine cytology are Cryptococcus neoformans, Blastomyces dermatitidis, Coccidioides, and Histoplasma capsulatum. We refer the reader to distinguished textbooks, directed publications, and internet data bases for detailed information and morphologic descriptions of mycotic pathogens.

\subsubsection{Most Common Opportunistic Fungi}

Opportunistic organisms are saprophytes that contribute to the normal flora in different body sites, but that may become pathogenic in immunosuppressed individuals. Sputum specimens, endoscopically sampled respiratory material, and fineneedle aspirates exhibiting fungi of any opportunistic type together with a purulent inflammation should raise suspicion of a mycosis.

\section{Candida albicans}

Candida albicans can be found in a high percentage of the sputum probes, but its presence most often has no clinical significance. Candida albicans in lavages and brushings from the respiratory system suggests true infectious disease, provided that a contamination from oropharyngeal sites is excluded.

O Candida albicans appears by light microscopy as round to oval single yeast cells, in groups of two, and as chains called pseudohyphae (Fig. 2.22).

\section{Aspergillosis}

Aspergillosis may present as diffuse pulmonary infection or may occur as a solitary lung lesion by colonization with Aspergillus species of a preexisting cavity in the lung (aspergilloma). A third form of aspergillosis are the Aspergillus-associated hypersensitivity respiratory disorders [86]; allergic bronchopulmonary aspergillosis can be suspected if bronchial secretions and brushings reveal aspergillus hyphae intermingled with eosinophilic granulocytes.

○ Aspergilli are easily recognized by the uniformly wide and septate hyphae with their rectangular branching (Figs. 2.23 and 2.24).

○ A key feature of allergic bronchopulmonary aspergillosis is the additional presence of eosinophils. 
Mucormycosis is caused by inhalation of Mucor spores. The disorder most commonly affects the nose and the brain (rhinocerebral mucormycosis) and is a severe and potentially fatal infection. Widespread extension and invasion of the blood vessels is pathognomonic for this fungus.

O The morphology of Mucor is similar to Aspergillus with branching of the hyphae at a $90^{\circ}$ angle. Contrary to Aspergillus, the hyphae are nonseptate and show great variability in width. The presence of conidiophores is a distinctive feature (Fig. 2.25).

$\circ$ Neutrophilic infiltrates and detritus are usually pronounced.

\section{Pneumocystis}

Pneumocystis (Pneumocystis jirovecii, formerly known as Pneumocystis carinii)

- Phylogenetic reclassifications of Pneumocystis as a fungus resulted in a nomenclatural shift from the Zoological Code to the International Code of Botanical Nomenclature [77]. The correctness of the newly proposed names is controversial [26]. The nomenclature of Pneumocystis has recently been reviewed by Redhead and colleagues [77].

- Pneumocystis pneumonia (PCP) is a potentially lifethreatening opportunistic infection in organ-transplant recipients and in patients suffering from acquired immune deficiency syndrome (AIDS).

- In certain areas of the world and in poor environmental conditions, Pneumocystis is still considered an important cause of pneumonia in children.

\section{Microscopic features (Figs. 2.26 and 2.80)}

The organism is found in three distinct morphologic stages: the trophozoite or trophic form, the sporozoite as a precystic form, and the cyst, which contains several intracystic bodies also known as spores [74].

O Hallmarks: The organisms are tiny and more or less spherical, measuring 4-5 $\mu \mathrm{m}$ in diameter. The capsule is smooth and deeply stained. Disintegrated cysts show a single deep groove or may be crescent shaped or crinkled. Focal thickening of the cyst wall is easily recognized by light microscopy. This phenomenon has been reported as an important diagnostic criterion for the identification of Pneumocystis and to differentiate them from yeast-form fungi [107]. Organisms presenting as a dense, foamy mass with irregular margins on Pap-stained smears is characteristic in such a manner that an accurate diagnosis even without special stains can be rendered $[30,85]$.

$\bigcirc$ The different morphologic stages of the organism with their intracystic bodies are more easily identified by Giemsa stain than by the Papanicolaou staining method.

O Restaining of Pap preparations with methenamine silver immediately accentuates the pathognomonic diagnostic features of Pneumocystis (Fig. 2.26). Toluidine blue $\mathrm{O}$ is also suitable for quick identification of the agents.

O Small numbers of organisms that are haphazardly arranged can only be recognized by use of special stain (methenamine silver).

The diagnostically reliable dense foamy masses of organisms generally occur in bronchoalveolar lavage and in lavage and brushing from the very peripheral areas of the bronchial system, as well as in fine-needle aspirations. Induced or postbronchoscopy sputum specimens may have an acceptable diagnostic accuracy as well [10]. Spontaneous sputum has a low sensitivity in detecting Pneumocystes; therefore this method should not be applied in the routine evaluation of patients with AIDS and pulmonary complaints [18].

\section{Differential Diagnosis}

Pneumocystes should not be confused with non-living elements such as degenerating and leached out erythrocytes clustering together. Furthermore, it is difficult to separate Pneumocystis from other organisms, in particular from yeast-form fungi such as Candida species and Histoplasma $[13,107]$.

\subsubsection{Parasitic Infections}

A number of parasites can be detected cytologically in respiratory material and have been reported in the medical literature including Strongyloides stercoralis [46, 114], Echinococcus (pulmonary echinococcosis) [68] (Figs. 9.7, 9.8, 12.5), Trichomonas [21, 67], Microfilaria [38, 57], Toxoplasma gondii, Cryptosporidia [92, 93] , and others.

\subsubsection{Further Reading}

1. An-Foraker SH, Haesaert S. Cytomegalic virus inclusion body in bronchial brushing material. Acta Cytol 1977;21:181-182.

2. Ang TL, Tee AK, Fock KM, et al. Endoscopic ultrasound-guided fine needle aspiration in the evaluation of suspected lung cancer. Respir Med 2007;101:1299-1304.

3. Armbruster C, Bernhardt K, Setinek U. Pulmonary tumorlet. A case report of a diagnostic pitfall in cytology. Acta Cytol 2008;52:223227.

4. Auerbach O, Hammond EC, Garfinkel L. Changes in bronchial epithelium in relation to cigarette smoking 1955-1960 vs 19701977. N Engl J Med 1979;300:381-386.

5. Auffermann W, Böcking A. Early detection of precancerous lesions in dysplasias of the lung by rapid DNA image cytometry. Anal Quant Cytol Histol 1985;7:218-226.

6. Baba M, Iyoda A, Yasufuku K, et al. Preoperative cytodiagnosis of very small-sized peripheral-type primary lung cancer. Lung Cancer 2002;37:277-280

7. Baky AA, Winkler DG, Hunter NR, et al. Atypia status index of respiratory cells: a measurement for the detection and monitoring of neoplastic changes in squamous cell carcinogenesis. Anal Quant Cytol 1980;2:175-185.

8. Beskow CO, Drachenberg CB, Bourquin PM, et al. Diffuse alveolar damage. Morphologic features in bronchoalveolar lavage fluid. Acta Cytol 2000;44:640-646. 
9. Bewtra C, Dewan N, O'Donahue WJ Jr. Exfoliative sputum cytology in pulmonary embolism. Acta Cytol 1983;27:489-496.

10. Bigby TD, Margolskee D, Curtis JL, et al. The usefulness of induced sputum in the diagnosis of Pneumocystis carinii pneumonia in patients with the acquired immunodeficiency syndrome. Am Rev Respir Dis 1986;133:515-518.

11. Bonime RG. Improved procedure for the preparation of pulmonary cytology smears. Acta Cytol 1972;16:543-545.

12. Breuer RH, Pasic A, Smit EF, et al. The natural course of preneoplastic lesions in bronchial epithelium. Clin Cancer Res 2005; $11: 537-543$

13. Chan JK, Tsang DN, Wong DK. Penicillium marneffei in bronchoalveolar lavage fluid. Acta cytol 1989;33:523-526.

14. Chang JP, Aken M, Russell WO. Sputum cell concentration by membrane filtration for cancer diagnosis: a preliminary report. Acta Cytol 1961;5:168-172.

15. Collis $\mathrm{CH}$. Lung damage from cytotoxic drugs. Cancer Chemother Pharmacol 1980;4:17-27.

16. Crapanzano JP, Zakowski MF. Diagnostic dilemmas in pulmonary cytology. Cancer 2001;93:364-375.

17. Crapo JD. Morphologic changes in pulmonary oxygen toxicity. Annu Rev Physiol 1986;48:721-731.

18. del Rio C, Guarner J, Honig EG, Slade BA. Sputum examination in the diagnosis of Pneumocystis carinii pneumonia in the acquired immunodeficiency syndrome. Arch Pathol Lab Med 1988;112:12291232.

19. D'Ippolito R, Foresi A, Chetta A, et al. Induced sputum in patients with newly diagnosed sarcoidosis: comparison with bronchial wash and BAL. Chest 1999;115:1611-1615.

20. Dodson RF, Atkinson MA, O'sullivan M. Stability of ferruginous bodies in human lung tissue following death, embalmment, and burial. Inhal Toxicol 2005;17:789-795.

21. Duboucher C, Caby S, Chabé M, et al. Human pulmonary trichomonoses. Presse Med 2007;36:835-839.

22. Fernandez-Esparrach G, Gines A, Belda J, et al. Transesophageal ultrasound-guided fine needle aspiration imprroves mediastinal staging in patients with non-small cell lung cancer and normal mediastinum on computed tomography. Lung Cancer 2006;54:35-40.

23. Fields MJ, Martin WF, Young BL, Tweeddale DN. Application of the Nedelkoff-Christopherson millipore method to sputum cytology Acta Cytol 1966;10:220-222.

24. Fiorella RM, Gurley SD, Dubey S. Cytologic distinction between bronchioloalveolar carcinoma and reactive/reparative respiratory epithelium: a cytomorphometric analysis. Diagn Cytopathol 1998;19:270-273

25. Frable WJ, Frable MA, Seney FD. Viral infections of the respiratory tract . Cytopathologic and clinical analysis. Acta Cytol 1977;21:32-36.

26. Gigliotti F. Pneumocystis carinii: has the name really been changed? Clin Infect Dis 2005;41:1752-1755.

27. Glatz K, Savic S, Glatz D, et al. An Online Quiz uncovers limitations of morphology in equivocal lung cytology. Cancer(Cancer Cytopathol) 2006;108:480-487.

28. Gouliamos AD, Giannopoulos DH, Panagi GM, et al. Computed tomography-guided fine needle aspiration of peripheral lung opacities. An initial diagnostic procedure? Acta Cytol 2000;44:344-348.

29. Graham BS, Snell JD Jr. Herpes simplex virus infection of the adult lower respiratory tract. Medicine(Baltimore) 1983;62:384-393.

30. Greaves TS, Strigle SM. The recognition of Pneumocystis carinii in routine Papanicolaou-stained smears. Acta Cytol 1985;29:714720 .

31. Greenberg SD, Spjut HJ, Estrada RG, et al. Morphometric markers for the evaluation of preneoplastic lesions in the lung. Diagnostic evaluation by high-resolution image analysis of atypical cells in sputum specimens. Anal Quant Cytol Histol 1987;9:49-54.

32. Grotte D, Stanlery MW, Swanson PE, et al. Reactive type II pneumocytes in bronchoalveolar lavage fluid from adult respiratory distress syndrome can be mistaken for cells of adenocarcinoma. Diagn Cytopathol 1990;6:317-322.
33. Guzman J, Izumi T, Nagai S, Costabel U. Immunocytochemical characterization of isolated human type II pneumocytes. Acta Cytol 1994;38:539-542.

34. Halloush RA, Khasawneh FA, Saleh HA, et al. Fine needle aspiration cytology of lung lesions: a clinicopathological and cytopathological review of 150 cases with emphasis on the relation between the number of passes and the incidence of pneumothorax. Cytopathology 2007; 18:44-51.

35. Herth FJ, Eberhardt R, Vilmann P, et al. Real-time endobronchial ultrasound guided transbronchial needle aspiration for sampling mediastinal lymph nodes. Thorax 2006;61:795-798.

36. Hsu HS, Chen TP, Wen CK, et al. Multiple genetic and epigenetic biomarkers for lung cancer detection in cytologically negative sputum and a nested case-control study for risk assessment. J Pathol 2007;213:412-419.

37. Iyoda A, Baba M, Shibuya K, et al. Transbronchial fine needle aspiration cytological examination: a useful tool for diagnosing primary lung cancer. Thorac Cardiovasc Surg 2006;54:117-119.

38. Jain S, Sodhani P, Gupta S, et al. Cytomorphology of filariasis revisited. Expansion of the morphologic spectrum and coexistence with other lesions. Acta Cytol 2001;45:186-191.

39. Jain U, Mani K, Frable WJ. Cytomegalic inclusion disease: Cytologic diagnosis from bronchial brushing material. Acta Cytol 1973; 17:467-468.

40. Johnston WW, Frable WJ. Diagnostic respiratory cytopathology. Masson Publishing USA, Inc. 1979.

41. Kaminsky DA, Leiman G. False-positive sputum cytology in a case of pulmonary infarction. Respir Care 2004;49:186-188.

42. Katzenstein AL, Bloor CM, Leibow AA. Diffuse alveolar damage - the role of oxygen, shock, and related factors. A review. Am J Pathol 1976;85:209-228.

43. Kawecka M. Cytological evaluation of sputum in patients with bronchiectasis and the possibilities of erroneous diagnosis of cancer. Acta Unio Int Contra Cancrum 1959;15:469-473.

44. Kemp RA, Reinders DM, Turic B. Detection of lung cancer by automated sputum cytometry. J Thorac Oncol 2007;2:993-1000.

45. Kim H, Kwon YM, Kim JS, et al. Tumor-specific methylation in bronchial lavage for the early detection of non-small-cell lung cancer. J Clin Oncol 2004;22:2363-2370.

46. Kramer MR, Gregg PA, Goldstein M, et al. Disseminated strongyloidiasis in AIDS and non-AIDS immunocompromised hosts: diagnosis by sputum and bronchoalveolar lavage. South Med J 1990;83:1226-1229.

47. Lai R. Endoscopic ultrasound-guided fine needle aspiration for diagnosis of recurrent nonsmall cell lung cancer. Ann Thorac Surg 2005;80:2346-2349.

48. Li R, Todd NW, Qiu Q, et al. Genetic deletions in sputum as diagnostic markers for early detection of stage I non-small cell lung cancer. Clin Cancer Res 2007;13:482-487.

49. Linder J. Errors and pitfalls in lung and pleural cytology. Monogr Pathol 1997;39:40-59.

50. Losner S, Volk BW, Slade WR, et al. Diagnosis of lipid pneumonia by examination of sputum. Am J Clin Pathol 1950;20:539-545.

51. Marek W, Krampe S, Dickgreber NJ, et al. Automated quantitative image cytometry of bronchial washings in suspected lung cancer: comparison with cytology, histology and clinical diagnosis. Pneumologie 1999;53:583-595.

52. Matsuda M, Nagumo S, Horai T, Yoshino K. Cytologic diagnosis of laryngeal and hypopharyngeal squamous cell carcinoma in sputum. Acta Cytol 1988;32:655-657.

53. McCarty SA. Solving the cytopreparation problem of mucoid specimens with a mucoliquefying agent (Mucolexx) and Nuclepore filters. Acta Cytol 1972;16:221-223.

54. Micames CG, McCrory DC, Pavey DA, et al. Endoscopic ultrasound-guided fine-needle aspiration for non-small cell lung cancer staging: A systematic review and metaanalysis. Chest 2007;131:539548. 
55. Michael H, Ho S, Pollack B, et al. Diagnosis of intraabdominal and mediastinal sarcoidosis with EUS-guided FNA. Gastrointest Endosc 2008;67:28-34.

56. Morell R, Bardaji O, Delon J, et al. Cytopathological study of the sputum in cases of pulmonary cancer-tuberculosis association. Mars Med 1972;109:724-726.

57. Munjal S, Gupta JC, Munjal KR. Microfilariae in laryngeal and pharyngeal brushing smears from a case of carcinoma of the pharynx. Acta Cytol 1985;29:1009-1010.

58. Murray KL, Duvall E, Salter DM, Monaghan H. Efficacy and pattern of use of sputum cytology as a diagnostic test. Cytopathology 2002; 13:350-354.

59. Naib ZM, Stewart JA, Dowdle WR, et al. Cytological features of viral respiratory tract infections. Acta Cytol 1968;12:162-171.

60. Naryshkin S, Young NA. Respiratory cytology: A review of nonneoplastic mimics of malignancy. Diagn Cytopathol 1993;9:89-97.

61. Nash G, Foley FD. Herpetic infection of the middle and lower respiratory tract. Amer J Clin Pathol 1970;54:857-863.

62. Nasiell M, Kato H, Auer G, et al. Cytomorphological grading and Feulgen DNA analysis of metaplastic and neoplastic bronchial cells. Cancer 1978;41:1511-1521.

63. Nasiell M, Roger V, Nasiell K, et al. Cytologic findings indicating pulmonary tuberculosis. I. The diagnostic significance of epithelioid cells and Langhans giant cells found in sputum or bronchial secretions. Acta Cytol 1972;16:146-151.

64. Naylor B, Railey C. A pitfall in the cytodiagnosis of sputum of asthmatics. J Clin Pathol 1964;17:84-89.

65. Ogita S, Robbins DH, Blum RH, Harris LJ. Endoscopic ultrasound fine-needle aspiration in the staging of non-small-cell lung cancer. Oncology(Williston Park) 2006;20:1419-1425.

66. Olivieri D, D'Ippolito R, Chetta A. Induced sputum: diagnostic value in interstitial lung disease. Curr Opin Pulm Med 2000;6:411414.

67. Osborne PT, Giltman LI, Uthman EO. Trichomonads in the respiratory tract. A case report and literature review. Acta Cytol 1984;28:136-138.

68. Oztek I, Baloglu H, Demirel D, et al. Cytologic diagnosis of complicated pulmonary unilocular cystic hydatosis. A study of 131 cases. Acta Cytol 1997;41:1159-1166.

69. Pak HY, Ashdjian V, Yokota SB, Teplitz RL. Quantitative DNA determinations by image analysis. I. Application to human pulmonary cytology. Anal Quant Cytol 1982;4:95-104.

70. Palcic B, Garner DM, Beveridge J, et al. Increase of sensitivity of sputum cytology using high-resolution image cytometry: field study results. Cytometry 2002;50:168-176.

71. Papanicolaou GN. Degenerative changes in ciliated cells exfoliating from the bronchial epithelium as a cytologic criterion in the diagnosis of diseases of the lung. NY State J Med 1956;56:26472650.

72. Pedersen B, Brons M, Holm K, et al. The value of provoked expectoration in obtaining sputum samples for cytologic investigation. A prospective, consecutive and controlled investigation of 134 patients. Acta Cytol 1985;29:750-752

73. Perlman EJ, Erozan YS, Howdon A. The role of the Saccomanno technique in sputum cytopathologic diagnosis of lung cancer. Am J Clin Pathol 1989;91:57-60.

74. Pintozzi RL, Blecka LJ, Nanos S. The morphologic identification of Pneumocystis carinii. Acta Cytol 1979;23:35-39.

75. Rana DN, O'Donnell M, Malkin A, Griffin M. A comparative study: conventional preparation and ThinPrep 2000 in respiratory cytology. Cytopathology 2001;12:390-398.

76. Ranchod M. The histogenesis and development of pulmonary tumorlets. Cancer 1977;39:1135-1145.

77. Redhead SA, Cushion MT, Frenkel JK, Stringer JR. Pneumocystis and Trypanosoma cruzi: nomenclature and typifications. J Eukaryot Microbiol 2006;53:2-11.
78. Rintoul RC, Skwarski KM, Murchison JT, et al. Endobronchial and endoscopic ultrasound-guided real-time fine-needle aspiration for mediastinal staging. Eur Respir J 2005;25:416-421.

79. Rogers V, Nasiell M, Nasiell K, et al. Cytologic findings indicating pulmonary tuberculosis. II. The occurrence in sputum of epithelioid cells and multinucleated giant cells in pulmonary tuberculosis, chronic non-tuberculosis inflammatory lung disease and bronchogenic carcinoma. found in sputum or bronchial secretions. Acta Cytol 1972;16:538-541.

80. Rome DS, Olson KB. A direct comparison of natural and aerosol produced sputum collected from 776 asymptomatic men. Acta Cytol 1961;5:173-176.

81. Saccomanno G, Saunders RP, Ellis H, et al. Concentration of carcinoma or atypical cells in sputum. Acta Cytol 1963;7:305-310.

82. Sanerkin NG, Evans DMD. The sputum in bronchial asthma: Pathognomonic patterns. J Pathol Bacteriol 1965;89:535-541.

83. Savic S, Glatz K, Schoenegg R, Spieler P, et al. Multitarget fluorescence in situ hybridization elucidates equivocal lung cytology. Chest 2006;129:1629-1635.

84. Schreiber G, McCrory DC. Performance characteristics of different modalities for diagnosis of suspected lung cancer: summary of published evidence. Chest 2003;123(1 Suppl):115S-128S.

85. Schumann GB, Swensen JJ. Comparison of Papanicolaou's stain with the Gomori methenamine silver (GMS) stain for the cytodiagnosis of Pneumocystis carinii in bronchoalveolar lavage (BAL) fluid. Am J Clin Pathol 1991;95:583-586.

86. Shah A. Aspergillus-associated hypersensitivity respiratory disorders. Indian J Chest Dis Allied Sci 2008;50:117-128.

87. Shah S, Shukla K, Patel P. Role of fine needle aspiration cytology in diagnosis of lung tumours - a study of 100 cases. Indian J Pathol Microbiol 2007;50:56-58.

88. Sibille Y, Reynolds HY. Macrophages and polymorphonuclear neutrophils in lung defense and injury. Am Rev Respir Dis 1990;141:471-501.

89. Sozzi G, Pastorino U, MoiraghiL, et al. Loss of FHIT function in lung cancer and preinvasive bronchial lesions. Cancer Res 1998;58:5032-5037.

90. Spurzem JR, Saltini C, Rom W, et al. Mechanisms of macrophage accumulation in the lungs of as best-exposed subjects. Am Rev Respir Dis 1987;136:276-280.

91. Stanley MW, Henry-Stanley MJ, Gajl-Peczalska KJ, Bitterman PB. Hyperplasia of type II pneumocytes in acute lung injury. Cytologic findings of sequential bronchoalveolar lavage. Am J Clin Pathol 1992;97:669-677.

92. Strigle SM, Gal AA. A review of pulmonary cytopathology in the acquired immunodeficiency syndrome. Diagn Cytopathol 1989;5:44-54.

93. Sun T, Teichberg S. Protozoal infections in the acquired immunodeficiency syndrome. Electron Microsc Tech 1988;8:79-103.

94. Suprun H. A comparative filter technique study and the relative efficiency of these sieves as applied in sputum cytology for pulmonary cancer cytodiagnosis. Acta Cytol 1974;18:248-251.

95. Thunnissen FB. Sputum examination for early detection of lung cancer. J Clin Pathol 2003;56:805-810.

96. Tweeddale DN, Harbord RP, , Nuzum CT, et al. A new technique to obtain sputum for cytologic study: External percussion and vibration of the chest wall. Acta Cytol 1966;10:214-219.

97. Twohig KJ, Matthay RA. Pulmonary effects of cytotoxic agents other than bleomycin. Clin Chest Med 1990;11:31-54.

98. Valentine EH. Squamous metaplasia of the bronchus. A study of metaplastic changes occurring in epithelium of the major bronchi in cancerous and noncancerous cases. Cancer 1957;10:272-279.

99. van Beek FT, Maas KW, Timmer R, et al. Oesophageal endoscopic ultrasound with fine-needle aspiration biopsy in the staging of nonsmall-cell lung carcinoma; results from 43 patients. Ned Tijdschr Geneeskd 2006;150:144-150. 
100. Velo GP, Spector WG. The origin and turnover of alveolar macrophages in experimental pneumonia. J Pathol 1973;109:719.

101. Vilmann P, Puri R. The complete "medical" mediastinoscopy (EUS-FNA + EBUS-TBNA). Minerva Med 2007;98:331-338.

102. Walker KR, Fullmer CD. Progress report on study of respiratory spirals. Acta Cytol 1970;14:396-398.

103. Wallace WA, Monaghan HM, Salter DM, et al. Endobronchial ultrasound-guided fine-needle aspiration and liquid-based thinlayer cytology. J Clin Pathol 2007;60:388-391.

104. Wang NS, Huang SN, Thurlbeck WM. Combined Pneumocystis carinii and cytomegalovirus infection. Arch Pathol 1970;90:529535 .

105. Ward HE, Nicholas TE. Alveolar type I and type II cells. Aust N Z J Med 1984;14(5 Suppl 3):731-734.

106. Warner NE, McGrew EA, Nanos S. Cytologic study of the sputum in cytomegalic inclusion disease. Acta Cytol 1964;8:311315.

107. Watts JC, Chandler FW. Pneumocystis carinii pneumonitis. The nature and diagnostic significance of the methenamine silverpositive "intracystic bodies." Am J Surg Pathol 1985;9:744-751.

108. White DC. Chapter 4, lung. in: An Atlas of Radiation Histopathology. USERDA Technical Information Center, Oak Ridge; Tennessee USA. 1975

109. Wiersema MJ, Kochman ML, Cramer HM, Wiersema LM. Preoperative staging of non-small cell lung cancer: transesophageal US-guided fine-needle aspiration biopsy of mediastinal lymph nodes. Radiology 1994;190:239-242.
110. Wihman G, Bergstrom J. Histological technique for the examination of the cell content of sputum. Acta Med Scand (Stockh) 1952;142:433-440.

111. Wildi SM, Judson MA, Fraig M, et al. Is endosonography-guided fine needle aspiration (EUS-FNA) for sarcoidosis as good as we think? Thorax 2004;59;794-799.

112. Xing S, Khanavkar B, Nakhosteen JA, et al. Predictive value of image cytometry for diagnosis of lung cancer in heavy smokers. Eur Respir J 2005;25:956-963.

113. Yang J, Zhou Y. Detection of DNA aneuploidy in exfoliated airway epithelia cells of sputum specimens by the automated image cytometry and its clinical value in the identification of lung cancer. J Huazhong Univ Sci Technolog Med Sci 2004;24:407-410.

114. Yassin SM, Garret M. Parasites in cytodiagnosis: a case report of Strongyloides stercoralis in Papanicolaou smears of gastric aspirate, with a review of the literature. Acta Cytol 1980;24:539-544.

115. Yasufuku K, Chiyo M, Koh E, et al. Endobronchial ultrasoundguided transbronchial needle aspiration for staging of lung cancer. Lung Cancer 2005;50:347-354.

116. Yoss EB, Berd D, Cohn JR, Peters SP. Flow cytometric evaluation of bronchoscopic washings and lavage fluid for DNA aneuploidy as an adjunct in the diagnosis of lung cancer and tumors metastatic to the lung. Chest 1989;96:54-59.

117. Zaman SS, van Hoeven KH, Slott S, Gupta PK. Distinction between bronchioloalveolar carcinoma and hyperplastic pulmonary proliferations: a cytologic and morphometric analysis. Diagn Cytopathol 1997;16:396-401. 
Fig. 2.1 Tissue fragment of the bronchial wall in cytologic material.

Low magnification reveals connective tissue and smooth muscle bundles (arrows) in bronchial brush cytology (from the right lower pulmonary lobe) (Pap stain).

\section{Fig. 2.2 Common cell content of a sputum probe.}

The specimen is stained according to Papanicolaou (high magnification).

Individual ciliated bronchial epithelial cells.

Goblet cells (arrow), nuclei are displaced to the periphery of the cell, mucoid inclusions appear foamy and stain pinkish.

Carbon-laden (anthracotic pigment) macrophages (upper right), nuclei show features indicating reactive changes (rounded shape, prominent nucleolus).

Degenerating epithelial cells (arrowhead).

\section{Fig. 2.3 Ciliocytophthoria.}

Ciliocytophthoria is characterized by the presence of:

Cellular debris representing degenerate cytoplasmic fragments with or without pyknotic nuclei. Note the cytoplasm revealing homogeneous eosinophilic staining quality (arrows) and/or eosinophilic inclusions (arrowhead).

Detached ciliary tufts.

Amorphous detritus.

Elements are depicted from a bronchial washing (Pap stain, lower magnification).

Cytologic appearance may mimic tumor necrosis in samples where detached ciliary tufts are absent. 


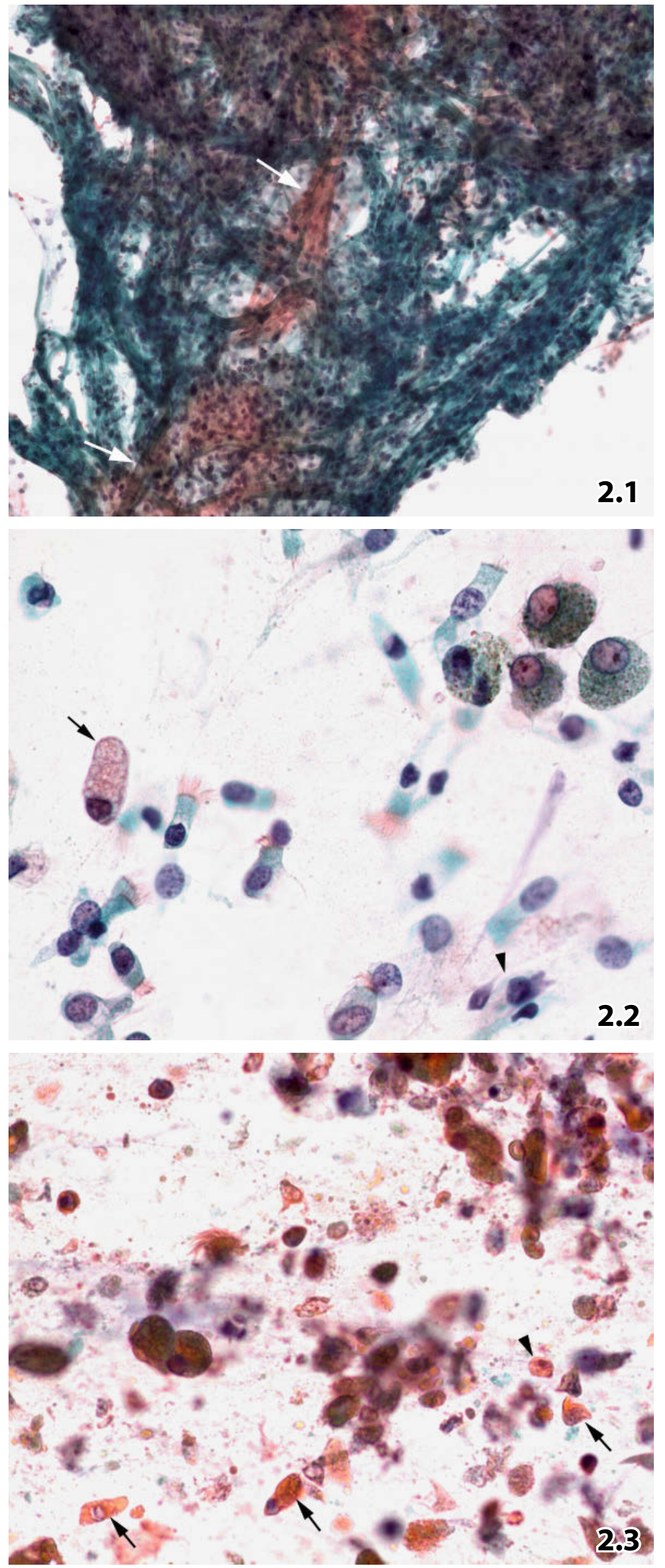


Fig. 2.4 Reserve cell hyperplasia.

A compact cluster of reserve cells. Note the small size of cells and nuclei in comparison to nuclei of the blurred columnar epithelial cells(bottom), the deep-blue-stained nuclei, occasional nuclear molding, and the small rims of homogeneous cyanophilic cytoplasm (bronchial aspirate, Pap stain, lower magnification).

\section{Fig. 2.5 Langhans-type giant cells.}

Three Langhans-type giant cells presenting in varied positions (FNAB of lung, low magnification, Pap stain):

(1) The multinuclear cell at the right side of the field gives an impression of three-dimensionality of the cell.

(2) Horseshoe-like arrangement of the nuclei is best recognized in profile (centrally located cell).

(3) The same nuclear arrangement is seen top-down (cell on left).

Cytology is highly suspicious for mycobacterial granulomatosis. Ziehl-Neelsen staining for acid-fast bacteria was negative (no information as to further investigations).

\section{Fig. 2.6 Epithelioid histiocytes.}

Two aggregates of loosely arranged activated epithelioid cells are shown (arrows). Enlarged nuclei exhibiting loose reticular chromatin and usually distinct nucleoli. Interspersed small lymphocytes and absence of debris raise suspicion of sarcoidosis (no further diagnostic evaluation) (sputum probe, Pap stain, lower magnification).

\section{Fig. 2.7 Squamous metaplasia.}

A flat sheet composed of metaplastic squamous cells is depicted at high magnification. The polygonal shape of the cytoplasm and sharp cytoplasmic borders show a cobblestone-like aspect. Few cells exhibit keratinization. Note patternless or shadowy nuclei and occasional perinuclear cytoplasmic clearing (arrows) (sputum probe, Pap stain).

\section{Figs. 2.8 and 2.9 Atypical squamous metaplasia.}

Two examples of atypical squamous metaplastic epithelium are presented. The cytologic specimens have been stained with the Papanicolaou method.

Fig. 2.8 (case \#1) A sputum probe of a 55-year-old smoker suffering from COPD shows numerous sheets of abnormal squamous metaplastic epithelium. High magnification of loosely arranged cells discloses characteristics of squamous metaplasia (sharply delineated cyanophilic cytoplasm, partly intact cobblestone-like cell arrangement, perinuclear clearing). Still, variability in cell size, irregular chromatin texture, and distinct nucleolar pleomorphism indicate atypia.

Follow-up: Clinical and cytologic long-term follow-up revealed no malignancy.

Fig. 2.9 (case \#2) FNAB of the lung in a 54-year-old woman reveals an inflammatory infiltrate and few highly atypical squamous cells (low N/C ratio, severe nuclear irregularity, hyaline cyanophilic and concentrically laminated cytoplasm, intercellular bridges marked by an arrow) (high magnification). Apparent degenerative nuclear changes (nuclear vacuoles, patternless clear nuclear areas, and absence of nucleoli) do not permit a conclusive diagnosis of malignancy.

Tissue diagnosis: Open thoracotomy followed by microscopic evaluation of excised tissue rendered a diagnosis of an abscess accompanied by severe reactive change of the bronchial and alveolar lining cells. 


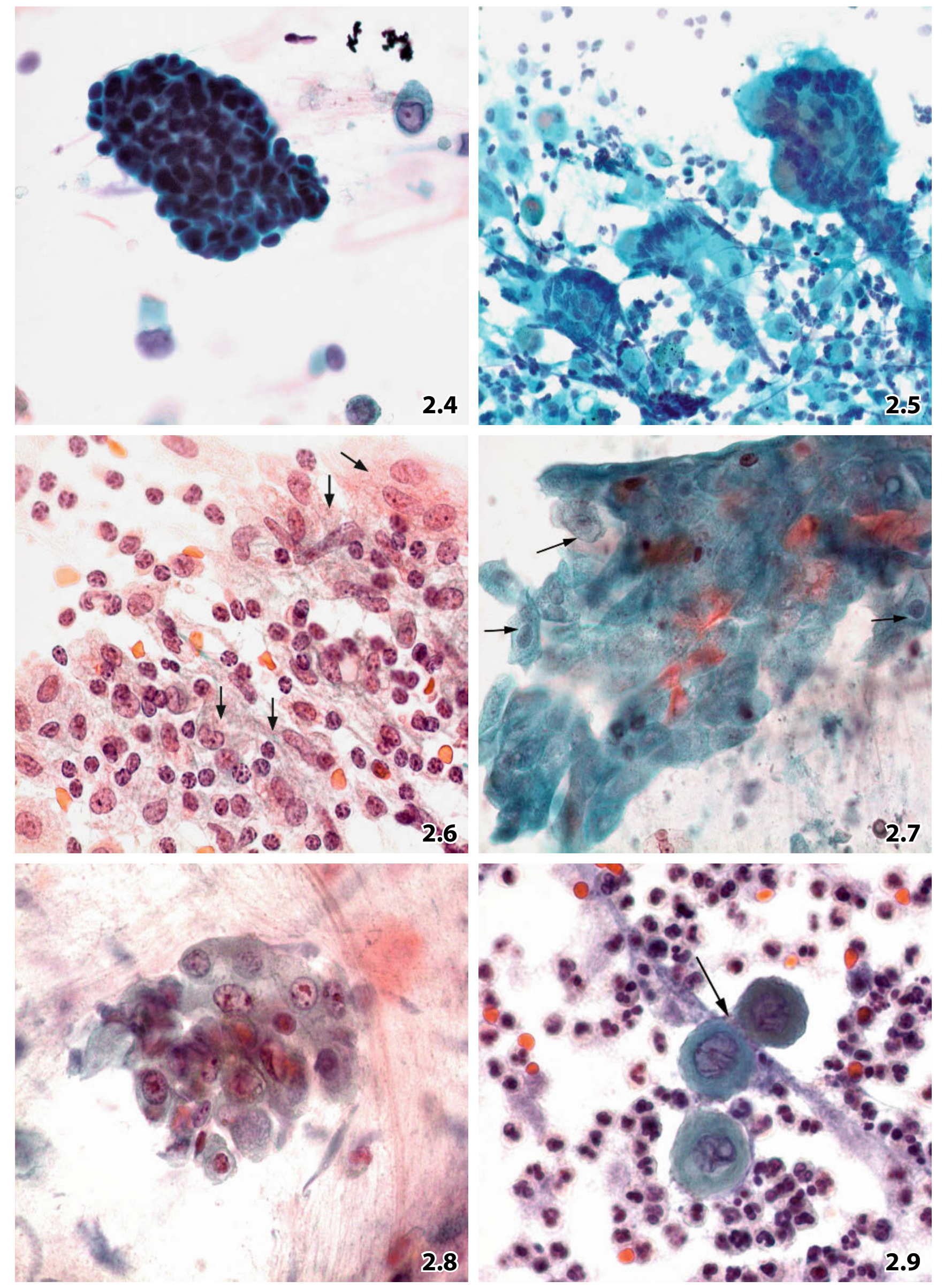


Fig. 2.10A Hyperplastic bronchial epithelium.

A patient suffering from bronchial asthma. Hyperplastic bronchial epithelial cells are depicted (sputum probe, lower magnification, Pap stain). Note regular loose cell arrangement, bland monomorphous nuclei containing centrally located nucleoli, terminal bars, and occasional cilia. A creola body (upper left) is composed of tightly packed reactive epithelial cells. The background shows cellular debris and eosinophils.

Figs. 2.10B, 2.11, and 2.12 Bronchial epithelial cells exhibiting severe atypia: diagnostic dilemma.

Examples from different patients have been selected (exfoliative cytology, Pap stain). Diagnostic challenge in standard cytology is emphasized.

Fig. 2.10B (case \#1) A 57-year-old man presented with pneumonia in the left lung. Sputum cytology revealed three-dimensional cell clusters, loss of nuclear polarity, nuclear irregularity, foamy cytoplasm.

Tentative cytologic diagnosis: Epithelial clusters suspicious of a monomorphic adenocarcinoma (possibly bronchioloalveolar carcinoma).

Follow-up: Clinical and radiographic symptoms disappeared within 6 months, no further evidence of cancer.

Cytologic reevaluation: Focally monolayered cell arrangement (arrowheads) and ciliated cells - cilia are not completely in focus (arrow) - should have favored a benign proliferative lesion. Occurrence and size of the nucleoli do not distinguish between regenerative and malignant lesions.

Fig. 2.11 (case \#2) A 68-year-old man presenting with pulmonary edema and a history of breast carcinoma. Imaging studies suggested neoplastic lung disease. A sputum sample yielded a few small clusters of highly atypical bronchial epithelial cells: nuclear molding, cleaving, and grooving together with pale chromatin texture (high magnification).

Cytology suspected bronchioloalveolar carcinoma or metastasis of breast carcinoma.

Clinical course revealed no malignant lung disorder.

Fig. 2.12 (case \#3) The bronchial aspirate from an 82-year-old woman with a history of pneumonia showed numerous atypical single cells and atypical cell clusters (higher magnification).

Tentative cytologic diagnosis: Most probably reactive bronchial epithelium than adenocarcinoma.

Tissue diagnosis (endobronchial biopsy): Adenocarcinoma.

Comment on case \#3:

- Sparse nuclear irregularities and loose chromatin suggest a benign reactive lesion.

- However, the large number of atypical single cells and cell clusters comprising virtually absence of nucleoli should be considered as indicator for malignancy.

\section{Fig. 2.13 Radiation-induced cell changes.}

Bronchial aspirate in the follow-up of a lung cancer patient, status postpneumonectomy and irradiation.

Low N/C ratio, well-demarcated round nuclei, bland nuclear texture punctuated by clear areas or vacuoles (arrows), huge nucleoli, bi(multi)nucleation are intrinsic postirradiation features (Pap stain, high magnification). 

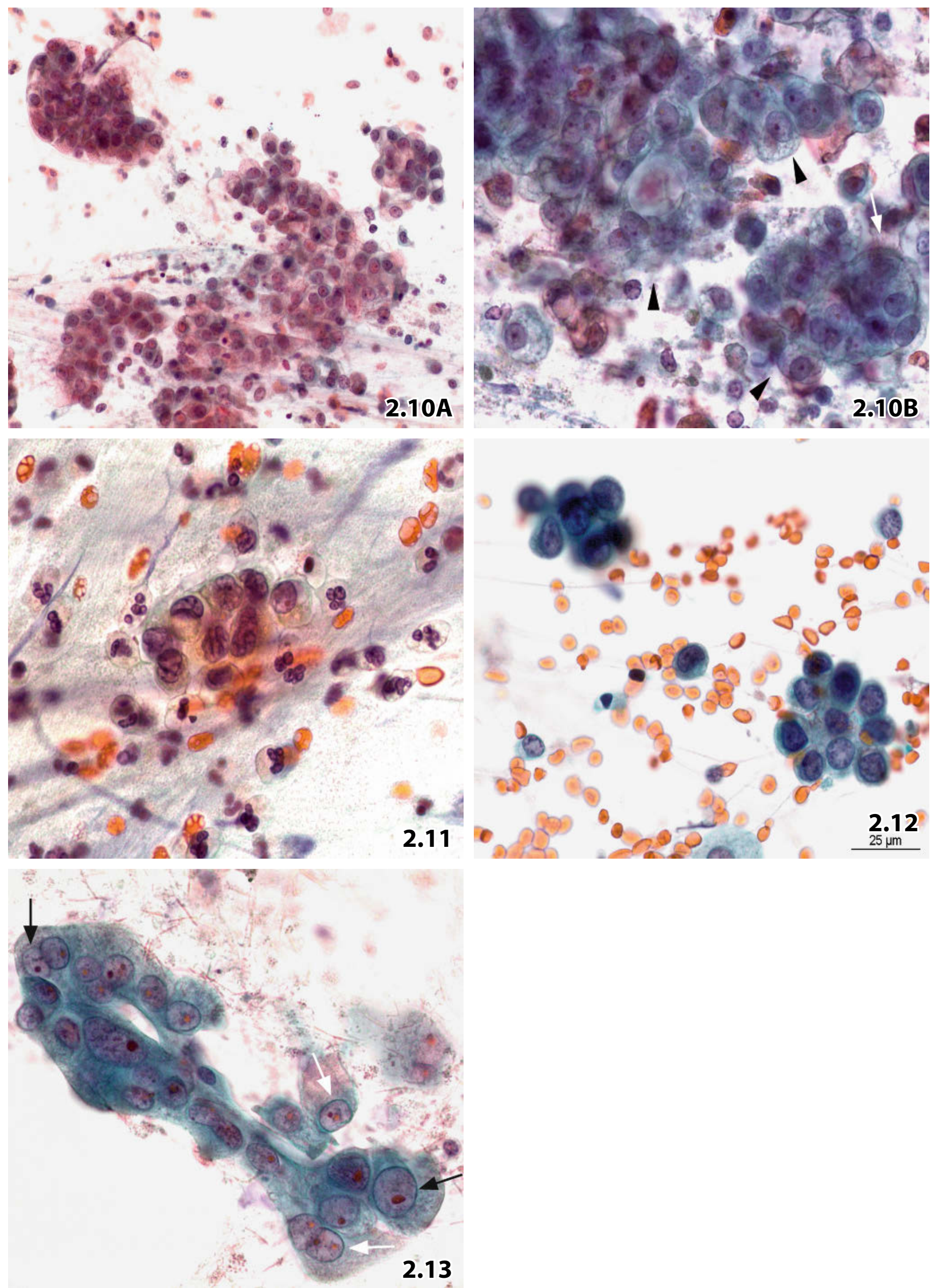
Fig. 2.14 Charcot-Leyden crystals.

A patient with bronchial asthma underwent bronchoscopy.

The bronchial aspirate contains crystalloid elements. Note typical shape, staining quality, and distinct variation in size of the Charcot-Leyden crystals (arrows). Background usually comprises degenerating eosinophils (Pap stain, high magnification).

\section{Fig. 2.15 Ferruginous bodies.}

Image-guided FNAB of a nodular lesion in a male patient's right lung. Squamous cell carcinoma was found in a subsequent sputum probe.

Asbestos bodies of varied size (lower right) and a large pseudo-asbestos body (upper left) are seen. Both ferruginous body variants are partly engulfed by macrophages (Pap stain, high magnification).

\section{Fig. 2.16 Plant cells.}

Material depicted from a sputum sample: histogenetic variants of plant cells with marked variation in size, shape, and arrangement (Pap stain, low magnification).

\section{Fig. 2.17 Microspores of pollen.}

Bronchial aspirate specimen sampled in spring. Microspores may originate from the respiratory tract or may occur as a contaminant from the laboratory environment. Beware of erroneous interpretation! (Pap stain, high magnification). 

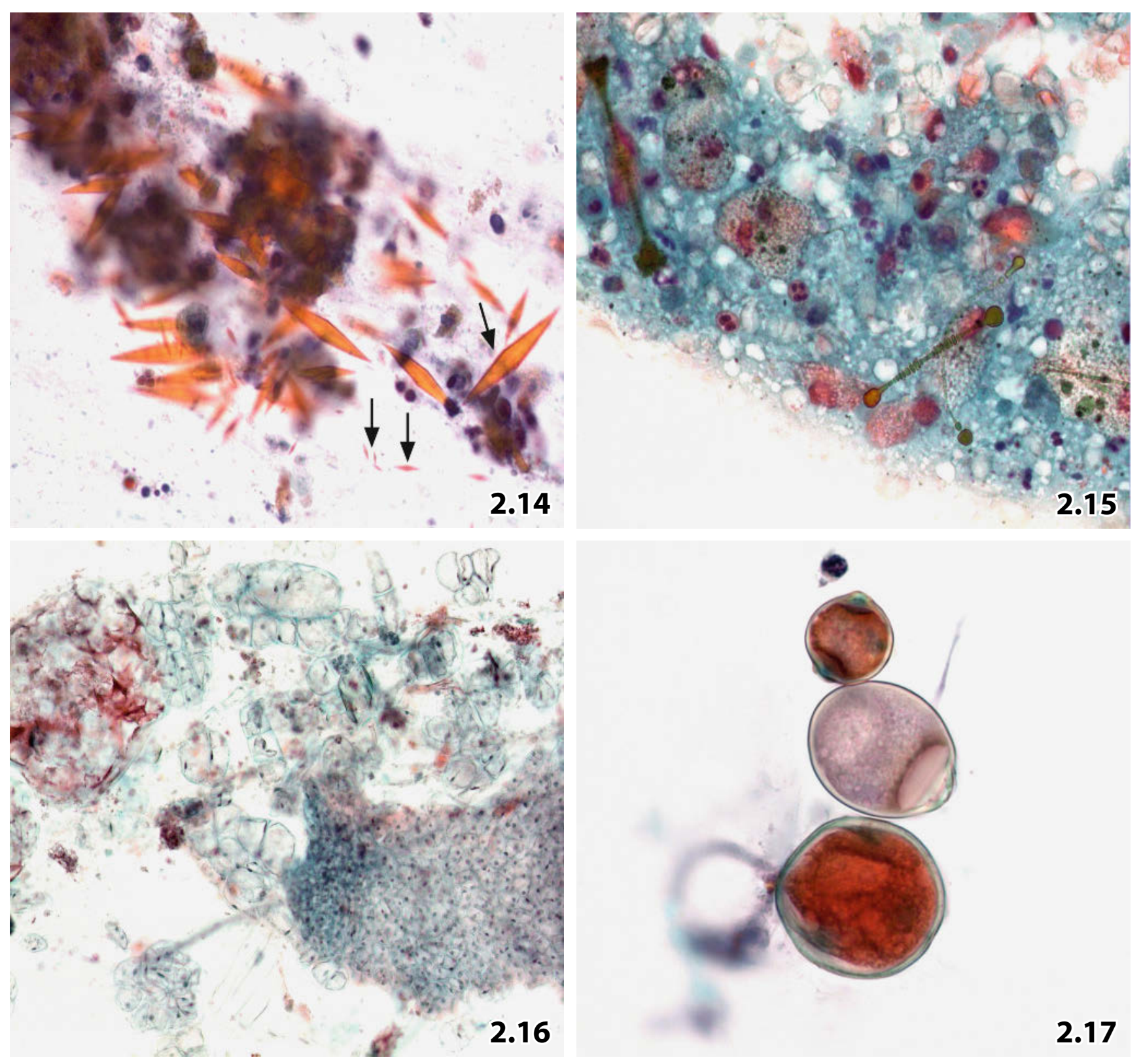
Fig. 2.18A, B Mycobacteriosis.

A sputum specimen showing morphologic characteristics of mycobacterial infection. A Lower magnification reveals key features of mycobacterial infection: three-dimensional aggregates of epithelioid cells partially exhibiting extremely slender and pyknotic nuclei (arrows), caseous detritus and tiny calcified deposits (Pap stain). Compare current epithelioid cells with those in a case of probable sarcoidosis (Fig. 2.6). B Strong positive reaction of acid-fast bacilli with Ziehl-Neelsen staining (oil immersion, Pap-prestained smear, objective $\times 100$ ).

\section{Fig. 2.19 Nonspecific virus-induced cell changes.}

Bronchial brushing containing numerous columnar bronchial epithelial cells, which occasionally show cilia. Abnormal cells exhibit virus-associated changes such as cellular enlargement, multinucleation, and pale nucleoplasm ; cell shape and N/C ratio are usually within normal range. (Pap stain, high magnification).

Viral culture tests (undertaken from cytologic material) provided a positive result for poliovirus type 1 .

Fig. 2.20 Herpes simplex.

Smears of a sputum sample present epithelial cells exhibiting characteristic herpes simplex features: nuclear ground-glass appearance, nuclear inclusions, marginalization of the chromatin (arrow), and a small to medium-sized cytoplasmic rim. The selected cell cluster may lead the inexperienced examiner to a false diagnosis of adenocarcinoma. (Pap stain, high magnification).

Fig. 2.21 Respiratory syncytial virus (RSV).

Key features of cellular alterations caused by $R S V$ : syncytial clusters of epithelial cells showing virus-induced nuclear features (marginalization of the chromatin, ground-glass-like nucleoplasm), and few sharply outlined cytoplasmic halos (the commonly associated darkstained inclusions are not in focus) (bronchial aspirate, Pap stain high magnification). 

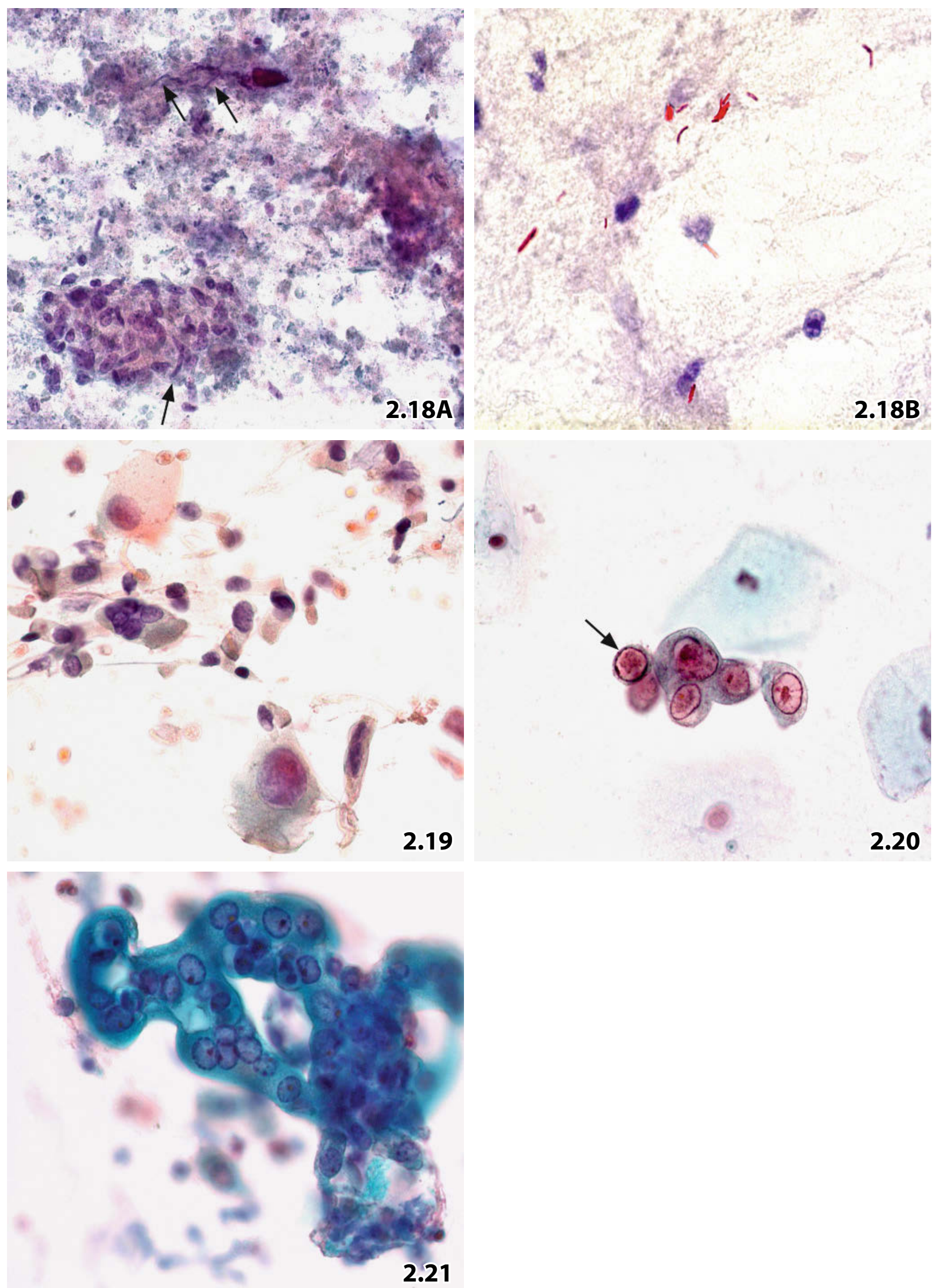
Fig. 2.22 Candida albicans.

Single round to oval yeast cells of variable size, dyads of yeast cells, and pseudohyphae are shown against a background of acute inflammation (sputum sample, Pap stain, higher magnification).

Figs. 2.23 and 2.24 Aspergillus.

Pulmonary aspergillosis that was detected in both exfoliative bronchial material and fine needle aspirate of the lung.

Fig. 2.23 Many branching septate hyphae that are characterized by prominent cell walls and steady width are embedded in an acute inflammatory background (sputum probe, Pap stain lower magnification).

Fig. 2.24 Post-therapeutic follow-up of the aspergillus pneumonia by means of FNAB of the lung and silver stain: small fungal fragments and degenerating hyphae are much more easily identified by methenamine silver staining than by conventional cytologic staining methods (high magnification).

Fig. 2.25 Mucormycosis.

Hyphae of mucor species are characterized by absence of septae and great variability in width. The typical morphologic features are readily recognized in a sputum sample ( Pap stain, high magnification).

\section{Fig. 2.26 Pneumocystis.}

Methenamine silver stain enhances the typical appearance of the cyst form: folding and dotlike thickening of the membrane and intracystic inclusions. Please compare the appearance of pneumocysts using Pap-staining method (Fig. 2.80) (bronchial aspirate, lower magnification, Pap-prestained smear). 

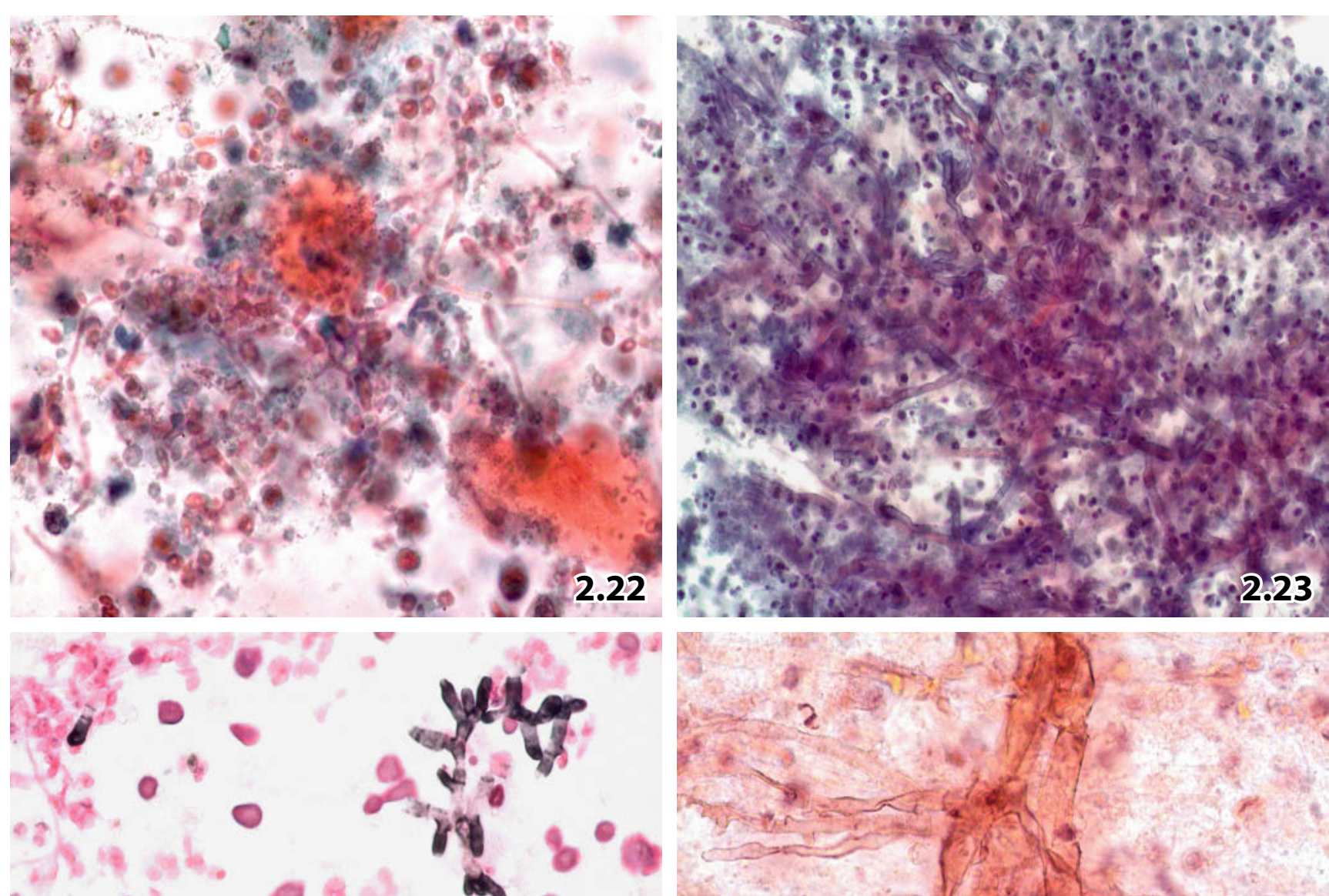

$\because j, 000$
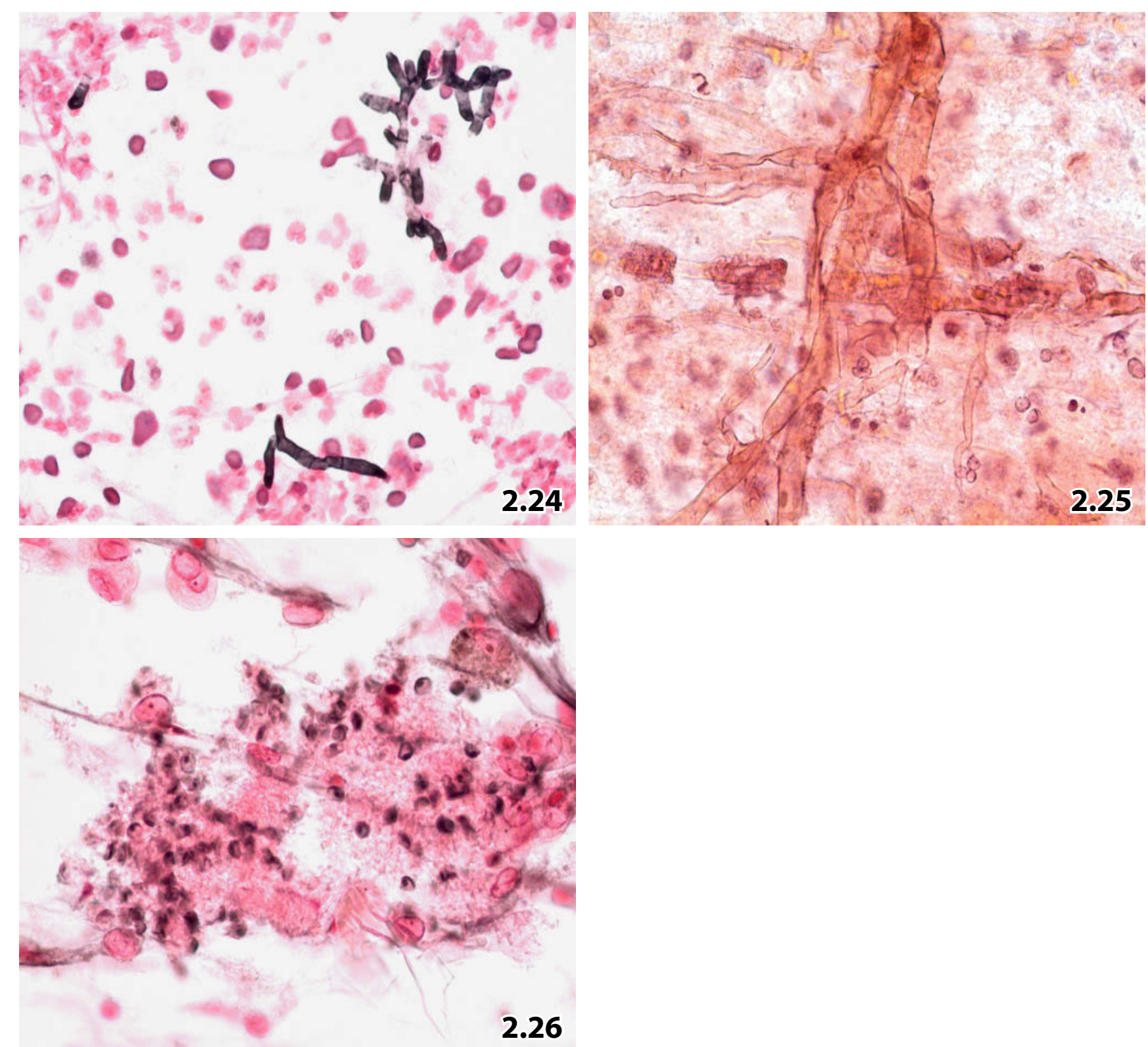


\title{
Section 2.2
}

\section{Respiratory Tract: \\ FNAB and Exfoliative Cytology}

\author{
Tumor-Like Lesions
}

Benign and Malignant Tumors

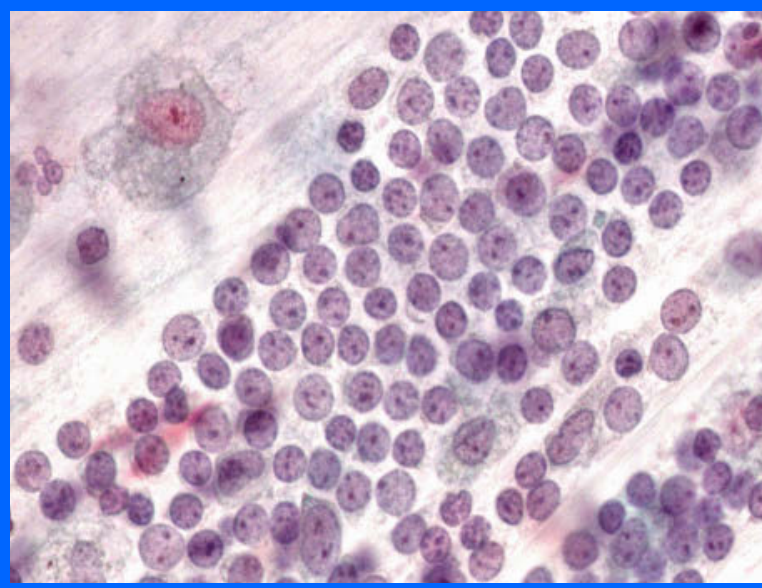

\subsubsection{Benign Tumors and Pseudotumorous Lesions of the Lung (Selected Entities)}

\section{General Comments}

- Tissue fragments of benign epithelial, mesenchymal, or biphasic lung tumors are uncommonly seen in exfoliative cytologic specimens. Single cells cannot be assigned to normal or neoplastic tissue.

- Benign tumorous lesions may be recorded with success in transthoracic fine-needle aspirates (FNAB) and, with increasing frequency, in endoscopic ultrasound-guided fineneedle aspirates.

- Benign disorders with a strong fibrotic component are unlikely to provide adequate cell yield, whichever sampling method is used.

- Our practical knowledge of diagnosing benign tumors is poor, but a number of such lesions have been described in the cytologic literature. Benign disorders of major interest to cytologic practice are discussed in the following.

\subsubsection{Squamous Cell Papilloma}

[98, 101, 122] (Fig. 2.27)

Most papillomas are exophytic but inverted papillomas may occur as well. The tumors exhibit papillary fronds composed of a delicate fibrovascular core and squamous epithelial surface. Squamous papillomas may be solitary or multiple; multiple tumors are referred to as papillomatosis. Papillomas and papillomatosis occur in the upper respiratory tract and in the bronchi, both in adults and in children. Bronchial papillomatosis may progress to dysplasia and in the course occasionally to invasive carcinoma [48].

\section{Microscopic Features and Differential Diagnosis}

O Regular squamous cells of the superficial and intermediate type. Small basal cells may be present as well.

O Minor cytoplasmic and nuclear irregularities may be observed.

O Nonkeratinizing squamous cells usually are arranged in regular compact groups.

O Koilocytosis may be present as a sign of human papilloma virus-associated etiology of the lesion [101, 119, $120]$.

Anucleated squames and atypias of nucleated squamous cells may suggest well-differentiated squamous cell carcinoma.

\subsubsection{Various Benign Adenomatous Lesions}

Mucinous cystic lesions (adenoma and papilloma arising from bronchial epithelium or tracheobronchial glands), which are composed of mucus producing cells, goblet cells, and any squamous components, should be distinguished from low-grade mucoepidermoid carcinoma (see Sect. 2.2.2.7.2, p. 146). Hamartoma that harbor a pronounced chondromyxoid matrix is difficult to distinguish from mucinous cystadenoma. 


\subsubsection{Hamartoma [124, 127 ] (Figs. 2.28 and 2.29)}

Pulmonary hamartoma is an uncommon diagnosis in FNAB practice, and the lesion can provoke a variety of erroneous diagnoses. The histologic pattern is that of an abnormal mixture of tissues normally found in the lung. The volume of aspirated material is often small. Tumors including large amounts of fibrotic connective tissue can prevent adequate cell sampling.

\section{Microscopic Features}

O The mesenchymal component is characterized by fibrous tissue, fibromyxoid stroma, and chondroid masses. A cellular component in a fibromyxoid background is that of stellate cells. Smooth muscle cells and lipomatous components are sporadically present.

O Epithelium is present in the majority of cytologic samples in terms of ciliated and nonciliated columnar cells. Sporadic tumors solely composed of mucin-producing cells have been reported.

\section{Immunocytochemistry}

Staining with an antibody against the $\mathrm{S} 100$ protein is helpful in making a correct diagnosis. The product comprises browncolored granules in the cytoplasm of stellate cells [124].

\section{Differential Diagnosis}

- A large epithelial component raises suspicions of lowgrade epithelial tumors.

- Hamartomas composed of numerous mucinous epithelial cells and a distinct myxoid background can be misinterpreted as mucinous cystadenoma [54].

- In cases with cellular atypias and detritus background, a false diagnosis of carcinoma can be made.

- Predominance of chondroid material mimics:

- Normal costochondral or bronchial cartilage.

- Bronchial chondroma.

- Tumors containing cartilage such as pleomorphic adenoma of bronchial glands.

- Teratoma.

- Additional abundant fibrous tissue might raise suspicion of a benign or low-grade spindle cell tumor, fibrotic granulomatous pseudotumor, or peritumoral fibrosis [127].

\subsubsection{Chondroma (Fig. 5.70)}

Chondroma is a benign encapsulated cartilaginous tumor, which has a characteristic lobular growth pattern.

\section{Microscopic Features and Differential Diagnosis}

O Tumor cells resemble normal cartilaginous cells (chondrocytes) and produce cartilaginous matrix. The latter consists of amorphous, basophilic material.
O The cartilaginous cells occur singly and in groups. They contain small round, deeply stained, pyknotic nuclei. The cytoplasm is pale and vacuolated, surrounded by cartilaginous matrix.

Differential diagnosis considerations are much the same as discussed for pulmonary hamartomas (see previous section).

\subsubsection{Granular Cell Tumor \\ [73, 117] (Figs. 1.63 and 1.64)}

Granular cell tumor is a benign mesenchymal tumor assumed to be of Schwann cell origin.

The tumors occur in many organs of the human body. Granular cell tumors of bronchial and tracheal [49] origin protrude into the bronchial/tracheal lumen and may mimic carcinoma. Thus, abundant granular cells can be found not only in FNABs but likewise in brushings and washings obtained during endoscopy. Granular cell tumor has a distinct microscopic appearance that should permit diagnosis in cytologic specimens.

\section{Microscopic Features}

O Uniform large cells with ill-defined borders and abundant, finely granular cytoplasm. Cells are single or grouped and fragile, leading to a background of granular material.

O The nuclei are small and may be eccentrically positioned with bland granular chromatin. The nucleoli are inconspicuous.

\section{Immunocytochemistry and Cytochemistry}

(Figs. 1.63B and 1.63C)

Tumor cells stain immunocytochemically positive for the S100 protein, neuron-specific enolase, and vimentin.

The cytoplasmic granules are PAS-positive and diastaseresistant [57].

\section{Differential Diagnosis}

Granular tumor cells may be misinterpreted as foamy alveolar macrophages, as cells from primary or metastatic lowgrade oxyphilic lesions, or as cells from malignant melanoma.

\subsubsection{Germ Cell Tumors [93]}

Primary lung teratoma is defined as having no evidence of a gonadal or extragonadal teratomatous neoplasm, including mediastinum. Most pulmonary teratomas are composed of mature elements and are cystic; however, atypical and malignant tissue may occur. Investigation of lung teratoma by FNAB is an exception. 


\section{Microscopic Features and Differential Diagnosis}

O Most intrapulmonary teratomas have a cystic phenotype with the inner surface of the cystic cavity lined with mature squamous cells, comparable to dermoid cysts of the ovary. Other types of tissue may be encountered such as pancreatic, cutaneous, chondroid, and neural tissue, among others.

Low-grade squamous cell carcinoma may be suspected if atypical squames are encountered.

\section{Caution}

Lung metastasis from a primary germ-cell malignancy in an extrapulmonary location with previous successful therapy may mimic mature teratoma.

\subsubsection{Clear Cell Tumor}

Synonym: PEComa.

Clear cell sugar tumor is a rare benign tumor of uncertain histogenesis, usually located in the periphery of the lungs. Single reports suspect clear cell tumors of stemming from perivascular epithelioid cells because the tumor cells exhibit features of pericytes at ultrastructural and immunocytochemical investigations [64]. A few cases diagnosed by FNAB are documented in the literature $[31,79,91]$.

\section{Microscopic Features}

$\bigcirc$ Polygonal and spindle-shaped cells occur either single or arranged in irregular cohesive clusters. Stripped nuclei are frequently observed in the background of a smear.

O The nuclei, oval to elongated, show bland features comprising thin dispersed chromatin and smooth contour. The nucleoli are indistinct. The N/C ratio is low. The cytoplasm is abundant, finely vacuolated, and granular.

O Cell clusters occasionally contain delicate small vessels.

\section{Cytochemistry}

A characteristic, but inconstant feature of clear cell tumors is the presence of abundant cytoplasmic glycogen reliably verified by a positive periodic-acid Schiff reaction [64].

\section{Immunocytochemistry}

Most tumor cells demonstrate strong positivity for HMB-45 and Melan-A. Immunoreactivity with antibodies for CD34 points out the endothelial cells of blood vessels. Negative immunostaining has been established for epithelial antigens, keratins, factor VIII, smooth muscle actin, S100, and for RCCMa (renal cell carcinoma-associated cell marker) $[64,91]$.

\section{Differential Diagnosis [91]}

- The differential diagnosis includes primary bronchogenic carcinoma of the clear cell variant, the extremely rare primary acinic cell carcinoma, and secondary clear cell tumors.

- Clear cell variant lung carcinoma should exhibit squamous or glandular differentiation and positive immunoreactivity with antibodies to cytokeratins, epithelial antigens. TTF-1 is likely positive in cells from glandular portions.

- Metastatic tumors with clear cell features may originate from a number of organs, the most important are kidney, breast, liver, and female genital organs. A definitive diagnosis of the primary tumor site should be possible considering the morphologic features, clinical history, and the results from an appropriate immunocytochemical panel.

- Occasionally, bronchogenic clear cell tumors may raise diagnostic problems with mesenchymal tumors [79].

\subsubsection{Pulmonary Oncocytoma $[28,24]$}

Oncocytomas in bronchial glands are usually small and occur extremely rarely. They are incidentally found in bronchial brushings and secretions after endoscopy.

\section{Microscopic Features}

$\bigcirc$ The tumor cells are similar to oncocytes in benign and malignant lesions of various organs. The cells are round to ovoid, showing granular eosinophilic cytoplasm and small bland nuclei.

O Cytoplasmic features correspond ultrastructurally to mitochondrial hyperplasia. Abundance of mitochondria may also lead to a condensed deeply eosinophilic stained cytoplasm.

\section{Differential Diagnosis}

- Due to the bronchial location of oncocytoma, oncocytic neuroendocrine tumor (oncocytic carcinoid tumor) must be considered first. Endocrine markers are valuable to achieve a correct diagnosis.

- Metastasis of a well-differentiated renal cell carcinoma of granular or chromophobe cell type may masquerade primary lung oncocytoma. Immunocytochemical work-up could possibly be helpful in this setting (see Sect. 12.1.8.1.3, p. 740).

\subsubsection{Tumor-Like Lesions}

\subsection{Amyloid Tumor [89, 90] (Fig. 4.62)}

Amyloid tumor is a tumor-like accumulation of amorphous amyloid protein in the lung parenchyma. Pathogenesis of nodular pulmonary amyloidosis is not clearly understood. In contrast, diffuse amyloidosis is usually part of systemic amy- 
loid disease or caused by lymphoid neoplasms [65]. Lung deposits may occur alone or as multiple foci in both lungs [115].

\section{Microscopic Features}

O Congo-red stain positivity by light microscopy and apple-green birefringence upon polarization are reliable diagnostic criteria. Protein masses may be accompanied by a lymphoproliferative infiltrate and foreign body giant cells.

\subsection{Endometriosis (Fig. 16.19)}

- The term "thoracic endometriosis" refers to the respiratory manifestations that result from the presence of endometrial tissue in thoracic structures. The pathogenesis of thoracic endometriosis is still unclear. Hematogenous and lymphatic embolization of endometrial tissue and other mechanisms have been discussed $[9,131]$. In cases with pleuropulmonary nodules, FNAB may be used to establish a definitive diagnosis [39].

- The clinical manifestations consisting of pneumothorax, hemothorax, and hemoptysis classically recur in accordance with the menstrual cycle $[9,82]$.

\section{Microscopic Features}

Characteristic cytomorphologic properties in FNAB specimens are also presented in several chapters of this book, for instance in Sect. 16.4.3 (p. 1035), together with general remarks and a list of references.

O Hallmarks: The smears are usually cellular. The background is hemorrhagic composed of detritus and hemosiderin-laden macrophages. A varied number of epithelial cell groups (in a honeycomb pattern, in a syncytial or tubular formation) may be present, in addition to aggregates of fusiform stromal cells.

O Endometrial glandular cells are small to medium-sized, the cytoplasm is scant and cyanophilic. Distinct nuclear membranes are wrinkled. The nucleoli are usually inconspicuous and the chromatin is granular and evenly distributed. Mild to moderate epithelial atypia may be observed depending on hormonal cell activation.

O A tendency to squamous metaplasia may be detected: glandular cells transform into immature squamous cells comprising large polygonal cytoplasm and cobblestone arrangement.

O The nuclei of stromal cells show crowding with varied degrees of overlap.

O Endometrial decidualization may rarely develop, characterized by tall stromal cells embedded in a distinctive myxoid background.

\section{Differential Diagnosis and Immunocytochemistry}

- Cellular detritus and hemosiderophages in combination with the absence of glandular cells in aspirates from thoracic endometriosis may lead to a diagnosis of granulomatosis, infarct, or tumor necrosis.
- Glandular endometrial cell groups composed of enlarged reactive cells comprising nuclear hyperchromasia, irregular nuclear outline, and nuclear overlapping could lead to a misdiagnosis of primary or metastatic carcinoma.

- Immunocytochemistry is an important tool to reach a final morphological diagnosis. Epithelial endometrial cells should reliably demonstrate positivity for hormone receptors.

\subsection{Inflammatory Pseudotumor}

[70] (Fig. 2.30)

Synonyms include (pseudosarcomatous) inflammatory myofibroblastic tumor, plasma cell granuloma, fibroxanthoma, fibrous histiocytoma, and invasive fibrous tumor of the tracheobronchial tree.

The tumor can occur at any age, but it is one of the most common lung tumors in children. The nature of this disorder (reactive versus neoplastic) has not been completely elucidated yet.

\section{Microscopic Features}

Histology shows a wide spectrum of fibroblastic/myofibroblastic proliferation and varying infiltrates of histiocytes, lymphoid cells, and mature plasma cells. There is a considerable overlap of multiple phenotypes of this lesion.

The cytologic pattern has repeatedly been described in the current literature:

O Proliferation of spindle cells and histiocytes intermixed with varying numbers of lymphoid cells and typical plasma cells. Small and large tissue fragments may occur $[36,45,118]$.

\section{Differential Diagnosis and Immunocytochemistry}

- Inflammatory pseudotumor is usually diagnosed accurately by FNAB, but the cytologic findings are rather suggestive and nonspecific [45]. A tumor subtype with a lack of plasma cells and aggressive forms of the disorder comprising atypical mesenchymal cells may raise diagnostic difficulties with benign and malignant spindle cell lesions [47] (Fig. 2.30).

- Spindle cells are immunoreactive for vimentin and smooth muscle actin [45].

- ALK1 positivity either by immunocytochemistry or by rearrangement tests such as FISH allows the diagnosis of the neoplastic subtype of inflammatory pseudotumor [112A].

\subsection{Other Tumor-Like Lesions}

- Langerhans cell histiocytosis is described in Sect. 2.3.7.1, p. 189.

- The tumorlet is discussed together with endocrine tumors in Sect. 2.2.3.5, p. 151. 


\subsubsection{Malignant Tumors of the Lung}

\section{General Comments}

- Lung cancer is currently the most commonly diagnosed noncutaneous malignancy in the world and the most common cause for cancer mortality worldwide. Clinical, epidemiologic, and experimental evidence exists that cigarette smoke has strong carcinogenic effects. Thus, future smoking habits will greatly influence incidence and mortality of lung cancer and will also have an impact upon the histologic tumor types. Other factors that are contributing to the development of lung cancer include asbestos exposure, ionizing, and chemical agents of which environmental pollution supports a synergistic effect [87, 105].

- Although the World Health Organization (WHO) classification [119], in contrast to the recently published IASLC/ ATS/ERS lung adenocarcinoma classification [119A], does not address cytology, the authors prefer the WHO nomenclature for practical reasons as well as cytologic purposes. From cytology alone, it is possible to diagnose the major tumor categories and certain tumor subtypes of lung cancers, but it is definitely not possible to identify each tumor type within the WHO nomenclature [8] or the IASLC/ATS/ERS lung adenocarcinoma classification.

- A definitive treatment of lung cancer is feasible, solely on the basis of cytological findings [14].

- Examination of one or repeated sputa will detect the more centrally located neoplasms, whereas washings, brushings, and FNAB will collect adequate samples from tumors in the periphery of the bronchial system and from subpleural lesions. Combined application of multiple sampling methods in the same session can considerably enhance the impact of cytology on primary lung cancer diagnosis and tumor staging.

- The heterogeneity of lung cancers is less frequently detectable in cytologic specimens compared to histologic sections from multiple tumor areas. For cytologic diagnosis of adenosquamous carcinoma, respiratory material or fineneedle aspirates must exhibit malignant cells with evidence of both keratinization and mucus secretion. In our cytologic practice over three decades, we could only sporadically find a combination of small-cell/large-cell carcinoma. Tumor heterogeneity versus synchronous primary tumors of different localization within the respiratory tract has to be considered using exfoliative cytologic methods [125].

- Due to possible therapeutic consequences, the diagnostic term "non-small-cell carcinoma" should be avoided also for cytologic specimens. Additional immunocytological and molecular genetic testing further differentiates adenocarcinoma and squamous cell carcinoma in most cases [119A, 119B, 106A]. Molecular diagnostic methods detecting tumor specific genes in lung cancer specimens for diagnostic and therapeutic purposes (e.g., EGFR or KRAS mutation, $A L K$-rearrangement) may also be performed on a cytological specimen [2, 119B]. Most particularly, mini- mally invasive FNAB should provide enough cellular material for such supplementary studies.

\subsubsection{Preinvasive Lesions}

- A preinvasive (in situ) lesion of squamous cell carcinoma was postulated by Black and Ackerman in 1953 [10]. The progression of dysplastic changes in squamous metaplastic epithelium to carcinoma in situ and invasive cancer has been documented in the past and is currently accepted [22, 103]. Furthermore, it could be shown that increasing degrees of atypical DNA distribution patterns can serve as an additional biomarker indicating progression toward neoplasia. Further details and references concerning DNA ploidy analysis are provided in Sect. 2.1.4.2, “Additional Analyses," p. 113.

- Two major categories have been added to the group of preinvasive pulmonary lesions in recent years. Atypical adenomatous hyperplasia and diffuse idiopathic pulmonary neuroendocrine cell hyperplasia are believed to progress into adenocarcinoma and carcinoid tumor, respectively [62, 119].

- Many molecular changes in the gradual development of invasive cancer have been observed in recent years. These molecular characteristics may in the future not only provide a useful tool for diagnosis but possibly even for treatment of preneoplastic disorders [26, 62, 88,126].

\section{Caution}

- Many epithelial atypias are cytomorphologically delicate to assess and the reproducibility of the system is not well established (see Sect. 2.1.4, p. 112). Exfoliated cells from severe dysplasia and in situ carcinoma, both squamous and adenomatous, do not permit a reliable separation from invasive cancer (Fig. 2.31). Proliferation of type II pneumocytes may be indistinguishable from adenocarcinoma and bronchioloalveolar carcinoma, and peripheral squamous cell carcinoma of the lung may shed cells that strongly mimic tumor cells from squamous in situ cancer [60].

- Positive bronchial respiratory cytology in combination with negative imaging results is no proof for in situ cancer; an occult (early) invasive cancer may exist. Endoscopic localization of the cytologically detected disorder is necessary by systematic endoscopic brushings and other targeted procedures.

\section{Microscopic Features of In-Situ Squamous Cell Carcinoma (Fig. 2.32)}

A number of reports have documented in detail the cytologic appearance of in situ squamous cancer [56]. Morphologic key features include:

O Single small cells of round to oval shape; the N/C ratio is notedly increased. 
O The nuclei exhibit obvious malignant features including a dense granular chromatin structure, hyperchromasia, and irregularities of the membrane. Nucleoli variably occur.

The cytoplasm of the majority of cells is densely keratinized.

O Necrosis and inflammatory infiltrates are rarely encountered.

\section{Differential Diagnosis}

Distinction of in situ squamous carcinoma from invasive cancer is difficult if not impossible (Fig. 2.32). Diagnostic considerations include:

- Invasive squamous cancer of the early type.

- Squamous cancer from the lung periphery [60].

- Squamous cancer of the oropharyngeal region.

In contrast, invasive squamous cell carcinoma of the common type includes larger cells with pronounced polymorphism, necrosis, and an inflammatory background.

\subsubsection{Invasive Squamous Cell Carcinoma}

\section{General Comments}

- Squamous cell carcinoma (SCC) is still the most frequent histologic type among lung cancers and highly attributed to cigarette smoking. This tumor type accounts for approximately $50 \%$ of lung cancers in males and $20 \%$ in females. Epidermoid carcinoma is known as a neoplasm of the major bronchi, but a large number of these tumors may start in a small peripheral bronchus followed by a usually centripetal extent into the larger bronchi [34].

- Histological variants of SCC include tumors with papillary, clear cell, small-cell, and basaloid features. In rare cases, such features are present throughout the whole tumor mass; more commonly they occur focally.

- SCCs are graded histologically in well-differentiated (extensive keratinization), moderately differentiated (keratinized tumor cells but not widespread), and poorly differentiated (focal signs of keratinization) tumors. Histological grading may reliably be used on highly cellular FNAB samples but to a lesser extent on exfoliative respiratory cytology.

- Generally, neoplastic squamous cells occur singly and in loose groups except for FNAB and brushings where tissue fragments are common.

\section{Caution}

- A key feature of squamous cell carcinoma in sputum cytology is the occurrence of the characteristic triad: tumor cells, tumor necrosis, and red blood cells, enmeshed in mucoid masses and mucus strands (Fig. 2.33).
- Thus, specimens of sputa that contain only a few small mucoid strands with the typical cellular entrapments are reliably diagnostic for SCC. In contrast, SCCs exfoliate their cells in washings and brushings in a stochastic distribution pattern.

- Paucity of squamous carcinoma cells may raise difficulties for proper diagnostic assessment, especially in samples where the cells are hidden due to a sanguineous background.

- SCCs composed of tumor cells exhibiting large lucid cytoplasm, bright vesicular nuclei, inconspicuous chromatin texture, variable nucleoli, and indistinct membrane irregularities are difficult to classify as malignant (Fig. 2.36).

- Malignant squamous cells in sputum specimens can originate from extrabronchial sites. SCC of the trachea, larynx, pharynx, oral cavity, and even esophagus may be source for a positive sputum probe.

- Squamous cells and metaplastic squamous cells that display strong nuclear hyperchromasia, focal nucleoplasmic clearing, and a tendency toward degeneration raise diagnostic difficulties with (incomplete list):

- Degenerating cells of SCC.

- Severe actinic alterations on malignant or benign squamous cells.

- Dysplastic changes in squamous metaplastic epithelium (Fig. 2.31).

- Atypical metaplastic squames due to long-standing lung disorders.

- Atypical metaplastic squames in specimens obtained by aspiration through a tracheostoma, or from patients with endotracheal intubation.

- Carcinomas composed of small tumor cells do not always mean classic small cell carcinoma. The latter must be distinguished from undifferentiated SCC of the small-cell variant and from combined small-cell carcinoma/squamous cell carcinoma. Please note the characteristic morphology of cells from true small-cell carcinoma (Sect. 2.2.2.6, p. 144)!

\subsection{Keratinizing Squamous Cell Carcinoma}

(Fig. 2.34)

\section{Microscopic Features}

O Hallmarks: Obviously malignant cells include:

- Extreme cellular polymorphism with varying cytoplasmic shape, ranging from small round cells to huge spindle or caudated cells, so-called tadpole cells.

- The N/C ratio ranges from extremely high to extremely low depending on the amount of cytoplasm of individual cells. 
- The nuclei show marked hyperchromasia. The chromatin is homogenized or clumped together; areas of nucleoplasmic clearing are frequent (Fig. 2.34B). The nucleoli are difficult to recognize as a result of the deeply stained chromatin.

- Keratinization of the cytoplasm is obvious, characterized by an intense eosinophilia and orangeophilia or a deep cyanophilic staining. The hyaline appearance of the cytoplasm and concentric lamination are other striking features of keratinized squamous carcinoma cells. The latter is particularly observed in tumor cells with cyanophilic stained cytoplasm(Fig. 2.34).

- Keratin pearls and intercellular bridges are occasionally observed in compact cell clusters.

O Absence of tumor necrosis and a sanguineous background is extremely rare in cytologic specimens that contain SCC cells, independent of the sampling method.

\section{Differential Diagnosis}

Differential diagnosis considerations include a variety of benign and malignant conditions.

- Squamous cell carcinomas composed of predominantly small rounded malignant squamous cells may more likely originate from the periphery of the bronchial tree or from the upper aerodigestive tract [60]. As specified above, in situ squamous cell carcinoma may exhibit a quite similar appearance (Fig. 2.32).

- Squamous carcinoma cells with strong nuclear hyperchromasia in combination with a tendency toward pyknosis and areas of cleared nucleoplasm are difficult to distinguish from benign squamous cells with severe actinic changes (Fig. 2.13). Additive DNA ploidy analysis will be of little help in assessing malignancy since radiotherapy can cause major quantitative and structural alterations to the genome.

- Squamous metaplasia with reactive-reparative changes and true dysplastic squamous metaplasia generally comprise, although to a lesser degree, nuclear atypia and smaller cells (Fig. 2.8); benign sheets of metaplastic phenotype are usually present as well. Individual squamous metaplastic cells with severe atypia may be indistinguishable from cancer cells (Figs. 2.9 and 2.31).

- Atypical squamoid cells with severely degenerated nuclei should not lead to a false-positive diagnosis. Such cells may occur in respiratory samples from patients with longstanding lung disorders, from patients with endotracheal intubation, and in specimens obtained by aspiration through a tracheostoma [83].

- Highly elongated, slender malignant squamous cells bearing a small darkly stained, elongated nucleus with a smooth contour may lead to diagnostic confusion with hyperplastic mesenchymal cells, particularly smooth muscle fibers. Spindle-shaped cells are encountered particularly in verrucous SCCs of the upper respiratory tract (trachea, larynx, oropharynx) (Fig. 2.35).
- Plant cells may be misinterpreted as squamous cell carcinoma by inexperienced interpreters (Fig. 2.16).

\subsection{Keratinizing Squamous Cell Carcinoma} with Clear Nuclei (Figs. 2.36 and 2.37)

Scattered tumor cells with extremely clear nuclei may occasionally be observed in squamous cell carcinoma; however, SCC that is thoroughly composed of cells with clear-type nuclei rarely occurs.

\section{Microscopic Features}

O Clear vesicular nuclei with inconspicuous chromatin texture, variably sized nucleoli, and indistinct membrane irregularities.

O The cells are large, usually comprising broad lucid, eosinophilic, or cyanophilic stained cytoplasm of hyaline appearance.

O Necrosis is usually not pronounced.

\section{Differential Diagnosis}

Malignancy is difficult to assess in samples containing only a few tumor cells.

Clear-nuclear variant of SCC is most frequently encountered as a primary tumor from the oropharyngeal area (Fig. 2.37).

\subsection{Poorly Differentiated Squamous Cell}

Carcinoma (Fig. 2.38)

As malignant degeneration of the tumor increases, nuclear and cytoplasmic features of squamous differentiation are less pronounced.

\section{Microscopic Features}

O Tumor cells with cytoplasmic keratinization are sparse or completely absent. Dense and concentrically structured, cyanophilic cytoplasm with sharp outlines may be the only reliable morphological criterion of squamous differentiation (Fig. 2.34B). Generally, cytoplasm shows highly varied vacuolization.

O Clusters of poorly differentiated squamous cells frequently exhibit a focal streaming pattern (Fig. 2.38A).

O The nuclei are pleomorphic including pronounced irregular outlines (indentations, cleaving), irregular and coarse chromatin clumping, and conspicuous polymorphous nucleoli.

O Marked necrotic debris.

\section{Differential Diagnosis and Immunocytochemistry}

- Poorly differentiated SCCs lacking clear signs of squamous differentiation can potentially be misinterpreted as poorly differentiated adenocarcinoma or large-cell undifferentiated carcinoma.

- Regeneration and repair within the epithelium of the respiratory tract may produce large atypical single cells 
mimicking nonkeratinizing SCC; however, differential diagnosis problems of proliferative bronchial/alveolar lining cells are much more accentuated against adenocarcinoma.

- Proliferating histiocytes and fibroblasts shed from a florid granulomatous process into the bronchial system may look like poorly differentiated carcinoma cells, in particular in specimens with a tendency toward dense epithelioid clustering of the mesenchymal cells. Immunocytochemical positivity for CD68 and negativity for cytokeratins indicate a histiocytic origin of morphologically equivocal cells.

- An appropriate panel of antibodies proved to be helpful in determining a definite diagnosis: pulmonary squamous cell carcinoma stains positively for CK5/6 [30, 51]. CK20 and CK7 are rarely expressed in malignant squamous cells of the lung, and TTF-1 and leukocyte antigen are never expressed.

- The following primary and secondary neoplasms should primarily be included in the differential diagnosis of nonkeratinizing SCC:

- Poorly differentiated adenocarcinomas of the lung show positive immunoreactivity for CK7 and TTF-1 [30]. However, CK7 has a low specificity since it is also expressed in pulmonary SCC, in large-cell carcinoma NOS (not otherwise specified), in large-cell neuroendocrine carcinoma, and in a variety of adenocarcinomas secondary to the lung [51].

- Transitional cell carcinoma demonstrates immunopositivity for CK7 and CK20.

- Mesothelioma of the undifferentiated epithelial or sarcomatoid variant. Immunocytochemistry, see Sect. 3.2.1.3, "Additional Analyses," p. 262.

- Melanoma is characterized by positive immunostaining for melanoma-specific antigens (e.g., Melan A, HMB45).

- Large-cell malignant lymphoma is determined by positive immunostaining with antibodies against leukocyte antigen and lymphocytic markers.

\section{Caution}

A minimal marker panel of $\mathrm{p} 63$ and TTF- 1 has been proposed, differentiating pulmonary squamous carcinomas from pulmonary adenocarcinoma, while other markers such as CK5/6 or CK7 could be added [119A]. However, many types of nonpulmonary adenocarcinomas may be positive for CK5/6 [20].

\subsection{Squamous Cell Carcinoma: Small-Cell} Variant (Fig. 2.39)

The small-cell variant of SCC is composed of cells lacking the typical nuclear morphology of true small-cell carcinoma (see Sect. 2.2.2.6, p. 144).

\section{Microscopic Features}

O The tumor cell population includes small tumor cells that retain certain properties of malignant squamous cells and cells with obvious squamous differentiation.

O The nuclei exhibit coarse chromatin and prominent nucleoli.

O The cytoplasm is conspicuous, elongated, and sharply outlined. Intercellular bridges may be found in loose tumor cell clusters.

\section{Differential Diagnosis}

Small-cell variant SCC, a mixture of small-cell carcinoma and squamous cell carcinoma, and true small-cell carcinoma may show similar cytologic patterns. But true small-cell carcinoma has characteristic cell features that are not shared with other carcinomas of the small-cell type.

\subsubsection{Adenocarcinoma}

\section{General Comments}

- The frequency of adenocarcinoma is increasing worldwide. The increase in lung cancer in women is attended by a parallel increase in adenocarcinomas. Females are thought to be predisposed to adenocarcinoma due to a specific determination of the pulmonary epithelial cells to inhaled cigarette smoke $[55,87,105]$.

- Adenocarcinoma is a malignant epithelial tumor with glandular differentiation, with or without mucin production. Adenocarcinoma is further classified histologically into the main subtypes: acinar, papillary, solid, and bronchioloalveolar. However, a mixture of the four patterns is common and the mixed subtype is most frequently encountered in routine practice.

- Adenocarcinomas are usually situated more peripherally in the lung compared to SCCs. Thus, adenocarcinoma may shed small numbers of cells or no cells at all into the bronchial system. The yield of exfoliation mainly depends on tumor site and tumor size.

- The differences in cytologic presentation of the varied subtypes of adenocarcinoma have been studied by numerous authors [43, 97, 109]. The studies mainly focused on the cytologic properties and differential diagnosis challenges of bronchioloalveolar carcinoma related to different sampling modalities $[85,104,108,110,116]$.

\section{Caution}

- In order to avoid false-positive results, diagnosis of adenocarcinoma in sputum, washings, and brushings must be based on a large number of atypical cells and clusters that exhibit unequivocal features of malignancy. Sparse cells with severe atypia are more likely to be shed from a reactive disorder (Figs. 2.11 and 2.40). 
- In contrast, bronchoalveolar lavage may contain numerous atypical clusters with severe regenerative cell changes that are indistinguishable from bronchial adenocarcinoma and bronchioloalveolar carcinoma (Fig. 2.84).

- The presence of micropapillary patterns in adenocarcinomas of the lung and of various other organs has been established to be associated with a poor prognosis. Small papilliform fragments resembling micropapillary tufts in cytologic specimens are not specific and should not render a final diagnosis of adenocarcinoma with micropapillary features [102].

\subsection{Adenocarcinoma of the Conventional Type (Predominant Acinar) (Figs. 2.41-2.43) \\ Microscopic Features}

O Hallmarks: malignant morphologic cell features are evident, at least in specimens with numerous tumor cells:

Both single cells and clusters are encountered. Cell groups may consist of syncytial cell arrangement, compact balls, true acini, or papillary fragments.

A radiating flower petal pattern is obvious in well-differentiated carcinomas.

The nuclei are eccentrically placed; they are vesicular in appearance and may be lobulated. The nuclear membranes show varying degrees of irregularity. The chromatin is regularly dispersed and finely granular or powdery.

A centrally placed macronucleolus is a distinct feature for this tumor type.

O The cytoplasm can vary extremely in structure and size. It can appear homogeneous, foamy, or vacuolated; huge vacuoles may lead to a margination of the nucleus.

The cytology varies considerably with the degree of differentiation. A high N/C ratio, nuclear pleomorphism, hyperchromasia, and chromatin coarsening are more prominent the less differentiated the tumor is.

\section{Differential Diagnosis}

- Well-differentiated adenocarcinoma may be extremely difficult to discriminate against proliferating bronchial and alveolar epithelium (type II pneumocytes). Bronchial and alveolar epithelial hyperplasia has been described in detail in Sect. 2.1.4.3, "Abnormalities of Bronchial and Alveolar Epithelium," p. 113 (Figs. 2.10B, 2.11 and 2.12).

- Poorly differentiated adenocarcinomas share cytological features with several primary and metastatic malignancies of the large-cell type such as poorly differentiated lung carcinoma (squamous and undifferentiated cell type), amelanotic melanoma, large-cell malignant lymphoma, among others. See also Sect. 2.2.2.2.3, p. 140, including immunocytochemical panels.

\section{Caution}

Proliferative type II pneumocytes share many antigens with epithelial tumor cells including keratins and TTF1. Thus, immunocytochemical tests are of little help in differentiating between reactive and malignant pneumocytes

\subsection{Papillary Adenocarcinoma (Fig. 2.44)}

Adenocarcinoma with a predominance of papillary structures is rarely encountered in respiratory cytopathology, but single papillary fragments are occasionally seen.

O Branching papillary fragments consist of fibrovascular cores, layered either by a low-columnar nonmucinous epithelium or by tall cuboid to columnar cells with or without mucin production. Papillary adenocarcinoma shares many criteria with bronchioloalveolar carcinoma.

\subsection{Bronchioloalveolar Carcinoma}

(Figs. 2.45, 2.46, 2.85)

Bronchioloalveolar carcinoma (BAC) may arise from cells of the terminal bronchioles and from the alveolar type II pneumocytes [55]. Pure BAC is characterized by a distinct histological growth pattern: tumor cells are growing along preexistent alveolar and fibrovascular septa lacking parenchymatous, vascular, or pleural invasion. The histological architecture is virtually not reproducible in cytologic material; nevertheless, a number of cytologic features exist that may suggest BAC.

\section{Microscopic Features}

A number of studies have been published over the last decades as well as in recent years, contributing to the cytological diagnosis and differential diagnosis of BAC $[43,85,97$, $104,108,110,116]$. However, for many cases it will not be possible to establish a final diagnosis.

O Cell groups and single cells are present, but the latter are sparse compared with cytologic specimens from bronchial adenocarcinoma

O Hallmarks:

Cells are small to medium-sized and uniform.

They occur in tightly packed spherical or papilliform clusters and in flat sheets. Many cell groups show a striking radiating flower petal pattern. Some authors have emphasized the distinct depth of focus for the cells in three-dimensional clusters and the lack of nuclear overlapping.

The round to oval nuclei are extremely uniform in size, but nuclear grooves are commonly observed together with occasional cytoplasmic invaginations.

The chromatin is finely granular or powdery and evenly distributed. 
The nucleoli are indistinct, but exceptions may occur. The cytoplasm varies in volume from modest to abundant. It may be homogeneous, granular, foamy, or coarsely vacuolated.

A clean background in cytologic preparations is pathognomonic of BAC.

O Psammoma bodies are present in a minority of tumor cases [42, 108] (Fig. 2.46).

O Bronchioloalveolar tumors of the mucinous type exhibit more abundant cytoplasm with the nuclei pushed to the periphery (Fig. 2.45).

O A small number of BACs are poorly differentiated. These tumors show morphologic features that are very similar to those present in common adenocarcinoma of the bronchial type (Fig. 2.41).

O The morphologic characteristics of BAC vary somewhat with the type of cytologic preparation. Clusters of tumor cells may be prominent, particularly in FNABs comprising intact alveolar septa intersecting tumor fragments [67, 108, 116].

\section{Caution}

- It is a fact that adenocarcinomas of the lung frequently include a mixture of acinar, papillary, and bronchioloalveolar patterns. Accordingly, a reliable distinction of BAC from other adenocarcinomas is often impossible from cytology alone.

- However, it is of utmost importance to be aware of the bland morphologic features that BACs may exhibit in respiratory cytologic specimens.

\section{Differential Diagnosis}

- Confusion of BAC with proliferative epithelium of terminal bronchioli and reactive type II pneumocytes has been reported elsewhere in the lung chapter (see Sect. 2.1.4.3.2, "Hyperplasia of Terminal Bronchiolar and Alveolar Epithelium," p. 114) (Figs. 2.84-2.86).

- BAC shares many morphological criteria with papillary adenocarcinoma. It is difficult to separate pseudopapillary tumor clusters of BAC from those of papillary bronchial adenocarcinoma.

- BAC of the mucinous type is likely to be overlooked or misinterpreted as mucinous cell hyperplasia: nuclei are pushed to the periphery, and their morphology is obscured by nuclear molding.

- Isolated tumor cells may express a macrophage-like phenotype, which makes it extremely difficult to determine the histogenesis of these elements. On the other hand, clumps of highly atypical (activated) histiocytes/macrophages may mimic adenocarcinoma. Immunocytochemical tests with antibodies against CD68 and cytokeratins can be helpful in cases with uncertain cytology.

- Metastatic carcinoma composed of monomorphic cells may share distinct nuclear features with BAC tumor cells, such as grooving, pseudo-inclusions, chromatin texture, and inconspicuous nucleoli. Most diagnostic difficulties cause breast carcinoma [25], renal cell carcinoma, papillary transitional cell carcinoma, and papillary thyroid carcinoma [16]. In such cases, clinical correlation and appropriate immunostains will be contributory to the diagnosis.

- Poorly differentiated bronchioloalveolar carcinomas share many features with common adenocarcinoma of the bronchial epithelium.

\section{Immunocytochemistry}

- Hormone receptors: Breast carcinoma is one of the most common secondary malignancies to the lung encountered in respiratory cytology. Diagnosis of metastatic breast carcinoma is usually based on the nuclear presence of estrogen (ER) and progesterone (PR) receptors detected by immunocytochemical assay. A few studies revealed the presence of ER in lung carcinoma as well, but the results are conflicting [11, 114]. Dabbs and associates suggest that the detection of ER in pulmonary adenocarcinomas is dependent upon the antibody clone that has been used (e.g., clone 6F11) [25].

- Thyroid transcription factor 1 (TTF-1) (Fig. 2.42): TTF-1 distinguishes primary adenocarcinomas of the lung from the majority of nonadenomatous primary and metastatic neoplasms, excluding metastatic carcinoma of the thyroid.

- Cytokeratin 7 reliably yields positive immunoreactivity in cells of pulmonary adenocarcinomas. However, the marker has a low specificity since it is also expressed in SCC, large-cell carcinoma, and large-cell neuroendocrine carcinoma of the lung, and in a variety of adenocarcinomas metastatic to the lung [51].

- p53 reactivity may be helpful in separating BAC from common lung adenocarcinoma [104].

- Immunocytochemistry in general provides significant information in addition to morphological diagnosis in a high percentage of neoplastic lung disorders [86]. Appropriate panels of immunocytochemical stains have to be used according to the morphological and clinical findings. They enable cytopathologists to differentiate between various types of primary large-cell tumors of the lung and to assess the site of origin of metastatic neoplasms.

\section{Caution}

- Immunocytochemical positivity of tumor cell nuclei against estrogen receptors may not be absolutely specific for metastatic breast carcinoma (or other sex-hormone-producing tumors). ER may also be present in cells of pulmonary adenocarcinomas.

- TTF-1 immunocytochemical staining cannot distinguish between primary adenocarcinoma of the lung, metastatic thyroid cancer, and proliferative type II pneumocytes mimicking adenocarcinoma. 
- CK7 provides high sensitivity for primary pulmonary adenocarcinomas, but the marker has a low specificity.

\section{Additional Analyses}

DNA ploidy, cytophotometry, and molecular genetics have been discussed in Sect. 2.1.4.3, "Additional Analyses", p. 115 .

\subsubsection{Large-Cell Carcinoma (Fig. 2.47)}

Undifferentiated large-cell pulmonary carcinoma is composed of highly malignant anaplastic cells that lack morphologic features of squamous or glandular differentiation. The tumor comprises about $10 \%$ of all lung carcinomas.

Diagnosis of large-cell undifferentiated carcinoma does not exclude a tumor with focally more differentiated areas of specific morphology whose cells are currently absent in the cytologic specimen.

\section{Microscopic Features}

O Hallmarks:

Preponderance of very large single cells.

Cellular grouping occurs in a syncytial modality.

The N/C ratio is high.

The nuclear contour is highly abnormal, cleaved, and lobulated. The chromatin is irregularly dispersed exhibiting strands and clusters. The parachromatin may be hyperchromatic or lucid. The nucleoli are large and pleomorphic and their number varies from cell to cell.

O The cytoplasm is frequently ill defined, and the configuration and staining are variable.

○ Giant tumor cells and tumor necrosis are common.

\section{Differential Diagnosis}

Differential diagnosis considerations are similar to those of poorly differentiated SCC and poorly differentiated adenocarcinoma including: metastatic undifferentiated carcinoma, pulmonary invasive mesothelioma (undifferentiated epithelial or sarcomatoid type), amelanotic melanoma, sarcoma, large-cell lymphoma, cellular alterations due to chemotherapy and irradiation.

Other tumor entities presenting with large tumor cells are discussed in subsequent sections of this chapter.

\subsubsection{Adenosquamous Carcinoma}

Adenosquamous carcinoma is a histologically heterogeneous neoplasia due to dual differentiation into squamous cell carcinoma and adenocarcinoma.

Adenosquamous carcinoma is generally easily recognized as malignant neoplasia in cytologic routine practice, but proper subtyping is often not possible: the cytological diagnosis of this tumor entity requires unequivocal evidence of malignant keratinized squamous cells and mucin-secreting cells of the adenocarcinoma type.

\subsubsection{Small-Cell Carcinoma}

\section{General Comments}

- Small-cell carcinoma belongs to the group of neuroendocrine tumors of the lung (see Sect. 2.2.3, p. 149). A majority of small-cell carcinomas demonstrate neuroendocrine differentiation by immunocytochemical staining for neuroendocrine markers (see "Immunocytochemistry" below), both on tissue sections and cytologic specimens [72].

- Small-cell carcinoma is a highly aggressive tumor with a high mitotic activity; they are known to have a poor clinical course [13, 32, 119].

- Cytology, especially FNAB, has proved to be an excellent method to distinguish small-cell carcinoma from other lung cancers $[15,29]$. Fundamental and specific cytologic features of small-cell carcinoma include cellular/nuclear molding and fine, smudgy chromatin.

\section{Caution}

- We emphasize a careful evaluation of all respiratory cytologic specimens from patients with clinically suspected lung cancer. In so doing, a very few wellpreserved individual and grouped small undifferentiated tumor cells can be detected and generally allow a correct diagnosis (Fig. 2.48).

- Nuclear hyperchromasia and dyschromasia in small carcinoma cells appear deep blue to black and dark pink to bright pink, respectively.

- Tumor cells of small-cell carcinoma entrapped in blood may be obscured and easily missed.

- Dense clusters of hyperplastic basal cells entrapped in thick blood masses may be misinterpreted as tumor cell clusters from a small-cell carcinoma of the oat cell type.

\section{Classification of Small-Cell Carcinomas}

The 1981 WHO classification scheme differentiated three subtypes of small-cell carcinoma: oat cell carcinoma, smallcell carcinoma of the intermediate cell type, and combined small-cell carcinoma [128]. Later on, the terms "oat cell carcinoma" and "intermediate cell type" were dropped. The 1999 and 2004 WHO classification [119] propose the terms:

(1) "Small-cell carcinoma" to be used for tumors with a pure small-cell pattern lacking a non-small-cell component.

(2) "Combined small-cell carcinoma" for tumors that show a mixture of small-cell carcinoma and any other non-smallcell component [132]. 


\section{Caution}

For cytodiagnostic purposes, it is highly recommended to remember the two small-cell types: oat cell and intermediate. These two cell types contribute to diversified differential diagnostic considerations.

Microscopic Features [6, 96, 132]

The cytologic pattern and cellular morphology are pathognomonic in such a manner that a determinate diagnosis should be possible even on single cells.

(1) Cytologic appearance affected by sampling and preparatory modalities:

O Freshly prepared sputum: the tumor cells may be entrapped in strands of mucus or arranged along mucus streaks. Tumor cells occur singly but also arranged in small round aggregates and in linear fashion (singlefile cellular arrangement), exhibiting the characteristic nuclear molding and focally marked compression of the nuclei (Fig. 2.49).

O Bronchial washing producing a similar cytologic appearance as fresh sputum. Obscuration of individual tumor cells and small dense tumor cell clusters by blood masses may offer a tentative diagnosis (Fig. 2.50).

O Bronchial brushing and FNAB usually provide cellrich cytologic smears. Tissue fragments are common, but nuclear molding may be less pronounced, and the tumor cells usually appear larger compared to those in sputum probes or washings.

O Liquid-based cytology is increasingly used for the processing material sampled by transthoracic or transbronchial FNAB from lung lesions or mediastinal lymph nodes. Advantages and interpretative cautions concerning liquid-based preparation are reported in the literature [92]. The most distracting morphologic changes of tumor cells processed by means of liquidbased methods include:

- Cell aggregates that may be crowded and tight.

- Cell shrinkage and disruption of the cytoplasm that are usually more pronounced compared to direct smearing.

- More distinct nucleoli.

(2) Pathognomonic cytologic features: cells of the oat cell type (Figs. 2.48B, 2.49, 2.51)

O Tumor cells of the oat cell type are approximately oneand-a-half to two times the size of a lymphocyte.

$\circ$ The nuclei may appear round with a wrinkled membrane or very irregular in shape and outline.

O The chromatin is very dense and evenly distributed. Hyperchromasia (deep-blue staining) or dyschromasia (dark-pink to bright-pink staining) are invariably present.

O Nucleoli are frequently absent; if present they are inconspicuous.
O The cytoplasm is recognized as a thin cyanophilic rim.

O Intercellular molding of cells and nuclei together with nuclear compression are of the most conspicuous diagnostic features.

O The tumor cells are individually distributed, arranged in small dense clusters or in single files.

$\circ$ Apoptosis and tumor necrosis are frequent.

(3) Pathognomonic cytologic features: cells of the intermediate cell type (Fig. 2.52)

O In comparison to the oat cell tumor type, the cells of the intermediate subtype are slightly larger in size and the nucleoli are frequently conspicuous.

O The cytoplasmic rim is larger and the cytoplasm tends to be elongated.

O However, the basic features for the diagnosis of smallcell carcinoma are the same as listed above in terms of nuclear shape, nuclear border, chromatin texture, and staining properties.

\section{Immunocytochemistry}

- Small-cell carcinoma stain most frequently with epithelial markers (e.g., EMA, BerEp-4) [41]. Cytokeratin staining is more variable but a dot-like cytoplasmic positivity is characteristic for small-cell carcinoma.

- Immunocytochemistry for neuroendocrine markers such as CD56, chromogranin, synaptophysin, and neuron-specific enolase shows a positive reaction in a high percentage of small-cell carcinomas [41].

- Immunocytochemical staining for TTF-1 provides a positive reaction in up to $90 \%$ of cases [18].

\section{Caution}

- Negative staining for neuroendocrine markers occurs in about $25 \%$ of small-cell carcinomas.

- The immunoprofile TTF-1/ CK20 cannot reliably distinguish between pulmonary and extrapulmonary small-cell carcinoma [18].

\section{Differential Diagnosis}

- Basal cell hyperplasia (Fig. 2.4): Densely clustered hyperplastic basal cells with their darkly stained nuclei may simulate small-cell carcinoma (oat cell type), but basal cells are usually extremely small (smaller than cells of small-cell carcinoma or even lymphocytes) and show round to polygonal shapes.

O The cytoplasm appears as small, densely structured cyanophilic rim and often has a polygonal shape. The nuclei are tiny, darkly stained, and homogeneously structured. Hyperplastic basal cells are arranged in cohesive flat sheets.

Hyperplastic basal cells show highly significant difference in proliferative activity in comparison to small-cell carcinoma, which may be helpful in discriminating the 
two entities by application of an immunoassay using antibodies against Ki-67 antigen [40].

- Carcinoid tumors: Typical carcinoid tumors should rarely cause problems discriminating from small-cell carcinoma. However, cases with numerous small and large spindle-shaped cells, pronounced variation in cellular size and shape, and nuclear features of small-cell carcinoma (color, chromatin structure, shape) may easily be misclassified as small cell carcinoma. Still, carcinoid tumors do not produce tumor diathesis and have a mitosis index much lower than small-cell carcinomas. Renshaw and colleagues have studied in detail the cellular features provoking confusion of carcinoid tumors with small cell carcinoma of the lung [95].

- Merkel cell carcinoma: Merkel cell carcinoma shares many cytologic features with small-cell carcinoma. Immunostaining for CK20 and TTF-1 are helpful in distinguishing between these two entities: Merkel cell carcinoma is CK20-positive (often in a dot-like pattern), and TTF-1-negative, and vice versa [18].

- Poorly differentiated squamous cell carcinoma: Small cell carcinoma predominantly composed of cells of the intermediate subtype may be suggestive of poorly differentiated squamous cell carcinoma of the small-cell variant. Immunocytochemical stains for p63 and TTF-1 were shown to reliably distinguish between small-cell carcinoma of the lung and small-cell SCC [59].

- Malignant lymphoma (Figs. 2.53 and 2.56): Distinguishing small-cell carcinoma from malignant lymphoma can be difficult, particularly in bronchial washings and brushings. Problems arise when (1) all carcinoma cells occur isolated and (2) malignant lymphocytes are small to medium-sized, lacking distinct nucleoli, appearing as cohesive clusters, and exhibiting degenerative changes. Nuclear irregularities and tumor debris are not helpful in separating the two tumor entities. Immunoreactivity for leukocyte antigen (CD45) and various lymphocytic markers reliably indicate the lymphatic nature of a tumor. Lymphomas are negative for cytokeratins, neuroendocrine markers, and TTF-1.

\section{Caution}

There are various reasons for a biphasic small-cell / large-cell tumor pattern:

- Combined small-cell carcinoma shows a distinct mixture of cells of small-cell carcinoma and any other malignant non-small-cell component such as squamous cells, glandular cells, and large cells of neuroendocrine origin.

- Atypical/ malignant squamous cells may originate from dysplastic squamous epithelium and carcinoma in situ of the bronchial epithelium, adjacent to small-cell carcinoma.

- Concomitant squamous cell carcinoma from varying sites of the respiratory tract, oropharynx, and esophagus should always be kept in mind.

\subsubsection{Carcinomas of the Salivary Gland Type}

This tumor group comprises neoplasms that are probably of bronchial gland origin. The morphology of these tumors is similar to their counterparts in the salivary glands and in other organs. They are described in more detail in Sect. 5.1.5, p. 414. Several reports in the literature indicate cytomorphologic features and diagnostic problems of the various tumor entities (references are provided in Sect 5.1 together with the various tumor types, p. 401).

\subsection{Adenoid Cystic Carcinoma (Fig. 2.54)}

Adenoid cystic carcinomas usually arise in large bronchi and in the trachea. Distinction from well-differentiated pulmonary adenocarcinoma and mucin-producing adenocarcinomas with a histologically pronounced cribriform architecture may be difficult $[21,27,77,107]$. A pure epithelial component can lead to a misdiagnosis of carcinoid tumors.

\subsection{Mucoepidermoid Carcinoma (Fig. 2.55)}

Mucoepidermoid carcinoma usually arises in the periphery of the bronchial tree. An admixture of neoplastic squamoid cells and mucin-containing tumor cells together with variable amounts of extracellular mucus will definitely provide a correct diagnosis. However, epidermoid features of the malignant squamous cells may be poor and are likely to be overlooked; their cytoplasm may be dense or finely vacuolated.

- Low-grade mucoepidermoid carcinoma is composed of a monotonous tumor cell population with lack of unambiguous evidence of malignancy; the diagnosis will more frequently be suggestive than definite. Differential diagnoses include mucous gland adenoma, bronchioloalveolar carcinoma, mucinous adenocarcinomas (primary and metastatic), among others [77, 99, 107].

- High-grade mucoepidermoid carcinoma is difficult to separate from adenosquamous carcinoma, as keratinized epidermoid cancer cells frequently occur.

\subsection{Other Rare Tumors}

The group of salivary-gland-type carcinomas further includes epithelial-myoepithelial carcinoma.

\subsubsection{Other Primary Neoplasms of the Lung Rarely Seen in Cytologic Practice}

\subsection{Clear Cell Carcinoma}

Clear cell carcinoma is composed of large polygonal tumor cells with clear foamy cytoplasm whose glycogen content is highly variable. It is important to emphasize a number of secondary lung lesions that highly resemble pulmonary clear cell carcinoma: Extrapulmonary clear cell carcinoma may be situated in the kidney, thyroid, salivary gland, female genital organs, or breast. Benign clear cell tumor of the lung - sugar tumor - has to be excluded as well. 


\subsection{Lymphoepithelioma-Like Carcinoma}

Lymphoepithelial carcinoma is an undifferentiated epithelial neoplasia of the large-cell type associated with prominent benign lymphoid infiltration. This tumor entity is typically located in the nasopharynx and occurs extremely rarely in other sites including the lung. The cytomorphologic features of this tumor are provided in Sect. 8.7.3, p. 568 .

Pulmonary lymphoepithelioma-like carcinoma has to be distinguished from benign and malignant lung disorders that are accompanied by pronounced lymphatic hyperplasia such as granulomatous disorders (abundant lymphocytosis and activated histiocytes that mimic carcinoma cells), malignant lymphoma (large-cell blastic type accompanied by benign lymphoid hyperplasia), melanoma, or sarcoma [19].

\subsection{Sarcomatoid Carcinoma}

Sarcomatoid carcinomas are poorly differentiated non-smallcell lung cancers that are accompanied by spindle cells, giant cells (or a mixture of both cell types), or a sarcomatous component $[1,74,75,100,119]$.

- Giant cell carcinomas are composed of mono- and/or multinucleated large polygonal cells with distinct malignant cytological features. Pure giant cell carcinoma is very rare.

- Spindle cell carcinomas consisting exclusively of spindleshaped tumor cells are rare; an admixture of giant elements is frequently observed. Spindle cell areas display a sarcoma-like growth pattern, but the cells show epithelial differentiation in immunocytochemistry for epithelial markers [75]. If immunostaining for cytokeratins is negative, separation from true sarcoma is practically impossible from cytomorphology alone.

- Carcinosarcoma [23] is a highly malignant tumor with carcinomatous and sarcomatous areas. The latter should include heterologous elements such as cartilage, bone, and skeletal muscle. Rhabdomyoid cells together with carcinomatous elements have been reported by Ishizuka and coauthors in a sputum probe [50].

- Pulmonary blastoma is a biphasic tumor containing a primitive epithelial component and primitive stroma; the latter show areas of heterologous mesenchymal tissue. The classic pulmonary blastoma is usually encountered in adults [76], whereas pleuropulmonary blastoma is a tumor of early childhood $[37,81]$.

O Stromal cells show scant cytoplasm containing ovoid to elongated nuclei with coarse chromatin and irregular nucleoli. Epithelial cells are arranged in sheets, the cytoplasm is vacuolated or foamy and ill defined. The nuclei are eccentrically located and contain irregularly shaped nucleoli [76].

\subsection{Soft Tissue Tumors}

Sarcomas rarely occur in the lung and a diagnosis from cytology is rather ambivalent. They are more likely encountered in fine-needle aspirates than in exfoliative cytologic samples; stromal tumors rarely exfoliate their cells into the bronchial tree. Only a few cases are on record in the literature, leiomyosarcoma [3, 84, 129], chondrosarcoma [71], synovial sarcoma, fibrosarcoma [66], and malignant fibrous histiocytoma $[35,46]$. Leiomyosarcoma is most frequently reported.

Hummel and coauthors recently reviewed a large number of pulmonary spindle cell and mesenchymal lesions in transthoracic FNABs with respect to cytomorphologic features, differential diagnosis, and pitfalls [47]; Wakely studied the features and limitations of FNAB in the analysis of pulmonary spindle cell lesions [121].

\subsection{Germ Cell Tumors}

Malignant germ cell tumors of the lung are extremely rare. In suspicious cases, an anaplastic primary lung carcinoma should always be excluded.

As known from other body sites (e.g., mediastinum, retroperitoneum), metastatic germ cell neoplasms to the lung may be solely composed of mature tumor elements after successful chemotherapy and radiotherapy of the remote primary tumor.

\subsubsection{Malignant Lymphoid and Myelogenic} Tumors

\subsection{Non-Hodgkin Lymphoma and Leukemia}

[7, 68] (Figs. 2.53, 2.56 and 2.57)

- The prognosis of patients with malignant lymphoma has dramatically improved over the last few decades under new therapeutic regimes, and the tumors are given additional time for recurrence and dissemination. Accordingly, the lung becomes more frequently involved with malignant lymphoid lesions and cytopathologists are more frequently confronted with such cases.

- Differential diagnosis with small-cell carcinoma may be crucial, particularly in cases when small-cell carcinomas are composed of a predominant intermediate cell population. Considerations to distinguish between these two entities are discussed in Sect. 2.2.2.6, p. 144 (Figs. 2.53, 2.56 and 2.57).

- Acute lymphoid and myeloid leukemia share many cytomorphologic features; discrimination may be difficult unless immunocytochemical tests are used. Both tumor entities have to be distinguished from pulmonary and nonpulmonary large-cell neoplasia, particularly large-cell carcinoma and amelanotic melanoma.

\subsection{Hodgkin Lymphoma}

[33, 38, 111] (Fig. 2.58)

- Hodgkin lymphoma (HL) in the lung can develop during the course of the disease. Pulmonary Hodgkin disease without lymph node involvement is extremely rare [17]. 
- Cytologic specimens reveal a polymorphous lymphohistiocytic background pattern:

O Small and large benign mononuclear lymphoid and histiocytoid cells are intermingled with atypical lymphocytes. The latter comprise enlarged nuclei with irregular outlines and conspicuous nucleoli. This cell pattern is not specific for HL; malignant non-Hodgkin lymphoma, various benign lymphoproliferative pulmonary disorders, and small-cell carcinoma should be taken into consideration.

O Cytology is diagnostic of Hodgkin disease solely in the presence of classic Hodgkin- and Reed-Sternberg cells.

\section{Caution}

- Large-cell malignant lymphoma and acute myelomonocytic leukemias may simulate large-cell cancer.

- Malignant lymphoma composed of small to medium-sized cells together with features of cell degeneration may lead to a misdiagnosis of small-cell carcinoma.

- The classic pleomorphic lymphoid-histiocytic background of Hodgkin lymphomas is nonspecific; unequivocal Reed-Sternberg cells must be present for a conclusive cytologic diagnosis.

\subsubsection{Secondary Tumors (Metastatic and Invading from Adjacent Organs and Structures)}

- The lung is the most common site of metastatic tumor implants. Approximately $50 \%$ of all metastatic tumors to the lung shed their cells into the pulmonary airways [61]. Numerous metastatic neoplasms mimic primary lung cancer morphologically, clinically, and on imaging studies. Cavitation, interstitial growth, and an alveolar wall-lining pattern may be marked in varied secondary tumors.

- Adenocarcinoma is by far the most common metastatic tumor detected in exfoliative bronchial specimens. Among these, adenocarcinoma from the colon and breast are the most frequently encountered cancers, both in the past and in current practice [4]. Other relatively frequently encountered metastases and invasive lung tumors from adjacent sites are renal cell carcinoma, transitional cell carcinoma, squamous cell carcinoma, malignant melanoma, and malignant lymphoma.

- Immunocytochemical studies are extremely helpful to establish the primary tumor site for the majority of suspected metastatic tumors with indistinct cytologic findings [86]. Further help may be provided by a positive clinical history and correlative studies with relevant histologic material from the same patient.

- The cytomorphologic pattern of the majority of secondary tumors is relatively nonspecific. Still, a definite or at least peculiar cell pattern in exfoliative specimens may raise suspicions of a neoplasm from a particular extrapulmonary origin.

Selected entities are discussed:

\subsection{Breast Carcinoma (Fig. 2.59)}

Some breast cancers exhibit small monomorphic tumor cells.

O The nuclei are irregular including deep grooves, the chromatin is fine and pale, and nucleoli may be inconspicuous. In addition, many cases will reveal a singlefile tumor cell arrangement.

Thus, the resemblance to bronchioloalveolar carcinoma is striking, as it is to other secondary tumors that exhibit similar nuclear features such as renal cell carcinoma, papillary thyroid carcinoma, and papillary transitional cell carcinoma.

Immunocytochemistry: Breast carcinoma (hormone receptors + ) and lung adenocarcinoma (TTF-1+) show an opposite immunoprofile (please see "Cautions", p. 149).

\subsection{Colonic Carcinoma (Fig. 2.60)}

Lung metastases of colonic adenocarcinoma are commonly associated with small and large tight cell clusters.

O Less poorly differentiated tumors exhibit a palisadelike arrangement of columnar cells. The nuclei are hyperchromatic and coarsely structured. Pleomorphic tumor detritus is frequently observed.

Immunocytochemistry: CDX2 and CK20 positivity and CK7 negativity are reliable indicators for metastatic colonic carcinoma.

\subsection{Transitional Cell Carcinoma}

Cells of poorly differentiated urothelial carcinoma metastatic to the lung may look like those exfoliating from a poorly differentiated squamous cell carcinoma.

O Both tumor entities may contain large cells with pleomorphic nuclei, large nucleoli, and dense cyanophilic cytoplasm; the latter may show vague concentric lamellation. Pronounced necrotic debris raises suspicions of transitional cell carcinoma.

Immunocytochemistry: An immunocytochemical profile including positivity for CK7, CK20, and CK13 raises suspicions of transitional cell carcinoma. CK20 usually show no positive reaction on malignant squamous cells of primary lung origin.

\subsection{Adenocarcinoma of the Prostate}

This tumor is composed of rather monomorphic mediumsized to large cells showing a characteristic round nucleus, a single pronounced nucleolus, and evenly distributed granular chromatin. The tumor cells are arranged in compact and regular sheets and clusters. 
Immunocytochemistry: Positivity for specific prostatic cellular antigens (e.g., PSA) helps to provide a final diagnosis.

\subsection{Malignant Melanoma (Fig. 2.61)}

Pigmented melanoma should raise no diagnostic problems except in rare cases of carcinoid tumors that exhibit nuclear polymorphism and melanin production. However, nonpigmented melanoma may be difficult to differentiate from poorly differentiated squamous cell carcinoma, poorly differentiated adenocarcinoma, and undifferentiated carcinoma of the lung. All these tumors are characterized by large cells, pleomorphic nuclei, huge nucleoli, clumped chromatin, and cytoplasm of varying shape, size, and structure. Absence of cell clustering is pathognomonic for large-cell neoplasms.

Immunocytochemistry: Reactivity for melanoma-typical markers (HMB-45, Melan A) together with a strong positivity for S100 are indicators for the presence of amelanotic melanoma.

\subsection{Malignant Mesothelioma}

Pleural mesothelioma is a diffusely spreading tumor involving primarily parietal and visceral surfaces of the thoracic cavity and lung. Mesothelioma, mainly of the sarcomatoid type, may infiltrate beyond the pleura visceralis into the lung parenchyma. Infiltrates may mimic a peripheral lung tumor and can be investigated by FNAB. Mesothelioma cells may rarely be encountered in exfoliative samples from the bronchial system.

Immunocytochemistry: Calretinin-positive epithelioid tumor cells that show negative reactivity for TTF-1 raise high suspicions of a mesothelioma invading the lung.

2.2.2.10.7 Malignant Mesenchymal Tumors (Fig. 2.62) A distinct tendency exists for sarcomas to metastasize into the lung parenchyma. Spindle cell pulmonary carcinoma, undifferentiated carcinoma, and mesothelioma of the sarcomatoid type have to be excluded by immunocytochemical testing (Fig. 2.62)

\section{Caution}

- Patients with a long-standing tumor-free interval, whose primary tumor had been successfully treated several years before are most likely to get a diagnosis of primary lung cancer at the time of pulmonary recurrence if the exact clinical history is not available.

- Breast carcinoma: Isolated cells from monomorphic breast carcinoma in exfoliative material are likely to be overlooked unless a clinical history of breast cancer is kept in the medical records. Estrogen receptors may be detected in pulmonary adenocarcinomas as well [25].

- Colonic carcinoma may be strongly suspected in the presence of clearly malignant columnar carcinoma cells in a palisade arrangement.
- Transitional cell carcinoma: Cells of poorly differentiated urothelial carcinoma may look like cells of poorly differentiated squamous cell carcinoma of the lung.

- Malignant melanoma: Amelanotic melanoma mimics poorly differentiated and undifferentiated primary cancers of the lung.

\subsubsection{Neuroendocrine Tumors}

\subsubsection{Introduction}

- Lung tumors with neuroendocrine tumor (NET) differentiation include four entities that are different in their epidemiologic, clinical, (cyto)morphologic and molecular properties [32]. The two main groups of NET include:

(1) Typical and atypical carcinoid tumors that are considered low-grade and intermediate-grade carcinomas having a moderate to good prognosis;

(2) Large-cell neuroendocrine carcinoma and small-cell carcinoma, known to have a poor clinical course [13, 32].

Typical and atypical carcinoid tumors are distinguished from each other by their appearance under the light microscope (see below).

- Immunocytochemical reactivity for neuroendocrine markers (chromogranin, synaptophysin, and CD56) acts as an indicator for neuroendocrine differentiation. Immunostaining reveals no crucial differences between the four subtypes of neuroendocrine tumors.

- Carcinoids typically appear as nodular exophytic lesions protruding into the bronchial lumen, but tumor cells are rarely observed in sputum and bronchial secretion due to the intact covering mucosa. In contrast, carcinoids generally provide a large number of cells in specimens sampled by brushing and fine-needle aspiration.

- Neuroendocrine differentiation has been found to be an attribute not only of NET but also of a proportion of nonsmall-cell lung carcinomas. Detection of focal neuroendocrine features in the latter depends on a spectrum of technical approaches and biological properties (antibodies used, nature of tissue specimen, etc.) [12, 112].

\subsubsection{Typical Carcinoid Tumors}

[13, 78, 80] (Figs. 2.63 and 2.64)

Typical carcinoid tumors grow slowly and rarely spread beyond the lungs. They are nine times as common as atypical carcinoids. Nearly all central carcinoid tumors are typical carcinoids located in the walls of large bronchi near the lung center. 


\section{Microscopic Features}

O Hallmarks: Uniformity of the neoplastic cells is a pathognomonic feature of this tumor.

The tumor cells occur singly, in loose sheets, or as three-dimensional cohesive clusters. Cell clusters may show an acinus-like and rosette formation.

The cells and nuclei are small to medium-sized, round to ovoid. The nucleus is usually displaced to the periphery of the cytoplasm, giving the cell a plasma celllike appearance.

The chromatin pattern is finely granular and the nucleoli are inconspicuous.

Basophilic or eosinophilic cytoplasm is moderate in size and contains fine granules.

Very few mitoses.

O The N/C ratio is variable.

O On occasion one can observe nests of small spindle cells.

O The background of cytologic specimens is clean, necrosis is absent.

\section{Caution}

Sputum probes that contain typical carcinoid cells may likely be attended by pronounced cell detritus and necrosis derived from the traumatized mucosal surface area and not from the tumor parenchyma itself.

\section{Differential Diagnosis}

- A solid epithelial component of adenoid cystic carcinoma that is composed of small monomorphic cells may be mistaken for carcinoid cells. Cells of adenoid cystic carcinoma are immunocytochemically negative for neuroendocrine markers.

- Low-grade non-Hodgkin lymphoma may mimic carcinoid tumors in cases exfoliating numerous isolated monomorphic tumor cells (Fig. 2.56).

- Metastases of monomorphic small-cell adenocarcinomas (e.g., breast carcinoma) exhibiting fine granular chromatin, inconspicuous nucleoli, and variably granular cytoplasm must be eliminated. Immunocytochemically, hormone receptors are not expressed in cells of carcinoid tumors, but cells of breast carcinoma may coexpress neuroendocrine markers.

\subsubsection{Atypical Carcinoid Tumors}

[13, 80, 95] (Figs. 2.65 and 2.66)

Atypical carcinoids account for about $10 \%$ in the carcinoid tumor group. They grow slightly faster and are more likely to spread to other organs. They have more cells in the process of dividing.

\section{Microscopic Features}

O The same cytological features appear as described for typical carcinoids, but the neoplastic cells exhibit greater cellular polymorphism. In particular, they are more frequently spindle-shaped.

O The nuclei are more irregular in shape and occasionally molded. The chromatin is coarse. Hyperchromasia and nucleoli are distinct.

○ Mitotic figures and necrosis are common.

\section{Differential Diagnosis}

- Generally, nuclear size and nucleoli are important diagnostic features distinguishing typical carcinoids from atypical carcinoid tumors and large cell neuroendocrine carcinoma.

- Small-cell lung carcinoma [95] and large-cell neuroendocrine carcinoma are distinguished from atypical carcinoid by a notably higher mitotic rate and extensive necrotic background.

- Adenocarcinoma and mucoepidermoid carcinoma with absence of mucin and immunocytochemical positivity for neuroendocrine markers raise suspicions of atypical carcinoid tumor.

- Mesenchymal neoplasms, particularly smooth muscle tumor, are the most frequent lesions, which have to be separated from atypical carcinoids with spindle cell features. An appropriate panel of antibodies generally resolves the problem.

- Rare melanin-producing carcinoids of the spindle cell type share features with fusiform, small-cell pigmented melanoma.

- Prostate carcinoma is characterized by a finely granular chromatin texture, large nucleoli, and occasionally granular cytoplasm. Tumors composed of small to mediumsized cells may resemble atypical carcinoid tumors. An immunocytochemical panel comprising prostate-typical and neuroendocrine antibodies will provide the correct diagnosis.

- Paraganglioma composed of epithelioid cells with carcinoid-like nuclear features is difficult to separate from atypical carcinoid cells [63]. However, pulmonary paraganglioma is extremely rare and cytokeratins are not expressed by use of immunocytochemistry. 


\subsubsection{Large-Cell Neuroendocrine Carcinoma} [52, 53, 69, 80, 123] (Fig. 2.67)

The WHO 2004 nomenclature categorizes large-cell neuroendocrine carcinoma (LCNC) as large-cell pulmonary carcinoma [119]. LCNCs may appear in a pure form, but occasionally they are combined with fractions of small-cell carcinoma or non-small-cell carcinoma. LCNCs have a poor clinical outcome.

\section{Microscopic Features}

O Hallmarks:

Hypercellular smears containing numerous single tumor cells and stripped nuclei.

Three-dimensional tumor cell clusters may display distinct peripheral palisading and rosette-like structures.

The cells are of medium to large size with variable-size cytoplasm.

The nuclei are pleomorphic comprising irregular contours, molding, and finely or coarsely granular chromatin.

The prominent nucleoli most often occur singly, but tumors have been observed containing small and inconspicuous nucleoli.

Necrosis and mitotic figures are common.

O Giant cells may be present.

O A single-file cell arrangement may be encountered.

$\bigcirc$ Apoptotic changes are frequently observed.

\section{Immunocytochemistry}

Clear positivity with one neuroendocrine marker is sufficient for a definite diagnosis of LCNC. Synaptophysin seems to be the perfect neuroendocrine marker for this particular tumor entity. Synaptophysin is highly specific and more sensitive than chromogranin $[44,123]$.

About 50\% of the large-cell neuroendocrine carcinomas show nuclear positivity for TTF-1 antigen $[53,113]$.

\section{Differential Diagnosis}

- LCNC comprising pronounced nucleolar polymorphism and large cytoplasm may be confused with poorly differentiated primary lung carcinoma of squamous or glandular origin [58] (Fig. 2.67).
- Rarely, LCNC can be misdiagnosed as small-cell carcinoma; even so, single-file cell arrangement, small nuclear size, nuclear molding, and absence of nucleoli are important differential features typically occurring in small-cell carcinoma [58, 130].

- Large-cell-type prostatic carcinoma (large nucleoli, finely granular chromatin, cytoplasmic similarity) may mimic LCNC. Immunocytochemical reactivity for prostate-specific markers and negative immunostaining for neuroendocrine antigens exclude $\mathrm{LCNC}$, and vice versa.

\section{Caution}

Fifty percent of LCNCs show immunocytochemical positivity for TTF-1. Distinction from poorly differentiated pulmonary adenocarcinoma may be difficult.

\subsubsection{Pulmonary Tumorlet}

- Pulmonary tumorlets are evidenced to originate from pulmonary Kulchitsky-type cells. Therefore, tumorlets can be defined as benign localized neuroendocrine cell proliferations looking like tiny peripheral carcinoids (less than $5 \mathrm{~mm}$ in diameter). Tumorlets are frequently associated with neuroendocrine cell hyperplasia in the adjacent bronchiolar mucosa [94].

- Nodules with an exceptional protrusion into the bronchial lumen are visualized by endoscopy and may be followed by brushing or transbronchial FNAB.

- Tumorlets are usually composed of spindle cells or epithelial-type cells; therefore, their morphology is indistinguishable from typical or atypical carcinoid tumors.

- The cell pattern of tumorlets can occasionally mimic small-cell carcinoma, well-differentiated adenocarcinoma, or a nonepithelial malignant neoplasm $[5,106]$. However, the regularity of the tumorlet nuclei and a very low mitotic activity should exclude malignancy.

- The neuroendocrine origin of the aspirated cells can immunocytochemically be confirmed using antibodies to synaptophysin, chromogranin, and NSE. 


\subsubsection{Further Reading}

1. Alasio TM, Sun W, Yang GC. Giant cell carcinoma of the lung impact of diagnosis and review of cytological features. Diagn Cytopathol 2007;35:555-559.

2. Al-Haddad M, Wallace MB. Molecular diagnostics of non-small cell lung cancer using mediastinal lymph nodes sampled by endoscopic ultrasound-guided needle aspiration. Cytopathology 2006;17:3-9.

3. Ali SZ, Kronz JD, Plowden KM, Erozan YS. Metastatic pulmonary leiomyosarcoma: cytopathologic diagnosis on sputum examination. Diagn Cytopathol 1998;18:280-283.

4. Ali TZ, Zakowski MF, Yung RC, et al. Exfoliative sputum cytology of cancers metastatic to the lung. Diagn Cytopathol 2005;33:147151.

5. Armbruster C, Bernhardt K, Setinek U. Pulmonary tumorlet. A case report of a diagnostic pitfall in cytology. Acta Cytol 2008;52:223227.

6. Arora VK, Singh N, Chaturvedi S, Bhatia A. Significance of cytologic criteria in distinguishing small cell from non-small cell carcinoma of the lung. Acta cytol 2003;47:216-220.

7. Bardales RH, Powers CN, Frierson HF Jr, et al. Exfoliative respiratory cytology in the diagnosis of leukemias and lymphomas in the lung. Diagn Cytopathol 1996;14:108-113.

8. Berg J, Aase S, Soland TH, et al. The value of cytology in the diagnostics of lung cancer. APMIS 2005;113:208-212.

9. Berwanger I, Bonnet R, Jacobsen JP, et al. Thoracic endometriosis - 2 case reports and review of the literature. Pneumologie 1992;46:236-238.

10. Black H, Ackerman LV. The importance of epidermoid carcinomas in situ in the histogenesis of carcinoma of the lung. Ann Surg 1953;136:44-55.

11. Canver CC, Memoli V A, et al. Sex hormone receptors in nonsmall-cell lung cancer in human beings. J Thorac Cardiovasc Surg 1994;108:153-157.

12. Carey FA, Save VE. Neuroendocrine differentiation in lung cancer. J Pathol 1997;182:9-10.

13. Carter D, Yesner R. Carcinomas of the lung with neuroendocrine differentiation. Semin Diagn Pathol 1985;2:235-254.

14. Caya JG, Gilles L, Tieu TM, et al. Lung cancer treated on the basis of cytologic findings: an analysis of 112 patients. Diagn Cytopathol 1990;6:313-316.

15. Caya JG, Wollenberg NJ, Clowry LJ, Tieu TM. The diagnosis of pulmonary small-cell anaplastic carcinoma by cytologic means: a 13-year experience. Diagn Cytopathol 1988;4:202-205.

16. Chen C, Hoda RS, Hoda SA. Intranuclear cytoplasmic inclusions in the differential diagnosis of papillary thyroid carcinoma and bronchioloalveolar carcinoma. Diagn Cytopathol 1998;18:384-386.

17. Chetty R, Slavin JL, O'Leary JJ, et al. Primary Hodgkin's disease of the lung. Pathology 1995;27:111-114.

18. Cheuk W, Kwan MY, Suster S, Chan JK. Immunostaining for thyroid transcription factor 1 and cytokeratin 20 aids the distinction of small cell carcinoma from Merkel cell carcinoma, but not pulmonary from extrapulmonary small cell carcinomas. Arch Pathol Lab Med 2001;125:228-231.

19. Chow LT, Chow WH, Tsui WM, et al. Fine-needle aspiration cytologic diagnosis of lymphoepithelioma-like carcinoma of the lung Report of two cases with immunohistochemical study. Am J Clin Pathol 1995;103:35-40.

20. Chu PG, Weiss LM. Expression of cytokeratin 5/6 in epithelial neoplasms: an immunocytochemical study of 509 cases. Mod Pathol 2002;15:6-10

21. Chuah KL, Lim KH, Koh MS, et al. Diagnosis of adenoid cystic carcinoma of the lung by bronchial brushing: a case report. Acta Cytol 2007;51:563-566.
22. Cohen MH. Guest Editorial. Lung Cancer: A status report. J Natl Cancer Inst 1975;55:505-511.

23. Cohen-Salmon D, Michel RP, Wang NS, et al. Pulmonary carcinosarcoma and carcinoma: report of a case studied by electron microscopy, with critical review of the literature. Ann Pathol 1985;5:115-124.

24. Cwierzyk TA, Glasberg SS, Virshup MA, Cranmer JC. Pulmonary oncocytoma. Report of a case with cytologic, histologic and electron microscopic study. Acta Cytol 1985;29:620-623.

25. Dabbs DJ, Landreneau RJ, Liu Y, et al. Detection of estrogen receptor by immunohistrochemistry in pulmonary adenocarcinoma. Ann Thorac Surg 2002;73:403-405.

26. Dacic S. Pulmonary preneoplasia. Arch Pathol Lab Med 2008;132:1073--1078.

27. Daneshbod Y, Modjtahedi E, Atefi S, et al. Exfoliative cytologic findings of primary pulmonary adenoid cystic carcinoma: a report of 2 cases with a review of the cytologic features. Acta Cytol 2007;51:558-562.

28. de Aquino RT, Magliari ME, Saad R Jr, et al. Bronchial oncocytoma. Sao Paulo Med J 2000;118:195-197.

29. Delgado PI, Jorda M, Ganjei-Azar P. Small cell carcinoma versus other lung malignancies: diagnosis by fine-needle aspiration cytology. Cancer 2000;90:279-285.

30. Downey P, Cummins R, Moran M, Gulmann C. If it's not CK5/6 positive, TTF-1 negative it's not a squamous cell carcinoma of the lung. APMIS 2008;116:526-529.

31. Edelweiss M, Gupta N, Resetkova E. Preoperative diagnosis of clear cell „sugar" tumor of the lung by computed tomographyguided fine-needle biopsy and core-needle biopsy. Ann Diagn Pathol 2007;11:421-426.

32. Flieder DB. Neuroendocrine tumors of the lung: recent developments in histopathology. Curr Opin Pulm Med 2002;8:275-280.

33. Flint A, Kumar NB, Naylor B. Pulmonary Hodgkin'disease. Diagnosis by fine needle aspiration. Acta Cytol 1988;32:221-225.

34. Fontana RS, Sanderson DR, Woolner LB, et al. The Mayo lung project for early detection and localization of bronchogenic carcinoma: A status report. Chest 1975;67:511-522.

35. Fujita Y, Shimizu T, Yamazaki K, et al. Bronchial brushing cytology features of primary malignant fibrous histiocytoma of the lung. A case report. Acta Cytol 2000;44:227-231.

36. Fulciniti F, Vetrani A, Cozzolino I, et al. Fine-needle cytology of inflammatory myofibroblastic tumor of the lung. Report of a case. Pathologica 2004;96:430-432.

37. Gelven PL, Hopkins MA, Green CA, et al. Fine-needle aspiration cytology of pleuropulmonary blastoma: case report and review of the literature. Diagn Cytopathol 1997;16:336-340.

38. Giangreco A, Ettinger DS, Dragon LH, et al. Sputum cytologic diagnosis of Hodgkin's disease involving the lung. Arch Intern Med 1980;140:910-913.

39. Granberg I, Willems JS. Endometriosis of lung and pleura diagnosed by aspiration biopsy. Acta Cytol 1977;21:295-297.

40. Grefte JM, Salet-van de Pol MR, Gemmink JH, et al. Quantitation of Ki-67 expression in the differential diagnosis of reserve cell hyperplasia vs. small cell lung carcinoma. Acta Cytol 2004;48:608612.

41. Guinee DG Jr, Fishback NF, Koss MN, et al. The spectrum of immunohistochemical staining of small-cell lung carcinoma in specimens from transbronchial and open-lung biopsies. Am J Clin Pathol 1994;102:406-414.

42. Gupta PK, Verma K. Calcified (Psammoma) bodies in alveolar cell carcinoma of the lung. Acta Cytol 1972;16:59-62.

43. Gupta RK. Value of sputum cytology in the differential diagnosis of alveolar cell carcinoma from bronchogenic adenocarcinoma. Acta Cytol 1981;25:255-258. 
44. Hammar SP. Immunohistology of lung and pleural neoplasms. In: Dabbs D, ed. Diagnostic immunohistochemistry. 2nd ed. Churchill Livingston Elsevier; 2006: 329-403.

45. Hannah CD, Oliver DH, Liu J. Fine needle aspiration biopsy and immunostaining findings in an aggressive inflammatory myofibroblastic tumor of the lung: a case report. Acta Cytol 2007;51:239243.

46. Hoshi R, Satoh Y, Tsuzuku M, Horai T, Ishikawa Y. Fine needle aspiration cytology of fibrous histiocytomas of the lung. Acta Cytol 2004;48:290-292.

47. Hummel P, Cangiarella JF, Cohen JM, et al. Transthoracic fineneedle aspiration biopsy of pulmonary spindle cell and mesenchymal lesions: a study of 61 cases. Cancer 2001;93:187-198.

48. Inoue $\mathrm{Y}$, Oka M, Ishii $\mathrm{H}$, et al. A solitary bronchial papilloma with malignant changes. Intern Med 2001;40:56-60.

49. Ipakchi R, Zager WH, de Baca ME, et al. Granular cell tumor of the trachea in pregnancy: a case report and review of literature. Laryngoscope 2004;114:143-147.

50. Ishizuka T, Yoshitake J, Yamada T, et al. Diagnosis of a case of pulmonary carcinosarcoma by detection of rhabdomyosarcoma cells in sputum. Acta Cytol 1988;32:658-662.

51. Jerome Marson V, Mazieres J, Groussard O, et al. Expression of TTF-1 and cytokeratins in primary and secondary epithelial lung tumours: correlation with histological type and grade. Histopatho$\operatorname{logy} 2004 ; 45: 125-134$

52. Jiang SX, Kameya T, Shoji M, et al. Large cell neuroendocrine carcinoma of the lung: a histologic and immunohistochemical study of 22 cases. Am J Surg Pathol 1998;22:526-537.

53. Jimenez-Heffernan JA, Lopez-Ferre P, Vicandi B, et al. Fine-needle aspiration cytology of large cell neuroendocrine carcinoma of the lung. A cytohistologic correlation study of 11 cases. Cancer(Cancer Cytopathol) 2008;114:180-186.

54. Jin M-S, Ha H-J, Baek HJ, et al. Adenomyomatous hamartoma of lung mimicking benign mucinous tumor in fine needle aspiration biopsy. A case report. Acta Cytol 2008;52:357-360.

55. Johnston WW, Frable WJ. Diagnostic respiratory cytopathology. Masson Publishing USA, Inc. 1979.

56. Johnston WW, Elson CE. Chapter 14, Respiratory Tract. in:Comprehensive Cytopathology, ed. M.Bibbo. WB.Saunders Company, 1991.

57. Junquera LM, de Vicente JC, Vega JA, et al. Granular-cell tumours: an immunohistochemical study. $\mathrm{Br} \mathrm{J}$ Oral Maxillofac Surg 1997;35:180-184.

58. Kakinuma H, Mikami T, Iwabuchi K, et al. Diagnostic findings of bronchial brush cytology for pulmonary large cell neuroendocrine carcinomas: comparison with poorly differentiated adenocarcinomas, squamous cell carcinomas, and small cell carcinomas. Cancer 2003;99:247-254.

59. Kalhor N, Zander DS, Liu J. TTF-1 and p63 for distinguishing pulmonary small-cell carcinoma from poorly differentiated squamous cell carcinoma in previously pap-stained cytologic material. Mod Pathol 2006;19:1117-1123.

60. Kamiya M, Uei Y, Shimosato Y. Cytologic features of peripheral squamous cell carcinoma of the lung. Acta Cytol 1995;39:61-68.

61. Kern WH, Schweizer C. Sputum cytology of metastatic carcinoma of the lung. Acta Cytol 1976;20:514-520.

62. Kerr KM. Pulmonary preinvasive neoplasia. J Clin Pathol 2001;54:257-271.

63. Kim MK, Park SH, Cho HD, et al. Fine needle aspiration cytology of primary pulmonary paraganglioma. A case report. Acta Cytol 2001;45:459-464.

64. Lantuejoul Clear cell tumor of the lung: an immunohistochemical and ultrastructural study supporting a pericytic differentiation. Mod Pathol 1997;10:1001-1008.
65. Lee SC, Johnson H. Multiple nodular pulmonary amyloidosis. A case report and comparison with diffuse alveolar-septal pulmonary amyloidosis. Thorax 1975;30:178-185.

66. Logrono R, Filipowicz EA, Eyzaguirre EJ, Sawh RN. Diagnosis of primary fibrosarcoma of the lung by fine-needle aspiration and core biopsy. Arch Pathol Lab Med 1999;123:731-735.

67. MacDonald LL, Yazdi HM. Fine-needle aspiration biopsy of bronchioloalveolar carcinoma. Cancer 2001;93:29-34.

68. Manoharan A, Ford J, Hill J, et al. Sputum cytology in the diagnosis of pulmonary non-Hodgkin's lymphoma. Thorax 1984;39:392393.

69. Marmor S, KorenR, Halpern M, et al. Transthoracic needle biopsy in the diagnosis of large-cell neuroendocrine carcinoma of the lung. Diagn Cytopathol 2005;33:238-243.

70. Matsubara O, Tan-Liu NS, Kenney RM, Mark EJ. Inflammatory pseudotumors of the lung: progression from organizing pneumonia to fibrous histiocytoma or to plasma cell granuloma in 32 cases. Hum Pathol 1988;19:807-814.

71. Matsuo T, Kinoshita S, Iwasaki K, et al. Chondrosarcoma of the trachea. Acase report and literature review. Acta Cytol 1988;32:908912.

72. McCalip B, Reading C, Krishnamurthy S. Diagnosis of small cell carcinoma of the lung on fine needle aspiration samples. Cancer(Cancer Cytopathol 2007; Suppl 111:411-412.

73. Mermolja M, Rott T. Cytology of endobronchial granular cell tumor. Diagn Cytopathol 1991;7:524-526.

74. Mochizuki T, Ishii G, Nagai K, et al. Pleomorphic carcinoma of the lung: Clinicopathologic characteristics of 70 cases. Am J Surg Pathol 2008;32:1727-1735.

75. Nakajima M, Kasai T, Hashimoto T, et al. Sarcomatoid carcinoma of the lung: a clinicopathologic study of 37 cases. Cancer 1999;86:608-616.

76. Nakashima M, Inagaki T, Kunimura T, et al. Cytopathologic and histologic features of biphasic pulmonary blastoma: a case report. Acta Cytol 2005;49:87-91.

77. Nguyen GK. Cytology of bronchial gland carcinoma. Acta Cytol 1988;32:235-239.

78. Nguyen GK. Cytopathology of pulmonary carcinoid tumors in sputum and bronchial brushings. Acta Cytol 1995;39:1152-1160.

79. Nguyen GK. Aspiration biopsy cytology of benign clear cell (,sugar") tumor of the lung. Acta Cytol 1989;33:511-515.

80. Nicholson SA, Ryan MR. A review of cytologic findings in neuroendocrine carcinomas including carcinoid tumors with histologic correlation. Cancer 2000;90:148-161.

81. Nicol KK, Geisinger KR. The cytomorphology of pleuropulmonary blastoma. Arch Pathol Lab Med 2000;124:416-418.

82. Nunes H, Bagan P, Kambouchner M, Martinod E. Thoracic endometriosis. Rev Mal Respir 2007;24:1329-1340.

83. Nunez V. Melamed MR, Cahan W. Tracheo-bronchial cytology after laryngectomy for carcinoma of larynx. II. Benign atypias. Acta Cytol 1966;10:38-48.

84. Odashiro AN, Miiji LO, Nguyen GK. Primary lung leiomyosarcoma detected by bronchoscopy cytology. Diagn Cytopathol 2005;33:220-222.

85. Ohori NP, Santa Maria EL. Cytopathologic diagnosis of bronchioloalveolar carcinoma: does it correlate with the 1999 World Health Organization definition? Am J Clin Pathol 2004;122:44-50.

86. O'Reilly PE, Brueckner J, Silverman JF. Value of ancillary studies in fine needle aspiration cytology of the lung. Acta Cytol 1994;38:144-150.

87. Osann KE. Epidemiology of lung cancer. Curr Opin Pulm Med 1998;4:198-204.

88. Pankiewicz W, Minarowski L, Niklinska W, et al. Immunohistochemical markers of cancerogenesis in the lung. Folia Histochem Cytobiol 2007;45:65-74. 
89. Papla B, Rudnicka L. Primary amyloid tumors of the lungs - six cases. Pol J Pathol 2005;56:197-202.

90. Pitz MW, Gibson IW, Johnston JB. Isolated pulmonary amyloidosis: case report and review of the literature. Am J Hematol 2006;81:212-213.

91. Policarpio-Nicolas ML, Covell J, Bregman S, Atkins K. Fine needle aspiration cytology of clear cell „sugar“ tumor (PEComa) of the lung: report of a case. Diagn Cytopathol 2008;36:89-93.

92. Rana DN, O'Donnell M, Malkin A, Griffin M. A comparative study: conventional preparation and ThinPrep 2000 in respiratory cytology. Cytopathology 2001;12:390-398.

93. Rana SS, Swami N, Mehta S, et al. intrapulmonary teratoma: an exceptional disease. Ann Thorac Surg 2007;83:1194-1196.

94. Ranchod M. The histogenesis and development of pulmonary tumorlets. Cancer 1977;39:1135-1145.

95. Renshaw AA, Haja J, Lozano RL, et al. Distinguishing carcinoid tumor from small cell carcinoma of the lung: correlating cytological features and performance in the College of American Pathologists Non-Gynecologic Cytology Program. Arch Pathol Lab Med 2005;129: 614-618

96. Renshaw AA (2), Voytek TM, Haja J, et al. Distinguishing small cell carcinoma from non-small cell carcinoma of the lung: correlating cytologic features and performance in the College of American Pathologists Non-Gynecologic Cytology Program. Arch Pathol Lab Med 2005;129: . 619-623.

97. Roger V, Nasiell M, Linden M, Enstad I. Cytologic differential diagnosis of bronchiolo-alveolar carcinoma and bronchogenic adenocarcinoma. Acta Cytol 1976;20:303-307.

98. Roglic M, Jukic S, Damjanov I. Cytology of the solitary papilloma of the bronchus. Acta Cytol 1975;19:11-3.

99. Romagosa C, Morente V, Ramirez JF, et al. Intranuclear inclusions in fine needle aspirates of bronchial low grade mucoepidermoid carcinoma with clear cell change: a report of two cases. Acta Cytol 2002;46:57-60.

100. Rossi G, Cavazza A, Sturm N, et al. Pulmonary carcinomas with pleomorphic, sarcomatoid, or sarcomatous elements: a clinicopathologic and immunohistochemical study of 75 cases. Am J Surg Pathol 2003;27:311-324.

101. Rubel L, Reynolds RE. Cytologic description of squamous cell papilloma of the respiratory tract. Acta Cytol 1979;23:227-231.

102. Rudomina DE, Gatscha RM, Moreira AL. Cytologic diagnosis of pulmonary adenocarcinoma with micropapillary pattern (MPP). Does it correlate with the histologic findings? Cancer(Cancer Cytopathology) 2007;111 (Suppl):407-408.

103. Saccomanno G, Saunders RP, Archer VE, et al. Cancer of the lung: the cytology of sputum prior to the development of carcinoma. Acta Cytol 1965;9:413-423.

104. Saleh HA, Haapaniemi J, Khatib G, Sakr W. Bronchioloalveolar carcinoma: diagnostic pitfalls and immunocytochemical contribution. Diagn Cytopathol 1998;18:301-306.

105. Santos-Martinez MJ, Curull V, Blanco ML, et al. Lung cancer at a university hospital: epidemiological and histological characteristics of a recent and a historical series. Arch Broncopneumol 2005;41:307-312.

106. Satoh Y, Fujiyama J, Ueno M, Ishikawa Y. High cellular atypia in a pulmonary tumorlet. Report of a case with cytologic findings. Acta Cytol 2000;44:242-246.

106A. Schramm M, Wrobel C, Born I, Kazimirek M, Pomjanski N, William $\mathrm{M}$, et al. Equivocal cytology in lung cancer diagnosis:improvement of diagnostic accuracy using adjuvant multicolor FISH, DNA-image cytometry, and quantitative promoter hypermethylation analysis. Cancer Cytopathology 2011; 119:177-192.
107. Segletes LA, Steffee CH, Geisinger KR. Cytology of primary pulmonary mucoepidermoid and adenoid cystic carcinoma. A report of four cases. Acta Cytol 1999;43:1091-1097.

108. Silverman JF, Finley JL, Park HK, et al. Fine needle aspiration cytology of bronchioloalveolar-cell carcinoma of the lung. Acta Cytol 1985;29:887-894.

109. Smith JH, Frable WJ. Adenocarcinoma of the lung. Cytologic correlation with histologic types. Acta Cytol 1974;18:316-320.

110. Spriggs AI, Cole M, Dunnill MS. Alveolar-cell carcinoma: a problem in sputum cytodiagnosis. J Clin Pathol 1982;35:13701379.

111. Stanley C, Wolf P, Haghighi P. Reed-Sternberg cells in sputum from a patient with Hodgkin's disease. A case report. Acta Cytol 1993;37:90-92.

112. Stodkowska J. The value of immunohistochemical identification of neuroendocrine differentiation in non small cell lung carcinoma. Rocz Akad Med Bialymst 1997;42 Suppl 1:23-27.

112A. Stoll LM, Li QK. Cytology of fine-needle aspiration of inflammatory myofibroblastic tumor. Diagnostic Cytopathology 2011;39(9):663-672.

113. Sturm N, Rossi G, Lantuejoul S, et al. Expression of thyroid transcription factor- 1 in the spectrum of neuroendocrine cell lung proliferations with special interest in carcinoids. Hum Pathol 2002;33:175-182.

114. Su JM, Hsu HK, Chang H, et al. Expression of estrogen and progesterone receptors in non-small-cell lung cancer: immunohistochemical study. Anticancer Research 1996;16:3803-3806.

115. Tamura K, Nakajima N, Makino S, et al. Primary pulmonary amyloidosis with multiple nodules. Eur J Radiol 1988;8:128130.

116. Tao LC, Weisbrod GL, Pearson FG, et al. Cytologic diagnosis of bronchioloalveolar carcinoma by fine-needle aspiration biopsy. Cancer 1986;57:1565-1570.

117. Thomas L, Risbud M, Gabriel JB, et al. Cytomorphology of granular-cell tumor of the bronchus. A case report. Acta Cytol 1984;28:129-132.

118. Thunnissen FB, Arends JW, Buchholtz RT, ten Velde G. Fine needle aspiration cytology of inflammatory pseudotumor of the lung (plasma cell granuloma). Report of four cases. Acta Cytol 1989;33:917-921.

119. Travis WD, Brambilla E, Muller-Hermelink HK, Harris CC. (Eds.): World Health Organization Classification of Tumours. Pathology and Genetics of Tumours of the Lung, Pleura, Thymus and Heart. IARC Press: Lyon 2004.

119A. Travis WD, Brambilla E, Noguchi M, Nicholson A, Geisinger $\mathrm{K}$, Yatabe $\mathrm{Y}$, et al. International association for the study of lung cancer/american thoracic society/european respiratory society international multidisciplinary classification of lung adenocarcinoma. Journal of Thoracic Oncology 2011;6(2):244-285.

119B. Travis WD, Rekhtman N. Pathological Diagnosis and Classification of Lung Cancer in Small Biopsies and Cytology: Strategic Management of Tissue for Molecular Testing. Semin Respir Crit Care Med 2011;32(01):022,031.

120. Trillo A, Guha A. Solitary condylomatous papilloma of the bronchus. Arch Pathol Lab Med 1988;112:731-733.

121. Wakely P Jr. Pulmonary spindle cell lesions: correlation of aspiration cytopathology and histopathology. Ann Diagn Pathol 2001;5:216-228

122. Weingarten J. Cytologic and histologic findings in a case of tracheobronchial papillomatosis. Acta Cytol 1981;25:167-170.

123. Wiatrowska BA, Krol J, Zakowski MF. Large-cell neuroendocrine carcinoma of the lung: proposed criteria for cytologic diagnosis. Diagn Cytopathol 2001;24:58-64. 
124. Wiatrowska BA, Yazdi HM, Matzinger FR, Mac Donald LL. Fine needle aspiration biopsy of pulmonary hamartomas. Radiologic, cytologic and immunocytochemical study of 15 cases. Acta Cytol 1995;39:1167-1174.

125. Willett GD, Schumann GB, Genack L. Primary cytodiagnosis of synchronous small-cell cancer and squamous-cell carcinoma of the respiratory tract. Acta Cytol 1984;28:610-613.

126. Wistuba II, Gazdar AF. Lung cancer preneoplasia. Annu Rev Pathol 2006;1:331-348.

127. Wood B, Swarbrick N, Frost F. Diagnosis of pulmonary hamartoma by fine needle biopsy. Acta Cytol 2008;52:412-417.

128. World Health Organization. Histological typing of lung tumors, 2nd edn. WHO, Geneva, 1981.
129. Yamaguchi T, Imamura Y, Nakayama K, et al. Primary pulmonary leiomyosarcoma. Report of a case diagnosed by fine needle aspiration cytology. Acta Cytol 2002;46:912-916.

130. Yang Yj, Steele CT, OU XL, et al. Diagnosis of high-grade pulmonary neuroendocrine carcinoma by fine-needle aspiration biopsy: nonsmall-cell or small-cell type? Diagn Cytopathol 2001;25:292-300.

131. Yeh TJ. Endometriosis within the thorax: metaplasia, implantation, or metastasis? J Thorac Cardiovasc Surg 1967;53:201-205.

132. Zaharopoulos P, Wong JY, Stewart GD. Cytomorphology of the variants of small-cell carcinoma of the lung. Acta Cytol 1982;26:800-808. 


\section{Fig. 2.27 Squamous cell papilloma.}

An intrabronchial exophytic papillary tumor was detected by bronchoscopy in a 59-yearold man. Intra/transbronchial FNAB revealed papilliform microfragments composed of metaplastic-like squamous cells of small and intermediate size. Loss of cellular polarity and nuclear irregularities are distinct (direct smear, Pap stain, higher magnification).

Tentative cytologic diagnosis: Suggestive of squamous cell carcinoma (papillary neoplasm was not taken into consideration).

Tissue diagnosis (excisional biopsy): Squamous cell papilloma exhibiting focal epithelial dysplasia.

\section{Figs. 2.28 and 2.29 Hamartoma.}

Two examples of intrapulmonary hamartoma presenting with different tissue components.

Fig. 2.28 (case \#1) Transcutaneous FNAB of a long-standing nodular lesion in a 64-yearold man's right lung. Low magnification reveals large fragments of loose but cellular fibrous tissue, myxoid stroma (upper right), and a few groups of glandular cells (lower right) (direct smear, Pap stain).

Fig. 2.29 (case \#2) Transbronchial FNAB of parabronchial situated small nodules (middleaged male patient). Low magnification shows large sheets of ciliated columnar cells (upper left) and numerous chondroid fragments (lower right). Morphologic findings are consistent with a cartilaginous hamartoma (direct smear, Pap stain).

\section{Fig. 2.30 Inflammatory pseudotumor.}

A 69-year-old man presented with a small nodule in the periphery of his right lung. Transcutaneous FNAB was performed. The morphology is presented using a specimen immunostained for pancytokeratin-Lu-5 (Pap-prestained direct smear).

The aspirate included numerous compact heterogeneous cell clusters. High magnification disclosed Lu-5-positive staining of mesothelial cells, which are surrounded by clustered round and elongated immunonegative cells (fibroblasts/myofibroblasts, histiocytes, lymphoid cells).

Cytology assumed to be benign or malignant stromal tumor.

Histologic examination of the excised nodule provided a diagnosis of an inflammatory pseudotumor of the lung.

\section{Fig. 2.31 Severe dysplasia.}

Bronchial aspirate from a 59-year-old man giving rise to diagnostic dilemmas.

High magnification shows malignant epithelial cells of adenocarcinoma type (arrows) and keratinized squamous cells with severe atypia (direct smear, Pap stain).

Cytologic evaluation: The initial cytologic diagnosis from exfoliative respiratory material was adenocarcinoma accompanied by atypical squamous cells originating from adjoining dysplastic squamous metaplasia.

Subsequent mediastinal FNAB confirmed the diagnosis of adenocarcinoma (immunocytochemical TTF-1 positivity of the tumor cells).

The additional diagnosis of dysplastic squamous metaplasia of the bronchial epithelium is assumed to be correct.

Histologic results are not available. 

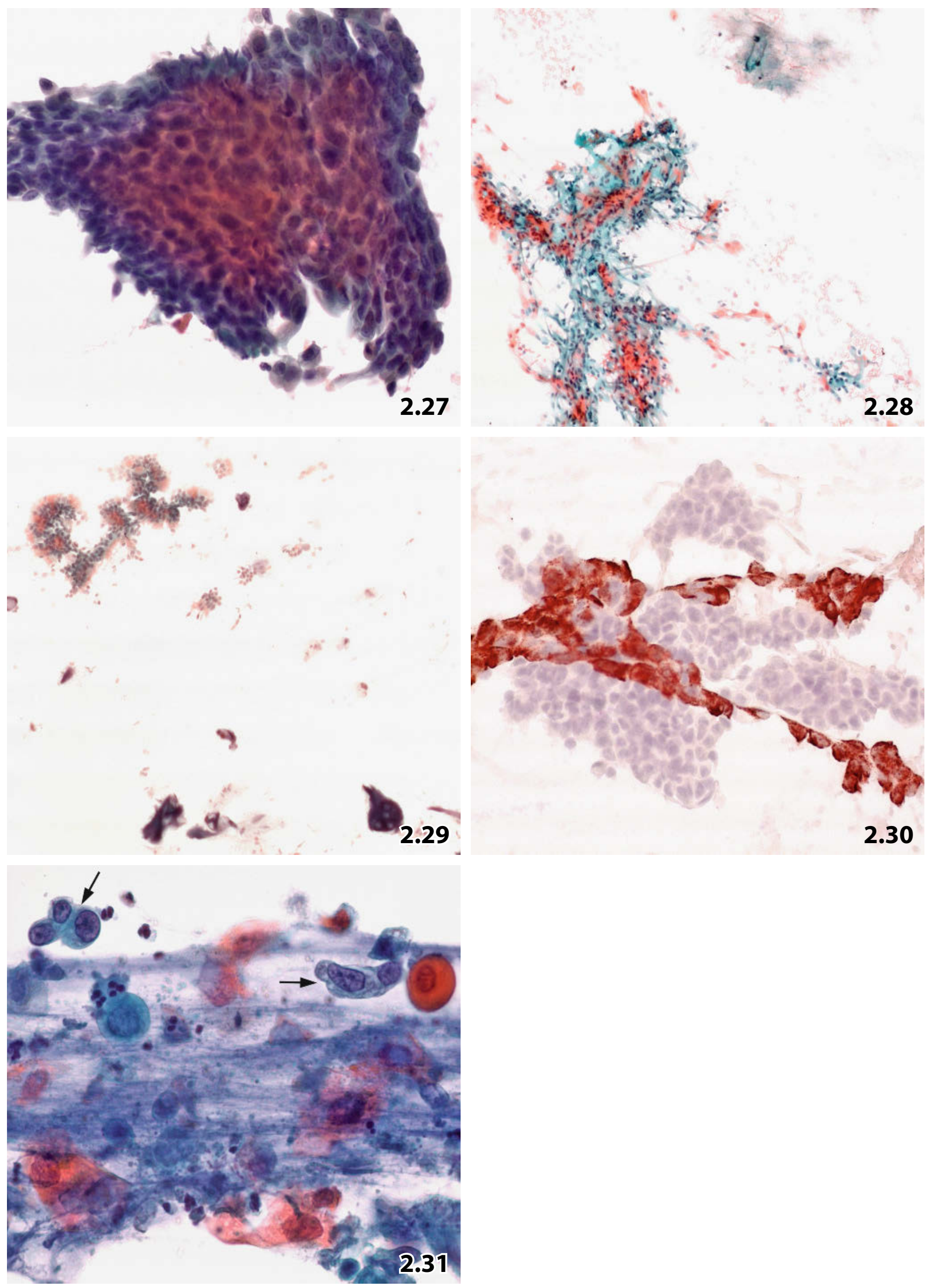
Fig. 2.32 In situ squamous cell carcinoma.

Sputum sample of a 75-year-old man without positive clinical history. Lower magnification shows numerous atypical/malignant squamous cells intermingled with necrotic tumor tissue (Pap stain). The squamous cells are exceptionally small.

Cytologic (over)diagnosis: Necrotizing keratinized squamous cell carcinoma.

Tissue diagnosis (endobronchial biopsy): Severe dysplastic squamous epithelium/in situ squamous cell carcinoma. Subsequent multiple tissue specimens from the bronchial tree did not reveal any invasive neoplasm.

\section{Fig. 2.33 Invasive squamous cell carcinoma.}

Very low magnification reveals the appearance of invasive squamous cell carcinoma as it used to be in sputum specimens. There is a triad of:

- Isolated neoplastic cells.

- Necrosis.

- Red blood cells.

All these elements are partly enmeshed in mucoid strands (Pap-stained direct smear).

Fig. 2.34A, B Keratinizing squamous cell carcinoma.

The two images demonstrate cells showing all characteristics of common squamous cell carcinoma (bronchial brushing, direct smears, Pap stain, high magnification). A Note the keratinized tadpole-like cells (two cells upper left), the marked nuclear hyperchromasia, and concentric lamination of the cytoplasm (arrows). B Note in particular the extreme variability of N/C ratio and the occasional pronounced nuclear clearing (arrows). 

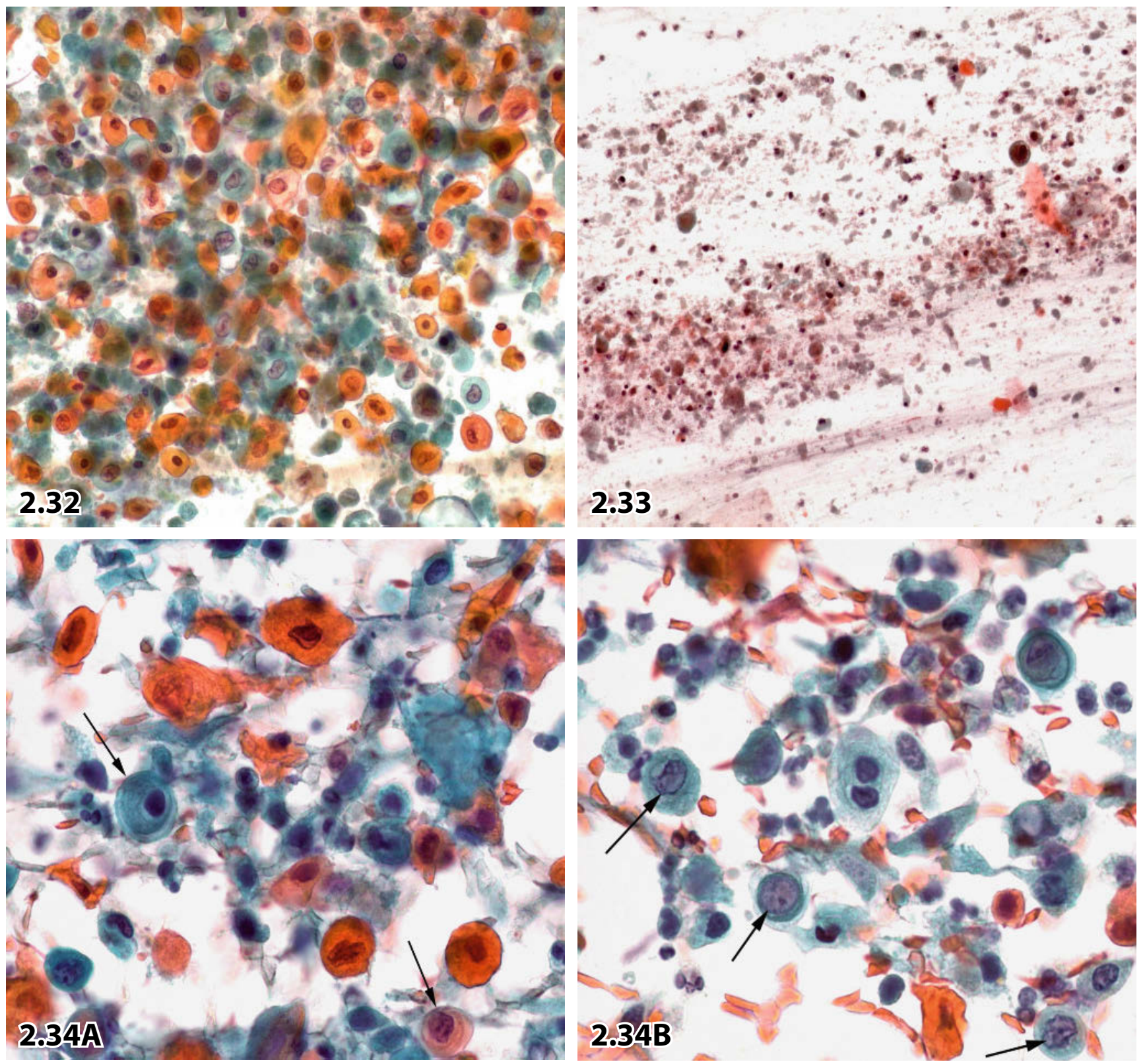

$2.33 \ldots+2,10$

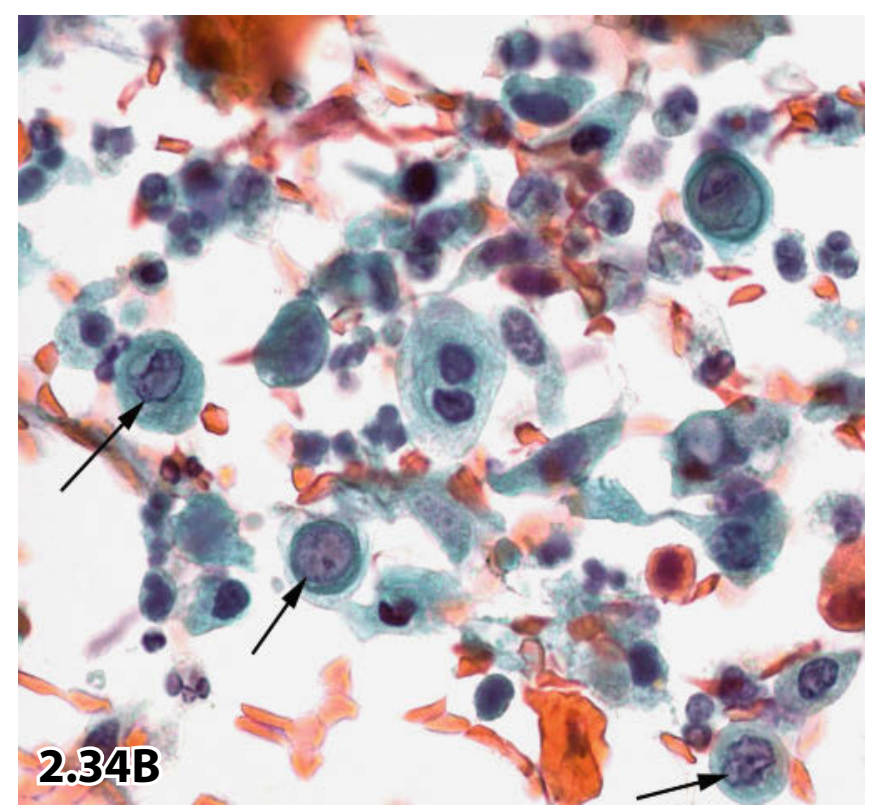


Fig. 2.35 Keratinizing squamous cell carcinoma: spindle cell variant.

Bronchial aspirate showing clusters of a keratinizing squamous cell carcinoma (upper half of the field). Numerous neoplastic spindle cells exhibit merely minor nuclear atypias (direct smear, Pap stain, lower magnification).

Figs. 2.36 and 2.37 Keratinizing squamous cell carcinoma: variant with clear nuclei. Two examples of keratinizing SCC are presented from a sputum probe and from a fine needle aspirate (see also Fig. 2.34B).

Fig. 2.36 (case \#1) Smears of a sputum sample contained predominantly dispersed single carcinoma cells. Neoplastic cells show extremely clear nucleoplasm frequently associated with a few chromatin clots. It is nearly impossible to differentiate between single tumor cells exhibiting broad vacuolated cytoplasm and activated histiocytes (both supposed cancer cells and supposed activated histiocytes are designated by the arrows). (Pap stain, high magnification).

Fig. 2.37 (case \#2) Transbronchial FNAB revealed an endobronchial metastasis of a keratinizing squamous cell carcinoma (site of origin was the tongue). Note the extremely clear nuclei in a few carcinoma cells partially not completely in focus (arrows) (direct smear, Pap stain, high magnification).

\section{Fig. 2.38A, B Poorly differentiated squamous cell carcinoma.}

Bronchial brushing in a 59-year-old man presenting with an endobronchial tumor mass that has been detected on the occasion of a fiberscopic examination. Direct brush smears were stained using the Papanicolaou technique. A Lower magnification shows dense clustering of elongated carcinoma cells focally providing a pronounced streaming pattern (asterisks). B High magnification exhibits obvious malignant nuclear features. The cytoplasm may be vacuolated or densely structured. Intercellular bridges can be identified (arrow). Cytoplasmic features of nonkeratinized malignant squamous cells are also illustrated in Fig. 2.34B.

\section{Fig. 2.39 Squamous cell carcinoma: small-cell variant.}

Bronchial brushing in an elderly man presenting with a tumor in his left lung. Direct brush smears were stained using the Papanicolaou technique. Coarse chromatin, prominent nucleoli, occasional sharp cytoplasmic outlines, and a few small keratinizing atypical cells (arrows; cytoplasm is not completely in focus) distinguish small-cell squamous cell carcinoma from classic small-cell carcinoma of the lung. 

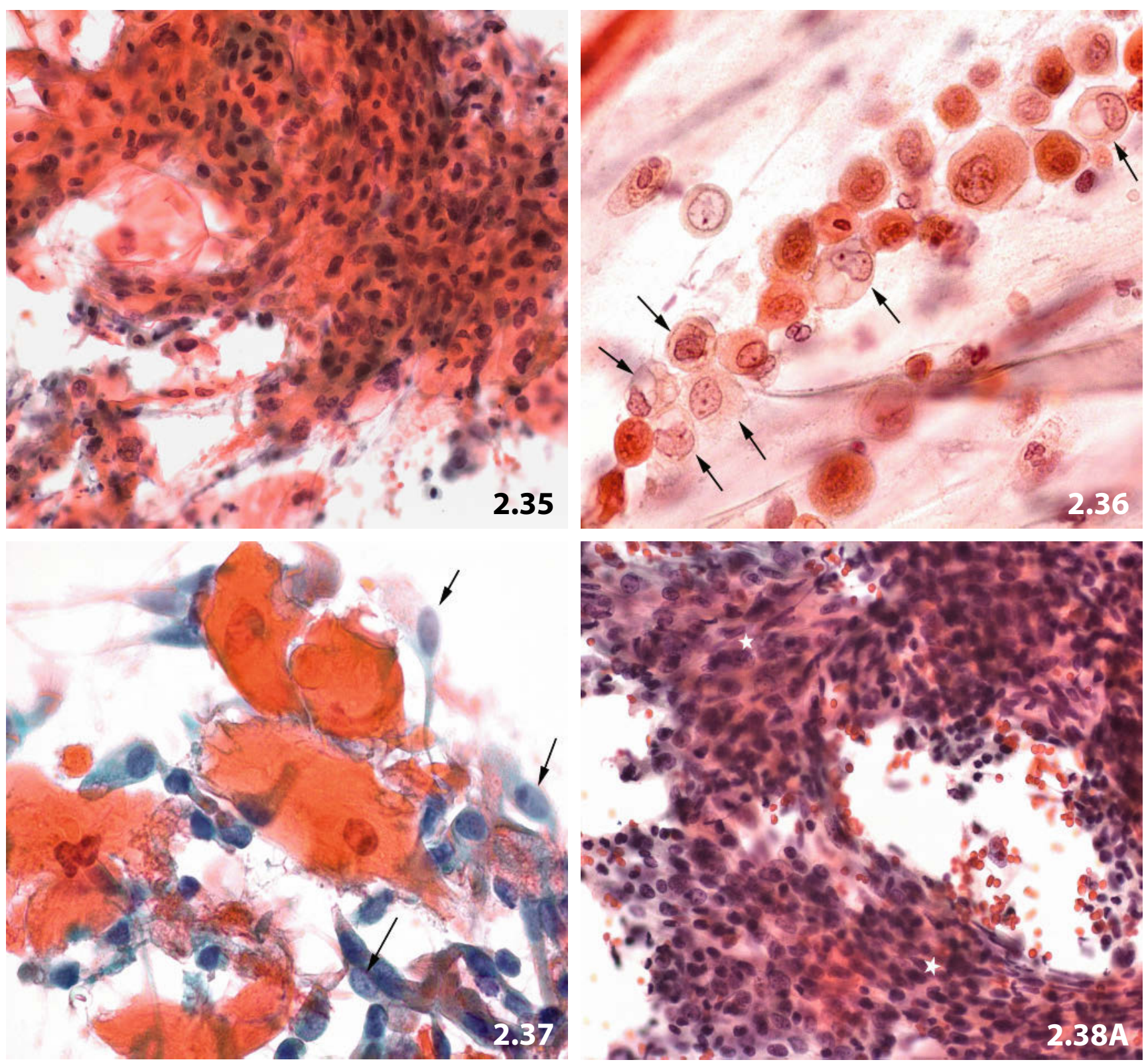

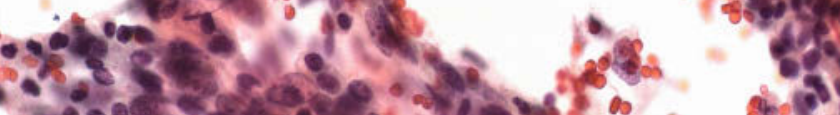

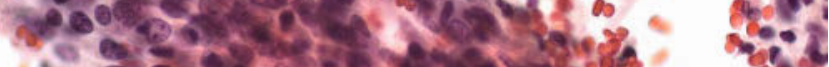

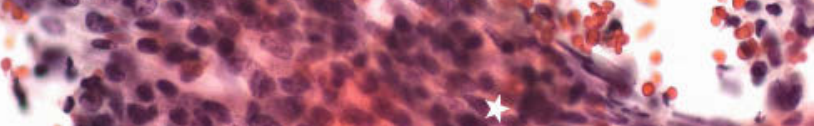

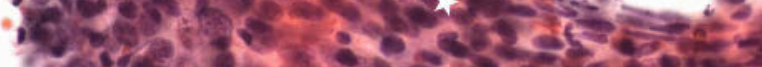

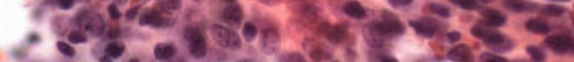

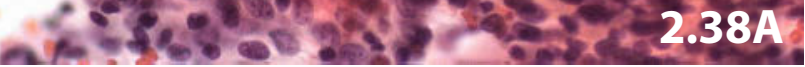
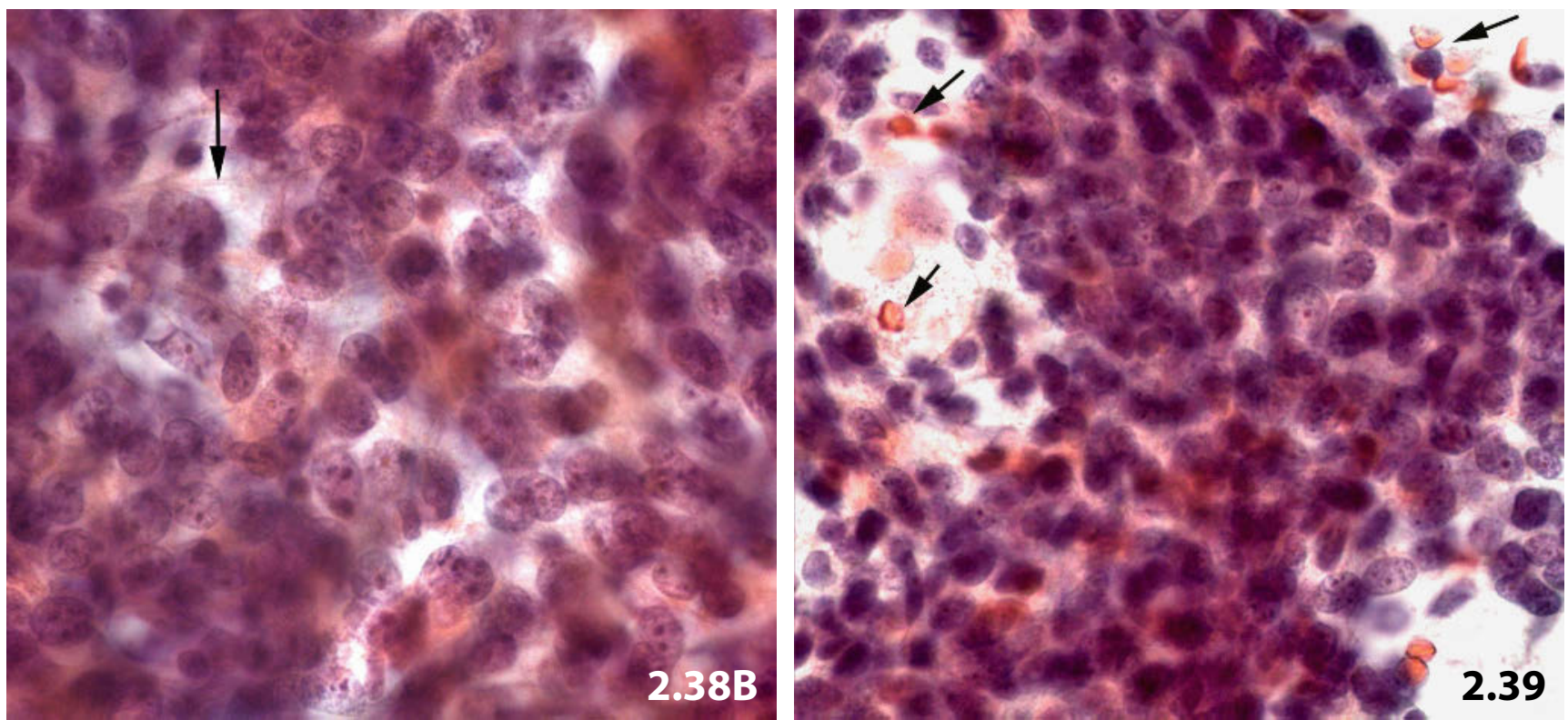
Fig. 2.40 Adenocarcinoma versus severe reactive cell changes.

A small cell cluster from a monomorphic adenocarcinoma of the lung. Take into consideration that severe reactive changes of glandular pulmonary cells may exhibit an identical cell pattern! Compare with the cell cluster depicted in Fig. 2.11 (bronchial aspirate, Pap stain, high magnification).

Diagnosis of adenocarcinoma requires a large number of atypical single cells and cell clusters partly exhibiting unequivocal features of malignancy.

Figs. 2.41 and 2.42 Adenocarcinoma: conventional type.

Typical cell features of adenocarcinomas from two patients (bronchial aspirates, Pap stain).

Fig. 2.41A, B (case \#1) Clusters and cells depicted from the same case showing the characteristic cytologic features of adenocarcinomas. A Three-dimensional cell clusters mainly papilliform (lower left) or of acinar type (upper right) (lower magnification). B Tumor cell cluster exhibiting radiating flower petal pattern (arrow). Note the cellular characteristics: irregular nuclear outline, powdery chromatin, centrally placed macronucleoli, distinctly outlined cytoplasm tha is eccentric and vacuolated (high magnification).

Fig. 2.42A, B (case \#2) The classic cellular morphology of adenocarcinoma and its immunocytochemical properties. A High-powered view demonstrates dense finely granular chromatin texture, the typical nucleoli, and abundant vacuolated cytoplasm (oil immersion, magnification, $\times 100$ ). B Positive nuclear immunostaining for TTF-1 is helpful in determining a definite diagnosis of pulmonary adenocarcinoma in equivocal cases. 


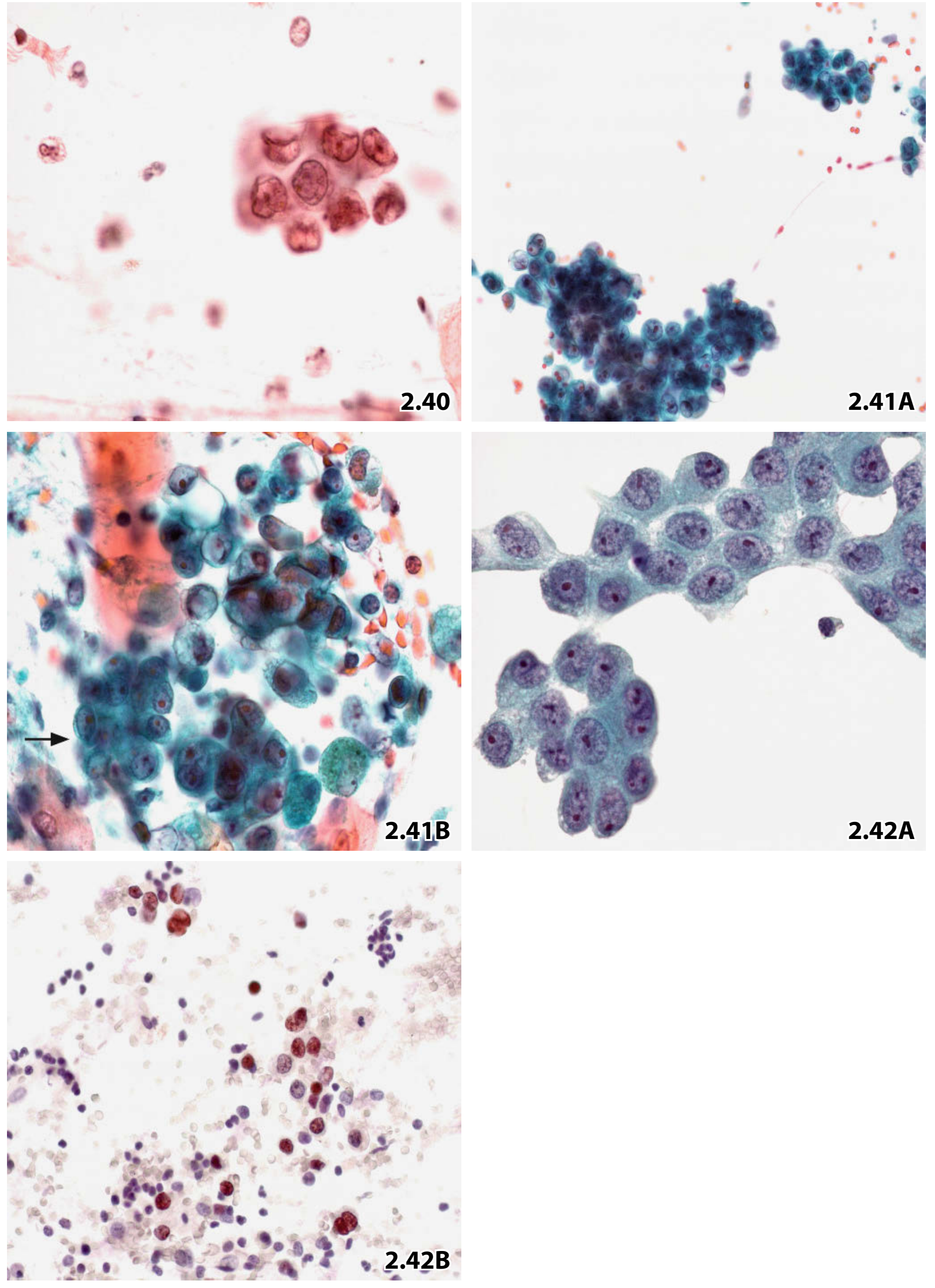


Fig. 2.43 Monomorphic adenocarcinoma versus benign bronchial epithelial cluster.

Note the striking similarity of the crescent carcinomatous cluster compared to the benign epithelial cluster (arrow): identical cellular and nuclear shape, identical nuclear texture and color, and an identical cytoplasmic structure. A major difference however, is observed regarding cellular arrangement, cellular size, and nucleoli (bronchial brushing, direct smear, Pap stain, high magnification).

\section{Fig. 2.44 Papillary adenocarcinoma.}

Transcutaneous FNAB of a lung tumor in the upper right lobe of an elderly male patient presenting with metastatic lung cancer. Subtyping of the lung neoplasm was not known at this stage. High magnification shows part of a papillary cluster composed of palisading, elongated atypical columnar cells (direct smear, Pap stain).

Cytologic findings are consistent with well differentiated mucinous papillary adenocarcinoma. The attending physicians abstained from histology.

Figs. 2.45 and 2.46 Bronchioloalveolar carcinoma.

Bronchial aspirates from two different patients, both suffering from bronchioloalveolar carcinoma. Pap-stained direct smears were performed. Additional figures are presented in Chap. 2.3. "Bronchoalveolar Lavage," Sect. 2.3.6 "Malignancies".

Fig.2.45 (case \#1) Lower magnification reveals a flat sheet (upper right) and three-dimensional compact clusters originating from an adenocarcinoma composed of small to mediumsized cells. Papilliform and acinus-like cell (arrows) arrangement and intracytoplasmic pinkish mucin (arrowheads) are overt. Nuclear irregularities (folds, molding) and loss of polarity indicate a malignant neoplastic lesion.

Fig. 2.46 (case \#2) High magnification focuses on bland chromatin, prominent nuclear irregularities, and occasional distinct nucleoli. Numerous psammoma bodies are encased within a neoplastic cell cluster (upper left).

Note single cells with histiocytoid nuclei and abundant vacuolated cytoplasm (arrows); distinguishing these cells from activated histiocytes is very difficult using conventional cytology alone.

\section{Fig. 2.47 Large-cell undifferentiated carcinoma.}

Dissociating clusters composed of large pleomorphic tumor cells exhibiting highly variable N/C ratio; strands of chromatin occur centrifugally (arrows). Exceptionally clear nucleoplasm and polyhedral cytoplasmic bodies are striking (bronchial brushing, direct brush smear, Pap stain, higher magnification). 

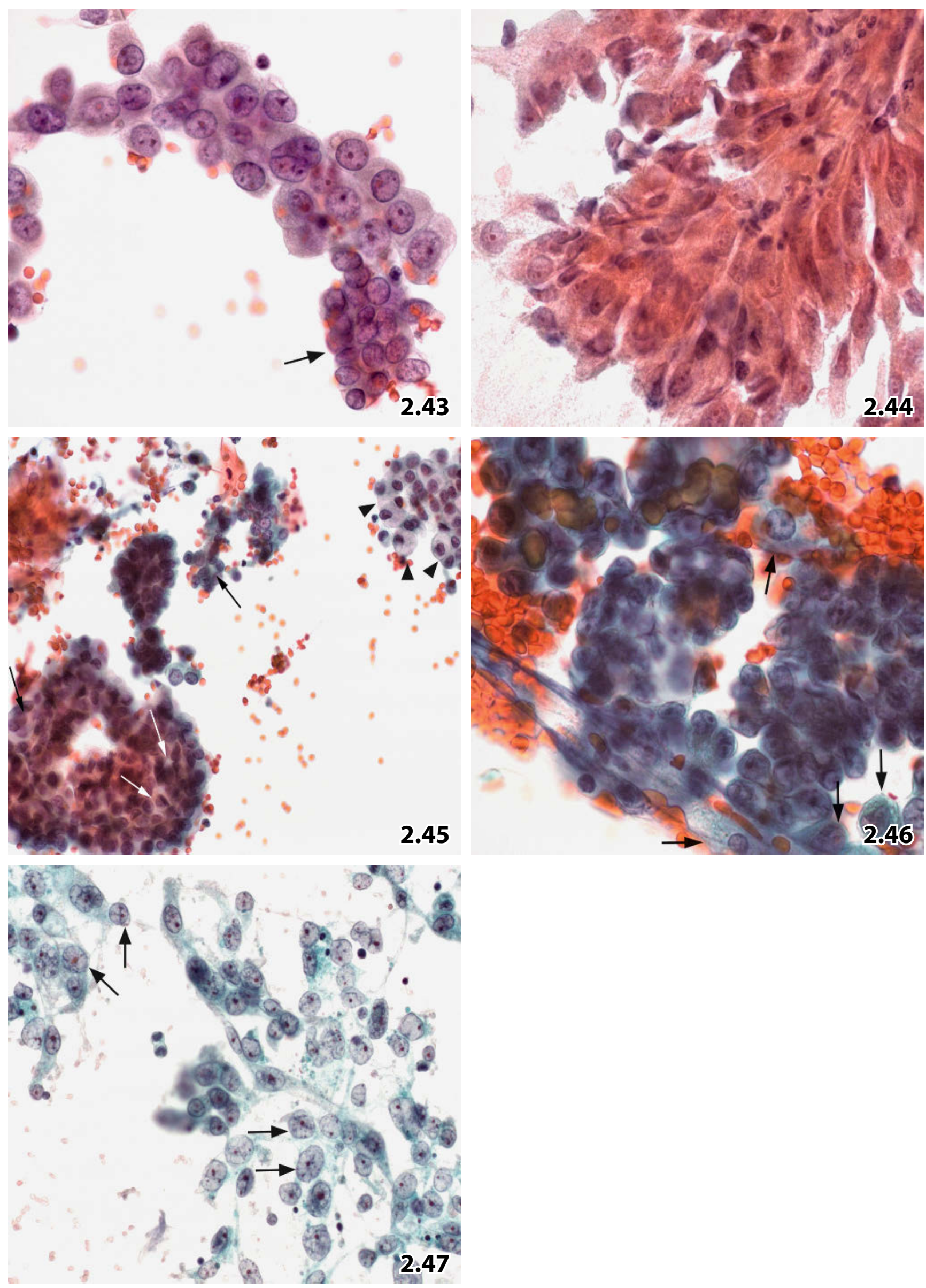
Fig. 2.48A, B Small-cell carcinoma: paucicellular exfoliative sample.

The cells depicted in these two images come from the same sputum probe (Pap stain). The examples emphasize the particular importance of careful microscopic screening in patients with small-cell carcinoma. A Very low magnification displays a single tumor cell cluster (arrow) that meets all criteria of small-cell carcinoma. B High magnification demonstrates a few single carcinoma cells (arrows) and a dyad of small carcinoma cells (arrowhead) amid benign lymphocytes. Attention should be paid to the size and chromatin texture of the neoplastic cells as compared to lymphocytes.

\section{Fig. 2.49 Small-cell carcinoma in sputum.}

Note the characteristic morphologic features: cell arrangement along mucus streaks, mainly in a linear fashion. The nuclei show pronounced variability in size, molding, indentations, and thin dispersed or glassy chromatin (Pap stain, high magnification).

\section{Fig. 2.50 Small-cell carcinoma in bronchial aspirate/washing}

Blood mass frequently masks individual neoplastic cells and small-cell clusters exfoliated from small-cell carcinomas. Unlike bronchial lining epithelial cells (arrows), the neoplastic cells (arrowheads) exhibit enlarged nuclei and irregular nuclear membranes (direct smear, Pap stain, lower magnification).

\section{Fig. 2.51 Small-cell carcinoma, oat cell type.}

Neoplastic cells from a sputum sample exhibit characteristic features of oat cell carcinoma. Identical features can be observed in Fig. 2.49. However, a few tumor cells in the current field are of the intermediate cell type (see Fig. 2.52) (Pap stain, high magnification).

\section{Fig. 2.52 Small-cell carcinoma, intermediate cell type.}

Neoplastic cells of small-cell carcinoma of the intermediate cell type are larger than the oat cell type. Multiple nucleoli and an enlarged but often indistinct cytoplasmic body are key features of the intermediate tumor variant. A few cells exhibit elongated cytoplasm (arrows) (bronchial aspirate, high magnification, Pap stain, direct smear). 

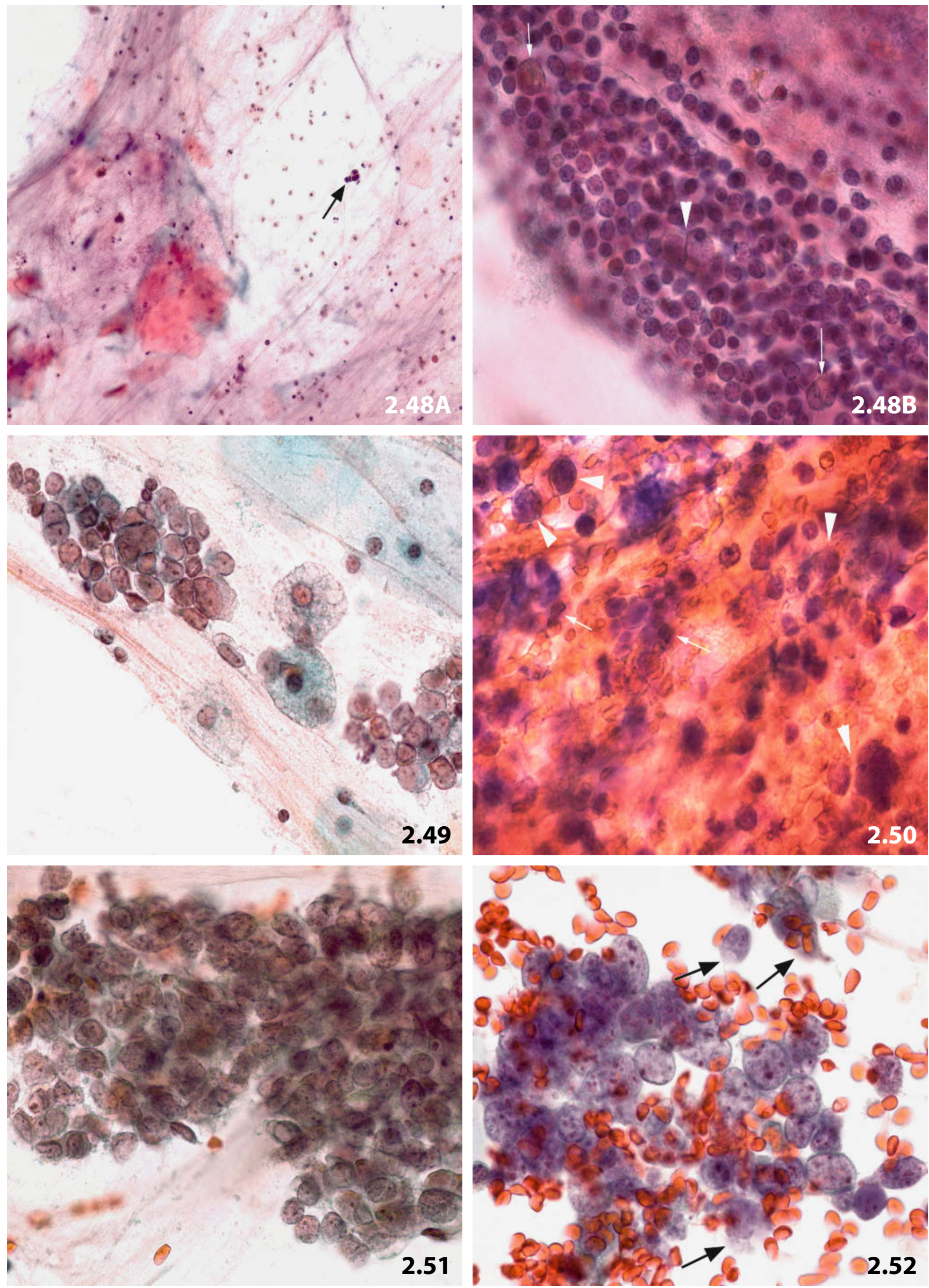
Fig. 2.53 Small-cell carcinoma versus malignant non-Hodgkin lymphoma.

Tumor cells of small-cell carcinoma (mainly of the oat cell type) occurring completely dissociated in a smear from a bronchial aspirate. Therefore, distinguishing between small-cell carcinoma and malignant lymphoma is difficult. Still, absence of unequivocal lymphoid cells, absence of cytoplasmic rims, and absence of nucleoli in the majority of the nuclei favor the diagnosis of small-cell carcinoma (direct smear, Pap stain, higher magnification).

\section{Fig. 2.54 Adenoid cystic carcinoma.}

Classic appearance of adenoid cystic carcinoma: three-dimensional clusters composed of small monomorphic tumor cells surrounding cores of pinkish hyaline material (bronchial aspirate, direct smear, Pap stain, lower magnification).

\section{Fig. 2.55 Mucoepidermoid carcinoma.}

A 63-year-old man presented with a tumor in his right lung. Antecedent exfoliative cytologic and histologic investigations yielded no conclusive diagnosis. Transbronchial FNAB revealed a heterogeneous cell pattern composed of metaplasia-like sheets of immature squamous cells interspersed with mucinous glandular cells and goblet cells (arrows) (direct smear, Pap stain, lower magnification). A few keratinizing squamous cells were also present (not shown). Cytologic diagnosis of a mucoepidermoid carcinoma was later verified with histology.

\section{Fig. 2.56 Follicular non-Hodgkin lymphoma.}

A 63-year-old man presented with a diffuse infiltrate in his right lung. Sputum cytology revealed a neoplasia consisting of atypical monomorphous cells characterized by conspicuous nucleoli, and mostly ill-defined cytoplasm; cytoplasmic vacuolization is overt, unlike the fuzzy granularity (Pap stain, high magnification).

Cytologic differential diagnosis: Malignant non-Hodgkin lymphoma, carcinoid tumor, and small-cell carcinoma of intermediate cell type.

Comments: The latter diagnosis seems rather unlikely due to the nuclear monomorphism, unfitting chromatin texture, and cytoplasmic features. Clarifying the histogenesis of this tumor requires immunocytochemical workup (not performed by cytology because of technical problems).

Tissue diagnosis (open lung biopsy): Follicular non-Hodgkin lymphoma, grade 2.

\section{Fig. 2.57A, B Burkitt lymphoma: diagnostic challenge.}

A 10-year-old boy presented with an intraabdominal tumor mass and a single subpleural node in his left lung. To investigate the nature of the lesion in the left lung, transcutaneous FNAB was performed as first-line diagnostic approach (direct smears).

Cytologic diagnosis: Non-Hodgkin lymphoma, blastic type.

Tissue diagnosis: Burkitt lymphoma.

A The deeply basophilic cytoplasm with the characteristic vacuoles (arrows) in MGG stain may indicate Burkitt lymphoma (high magnification). B Note single-file like tumor cell arrangement in the Pap-stained FNAB-specimen, which may give rise to diagnostic dilemmas, particularly with small-cell carcinoma (arrows) (lower magnification). 

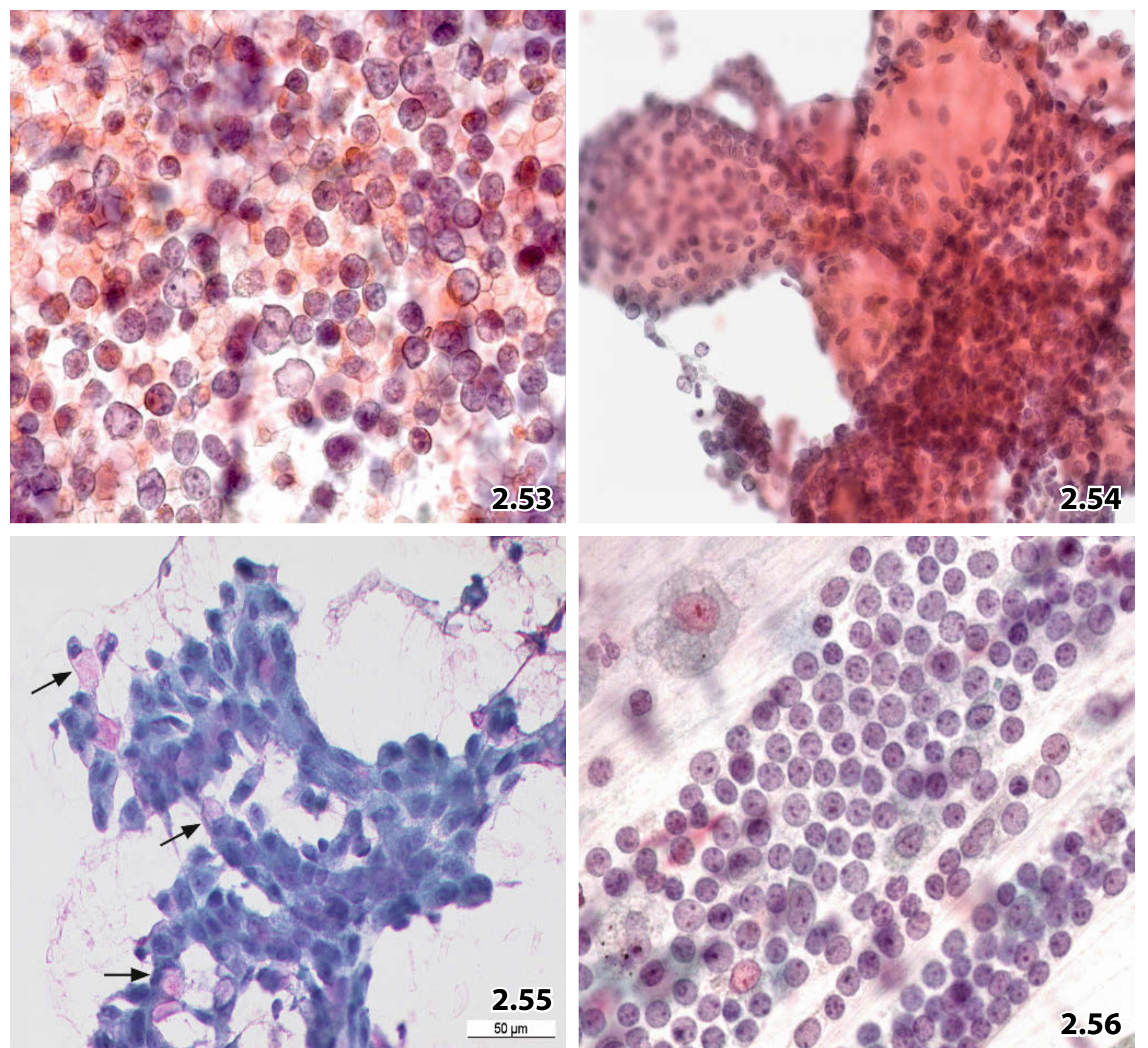

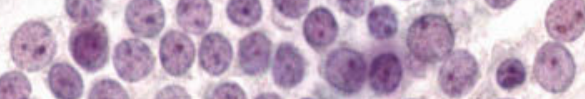

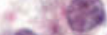

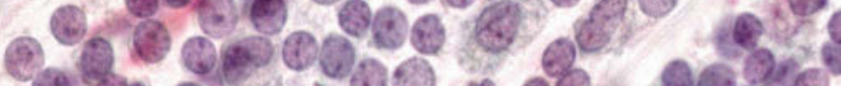
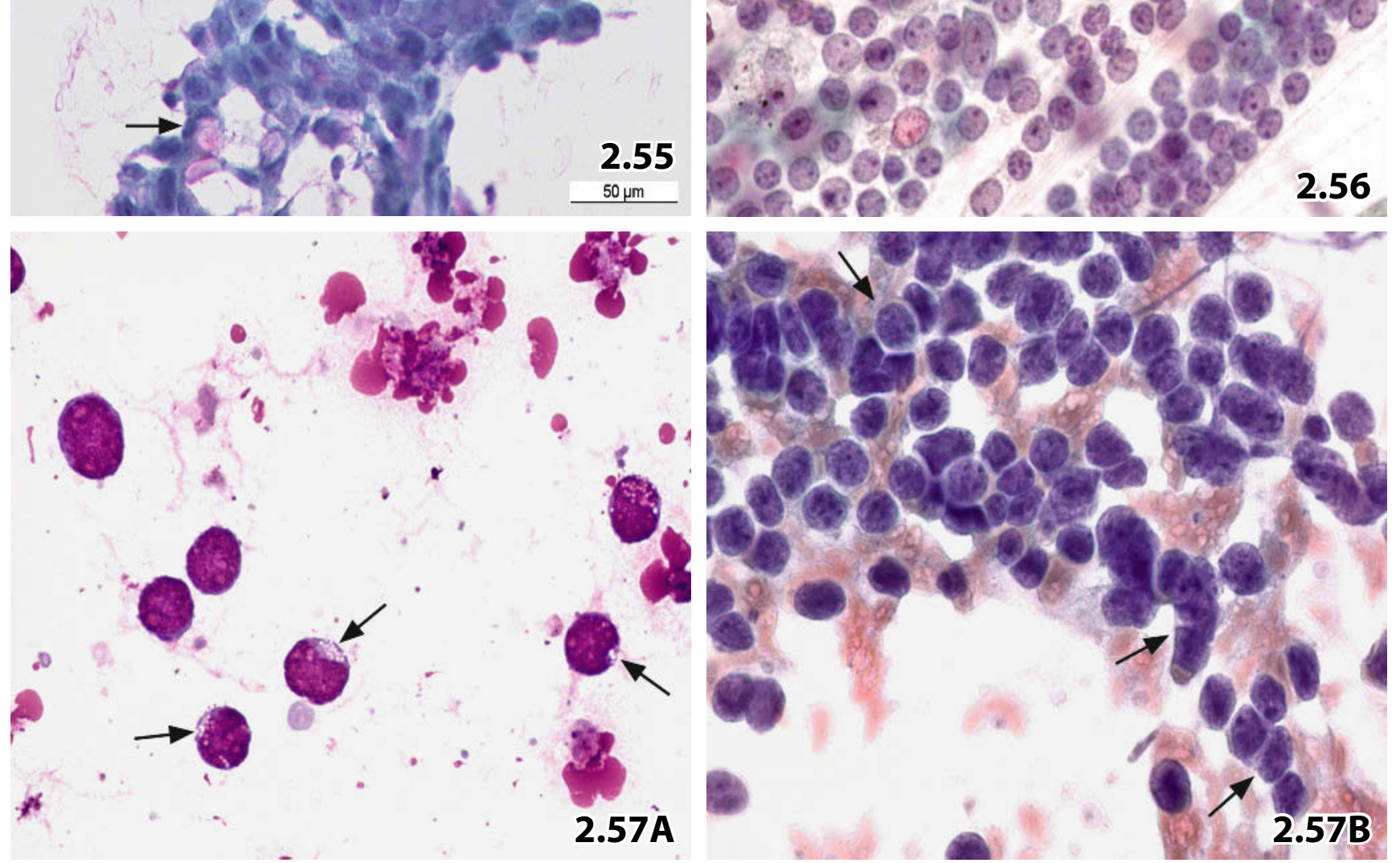
Fig. 2.58 Hodgkin lymphoma.

A female patient with a positive history of Hodgkin lymphoma; clinical findings suggest tumor dissemination into the lung. Numerous distinct Reed-Sternberg cells (arrow) and mononuclear Hodgkin cells were seen in the first sputum sample (Pap stain, higher magnification). Cytologic diagnosis: Hodgkin lymphoma.

Comment: The diagnosis of Hodgkin disease was easy in this case due to patient's history. However, distinguishing RSH cells from cells of anaplastic carcinoma would be very difficult without an appropriate clinical history.

\section{Fig. 2.59A-C Breast carcinoma.}

A 72-year-old woman with positive history of breast carcinoma (lumpectomy and irradiation 12 years before) presented with a tumorous lesion in her right lung. A Bronchial aspirates and bronchial brushings showed numerous isolated and clustered tumor cells consistent with a monomorphous well-differentiated adenocarcinoma (direct smears, Pap stain, high magnification). An appropriate immunopanel is essential in order to assess the primary site of the neoplasia (lung cancer versus metastasis of breast carcinoma).

B Nuclear positivity for estrogen receptors (Pap-prestained direct smears). C Negative immunoreactivity for TTF-1 (Pap-prestained direct smears).

Cytologic diagnosis: Selected immunostains established correct diagnosis of breast cancer.

\section{Fig. 2.60 Colonic carcinoma.}

A 53-year-old man presenting with lung disorders and a positive history of colonic carcinoma. A Compact cell clusters from a poorly differentiated adenocarcinoma were encountered in bronchial brushings (Pap stain, high magnification). B Positive immunostaining for CK20 proved helpful in determining a definite diagnosis of metastatic colonic carcinoma. 

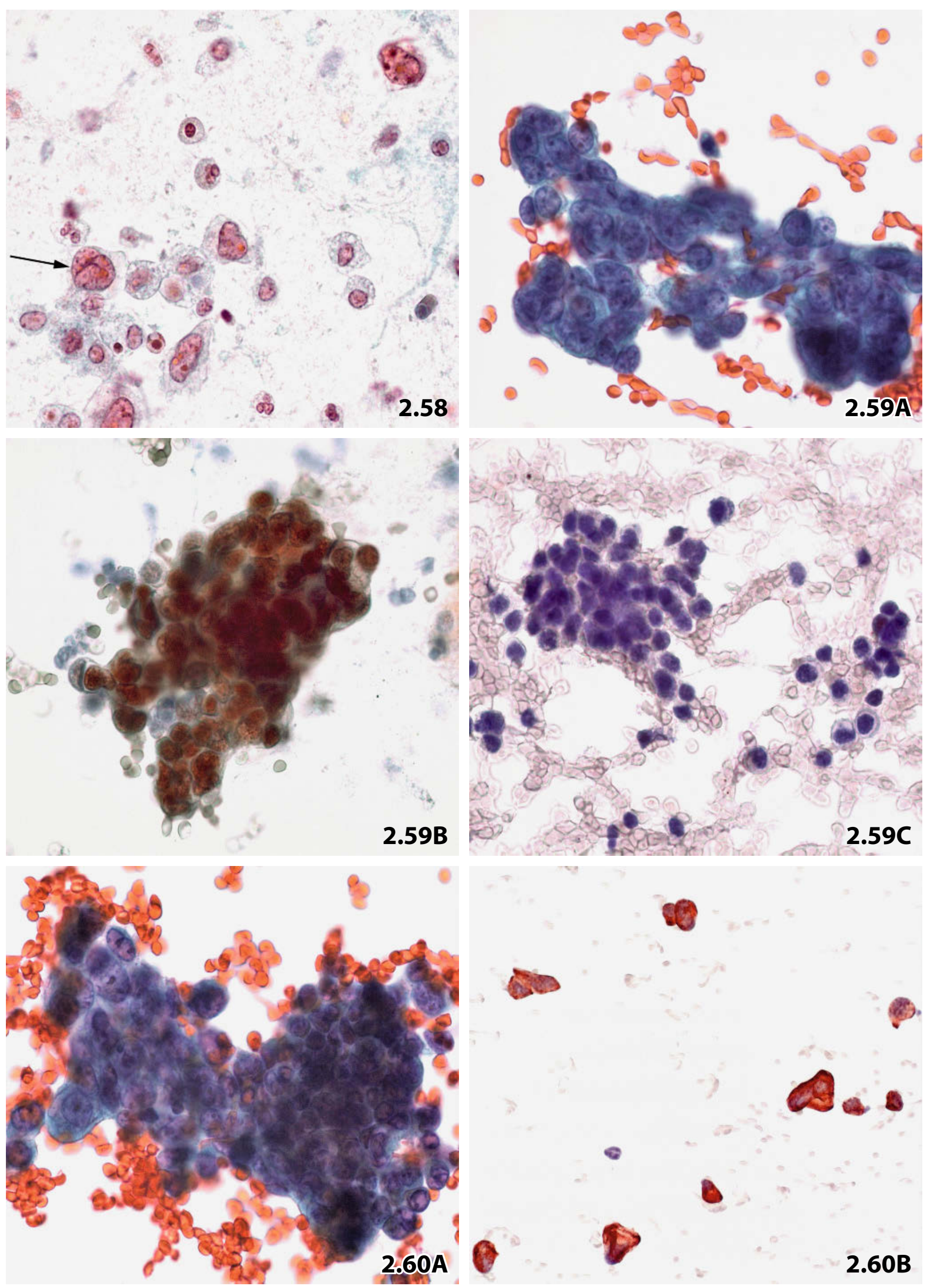
Fig. 2.61A, B Malignant melanoma.

A 91-year-old man presented with a nodular lesion in the upper lobe of his left lung, there was no further information available. A Bronchial brushing revealed mainly isolated large neoplastic cells exhibiting vulnerable vacuolated and granular cytoplasm. A macrophage (arrow) shows coarse granular cytoplasmic inclusions suspicious of melanin, but hemosiderin cannot be excluded by routine staining methods (direct smear, Pap stain, high magnification). B Positive immunostaining for HMB-45 (Pap-prestained direct smear).

Cytology: Cytomorphologic features and suspected melanophores favor the diagnosis of malignant melanoma (versus another undifferentiated nonepithelial tumor or anaplastic largecell carcinoma). Immunocytochemical work-up provided the correct diagnosis.

\section{Fig. 2.62A-C Leiomyosarcoma.}

A 73-year-old woman presenting with a complex clinical history: (1) leiomyosarcoma of the uterus 25 years before (hysterectomy), (2) metastatic breast carcinoma, (3) recent neoplastic process in the upper lobe of the left lung.

Cytologic diagnosis (confirmed by histology): Metastasis of a leiomyosarcoma.

A Transcutaneous FNAB of lung revealed isolated and aggregated undifferentiated neoplastic cells scattered in a background of proteinaceous material and debris (direct smear, Pap stain, high magnification). Immunocytochemical workup was required to determine the nature of the tumor cells. B Cells express strong immunopositivity for alpha smooth muscle actin (Papprestained specimen). C Negative immunostaining for pancytokeratin (MNF-116). Note the internal positive control using a bronchial epithelial cell (lower right) (Pap-prestained direct smear). 

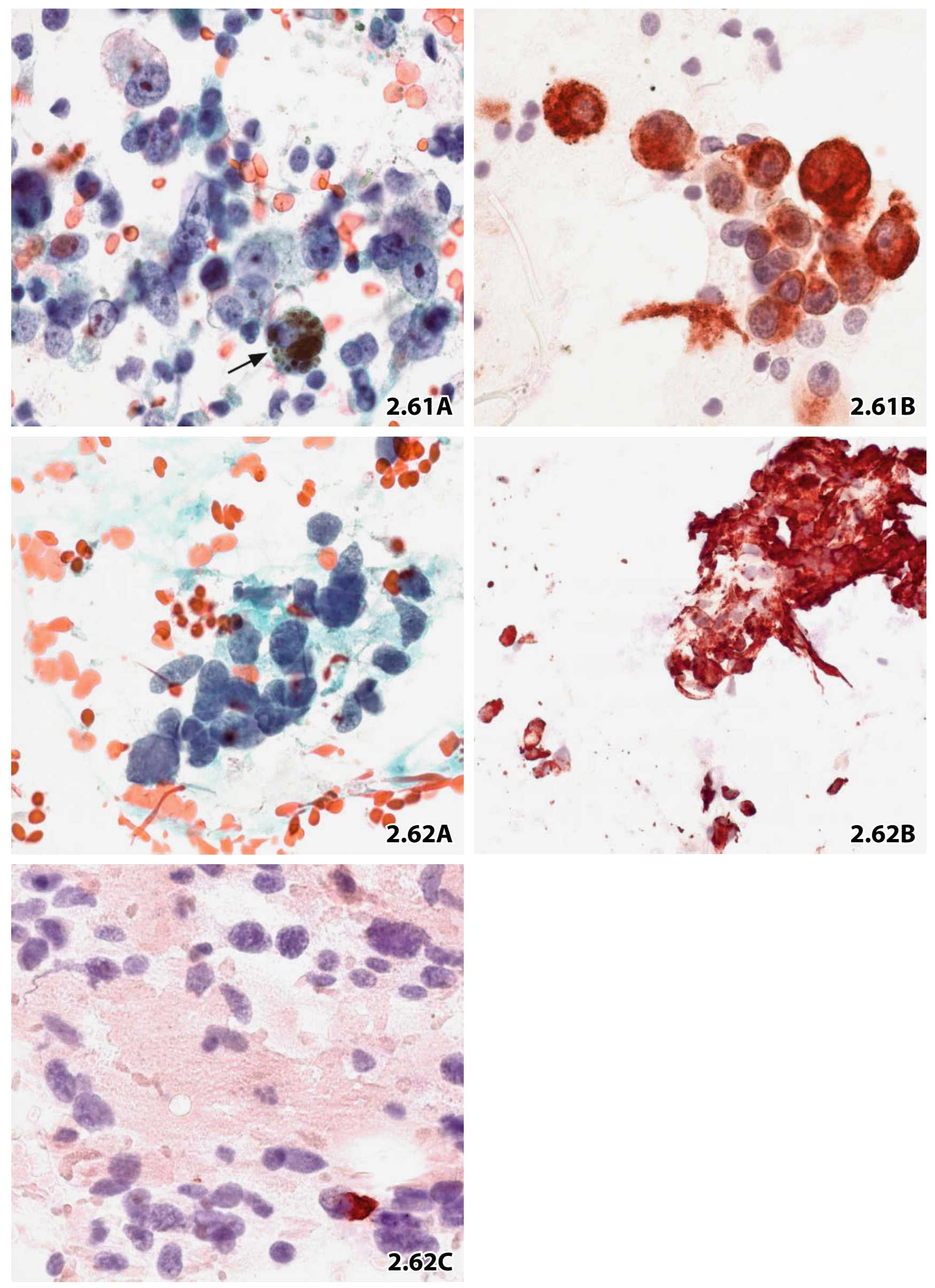
Figs. 2.63 and 2.64 Typical carcinoid tumor.

Classic cytologic features depicted from a fine needle aspirate and from exfoliated material.

Fig. 2.63A, B Carcinoid tumor: appearance in fine needle aspirates. Transbronchial FNAB providing the pathognomonic uniform appearance of the cell pattern (direct smear, Pap stain). A Note cohesive cell clusters combined with flat sheets, acini-like formations (arrows), and the plasma cell-like appearance of the majority of tumor cells (lower magnification). B Nuclear morphology of the neoplastic cells is bland compared to that of benign ciliated bronchial-lining cells (high magnification).

Fig. 2.64 Carcinoid tumor: appearance in exfoliative cytologic specimens. Bronchial aspirate from an elderly man containing cells of a neuroendocrine lung tumor. Tumor cells usually occur more crowded and occasionally spindle-shaped (arrows) in comparison with the cells in fine-needle aspirates (direct smear, Pap stain, lower magnification).

Figs. 2.65 and 2.66 Atypical carcinoid.

Cytomorphology and immunocytochemistry are shown.

Fig. 2.65 Atypical carcinoid.

Example of an atypical carcinoid in a transbronchial FNAB of the lung. Note similarity of the cytoarchitecture to that of small cell carcinoma. However, the monotonous pattern and nuclear features simulate those of common carcinoid tumor (direct smear, Pap stain, high magnification).

Fig. 2.66 Atypical carcinoid: immunocytochemistry.

Example of an endocrine immunodiagnostic marker. Bronchial aspirate containing numerous cells from an atypical carcinoid: immunocytochemical chromogranin A positivity (among other endocrine markers which are not shown) is a key feature in the diagnosis of all grades of neuroendocrine neoplasms ranging from well-differentiated to highly malignant (Papprestained direct smear, no nuclear counterstaining).

\section{Fig. 2.67 Large-cell neuroendocrine carcinoma.}

A 56-year-old man clinically presented with a bronchial carcinoma in the upper lobe of his left lung. Bronchial brushing revealed clearly malignant fusiform cells arranged in clusters exhibiting distinct streaming pattern (Pap stain, high magnification).

(False) cytologic diagnosis: Poorly differentiated nonkeratinizing squamous cell carcinoma. Comment: the cytologic diagnosis was established due to the cellular pleomorphism, coarse granular chromatin, and streaming pattern (we failed to perform immunocytochemical studies).

Tissue diagnosis: Large-cell neuroendocrine carcinoma; the tumor cells showed strong immunopositivity for NSE, chromogranin A, and synaptophysin. 

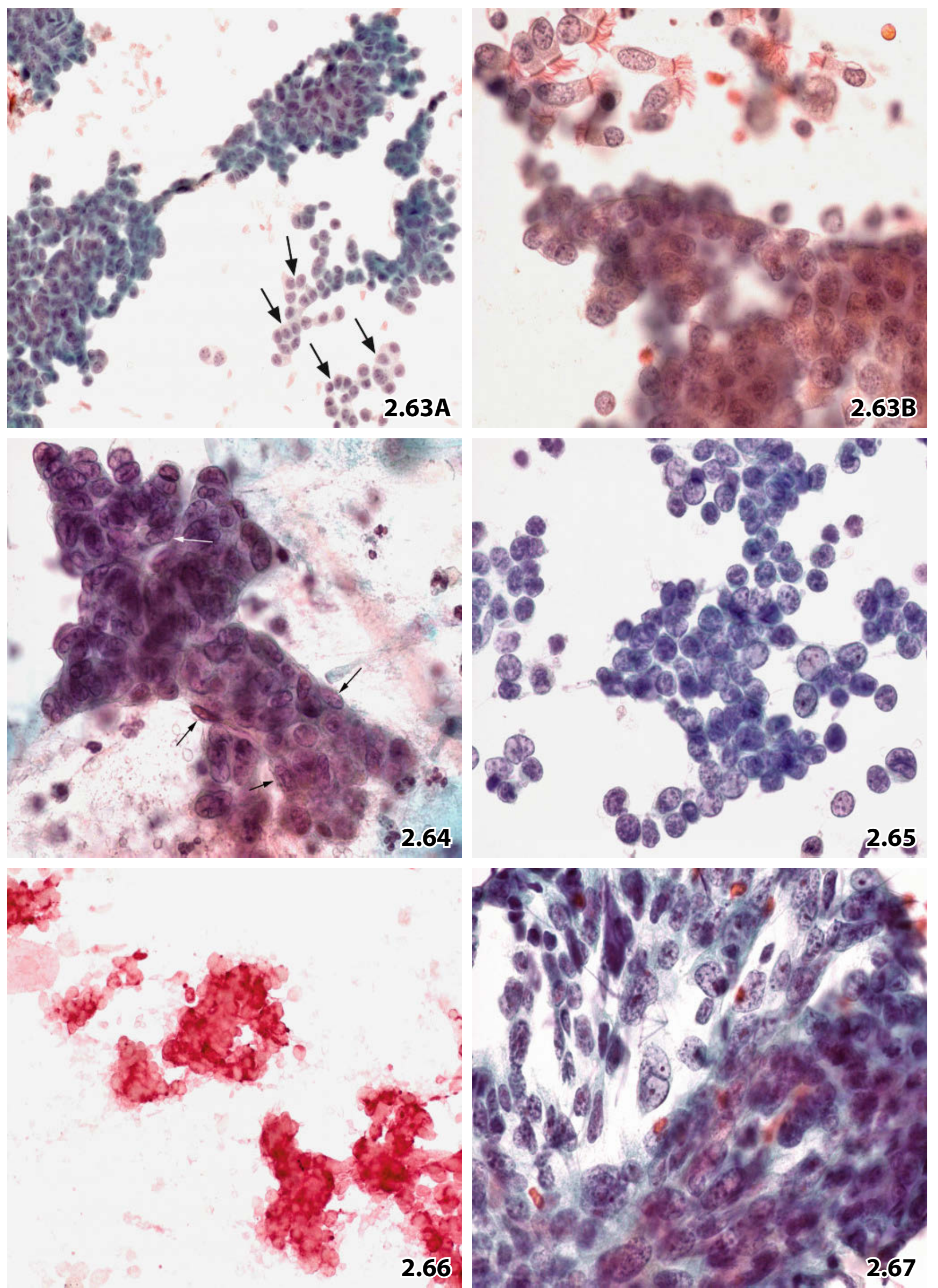


\section{Section 2.3}

\section{Respiratory Tract: \\ Bronchoalveolar Lavage}

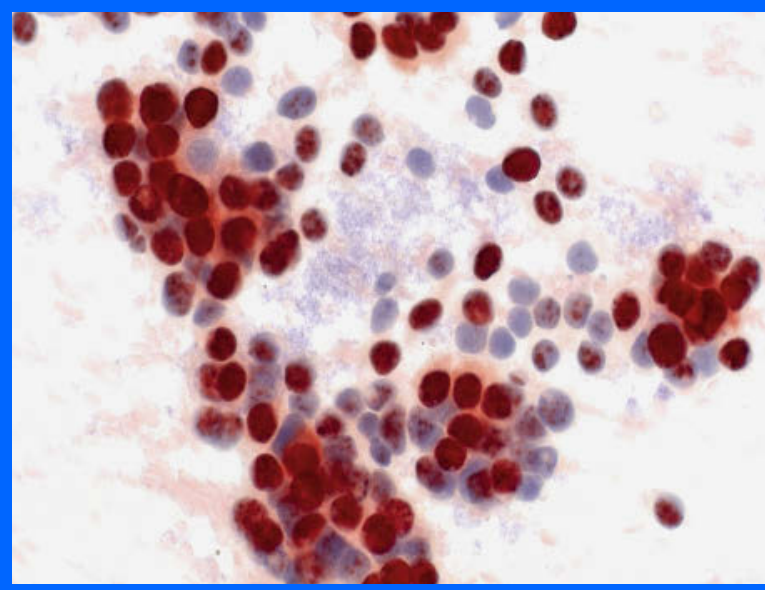

\subsubsection{Introduction}

- Diagnostic bronchoalveolar lavage (BAL) is a minimally invasive and highly cost-effective standard procedure that can contribute significantly to establishing a diagnosis in patients with uncertain interstitial lung disease or alveolar/pneumonic infiltration and may be helpful in monitoring lung allografts. Whether the cell composition in BAL can act as an indicator for activity and prognosis in interstitial lung disorders is still open. BAL complements clinical history, serologic results, biochemical assays, lung function tests, imaging results, and transbronchial lung biopsy.

- The clinical indications for BAL cover three groups of lung disorders:

- Interstitial infiltrates (indicating granulomatoses, fibrosis, pneumoconiosis, tumor lymphangiosis, among others).

- Alveolar infiltration (indicating pneumonias, hemorrhage, alveolar proteinosis, among others).

- Lung infiltration in immunocompromised hosts (e.g. AIDS, post lung transplantation, immunocompromising therapy regimens).

- BAL seems to be a promising tool for research in combination with new technologies [49].

- BAL samples are obtained by wedging a subsegmental bronchus using a flexible bronchoscope and lavaging a defined alveolar area with saline or another appropriate solution. The great advantage of BAL is that diagnostic material is obtained from a whole lung segment, whereas transbronchial lung biopsy provides only a small piece of tissue measuring a few millimeters from a circumscribed lung area.

- Risks of BAL mainly hinge on the bronchoscopic procedure; complications are of minor significance and usually transient [10].

- Information on the use of the BAL technique, clinical indications, technical lavage procedures [3], and diagnostic potential are provided next. Standard textbooks [10] and specialized sources from the literature $[8,30,36$, and other papers] are also available.

\subsubsection{Laboratory Procedures, Technical Aspects, Reporting}

\section{General Comments}

- At our institution, BAL fluid processing has followed standardized rules based on 15 years of experience with a total number of roughly 6,000 specimens. More than half of these BAL samples have been adequate for differential cell count and determination of the lymphocyte subset. Adequacy of the specimens was determined by the volume of the aspirate, by the amount of bronchial/bronchiolar cell admixture, by total cell count, and/or by the limitation of analyses as requested by the attending physician. The nonadequate specimens underwent routine screening for cellular composite, tumor cells, quality of histiocytes/ macrophages, dust particles, virus-induced cell changes, and organisms. 
- The following clinical informations should necessarily be transferred on the enclosed order form:

- Main clinical symptoms and/or diagnostic considerations.

- Issues concerning cytologic investigation.

- Previous treatment, in particular chemotherapy and irradiation.

- Smoking habits.

- Immunodeficiency and its direct cause.

- Total lavage fluid instillation; recovery of the instillate $(\mathrm{ml})$; and aliquots $(\mathrm{ml})$ of the recovered instillate removed for noncytologic laboratory tests.

- Date and time of the BAL fluid sampling.

- The management options as performed at our institution are presented in the following.

\subsubsection{Material Transfer and Processing}

\subsection{Material Transfer to the Cytologic Laboratory}

The BAL fluid is transported and processed as quickly as possible, i.e., within $6 \mathrm{~h}$ after sampling. Specimens from the hospital-based lung department are supplied immediately after completing the endoscopic investigation. BAL samples from county hospitals and community-based clinicians are supplied individually or by a pick-up service, both within 6 h. In this setting, the samples are delivered in native condition.

Each analysis is announced at least $2 \mathrm{~h}$ before the sample arrives at our laboratory.

\subsection{Material Processing}

1. The first aspirate, the contents of the bronchus segmentalis and bronchioli, is referred separately to our cytology laboratory. This sample generally has cellular and mucus content of the bronchial/bronchiolar system and is suitable for measuring the adequacy of the BAL specimen.

2. Delay of the procedure [14]. Samples arriving at the laboratory too late in the evening for complete routine processing are centrifuged with the sediment transferred to a suitable cell medium (we use MEM HBS without L-glutamine, Amimed BioConcept, Allschwil, Switzerland). Cell suspensions can be stored in the refrigerator $\left(4^{\circ} \mathrm{C}\right)$ and all routine BAL examinations are reliable for at least $24 \mathrm{~h}$.

3. Routine processing of BAL fluid and basic evaluation. The principle steps are described as performed at our laboratory. Technical details and conditions tailored to our particular needs are disregarded.

- Amount and gross appearance of the lavage fluid obtained are noted. Portions of the recovered instillation for supplemental noncytologic analyses, such as culture, viral analyses, biochemical tests, etc. have already been submitted to specialized laboratories by the endoscopist.

- The total amount of liquid is centrifuged (2800 rpm, 10 min). The supernatant is decanted by aspiration and may be deep-frozen for long-term storage. It can be used for subsequent noncellular analyses.

- Mucus from the sediment is liquefied by adding Shandon Mucolexx TM (Thermo Fisher Scientific Inc., Waltham, MA, USA); individual exposure is up to 10 min. Afterwards, the resuspended cell pellet with the above-mentioned cell medium $(2-3 \mathrm{ml})$, is again centrifuged (4000 rpm, $2 \mathrm{~min}$ ).

- Total cell counts are made in a Neubauer Cell Chamber. The result is reported per liter of recovery fluid.

- For differential cytology, a routine air-dried smear is stained according to the May-Grünwald-Giemsa (MGG) staining procedure. Differential cytology includes the percentage of macrophages, lymphocytes, neutrophils and eosinophils, mast cells, and plasma cells.

\section{Caution}

Pay attention to the fact that mast cell granules are faintly or not at all stained by the DiffQuik staining procedure.

- Two wet-fixed smears are routinely stained with the Papanicolaou method (Pap) and screened for entire cellular composite, tumor cells, quality of histiocytes/ macrophages, dust particles, virus-induced cell changes, and organisms. Further slides (wet fixed or/and air-dried) are prepared as simple smears or by cytocentrifugation according to the clinical requirements. Common additional analyses include special stains for iron and fat, Gram and Ziehl-Neelsen staining for bacteria, PAS and silver staining methods for fungi/pneumocysts, and immunostains to identify Langerhans cells, as indicated in Sect. 2.3.7.1.2, p. 189.

- The remaining sediment is resuspended and refrigerated at $4^{\circ} \mathrm{C}$ for 1 week as a reserve for potential subsequent analyses on cells and search for noncellular elements.

4. Rapid diagnosis can be performed within 20 min using a DiffQuik-rapid stain method, or rapid and ultrafast Papstaining techniques (see Sect. 1.1.4.4, "Rapid-Staining and Quick-Read, p. 5).

\subsection{Analysis of Lymphocyte Subpopulations}

Lymphocyte subpopulations can be identified using immunocytochemical methods on wet-fixed and air-dried cytospin preparations or alternatively by fluorescence-activated cell sorting (FACS ${ }^{\circledR}$ Becton Dickinson, San Jose, CA, USA), a specialized type of flow cytometry. The latter method, which we prefer, is based upon the specific light scattering 
and fluorescent characteristics of each cell and in particular lymphocytes (T-helper cells, T-suppressor cells, B cells, among others). Viability tests of lymphocytes are also possible by flow cytometry; at our laboratory, cellular viability is not routinely checked but utilized at random as quality control and in selected cases. Immunocytochemical lymphocyte subtyping is still used as a control method in specific cases.

\subsection{Documentation of the Cytologic Analyses}

- Diagnostic assessment ends in a written report including a summing up of the decisive cytologic findings, differential diagnostic considerations, and if feasible, a tentative or conclusive diagnosis.

- The written report is completed by a separate form that records:

- The volume lavage fluid obtained.

- The total cell count.

- The differential cytology.

- The lymphocyte subpopulations (per liter of recovery fluid) including activated lymphocyte subtypes.

- The CD4/CD8 ratio.

- The normal values for each cell type.

- Data files with the flow cytometric histograms are individually provided upon request.

\subsubsection{Normal Cytology in BAL Specimens}

\subsubsection{Nonsmokers (Fig. 2.68A)}

Differing normal values for differential cytology have been reported in the literature. Guidelines of a Task Group of the European Society of Pneumology recommend the following values as normal [29]:

Macrophages $>80 \%$.

Lymphocytes $\leq 15 \%$.

Neutrophils $\leq 3 \%$.

Eosinophils $\leq 0.5 \%$.

Mast cells $\leq 0.5 \%$.

The values can be applied to both cytocentrifuged specimens and direct smears.

\section{Microscopic Features}

O Macrophages are uniform, the nuclei exhibit a characteristic kidney shape, bland chromatin, and a cyanophilic /basophilic cytoplasm. Cytoplasmic vacuoles and particle inclusions are rare. Multinucleation is a normal finding in a small percentage of macrophages.

O The number of epithelial cells in an adequate BAL sample should not exceed $5 \%$.

○ The background is completely clean.

\subsubsection{Smokers (Fig. 2.68B)}

Total cell counts are markedly increased in otherwise healthy smokers, in the first instance due to the macrophage cell component [16]. Macrophages may show up as clearly increased and irregular cytoplasm bearing round inclusions (MGG stain: blue-black). These so-called smoker's inclusions consist of ingested particles from the inhaled smoke $[17,34]$.

The percentage of lymphocytes is reduced and that of granulocytes is the same as in nonsmokers.

\subsubsection{CD4/CD8 Ratio}

The determination of the lymphocyte subsets, T-helper cells (CD4), and T-suppressor cells (CD8) may be of substantial help in the diagnostic management of patients presenting with alveolar lymphocytosis. Changes in the CD4/CD8 ratio are quite typical for certain peripheral lung diseases.

The CD4/CD8 ratio of the normal lymphocytic population in BALs of healthy individuals and nonsmokers achieves a median value of 2.0 (range, 1.1-3.5), that of smokers is halved [33].

\section{Caution}

- Normal cellular composite of the BAL definitely excludes active sarcoidosis, active extrinsic allergic alveolitis, common and eosinophilic pneumonia, alveolar hemorrhage syndrome, and alveolar proteinosis.

- Abnormal components in a BAL that are interspersed between numerous normal bronchial epithelial cells call for careful diagnostic interpretation. These elements may originate exclusively from the bronchial and bronchiolar system.

\subsubsection{Diagnostic Findings in BAL Specimens}

Few pathologic lung conditions can be diagnosed by BAL alone. However, in many cases BAL serves as an important adjunct leading to a conclusive diagnosis in the context of clinical, radiologic, and biochemical findings. For other clinical entities, BAL cannot replace lung biopsy, hence a supplemental histologic evaluation is unavoidable.

A synopsis of the most significant findings in BAL specimens is provided in Table 2.3.1, below.

The cytologically most important lung disorders are subsequently focused in connection with diagnostic findings in bronchoalveolar lavage and differential diagnoses. For detailed information, we refer the readers to distinguished books and relevant publications [8, 10, 12, 37]. Several literature reports related to the various entities are cited. 
Table 2.3.1 A general view of significant findings in bronchoalveolar lavage and their related diseases

\begin{tabular}{|c|c|}
\hline Cellular and noncellular abnormalities & Differential diagnosis \\
\hline Lymphocytosis & $\begin{array}{l}\text { Sarcoidosis (Sect. 2.3.4.1, p. 179) } \\
\text { Extrinsic allergic alveolitis (Sect. 2.3.4.2, p. 180) } \\
\text { Drug-induced alveolitis (Sect. 2.3.4.4, p. 181) } \\
\text { Pneumoconiosis (Sect. 2.3.4.9, p. 184) } \\
\text { Berylliosis (Sect. 2.3.4.9.3, p. 186) } \\
\text { Neoplastic disease: } \\
\text { - Malignant lymphoma } \\
\text { - Lymphangiosis carcinomatosa }\end{array}$ \\
\hline $\begin{array}{l}\text { Neutrophilia } \\
\text { frequently together with lymphocytosis of varied degree } \\
\text { and/or eosinophilia }\end{array}$ & $\begin{array}{l}\text { Bacterial pneumonia } \\
\text { Idiopathic pulmonary fibrosis (Sect. 2.3.4.5, p. 182) } \\
\text { Cryptogenic organizing pneumonia (COP) (Sect. 2.3.4.3, p. 181) } \\
\text { Collagen / autoimmune disease (Sect. 2.3.4.6, p. 182): Lupus erythematosus, } \\
\text { Sjögren syndrome, Crohn disease, rheumatoid arthritis, and others } \\
\text { Acute respiratory distress syndrome (ARDS) }\end{array}$ \\
\hline Eosinophilia & $\begin{array}{l}\text { Eosinophilic lung disease (Sect. 2.3.4.7, p. 183): } \\
\text { - Eosinophilic pneumonias } \\
\text { - Drugs } \\
\text { - Hypereosinophilia syndrome } \\
\text { - Allergic bronchopulmonary aspergillosis } \\
\text { - Asthma } \\
\text { - Churg-Strauss syndrome }\end{array}$ \\
\hline Admixture of plasma cells & $\begin{array}{l}\text { Virtually exclusive with: } \\
\text { - Extrinsic allergic alveolitis } \\
\text { - Cryptogenic organizing pneumonia } \\
\text { - Chronic eosinophilic pneumonia } \\
\text { - Aspiration pneumonia (Sects. } 2.3 .7 .2 \text {, p. } 190 \text {, and } 2.3 .7 .3 \text {, p. 190) }\end{array}$ \\
\hline Increase of mast cells & $\begin{array}{l}\text { Extrinsic allergic alveolitis } \\
\text { Cryptogenic organizing pneumonia } \\
\text { Sarcoidosis } \\
\text { Chronic eosinophilic pneumonia } \\
\text { Idiopathic pulmonary fibrosis }\end{array}$ \\
\hline $\begin{array}{l}\text { Dust particles } \\
\text { as inclusions in macrophages and in the background }\end{array}$ & $\begin{array}{l}\text { Pneumoconiosis (Sect. 2.3.4.9, p. 184) } \\
\text { Asbestosis (Sect. 2.3.4.9.1, p. 185) }\end{array}$ \\
\hline Acellular corpuscles + cellular debris & Alveolar proteinosis (Sect. 2.3.4.10, p. 186) \\
\hline Hemosiderin and (degenerate) erythrocytes & Alveolar hemorrhage syndrome (Sect. 2.3.4.8, p. 184) \\
\hline Infectious agents (Sect. 2.3.5, p. 187) & $\begin{array}{l}\text { Opportunistic infections with: } \\
\text { - Pneumocystis jirovecii } \\
\text { - Other fungi } \\
\text { - Cytomegalovirus } \\
\text { Infectious diseases: } \\
\text { - Tuberculosis } \\
\text { - Viral pneumonia }\end{array}$ \\
\hline Malignant neoplastic cells (Sect. 2.3.6, p. 188) & $\begin{array}{l}\text { Bronchioloalveolar carcinoma } \\
\text { Lymphangiosis carcinomatosa of the lung parenchyma } \\
\text { Malignant lymphoma / leukemia }\end{array}$ \\
\hline Increased number of Langerhans cells & Langerhans cell histiocytosis (Histiocytosis X) (Sect. 2.3.7.1, p. 189) \\
\hline
\end{tabular}

\subsubsection{Sarcoidosis (Tab. 2.3.2)}

Sarcoidosis is a multisystem disorder commonly arising in young adults, characterized by noncaseating granulomas with typical cellular features. The cause of the disease is still unknown. Granulomas most often appear in the lungs or in the lymph nodes, but virtually any organ can be affected. The clinical course generally varies and ranges from an asymptomatic disorder to chronic debilitating disease. 
Table 2.3.2 Sarcoidosis: morphologic features and cautions

\begin{tabular}{lll}
\hline Bronchoalveolar lavage & & $\begin{array}{l}\text { Caution } \\
\text { see also "Differential Diagnosis" }\end{array}$ \\
\hline Morphologic key features & Additional morphology & $-\begin{array}{l}\text { Lower percentage quotation for } \\
\text { lymphocytosis in inactive sarcoidosis }\end{array}$ \\
\hline- Lymphocytosis: $30-60 \%$ & - Elevated total cell count & - CD4/CD8 ratio is highly variable \\
- Elevated CD4/CD8 ratio $\geq 3.5$ & - Normal percentage of eosinophils & - Minor specificity of noncaseating \\
& & granuloma cell components \\
& - Mast cells, variable & \\
& - No plasma cells & \\
& fragments of noncaseating granuloma & \\
\hline
\end{tabular}

\section{Additional Comments}

- The finding of lymphocytosis in BAL specimens is not specific and the CD4/CD8 ratio values vary considerably [27], but an increased proportion of T-helper lymphocytes is an important finding in the diagnostic evaluation of sarcoidosis. A CD4/CD8 ratio of 4.0 and greater has a high positive predictive value for the diagnosis of sarcoidosis, and ratios between 3.5 and 5 are diagnostic if clinical findings support this diagnosis (Fig. 2.69).

- Moderate lymphocytosis with a normal CD4/CD8 ratio is not uncommon in inactive sarcoidosis.

- Sarcoidosis can be reliably distinguished from most common interstitial lung diseases taking all BAL-cell populations into account (as listed above) [18, 67].

- Advanced disease with fibrotic changes may be associated with an increased number of neutrophils [32]. Neutrophilia together with an increase in NK cells may mean a higher probability of poor outcome [63].

- The presence of epithelioid histiocytes, giant cells of the Langhans type, and fragments of noncaseating granulomas (morphologic details, see Sect. 2.1.3.2.2, "Granuloma Cells and Sarcoidosis," p. 111) in BAL fluid is a strong indicator for sarcoidosis but not at all specific for this diagnosis (Figs. 2.5 and 2.6).

\section{Differential Diagnosis}

Berylliosis may show high CD4/CD8 ratios as well. Increased ratios are also valid for extrinsic allergic alveolitis, nonspecific interstitial pneumonia, idiopathic pulmonary fibrosis, pneumoconiosis, and other disorders. However, the nonlymphoid cell features differ from those in sarcoidosis.

\subsubsection{Extrinsic Allergic Alveolitis (Tab. 2.3.3)}

Extrinsic allergic alveolitis (EAA) is an immunologically mediated interstitial lung disease. Many airborne organic antigens in the form of fungal spores, bacteria, aerosolized proteins (predominantly from birds) can cause hypersensitivity pneumonitis after repeated inhalational exposure [26]. A wide variety of hypersensitivity lung diseases with their correspondent antigens are tabulated in Costabel's BAL Atlas [10]. Many people who are exposed to allergens and become sensitized can remain asymptomatic but may show characteristic abnormal BAL morphology. Ongoing alveolitis may progress in chronic illness with evidence of lymphocytic alveolitis, granulomatous reaction, and finally fibrotic interstitial changes.

\section{Additional Comments}

- EAA is associated with the highest total cell count and the highest number of lymphocytes in BAL compared with other interstitial lung disorders.

- Abnormalities in the bronchoalveolar lavage fluid cell counts are almost always seen in patients with EAA according to different phases of the disease: at an early stage of allergen exposure the number of neutrophils increases and returns to a normal range within 1 week. The pathognomonic BAL findings become apparent in the subacute and chronic phase of the disease.

- Mast cells have been reported to occur in higher rates in BAL of EAA compared to other interstitial lung diseases $[25,38]$.

Table 2.3.3 EAA: morphologic features and cautions

\begin{tabular}{lll}
\hline Bronchoalveolar lavage & & $\begin{array}{l}\text { Caution } \\
\text { see also "Differential Diagnosis" }\end{array}$ \\
\hline Morphologic key features & Additional morphology & - Lymphocytes may be activated \\
\hline - Pronounced lymphocytosis: $>50 \%$ & - Marked increase in total cell count & - Epithelioid histiocytes and granuloma \\
- Normal or reduced CD4/CD8 ratio & - Increase of activated HLA-DR+ T & \\
- Increase in CD57+ NK cells (in about & lymphocytes & \\
$\quad$ two-thirds of all cases) & - Plasma cell range: up to 2\% (in about & \\
- Presence of mast cells in nearly all cases & & two-thirds of all cases) \\
& - Slight increase in neutrophils \\
& - Macrophages often with foamy cytoplasm & \\
\hline
\end{tabular}


- Plasma cells are fairly characteristic of EAA, as they are observed in only a few other lung disorders such as cryptogenic organizing pneumonia, chronic eosinophilic pneumonia, and aspiration pneumonia [10].

\section{Differential Diagnosis}

- An activated lymphocytic population in EAA should not lead to a misdiagnosis of malignant lymphoma.

- In the course of EAA, the CD4 T-helper cell fraction and subsequently the CD4/CD8 ratio may increase, a finding that may be misinterpreted as sarcoidosis.

- Granulomatous reaction in chronic stages of EAA can also be encountered in BAL fluids, i.e., granulomatosis is not a specific sign of sarcoidosis. Evaluation of the lymphocyte surface antigen phenotypes provides a correct diagnosis.

\subsubsection{Cryptogenic Organizing Pneumonia}

(Fig. 2.70) (Tab. 2.3.4)

Synonym: Bronchiolitis obliterans with organizing pneumonia (BOOP)

Cryptogenic organizing pneumonia (COP) is an inflammatory lung disease with distinct clinical, radiological, and histopathological features. The latter consist of intraalveolar buds of granulation tissue, rich in active fibroblasts and myofibroblasts. COP may be triggered by infectious agents as well as by drugs and toxic fumes. The disease usually begins between the ages of 40 and 60 and affects men and women equally.

\section{Additional Comments}

- The lymphocyte rate is relatively high and the CD4/CD8 ratio is reduced to a degree barely observed in BAL fluids of other interstitial lung disorders.

- The proportion of $\mathrm{CD} 57^{+} \mathrm{NK}$ cells is not increased.

- Plasma cells are a common feature in both COP and EAA.

- Mast cells can be significantly increased in individual cases of COP [52].

\section{Differential Diagnosis}

- COP differs from EAA in a normal $\mathrm{CD} 57^{+} \mathrm{NK}$ cell number and in a lower CD4/CD8 ratio.
- Low lymphocyte percentage of less than $20 \%$ makes the diagnosis of COP quite unlikely; however, idiopathic pulmonary fibrosis should primarily be taken into consideration.

- Chronic eosinophilic pneumonia exhibits a high percentage of eosinophils exceeding $20 \%$ of the total cell count, a rate that has rarely been encountered in COP. Compared to BAL results in patients with COP, most patients with eosinophilic pneumonia show a higher eosinophil percentage than lymphocyte percentage [13].

\subsubsection{Drug-Induced Alveolitis (Tab. 2.3.5)}

Drug-induced lung damage induces a wide range of BAL cellular changes comprising lymphocytic, neutrophilic, or eosinophilic predominance. Still, lymphocytosis associated with a low CD4/CD8 ratio is most commonly seen.

Numerous drugs with their cytologic patterns observed in BAL fluids have been presented in table form by Costabel [10] and Tötsch and coauthors [59].

\section{Additional Comments}

- Alveolar hemorrhage syndrome may sometimes be linked with drug-related lung damage.

- A characteristic but not specific cell feature is observed in amiodarone lung (Fig. 2.71): macrophages displaying extremely pronounced cytoplasmic vacuolization. Ultrastructurally, the cytoplasmic deposits occur in lamellar arrangement similar to surfactant lamellar bodies [60]. The characteristic macrophages may also be found in BALs of patients taking amiodarone but lacking pneumopathy [4].

- Hyperplastic type II pneumocytes seem to occur mainly in combination with interstitial fibrosis [4].

\section{Differential Diagnosis}

- Differential cytology may sometimes mimic the cell constellation seen in EAA or COP.

- Amiodarone-induced foamy vacuolization in the cytoplasm of macrophages is not a specific feature but vacuolization of macrophages in EAA and COP is usually less pronounced.

Table 2.3.4 COP: morphologic features and cautions

\begin{tabular}{lll}
\hline Bronchoalveolar lavage & & $\begin{array}{l}\text { Caution } \\
\text { see also "Differential Diagnosis" }\end{array}$ \\
\hline Morphologic key features & Additional morphology & - Cell pattern in BAL may mimic EAA \\
\hline - Lymphocytosis & - Increase in total cell count & - BAL findings can closely resemble those \\
$\quad$ and & - Macrophages often with foamy & of EAA \\
$\quad \begin{array}{l}\text { Increase in neutrophils and eosinophils } \\
\text { and }\end{array}$ & - cytoplasm & \\
$\quad \begin{array}{l}\text { Presence of mast cells and plasma cells } \\
\text { - Markedly reduced CD4/CD8 ratio }<1.0\end{array}$ & & \\
\hline
\end{tabular}


Table 2.3.5 Drug-induced alveolitis: differential cytology and cautions

\begin{tabular}{|c|c|}
\hline Bronchoalveolar lavage & \multirow{2}{*}{$\begin{array}{l}\text { Caution } \\
\text { see also "Differential Diagnosis", }\end{array}$} \\
\hline Differential cytology & \\
\hline $\begin{array}{l}\text { - Predominant: } \\
\text { Lymphocytosis and decreased } \mathrm{CD} 4 / \mathrm{CD} 8 \text { ratio }\end{array}$ & $\begin{array}{l}\text { - Pronounced lymphocytosis together with distinct decrease of the } \\
\text { T-lymphocyte ratio may provoke misinterpretation (check clinical history!) }\end{array}$ \\
\hline $\begin{array}{l}\text { - Rather uncommon: } \\
\text { Neutrophilia, eosinophilia, or mixed cell pattern }\end{array}$ & \\
\hline $\begin{array}{l}\text { - Rarely seen: } \\
\text { Alveolar hemorrhage syndrome }\end{array}$ & \\
\hline $\begin{array}{l}\text { - Amiodarone lung (Fig. } 2.71 \text { ): } \\
\text { Macrophages with abundant foamy cytoplasm }\end{array}$ & $\begin{array}{l}\text { - Typical foamy macrophages indicate amiodarone intake even if lung disease } \\
\text { is absent }\end{array}$ \\
\hline $\begin{array}{l}\text { - Drug-induced cellular atypia } \\
\text { - Hyperplastic type II pneumocytes (Fig. 2.72) }\end{array}$ & $\begin{array}{l}\text { - Cytotoxic reaction may be pronounced to such a degree that cellular atypia } \\
\text { is mistaken for malignancy }\end{array}$ \\
\hline
\end{tabular}

- Reactive cell changes induced by chemotherapy (and irradiation) can reliably be recognized by experienced microscopists, even though substantial degenerative changes of atypical cells may raise differential diagnostic problems. A drug-induced hyperplastic process of the epithelium of the bronchi, terminal bronchioli, and alveoli (type II pneumocytes) may simulate adenocarcinoma, both on exfoliated single cells and cell clusters (Fig. 2.84). The varied morphologic characteristics, differential diagnostic considerations, cautions, and potential auxiliary analyses regarding hyperplastic cell alterations are discussed in Sect. 2.1.4, "Abnormal and Atypical Epithelial Cells," p. 112.

- Activated macrophages may closely mimic proliferating type II pneumocytes. Immunocytochemistry can separate the two histogenetically different cell types: macrophages are positive for lysozyme (and other histiocytic markers) and negative for EMA, CEA, and cytokeratins [4].

\subsubsection{Idiopathic Pulmonary Fibrosis [10] (Tab. 2.3.6)}

Idiopathic interstitial pneumonia (IIP) is an alveolar disorder of unknown etiology. A primary alveolitis is followed by chronic inflammation and progressive fibrosis of the pulmonary alveolar walls with steady progressive dyspnea as a striking clinical symptom. The disease usually affects males and females aged between 40 and 70 years.

\section{Additional Comments}

- An increased number of neutrophils is observed in up to $90 \%$ of all cases with idiopathic pulmonary fibrosis. Many of the cases (up to 60\%) show a parallel increase in eosinophilic granulocytes [43].

- Lymphocytosis may be observed in up to $20 \%$ of all cases.

- Differential cytology in BAL can be helpful in assessing the degree of activity of the disease and may act as prognostic indicator. In this respect, an increased percentage of lymphocytes is presumed to be an indicator of a better prognosis [51, 62].

\section{Differential Diagnosis}

- A normal cell distribution in BAL makes idiopathic pulmonary fibrosis an improbable diagnosis; in contrast, any abnormal BAL cell pattern caused by IIP has a large variety of differential diagnoses.

- Several reports in the literature deal with the subject of discrimination between different types of interstitial pneumonia using cell counts in BAL: the results have not been consistent $[17,51,64]$.

\subsubsection{Systemic Connective Tissue Disorders}

These disorders encompass an inhomogeneous group of inflammatory immune diseases with a progressive course, involving connective tissue, joints, blood vessels, and other

Table 2.3.6 IIP: morphologic features and cautions

\begin{tabular}{|c|c|c|}
\hline \multicolumn{2}{|l|}{ Bronchoalveolar lavage } & \multirow{2}{*}{$\begin{array}{l}\text { Caution } \\
\text { see also "Differential Diagnosis" }\end{array}$} \\
\hline Morphologic key features & Additional morphology & \\
\hline - Neutrophilia $( \pm 20 \%)$ & $\begin{array}{l}\text { - Lymphocytosis with CD4/CD8 ratio in } \\
\text { normal or slightly decreased range }\end{array}$ & $\begin{array}{l}\text { - Cell distribution pattern is not reliably } \\
\text { diagnostic }\end{array}$ \\
\hline - Eosinophilia $( \pm 5 \%)$ & $\begin{array}{l}\text { - Mast cells, variable } \\
\text { - Macrophages with variable cytoplasmic } \\
\text { vacuolization }\end{array}$ & $\begin{array}{l}\text { - Reactive cell changes: type II pneumocyte } \\
\text { hyperplasia versus carcinoma! (see Sect. } \\
\text { 2.1.4.3.2, p. 114) }\end{array}$ \\
\hline
\end{tabular}


organs with alternating intensity. The lung is not always affected.

BAL findings are similar to those in idiopathic pulmonary fibrosis. Lymphocytosis seems to be more common in immune conditioned inflammatory processes indicating a more favorable prognosis. Specialized sources in the literature should be consulted for further information $[10,31,42$, and others].

\subsubsection{Eosinophilic Lung Disease}

(Fig. 2.73) (Tab. 2.3.7)

Eosinophilic lung diseases are characterized by pulmonary eosinophilia that is an accumulation of abnormal quantities of eosinophils in air spaces and interstitial tissue of the lung.

\section{Additional Comments and Differential Diagnosis [10]}

- Infectious agents: Pulmonary eosinophilia includes parasitic infections, particularly ascariasis in children. Löffler syndrome is frequently associated with helminthic infections, but about one-third of the cases are idiopathic. Fungal pulmonary eosinophilia is in most cases caused by an aspergillus-associated hypersensitivity respiratory disorder referred to as allergic bronchopulmonary aspergillosis.

- Drugs: Crack, cocaine, and heroin inhalation have been reported to induce acute eosinophilic lung disorder [61].

- Vasculitis/systemic diseases:
Churg-Strauss syndrome (CSS) is characterized by clinical and pathological manifestations, which separate the condition from other eosinophilic disorders: blood eosinophilia, asthma, and organ-specific disorders effected by vasculitis; the diagnostic relevance of antineutrophil cytoplasmic autoantibodies (ANCA) is under debate. Histopathological findings include epithelioid granuloma, tissue eosinophilia, and necrotizing vasculitis [23]. Marked eosinophilia in BAL fluid is a hallmark of CSS.

In contrast, Wegener granulomatosis is not associated with asthma bronchiale and exhibits mild eosinophilia together with a definite higher percentage of neutrophils [53].

- Hypereosinophilic syndrome is not associated with vasculitis.

- Idiopathic acute and chronic eosinophilic pneumonia [15, 43]:

Alveolar eosinophilia is generally combined with peripheral blood eosinophilia. The proportion of alveolar eosinophiles always predominates in contrast to other pneumonic disorders such as ARDS or bacterial pneumonia.

Chronic eosinophilic pneumonia is almost always associated with the alveolar presence of plasma cells, but the neutrophil count is in normal range (in contrast to Wegener granulomatosis). Chronic idiopathic eosinophilic pneumonia is very sensitive to corticosteroids.

Table 2.3.7 Eosinophilic lung disease: causes, morphologic features, and cautions

\begin{tabular}{|c|c|c|c|}
\hline \multirow[t]{2}{*}{ Causes } & \multicolumn{2}{|c|}{ Bronchoalveolar lavage } & \multirow{2}{*}{$\begin{array}{l}\text { Caution } \\
\text { see also "Additional } \\
\text { Comments and Differential } \\
\text { Diagnosis" }\end{array}$} \\
\hline & $\begin{array}{l}\text { Morphologic } \\
\text { key feature }\end{array}$ & $\begin{array}{l}\text { Additional morphology } \\
\text { see also "Additional Comments } \\
\text { and Differential Diagnosis" }\end{array}$ & \\
\hline $\begin{array}{l}\text { Infectious diseases } \\
\text { - Parasites (Löffler syndrome, } \\
\text { tropical) }\end{array}$ & $\begin{array}{l}\text { Generally prominent } \\
\text { hypereosinophilia }\end{array}$ & $\begin{array}{l}\text { Usually increased number of } \\
\text { lymphocytes and neutrophils }\end{array}$ & \\
\hline \multicolumn{4}{|l|}{$\begin{array}{l}\text { - Mycobacterium tuberculosis } \\
\text { - Fungi }\end{array}$} \\
\hline $\begin{array}{l}\text { Drugs } \\
-\quad \text { Penicillin, etc. } \\
\text { - } \quad \text { Illegal drugs! }\end{array}$ & & Eosinophilia variable & \\
\hline $\begin{array}{l}\text { Vasculitis /systemic diseases } \\
-\quad \text { Churg-Strauss syndrome } \\
-\quad \text { Wegener granulomatosis } \\
-\quad \text { Hypereosinophilia syndrome }\end{array}$ & & $\begin{array}{ll}\text { - } & \text { Marked eosinophilia }>20 \% \\
\text { - } & \text { Varying lymphocytosis } \\
\text { - } & \text { Low eosinophilia/neutrophilia } \\
& \text { ratio }\end{array}$ & \\
\hline $\begin{array}{l}\text { No etiological agent / idiopathic } \\
\text { - Acute and chronic eosinophilic } \\
\text { pneumonia }\end{array}$ & & $\begin{array}{l}\text { Neutrophils are normal to mildly } \\
\text { increased }\end{array}$ & $\begin{array}{l}\text { Idiopathic disease is not } \\
\text { established before all possible } \\
\text { causes can be excluded }\end{array}$ \\
\hline \multicolumn{4}{|l|}{ Bronchial asthma } \\
\hline Malignancies & & & \\
\hline
\end{tabular}


- Bronchial asthma is commonly found in patients with Churg-Strauss syndrome, chronic eosinophilic pneumonia, and in most of the interstitial lung disorders caused by specific respiratory allergens. BAL cytology reveals mild to moderate eosinophilia and an occasional increase in neutrophils and mast cells. In general clinical practice, the cytologic examination of BAL fluids in patients with bronchial asthma is of little significance.

\subsubsection{Alveolar Hemorrhage Syndrome}

(Fig. 2.74) (Tab. 2.3.8)

Lung hemosiderosis may be caused by unknown factors (idiopathic hemosiderosis). However, many underlying disorders exist for hemorrhage syndromes of the alveolar space such as autoimmune disease, vasculitis, cardiovascular diseases, drugs, hematological diseases, or post-transplantation conditions. The most common causes for alveolar hemorrhage have been compiled and tabulated by Costabel [10].

\section{Additional Comments}

- The characteristic hemosiderin-relevant greenish or green-brown color of the cytoplasm of macrophages is not always clearly apparent on routine staining procedures (Papanicolaou and May-Grünwald-Giemsa). Therefore, iron staining (e.g., the Prussian-blue method) should always be performed in morphologically doubtful cases and in all cases with clinical doubt.

- The phenotype of hemosiderin content in macrophages appears variably (after Prussian-blue staining) (Fig. 2.74):

1. Faint blue coloring of a part of the cytoplasm.

2. Slight to moderate blue coloring of the whole cytoplasm.

3. In addition, deep blue granules occurring sporadically, or in variable quantities, or that are densely packed throughout the whole cytoplasm.

- Different scoring systems have been applied to create hemosiderin scores, but differential diagnostic conclusions on the basis of a semiquantitative assessment of the cytoplasmic hemosiderin deposits are limited. Grebski and coauthors found the highest hemosiderin scores in patients suffering from immunomediated diseases known to cause alveolar hemorrhage, and in selected groups of patient who had undergone heart transplantation [24].

- Chronic hemorrhage syndrome may show a cytologic appearance, as observed in idiopathic pulmonary fibrosis comprising increases in neutrophils and eosinophils.

- Certain occupational categories such as metal workers or welders are exposed to iron uptake from exogenous sources. Iron-laden macrophages are usually larger with more polymorphic cytoplasm and dust inclusions; ironcontaining particles are often bizarre and irregular in shape and size.

- In general, the overall pattern of severe endogenous and exogenous siderosis is not very different: up to $100 \%$ of the macrophages exhibit strong positivity to iron stains.

\subsubsection{Pneumoconiosis}

- Bronchoalveolar lavage in occupational lung diseases have been broadly covered by Costabel [10] and recently by Cordeiro and coauthors [7].

- Pneumoconiosis is an occupational lung disease caused by inhalation of inorganic dust particles. The disease usually runs a chronic course ending in generalized interstitial lung disease. Dust particles may be permanently but not completely removed from the alveolar space by uptake in the interstitium (elimination through the lymphatic system) and by proximal transport of the mucus stream. Dust particles may be found trapped in macrophages decades after exposure to dust.

- More information on alveolar macrophages and their morphology is provided in Sect. 2.1.3.2.1 "Pulmonary Alveolar Macrophages," p. 111.

Table 2.3.8 Alveolar hemorrhage syndrome: macroscopic features, microscopic features, and cautions

\begin{tabular}{lll}
\hline Bronchoalveolar lavage & Caution \\
Macroscopic features & Microscopy & also "Additional Comments" \\
\hline $\begin{array}{l}\text { Fresh bleeding: } \\
\text { Dark red coloring }\end{array}$ & Red blood cells substantially increased & $\begin{array}{l}\text { Bronchoscopy-related traumatic mucosal } \\
\text { lesion with bleeding has to be excluded }\end{array}$ \\
$\begin{array}{l}\text { Within } \mathbf{2} \text { days: } \\
\text { Orange-red staining }\end{array}$ & $\begin{array}{l}\text { Macrophages with intracytoplasmic } \\
\text { erythrocytes and Ec-fragments }\end{array}$ & \\
$\begin{array}{l}\text { More than } \mathbf{4 8} \text { h after onset of bleeding: } \\
\text { Red-brown staining }\end{array}$ & $-\begin{array}{l}\text { Macrophages with intracytoplasmic } \\
\text { hemosiderin. }\end{array}$ & $\begin{array}{l}\text { Exogenous iron contamination should } \\
\text { always be considered and is most } \\
\text { often distinguishable from endogenous } \\
\text { hemorrhage }\end{array}$ \\
$\begin{array}{l}\text { Older bleeding: } \\
\text { Dark and rust-brown staining }\end{array}$ & $\begin{array}{l}\text { In severe disorders, nearly all } \\
\text { macrophages show hemosiderin } \\
\text { inclusions }\end{array}$ & $\begin{array}{l}\text { Routine staining procedures may miss } \\
\text { intracytoplasmic hemosiderin load }\end{array}$ \\
\hline
\end{tabular}




\subsection{Asbestos-Related Disease}

- Inhalation of asbestos dust can induce variable occupational diseases such as pulmonary fibrosis (asbestosis), malignant mesothelioma, benign pleural fibrotic disorders, and bronchial carcinoma. Therefore, asbestos use has been banned in most developed countries but exposure still occurs, and asbestosis deaths are not expected to decrease sharply in the United States during the next couple of years [2].

- Pathogenesis, including associated immunological mechanisms of asbestosis, quantitation using the asbestos body filtration technique, and its clinical implication are highlighted in Costabel's atlas [10].

\section{Phenotype of Asbestos Bodies (Fig. 2.75)}

Asbestos bodies are easily recognized on light microscopy if they are surrounded by a proteinaceous iron-containing coat (ferruginous bodies).

O The classic asbestos body appears as an elongated, slender beaded rod that may display a translucent center and ends on both sides in protrusions exhibiting a smooth surface. The asbestos bodies are surrounded by histiocytic cells and usually phagocytized by one or several macrophages. Asbestos bodies can reach lengths of 20-200 $\mu \mathrm{m}$ and widths of about $5 \mu \mathrm{m}$.

$\circ$ The ferroprotein in the fiber coat yields the typical golden-brown color in Papanicolaou-stained specimens and a positive reaction with iron stains (e.g., Prussian blue).

\section{Asbestos and Alveolitis, microscopic features in BAL}

Early reaction to asbestos inhalation may consist of a mild lymphogranulocytic inflammatory process. Early asbestosis induces a marked inflammatory process that is easily recognized in BAL specimens. Ongoing development of the fibrotic process results in a decrease in the percentage of inflammatory cells. Lymphocytosis may reach $15 \%$ with an increased CD4/CD8 ratio. Lymphocytosis is presumed to be associated with a less aggressive course [10, 48, 65].

\subsection{Pseudo-asbestos Bodies (Fig. 2.75)}

True asbestos bodies have to be distinguished from pseudoasbestos bodies. The latter are inhaled fibers with a mineralogical composition unlike asbestos but a related iron-containing coat. Such fibers can be made up of carbon, aluminum, glass fibers, and other biological and artificial fiber types [10].

O Compared to classic asbestos bodies, pseudo-asbestos bodies lack the slender beaded shape, and the smooth surface of the terminal protrusions. The elements are more polymorphous and plump.

\section{Caution}

The term "ferruginous body" is commonly applied to asbestos bodies but can be used for each iron-coated fusiform element regardless of the nature of the central fiber.

\subsection{Other Pneumoconioses and Mixed-Dust} Disorders (Figs. 2.76 and 2.77)

\section{Silicosis}

Silicosis (also known as grinder's disease) is caused by inhalation of crystalline silica (quartz crystals) dust and characterized by marked inflammation and scarring nodular lesions in the upper lobes of the lungs.

O Macrophages in BAL fluids show cytoplasmic inclusions of small spicular elements that are birefringent upon polarization. Depending on the degree of contamination, the histiocytic cells may be enlarged with evidence of nuclear activation.

O Cell counts are usually markedly increased reflecting the high proportion of macrophages. Mild inflammation is represented by a mixture of granulocytes and lymphocytes.

\section{Anthracosilicosis/Coal Miner's Lung}

These are mixed forms of pneumoconioses caused by inhalation of coal dust, stone dust, and other minerals in which the degree of lung injury depends on the composition of the dust and the amount of quartz crystals.

O Carbon particles appear as dark-brown (MGG stain) to black (Pap stain) large and polyhedral cytoplasmic inclusions in macrophages; the elements occur singly or densely clustered. Coal dust inclusions do not stain with the iron-staining method. Quartz crystals, coated pseudo-asbestos fibers, and sporadic asbestos bodies may be encountered as well.

\section{Metal Worker Lung}

Metal workers are usually exposed to mixed dust inhalation; accordingly, the macrophages may strongly vary in their morphologic aspect. Fully mixed inclusion patterns are referred to as anthraco-sidero-silicosis:

O Cytoplasmic iron load is usually high; the cytoplasm shows blue coloring and varying numbers of deep blue granules. Siderosis results from exposure to inert metallic iron or iron oxides.

O Anthracotic pigment exhibits as small to moderately sized heavy, black, rough deposits.

O Crystalline silica dust particles (specified above).

O Other inclusions exhibit various sizes, shapes, and colors.

\section{Welder's Lung (Fig. 2.77)}

Welder's lung is a specific presentation of pulmonary siderosis caused by smoke inhalation during welding. Welding dust usually contains metallic iron and iron oxide, which are inert to the human lung. Large amounts of iron dust are ingested in macrophages and settle in lung parenchyma without distinct fibrosis unless crystalline silica is also present [28, 56]. 
Table 2.3.9 Berylliosis: morphologic features and cautions

\begin{tabular}{lll}
\hline Bronchoalveolar lavage & & Caution \\
\hline Morphologic key features & Additional morphology & \\
\hline $\begin{array}{l}\text { Similar to those in sarcoidosis: } \\
- \text { Lymphocytosis }\end{array}$ & $\begin{array}{l}\text { Activated lymphocytes (HLA-DR+ T } \\
\text { lymphocytes) }\end{array}$ & Granuloma cell components are very similar \\
to those in sarcoidosis and mycobacteriosis
\end{tabular}

O Alveolar macrophages are heavily laden with ironpositive particles. The particles are coarser compared to those packed in macrophages due to alveolar bleeding. But in general, the overall pattern of severe endogenous and exogenous siderosis is not very different: up to $100 \%$ of the macrophages exhibit strong positivity to iron stains.

\section{Chronic Berylliosis (Tab. 2.3.9)}

This is a chronic lung disease caused by exposure to beryllium and its compounds. In 1-3\% of workers with single or prolonged exposure by inhalation, the lungs become hypersensitive to beryllium and develop generalized inflammatory nodules. These granulomas are hard to distinguish from granulomas in tuberculosis and sarcoidosis. The similarities and disparities between sarcoidosis and chronic berylliosis have been reviewed by Rossman and Kreider [50].

\section{Other Work-Related Lung Diseases}

Hard metal lung: Specific elements such as cobalt, titanium, nickel, and others can be traced, for example through radiochemical analysis.

Antimony lung: Typical crystalline elements are found as cytoplasmic inclusions in BAL macrophages and as background material in BAL sediments.

\subsubsection{Alveolar Proteinosis}

[21] (Figs. 2.78 and 2.79) (Tab. 2.3.10))

- More than 15 years ago, idiopathic alveolar proteinosis (AP) was recognized as an autoimmune disease caused by neutralizing anti-granulocyte-macrophage colony-stimulating autoantibodies (anti-GM-CSF) [9, 54].

- Secondary AP can occur in patients with pulmonary infections, malignant diseases, particular hematologic malignancies, particular occupational exposures, and as a reaction to drugs.

- Impaired pulmonary surfactant homeostasis is regarded as an additional mechanism in the pathogenesis of AP. There is a strong association between incidence of alveolar proteinosis and tobacco use.

- BAL specimens with the characteristic macroscopic, cytologic and ultrastructural features provide a reliable diagnosis of alveolar proteinosis $[6,35,55]$.

\section{Additional Comments}

- The homogeneous granular material is typically PAS-positive and diastase-resistant (Fig. 2.78).

- Ultrastructural analysis with electron microscopy provides a more definitive diagnosis than cytomorphology alone: whorled myelin-like figures that resemble surfactant (Fig. 2.79). They are usually accumulated in the background of the smears, less frequently intracytoplas-

Table 2.3.10 AP: morphologic features and cautions

\begin{tabular}{|c|c|c|}
\hline \multicolumn{2}{|l|}{ Bronchoalveolar lavage } & \multirow{2}{*}{$\begin{array}{l}\text { Caution } \\
\text { see also "Additional Comments" } \\
\text { and "Differential Diagnosis" }\end{array}$} \\
\hline $\begin{array}{l}\text { Morphologic key features } \\
\text { see also "Additional Comments" }\end{array}$ & Additional morphology & \\
\hline $\begin{array}{l}\text { Gross inspection: } \\
\text { Fluid with milky-white appearance }\end{array}$ & \multirow{3}{*}{$\begin{array}{l}\text { - Globules may be included in macrophages } \\
\text { - Few inflammatory cells } \\
\text { - Occasional cholesterol crystals } \\
\text { - Lymphocytosis and mildly elevated CD4/ } \\
\text { CD8 ratio }\end{array}$} & \multirow{3}{*}{$\begin{array}{l}\text { - Less characteristic background and cell } \\
\text { pattern after therapeutic lavage } \\
\text { - Atypical background features and/or } \\
\text { quality of macrophages, together with } \\
\text { particular lymphocytic quantification } \\
\text { and phenotyping may raise diagnostic } \\
\text { confusion }\end{array}$} \\
\hline $\begin{array}{l}\text { Microscopy: } \\
\text { - } \text { Dirty background } \\
\text { - } \text { Proteinaceous amorphous globules } \\
\quad \text { (MGG: basophilic / Pap: pale } \\
\text { eosinophilic) } \\
\text { - } \text { Cellular debris } \\
\text { - }\end{array}$ & & \\
\hline $\begin{array}{l}\text { Electron microscopy: } \\
-\quad \text { Characteristic lamellar bodies }\end{array}$ & & \\
\hline
\end{tabular}


mic in macrophages. Surfactant is a complex substance containing phospholipids and a number of proteins. The substance is produced by the type II pneumocytes and lines the alveoli and smallest bronchioles. Surfactant reduces surface tension throughout the lung and stabilizes the alveoli.

- Treatment of alveolar proteinosis by lavage eliminates the majority of lipoproteins. The morphologic changes of BAL fluid in a patient with alveolar proteinosis successfully treated with GM-CSF has been reported by Schoch and coauthors [54].

\section{Differential Diagnosis}

- Lung disorders, other than alveolar proteinosis, which include a dirty background in cytologic preparations of BAL fluid should be diagnostically approached with caution. Such lesions include pulmonary edema, radiation pneumonitis, Pneumocystis jiroveci pneumonia, acute respiratory distress syndrome, among others [35].

- Persisting lymphocytosis and increased CD4/CD8 ratio, notably observed after successful treatment of alveolar proteinosis, may mimic other pulmonary disorders such as sarcoidosis, extrinsic allergic alveolitis, nonspecific interstitial pneumonia, idiopathic pulmonary fibrosis, and pneumoconiosis [54].

- AP lavage specimens containing the following elements may mimic lipid pneumonia [35]: lipoid background substance, large numbers of foamy macrophages with droplet-like cytoplasmic fat inclusions, and scant PAS-positive globular material.

\subsubsection{Infectious Diseases}

BAL is the method of choice for the detection of opportunistic pulmonary infection in immunocompromised patients, particularly in patients with HIV infection and after organ transplantation.

BAL may sporadically be applied in immunocompetent patients in conjunction with hospital-acquired (nosocomial) infections.

\section{Caution}

Whether an organism found in a BAL sample is pathogenic and responsible for the current lung disease must be considered in each individual case. Organisms in BAL fluids may be of no pathologic significance, in the sense of simple colonization of the mucosa, or of extraneous contamination.

Diagnostic relevance for infectious disease indicates:

- Bacteria included in the cytoplasm of neutrophils and macrophages

- Fungi associated with marked neutrophilia and/or eosinophilia (particularly allergic bronchopulmonary aspergillosis).

\subsubsection{Bacterial Infection}

Acute bacterial pneumonia is associated with masses of neutrophils. Bacteria are ingested in the cytoplasm of neutrophils and/or macrophages. Bacteria are easily recognized in May-Grünwald-Giemsa-stained specimens and with the Gram staining procedure.

\subsubsection{Tuberculosis (Tab. 2.3.11)}

- Search for acid-fast bacilli in cytologic material by means of the Ziehl-Neelsen stain is not always effective. Culture and/or the PCR method in specialized laboratories are recommended for an accurate diagnosis including mycobacterial typing.

- More information is provided in Sect. 2.1.6.1, "Mycobacterial Infection," p. 116.

\subsubsection{Mycoses}

\subsection{Pneumocystis jirovecii}

(Figs. 2.26 and 2.80) (Tab. 2.3.12)

- This is the most common pulmonary infection in patients with AIDS. Pneumocystis should be considered as pathogenic whenever it has been identified.

Table 2.3.11 Tuberculosis: morphologic features and cautions

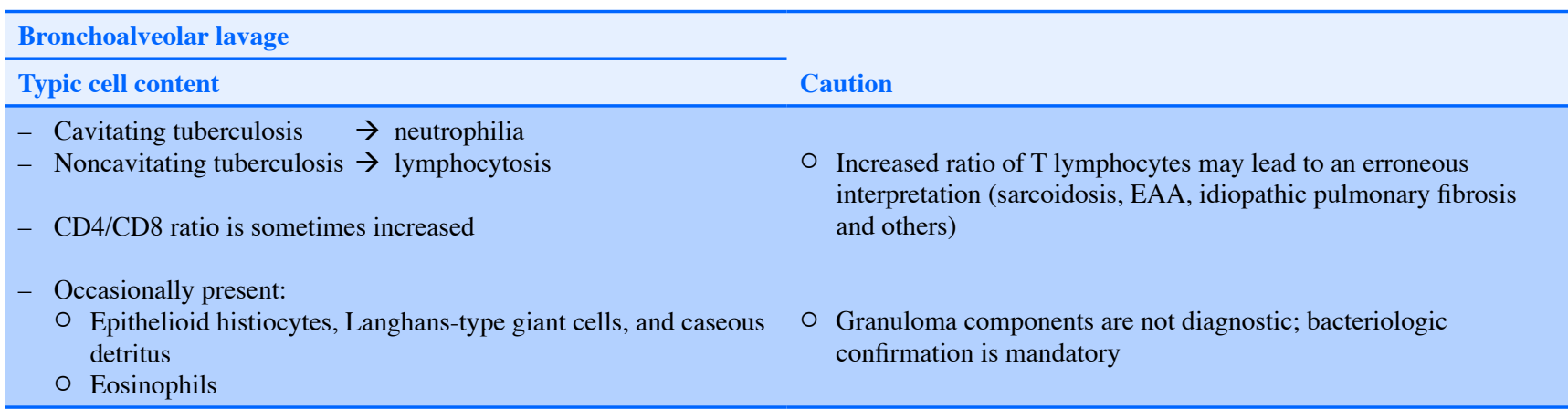


Table 2.3.12 Pneumocystis pneumonia: Typical cell content of BAL and cautions

\begin{tabular}{ll}
\hline Bronchoalveolar lavage: & Caution \\
\hline Typic cell content & $-\begin{array}{l}\text { Pronounced hyperplasia of pneumocytes should not lead } \\
\text { to an erroneous diagnosis of malignancy }\end{array}$ \\
\hline- Frequently: increased number of lymphocytes and granulocytes & - Concomitant cancer should be excluded \\
\hline
\end{tabular}

Table 2.3.13 Viral infections: Typical cell content of BAL and cautions

\begin{tabular}{ll}
\hline Bronchoalveolar lavage: & Caution \\
\hline Typic cell content in viral infections & $\begin{array}{l}\text { Any type of virus-induced cell change may be } \\
\text { mistaken for malignant cell alteration }\end{array}$ \\
\hline - Neutrophilia, mainly during first stages of viral pneumonia & \\
- Lymphocytosis is common (mainly CD8 lymphocyte phenotype) & \\
(bronspecific and specific virus-induced cell changes & \\
\hline
\end{tabular}

- Usually, this pathogen is detected in light microscopy by routine staining procedures (Papanicolaou and Giemsa) or by direct fluorescence stains of bronchoalveolar lavage fluids. The BAL processing mode has been shown not to affect detection of the organism, and silver staining has minor added value in the identification of pneumocysts [1, 40].

- New molecular diagnosis using a real-time PCR assay, performed on a LightCycler system, is potentially more sensitive compared with the use of conventional cytochemical stains and light microscopy. The technique may discriminate as well between colonization and infection with pneumocysts [20].

- Differential cytology in BAL of AIDS patients usually shows an increased number of lymphocytes and granulocytes [10]. Hyperplastic type II pneumocytes may be present.

- More information including morphologic appearance of this organism is provided in Sect. 2.1.6.3.2, "Pneumocystis," p. 118.

\subsection{Other Fungi}

(see also Sect. 2.1.6.3, "Pulmonary Mycoses," p. 117)

- Candida and Aspergillus are frequently identified in cytologic samples of the lung periphery, but they often indicate a nonpathogenic colonization. These two types of fungi have been shown to be pathogens in only a low percentage of all positive cytologic findings [44].

- Cryptococcus neoformans (Fig. 2.81) and Histoplasma (Fig. 2.82) should always be considered pathogenic whenever they are identified in BAL specimens

\subsubsection{Viral Infections (Tab. 2.3.13)}

Morphologic descriptions of the varied viral induced cell changes and additional information are given in Sect. 2.1.6.2, "Viral Infections," p. 116.

\subsection{Cytomegalovirus (Fig. 2.83)}

- Cytomegalovirus (CMV) belongs to the herpesvirus group. CMV is responsible for the most common viral infection in organ transplant recipients and may often be life-threatening.

- Cytologic findings of cytomegalic inclusion disease is highly specific; however, cytology is not very sensitive for this type of viral pneumonia. Other laboratory techniques such as culture, immunocytochemistry, in situ hybridization, as well as new developments in PCR technology are much more sensitive [19].

- It is a fact that highly sensitive methods may lead to overdiagnosis of CMV pneumonia because CMV is found worldwide and throughout all socioeconomic groups and infects a high proportion of the adult population without apparent illness [44].

\subsection{Other Viruses}

Herpes simplex virus, respiratory syncytial virus, or adenovirus, among others can be responsible for viral pneumonia, particularly after organ transplantation.

\subsubsection{Malignancies [45]}

\subsubsection{Carcinomas}

- Bronchoalveolar lavage is an extremely valuable tool in the diagnosis of diffusely spreading bronchioloalveolar carcinoma and suspected metastatic lung disease, particularly in cases with pronounced carcinomatous lymphangitis. Diagnostic accuracy ranges from 93\% (bronchioloalveolar carcinoma) to $83 \%$ (lymphangiosis carcinomatosa due to metastatic cancer) [46].

- Unlike bronchioloalveolar carcinoma, carcinomatous lymphangitis is usually accompanied by a lymphocytosis in BAL [11]. 
- BAL has turned out to be a minor help in the diagnosis of primary bronchial cancer since this type of cytologic investigation yields no additional information compared to bronchoscopy.

- Tumor markers are helpful to ascertain the primary site of a metastatic neoplasm (see Sect. 2.2.2.3.3, "Bronchioloalveolar Carcinoma," p. 142).

\section{Differential Diagnosis}

Reactive cell changes due to hyperplasia of terminal bronchiolar epithelial cells and type II pneumocytes occur in acute respiratory disorders such as acute interstitial pneumopathy, acute exacerbation of idiopathic pulmonary fibrosis, and ARDS [45]. We have experienced additional pathologic lung conditions causing severe benign hyperplastic processes in bronchiolar and alveolar epithelium, for instance organizing pulmonary fibrosis, pulmonary embolism, pulmonary infarct, and infections, particularly with viruses.

Benign epithelial hyperplasia can easily be confused with a malignant neoplastic process. To date, no reliable auxiliary analysis exists differentiating reactive pneumocytes from malignant cells (Figs. 2.84-2.86).

Diagnostic and differential diagnostic considerations concerning hyperplasia of terminal bronchiolar and alveolar epithelium versus adenocarcinoma are extensively discussed in Sect. 2.1.4.3.2, "Hyperplasia of Alveolar Epithelium," p. 114, and Sect. 2.2.2.3.3 "Bronchioloalveolar Carcinoma,", p. 142.

\section{Caution}

- Carcinoma cells are frequently sparse and haphazardly dispersed in cytologic preparations of BAL fluid. Single adenocarcinoma cells are very difficult to distinguish from activated type II pneumocytes.

- Malignant cell clusters of adenocarcinomas share many cytomorphologic and architectural features with cell groups of activated and hyperplastic type II pneumocytes.

- Numerous acute lung disorders and interstitial lung diseases (mentioned above) may induce pronounced hyperplasia of terminal bronchiolar epithelium and type II pneumocytes.

\subsubsection{Hematologic Malignancies}

The diagnostic yield of BAL in lung involvement by leukemia or malignant lymphoma ranges from about 40 to $60 \%$ [46]. Final diagnosis is reliably reached by immunocytochemical or flow cytometric phenotyping of the lymphoid cells and/or establishing clonality of the lymphoid population by immunocytochemistry or molecular tests. Lung-infiltrating Hodgkin lymphoma can reliably be diagnosed in BAL cytology if the pathognomonic tumor cells (Hodgkin and Reed-Sternberg cells) are present [39].

\section{Caution}

- It may be difficult to distinguish between inflammatory BAL lymphocytosis with evidence of reactive cell alterations and low-grade malignant non-Hodgkin lymphoma. However, the distinction should pose no major problems using differential cytology and additional analyses in order to assess monoclonality.

- It is impossible to distinguish between inflammatory BAL lymphocytosis with evidence of reactive cell alterations and the lymphoid population of lung-infiltrating Hodgkin lymphoma lacking the pathognomonic Hodgkin and Reed-Sternberg cells, neither by morphology nor by auxiliary analyses.

\subsubsection{Other Pulmonary Disorders with Particular BAL Cytology}

\subsubsection{Langerhans Cell Histiocytosis}

\subsection{Introduction}

The terms formerly used are "histiocytosis X" and "dendritic cell histiocytosis."

- Langerhans cells are derived from specific monocytes and contain large granules called Birbeck granules. The differentiation of the monocytes requires stimulation by colony-stimulating factor- 1 . The cells are similar in morphology and function to macrophages. Large quantities of Langerhans cells occur in the epidermis and are normally present in lymph nodes.

- Langerhans cell histiocytosis $(\mathrm{LCH})$ is a rare disease caused by a clonal proliferation of Langerhans cells.

The disorder may present as

1. Unifocal progressive disease (unifocal eosinophilic granuloma).

2. Multifocal unisystem disease (Hand-Schüller-Christian disease).

3. Multifocal multisystemic disease (Letterer-Siwe disease). Multifocal multisystem LCH is a rapidly progressing disease where Langerhans cells proliferate in many tissues. It is mostly seen in children during the 1 st and 2nd year of life and is considered a true neoplasm; the 5-year survival rate is only $50 \%$.

- Langerhans cell histiocytosis is also discussed in Sect. 17.1.13.2, "Langerhans Cell Histiocytosis,", p. 1068.

\subsection{Pulmonary Langerhans Cell Histiocytosis} [57] (Fig. 2.87)

Pulmonary Langerhans cell histiocytosis (PLCH) of adults is a rare, diffuse interstitial lung disease of unknown etiology that occurs foremost in young smokers. PLCH is believed to be a reactive process associated with Langerhans cell hyperplasia. Only a very small proportion of the patients have extrapulmonary affections. Characteristic high-resolution com- 
puted tomography (CT) findings together with distinctive clinical symptoms frequently allow a conclusive diagnosis. In patients with ambiguous imaging and clinical results, further diagnostic procedures may be needed such as surgical lung biopsies in order to confirm the diagnosis on tissue sections $[5,68]$. The diagnostic impact of BAL cytology is agreed to be low.

\section{Microscopic Features, Immunocytochemistry, and Electron Microscopy}

Histology: Tissue sections reveal Langerhans cell granulomas that are infiltrating and destroy distal bronchioles.

Cytology: Typical Langerhans cells may be detected in BAL fluids of patients suffering from active Langerhans cell histiocytosis. An increase in Langerhans cells greater than $4 \%$ of the total cell count is assumed to be reliably diagnostic for PLCH [12]. The total cell count in BAL fluids of patients with PLCH is increased due to proliferating Langerhans cells, and large numbers of histiocytes and macrophages.

$\bigcirc$ Langerhans cells may be larger in comparison to macrophages and they frequently show multinucleation. The nuclei are oval to kidney-shaped including deep grooves and indentations. Their chromatin is vesicular and distinct nucleoli are sometimes present. The cytoplasm is wide with neat margins and eosinophilic staining quality.

O A mild inflammatory background composed of granulocytes and lymphocytes may be seen.

O Macrophages are often present and exhibit the typical smoker's inclusions.

Immunocytochemistry and electron microscopy: Langerhans cells are easily identified by the immunocytochemical or flow cytometric positivity for the monoclonal antigen $\mathrm{CD1}$ a and for cytoplasmic S100 protein.

Birbeck granules are intracytoplasmic organelles specific to Langerhans cells. They are detected by electron microscopy showing the characteristic shape of a tennis racket or rod shape. Their function is still being debated.

\section{Caution}

- An increase in Langerhans cells greater than $4 \%$ in BALs should be diagnostic for PLCH in combination with the characteristic $C T$ results and clinical symptoms.

- Sarcoidosis and other pulmonary disorders may be accompanied by a lower percentage of Langerhans cells in BAL fluids; a reliable diagnosis will not be possible in such cases. Therefore, a surgical lung biopsy is necessary in a high percentage of equivocal cases.

\subsubsection{Lipoid Pneumonia}

Lipoid pneumonia together with inflammatory and fibrotic changes in the lungs are caused by inhalation of various fatty substances or provoked by accumulation of endogenous lipid material in the lungs.

Exogenous fatty material from outside the body includes, for example, inhaled nose drops with an oil base or accidental inhalation of cosmetic oil. Endogenous lipid pneumonia occurs when an airway is obstructed or following the fracture of a bone.

$\bigcirc$ A great number of macrophages showing abundant foamy cytoplasm together with droplet-like fat inclusions. Lipid-laden giant cells are common. Lipid inclusions stain positively with fat stains (e.g., Sudan III).

\subsubsection{Aspiration Pneumonia}

This is a pneumonia induced by aspiration of foreign material into the lungs. The extraneous material includes fat, proteolytic and toxic substances, as well as plant cells and muscle fibers accidentally breathed into the respiratory system instead of being swallowed into the stomach.

O Plant cells are in general much larger compared to human cells occurring in the alveolar space, and they disclose typical morphology and arrangement. Muscle fibers exhibit characteristic red staining and distinct transverse striations.

- Plasma cells are fairly characteristic of aspiration pneumonia as they are observed in only a few other lung disorders such as extrinsic allergic alveolitis, cryptogenic organizing pneumonia, or chronic eosinophilic pneumonia.

O Secondary bacterial infection and abscess formation is common.

\subsubsection{Bronchoalveolar Lavage in Lung Transplant Recipients}

BAL in transplantation patients may be effective for the detection of pulmonary infectious pathogens and rare disorders complicating the course after lung transplantation, such as alveolar proteinosis [22] and obliterative bronchiolitis [47]. Whether a surveillance of BAL cell profiles has additive diagnostic value in routine lung transplant monitoring and in patients in whom rejection is suggested, is highly controversial and more often refused than accepted $[47,58,66]$.

\section{Caution}

Occasional atypias of epithelial cells in BAL specimens from lung (heart-lung) transplant recipients may demonstrate significant resemblance to carcinoma cells [41]. 


\subsubsection{Further Reading}

1. Al-Za'abi AM, MacDonald S, Geddie W, Boerner SL. Cytologic examination of bronchoalveolar lavage fluid from immunosuppressed patients. Diagn Cytopathol 2007;35:710-714.

2. Antao VC, Pinheiro GA, Wassell JT. Asbestosis mortality in the United States: Facts and predictions. Occup Environ Med 2009;66:335-338

3. Baughman RP. Technical aspects of bronchoalveolar lavage: recommendations for a standard procedure. Semin Respir Crit Care Med 2007;28:475-485.

4. Bedrossian CWM, Warren CJ, Ohar J, Bhan R. Amiodarone pulmonary toxicity: Cytopathology, Ultrastructure, and Immunocytochemistry. Ann Diagn Pathol 1997;1:47-56.

5. Bianchi M, Cataldi M. Pneumothorax secondary to pulmonary histiocytosis X. Minerva Chir 1999;54:531-536.

6. Burkhalter A, Silverman JF, Hopkins MB 3rd, Geisinger KR. Bronchoalveolar lavage cytology in pulmonary alveolar proteinosis. Am J Clin Pathol 1996;106:504-510.

7. Cordeiro CR, Jones JC, Alfaro T, Ferreira AJ. Bronchoalveolar lavage in occupational lung diseases. Semin Respir Crit Care Med 2007;28:504-513.

8. Costabel U, Guzman J. Bronchoalveolar lavage in interstitial lung disease. Curr Opin Pulm Med 2001;7:255-261.

9. Costabel U, Guzman J. Pulmonary alveolar proteinosis: a new autoimmune disease. Sarcoidosis Vasc Diffuse Lung Dis 2005;22 Suppl 1:S67-73.

10. Costabel U, Mitchell JN. Atlas of Bronchoalveolar Lavage. Chapman\&Hall London 1998.

11. Costabel U, Bross KJ, Guzman J, Matthys H. Bronchoalveoläre Lavage bei diffusen malignen Lungenveränderungen. Atemw Lungenkr 1987;13:S79-S82.

12. Costabel U, Guzman J, Bonella F, Oshimo S. Bronchoalveolar lavage in other interstitial lung diseases. Semin Respir Crit Care Med 2007;28:514-524.

13. Costabel U, Teschler H, Guzman J. Bronchiolitis obliterans organizing pneumonia (BOOP): The cytological and immunocytological profile of bronchoalveolar lavage. Eur Respir J 1992;5:791-797.

14. Costabel U, Teschler H, Ziesche R, et al. Transport of bronchoalveolar lavage cells in appropriate medium for 24 hours does not affect cell differentials and lymphocyte subsets (abstract). Am Rev Respir Dis 1989;139:A472.

15. Cottin V, Cordier JF. Eosinophilic pneumonias. Allergy 2005;60:841-857

16. DeShazo RD, Banks DE, Diem JE, et al. Broncho-alveolar lavage cell-lymphocyte interactions in normal non smokers and smokers. Am Rev Respir Dis 1983;127:545-548.

17. Domagala-Kulawik J. BAL in the diagnosis of smoking-related interstitial lung disease: review of literature and analysis of our experience. Diagn Cytopathol 2008;36:909-915.

18. Drent M, Mansour K, Linssen C. Bronchoalveolar lavage in sarcoidosis. Semin Respir Crit Care Med 2007;28:486-495.

19. Drew WL. Laboratory diagnosis of cytomegalovirus infection and disease in immunocompromised patients. Curr Opin Infect Dis 2007;20:408-411.

20. Fillaux J, Malvy S, Alvarez M, et al. Accuracy of a routine realtime PCR assay for the diagnosis of Pneumocystis jirovecii pneumonia. J Microbiol Methods 2008;75:258-261.

21. Frazier AA, Franks TJ, Cooke EO, et al. From the archives of the AFIP: pulmonary alveolar proteinosis. Radiographics 2008;28:883899.

22. Gal AA, Bryan JA, Kanter KR, Lawrence EC. Cytopathology of pulmonary alveolar proteinosis complicating lung transplantation. J Heart Lung Transplant 2004;23:135-138.

23. Grau RG. Churg-Strauss syndrome: 2005-2008 update. Curr Rheumatol Rep 2008;10:453-458
24. Grebski E, Hess T, Hold G, et al. Diagnostic value of hemosiderincontaining macrophages in bronchoalveolar lavage. Chest 1992; 102:1794-179.

25. Haslam PL, Dewar A, Butchers P, et al. Mast cells, atypical lymphocytes and neutrophils in bronchoalveolar lavage in extrinsic allergic alveolitis. Am Rev Respir Dis 1987;135:35-47.

26. Ismail T, McSharry C, Boyd G. Extrinsic allergic alveolitis. Respirology 2006;11:262-268.

27. Kantrow SP, Meyer KC, Kidd P, Raghu G. The CD4/CD8 ratio in BAL fluid is highly variable in sarcoidosis. Eur Respir $\mathrm{J}$ 1997;10:2716-2721.

28. Kayser K, Hagemeyer O. Natural and synthetic mineral fibers affecting man. Zürich: BI-Wiss.-Verl., 1994; pp:182-184.

29. Klech H, Hutter C. Clinical guidelines and indications for bronchoalveolar lavage (BAL): Report of the European Society of Pneumology Task Group on BAL. Eur Respir J 1990;3:937-974.

30. Klech H, Hutter C, Costabel U. Clinical guidelines and indications for bronchoalveolar lavage (BAL): Report of the European Society of Pneumology Task Group on BAL. Eur Respir Rev 1992;2:47127.

31. König G, Behr J. Bronchoalveoläre Lavage be pulmonaler Beteiligung systemischer Erkrankungen. Atemw Lungenkr 1989;15:605609.

32. Lin YH, Haslam PL, Turner-Warwick M. Chronic pulmonary sarcoidosis: Relationship between lung lavage cell counts, chest radiograph, and results of standard lung function tests. Thorax 1985;40:501-507.

33. Mancini NM, Béné MC, Gérard H, et al. Early effects of short-time cigarette smoking on the human lung: a study of bronchoalveolar lavage fluids. Lung 1993;171:277-291.

34. Marques LJ, Teschler H, Guzman J, Costabel U. Smoker's lung transplanted to a nonsmoker. Long-term detection of smoker's macrophages. Am J Respir Crit Care Med 1997;156:1700-1702.

35. Maygarden SJ, Iacocca MV, Funkhouser WK, Novotny DB. Pulmonary alveolar proteinosis: a spectrum of cytologic, histochemical, and ultrastructural findings in bronchoalveolar lavage fluid. Diagn Cytopathol 2001;24:389-395.

36. Meyer KC. Bronchoalveolar lavage as a diagnostic tool. Semin Respir Crit Care Med 2007;28:546-560.

37. Mikuz G, Gschwendtner A. Value of bronchoalveolar lavage in the diagnosis of lung disease. Verh Dtsch Ges Pathol 2000;84:129-135.

38. Moises JA, Xaubet A, Agusti C, et al. Significance of the presence of mastocytes in bronchoalveolar lavage in the diagnostic evaluation of diffuse interstitial lung disease. Med Clin (Barc) 1989;92: 454-456.

39. Morales FM, Matthews JI. Diagnosis of parenchymal Hodgkin's disease using bronchoalveolar lavage. Chest 1987;91:785-787.

40. Nassar A, Zapata M, Little JV, Siddiqui MT. Utility of reflex Gomori methenamine silver staining for Pneumocystis jirovecii on bronchoalveolar lavage cytologic specimens: a review. Diagn $\mathrm{Cy}-$ topathol 2006;34:719-723.

41. Ohori NP. Epithelial cell atypia in bronchoalveolar lavage specimens from lung transplant recipients. Am J Clin Pathol 1999;112:204-210.

42. Owens GR, Paradis I, Gryzan S, et al. Role of inflammation in the lung disease of systemic sclerosis: Comparison with idiopathic pulmonary fibrosis. J Lab Clin Med 1986;107:253-260.

43. Pesci A, Bertorelli G, Manganelli P, et al. Bronchoalveolar lavage in chronic eosinophilic pneumonia. Analysis of six cases in comparison with other interstitial lung diseases. Respiration 1988;54 Suppl 1:16-22.

44. Pisani RJ, Wrigt AJ. Clinical utility of bronchoalveolar lavage in immunocompromised hosts. Mayo Clin Proc 1992;67:221-227.

45. Poletti V, Poletti G, Murer B, et al. Bronchoalveolar lavage in malignancy. Semin Respir Crit Care Med 2007;28:534-545.

46. Poletti V, Romagna M, Allen KA, et al. Bronchoalveolar lavage in the diagnosis of disseminated lung tumors. Acta Cytol 1995;39:472477. 
47. Reynaud-Gaubert M, Thomas P, Gregoire R, et al. Clinical utility of bronchoalveolar lavage cell phenotype analyses in the postoperative monitoring of lung transplant recipients. Eur J Cardiothorac Surg 2002;21:60-66.

48. Robinson BWS, Rose AH, James A, Whitaker D. Alveolitis of pulmonary asbestosis. Chest 1986;90:396-402.

49. Rose AS, Knox KS. Bronchoalveolar lavage as a research tool. Semin Respir Crit Care Med 2007;28:561-573.

50. Rossman MD, Kreider ME. Is chronic beryllium disease sarcoidosis of known etiology? Sarcoidosis Vasc Diffuse Lung Dis 2003;20:104-109.

51. Ryu YJ, Chung MP, Han J, et al. Bronchoalveolar lavage in fibrotic idiopathic interstitial pneumonias. Respir Med 2007;101:655-660.

52. Schildge J, Klar B, Hardung-Backes M. Mast cells in bronchoalveolar lavage fluid of patients with interstitial lung disease. Pneumologie 2003;57:202-207.

53. Schnabel A, Reuter M, Gloeckner K, et al. Bronchoalveolar lavage cell profiles in Wegener's granulomatosis. Respir Med 1999;93:498506.

54. Schoch OD, Schanz U, Koller M, et al. BAL findings in a patient with pulmonary alveolar proteinosis successfully treated with GMCSF. Thorax 2002;57:277-280.

55. Sosolik RC, Gammon RR, Julius CJ, Ayers LW. Pulmonary alveolar proteinosis. A report of two cases with diagnostic features in bronchoalveolar lavage specimens. Acta Cytol 1998;42:377-383.

56. Strobel SL. Pathologic quiz case: Recurrent spontaneous pneumothorax in an industrial worker. Arch Pathol Lab Med 2002;126:749750.

57. Tazi A. Adult pulmonary Langerhans cell histiocytosis. Eur Respir J 2006;27:1272-1285.

58. Tiroke AH, Bewig B, Haverich A. Bronchoalveolar lavage in lung transplantation. State of the art. Clin Transplant 1999;13:131-157.
59. Tötsch M, Guzman J, Theegarten D, et al. Bronchoalveoläre Lavage Pathologe 2007;28:346-353.

60. Trzpuc TD, Shidham VB, Nagarjun Rao R. Pathologic Quiz Case. Pulmonary infiltrates with characteristic light and electron microscopic features. Arch Pathol Lab Med 2002;126:745-746.

61. Tsapas A, Paletas K, Vlachaki E, et al. Eosinophilic pneumonia associated with heroin inhalation: a case report. Wien Klin Wochenschr 2008;120:178-180.

62. Turner-Warwick M, Haslam PL. The value of serial bronchoalveolar lavages in assessing the clinical progress of patients with cryptogenic fibrosing alveolitis. Am Rev Respir Dis 1987;135:26-34.

63. Tutor-Ureta P, Citores MJ, Castejon R, et al. Prognostic value of neutrophils and NK cells in bronchoalveolar lavage of sarcoidosis. Cytometry B Clin Cytom 2006;70:416-422.

64. Veeraraghavan S, Latsi PI, Wells AU, et al. BAL findings in idiopathic nonspecific interstitial pneumonia and usual interstitial pneumonia. Eur Respir J 2003;22:239-244.

65. Wallace JM, Oishi JS, Barbers RG, et al. Bronchoalveolar lavage cell and lymphocyte phenotype profiles in healthy asbestos-exposed shipyard workers. Am Rev Respir Dis 1989;139:22-38. 66. Wanner TJ, Gerhardt SG, Diette GB, et al. The utility of cytopathology testing in lung transplantation recipients. J Heart Lung Transplant 2005;24:870-874.

67. Winterbauer RH, Lammert J, Selland M, et al. Bronchoalveolar lavage cell populations in the diagnosis of sarcoidosis. Chest 1993;104:352-361.

68. Zeppa P, Cozzolino I, Russo M, et al. Pulmonary Langerhans cell histiocytosis (Histiocytosis X) on bronchoalveolar lavage. A report of 2 cases. Acta Cytol 2007;51:480-482. 
Fig. 2.68A, B BAL Normal findings in non-smokers and smokers.

A Findings in nonsmokers. The majority of cells are macrophages exhibiting isolated intracytoplasmic carbon particles. Occasional lymphocytes and ciliated epithelial cells (lower left) are also present (direct sediment smear, Pap stain, lower magnification). B BAL: Findings in a smoker. Less monotonous appearance of the macrophage population. Macrophages exhibit so-called cytoplasmic smoker's inclusions (arrows). A few lymphocytes and eosinophils are seen at the top end of the field (direct sediment smear, MGG stain, high magnification).

Fig. 2.69 Flow cytometry histograms in sarcoidosis from a bronchoalveolar lavage.

The framed dotplot in the upper histogram shows the selection of lymphocytes of the T phenotype. The lower histogram shows a dense plotting of a T-cell subpopulation (upper left) according to T4 lymphocytes (89\%), while a few dots matching T8 lymphocytes (11\%) appear in the lower right gate.

Fig. 2.70 Cryptogenic organizing pneumonia (synonym: BOOP).

Pronounced cytoplasmic vacuolization of the macrophages, marked lymphocytosis, increased numbers of eosinophils (arrows), and mast cells (arrowheads) are characteristic features of cryptogenic organizing pneumonia in BAL (direct sediment smear, MGG stain, high magnification). Both exogenous allergic alveolitis and drug-induced alveolitis may exhibit a similar cell pattern.

\section{Fig. 2.71 Amiodarone lung.}

Note the extremely pronounced cytoplasmic vacuolization of the macrophages (direct sediment smear, MGG stain, high magnification).

\section{Fig. 2.72 Activated type II pneumocytes.}

A 62-year-old man suffering from long-standing Behçet disease treated with cytostatic drugs (Endoxan). Drug-induced reactive hyperplasia of terminal bronchiolar epithelial cells (type II pneumocytes). Cellular arrangement, low N/C ratio, round nuclei, smooth nuclear outline, bland chromatin, and uniform centrally positioned nucleoli exclude malignancy (direct sediment smear, Pap stain, lower magnification). 


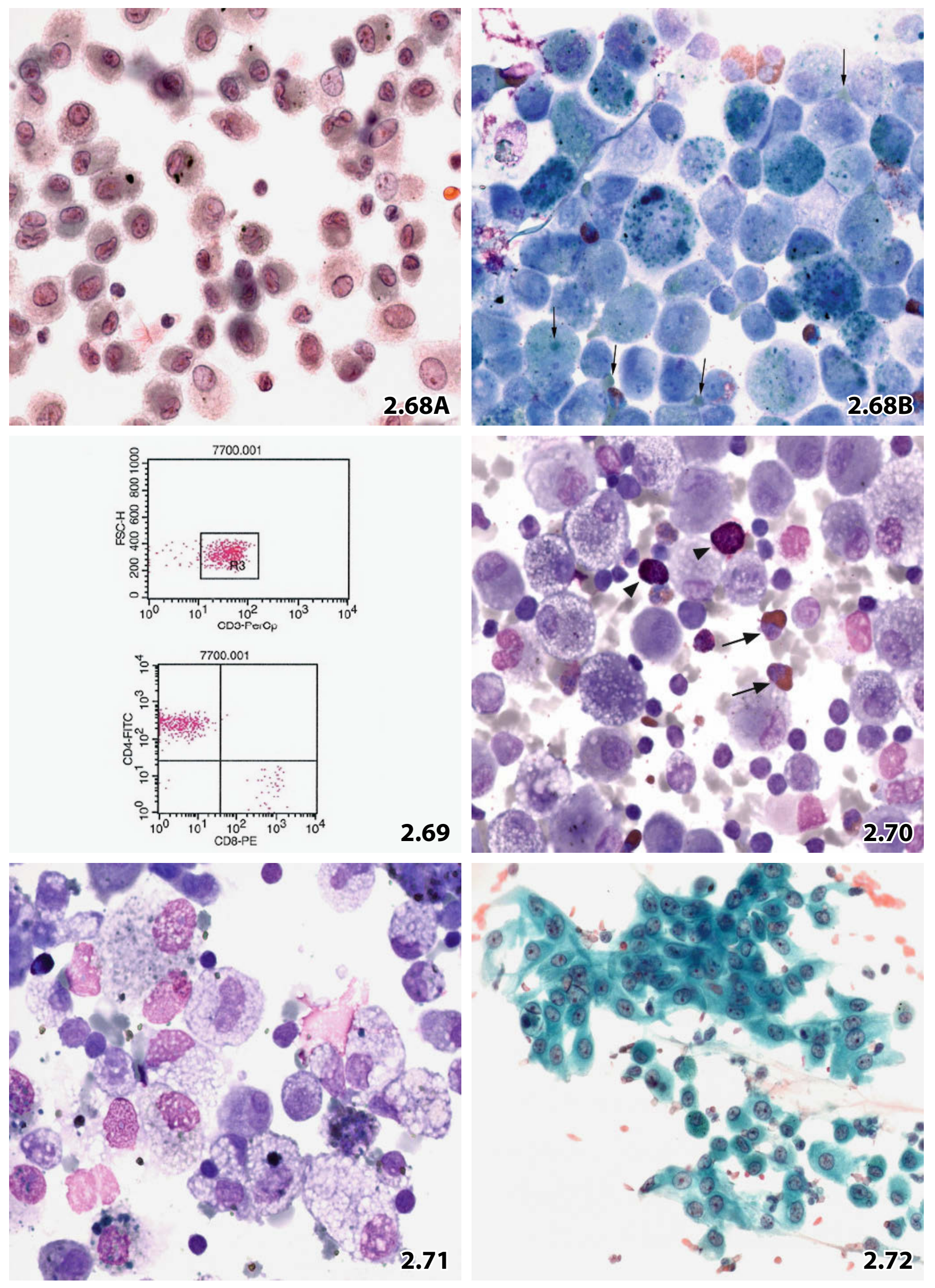


Fig. 2.73 Eosinophilic lung disease.

A middle aged woman presented with clinical symptoms of bronchial asthma. Direct smears from BAL sediment reveal mainly eosinophilic granulocytes (87\%) interspersed with macrophages and a few mast cells (arrows) (MGG stain, lower magnification).

Fig. 2.74 Alveolar hemorrhage syndrome.

Iron staining (Prussian blue) of a Pap-prestained direct smear of BAL sediment displays the variable phenotype of cytoplasmic hemosiderin inclusions in macrophages (higher magnification):

- Blue coloring of part of the cytoplasm (arrow).

- Blue coloring of the entire cytoplasm (arrowheads).

- Deep-blue coarse intracytoplasmic granules (large macrophage, lower right).

\section{Fig. 2.75 Ferruginous bodies.}

High magnification reveals the varied phenotypes of ferruginous bodies (direct sediment smear, Pap stain):

- Asbestos body (lower left): slender rod showing marked segmentation ending on both sides in Pprotrusions with smooth contours

- Pseudo-asbestos body (upper right): gross irregularly structured rod, ending with ridged protrusions on both sides (not completely in focus). 


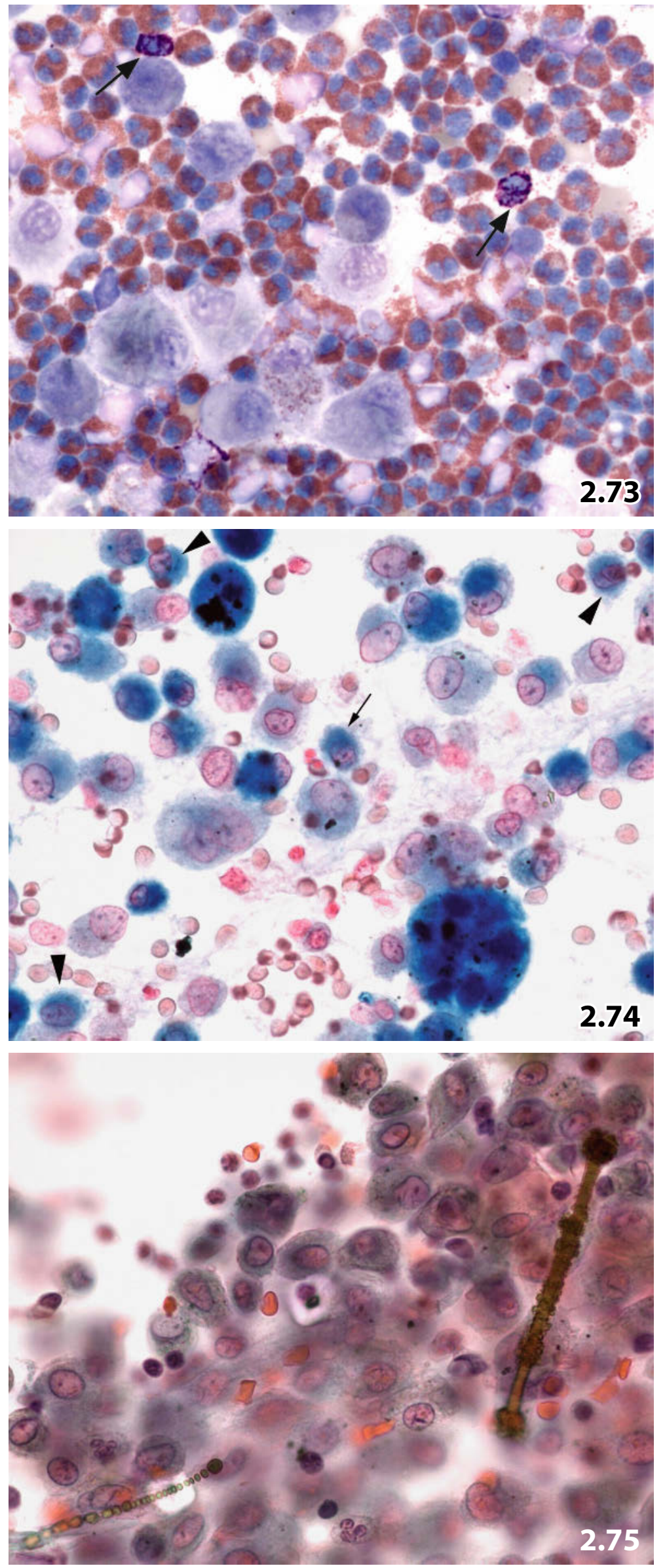


Fig. 2.76 Graphite dust exposure.

An elderly male patient with a positive history of graphite dust exposure. Numerous macrophages exhibit black-stained inclusions of variable size and shape (direct sediment smear, Pap stain, higher magnification).

Fig. 2.77 Mixed dust exposure.

Sidero-silico-anthracosis (Welder's lung) in a metal worker's BAL. The 52-year old man is welder by profession. Virtually all macrophages exhibit a blue staining cytoplasm. Coarse cytoplasmic deposits are deep blue (iron particles) or black (carbon particles). Quartz crystals could be visualized using the polarization microscope (not shown) (direct sediment smear, iron stain, higher magnification).

Figs. 2.78 and 2.79 Alveolar proteinosis..

Alveolar proteinosis is shown by conventional and electron microscopy.

Fig. 2.78 Characteristic dirty background in a smear of BAL from a patient with alveolar proteinosis: PAS-positive acellular amorphous globules and cellular debris. Two foamy macrophages are present in this field (arrows) (direct sediment smear, periodic-acid-Schiff stain, lower magnification).

Fig. 2.79 The BAL material was used for electron microscopic studies as well: myelin-like figures resembling lamellar bodies of surfactant are characteristic for alveolar proteinosis. 

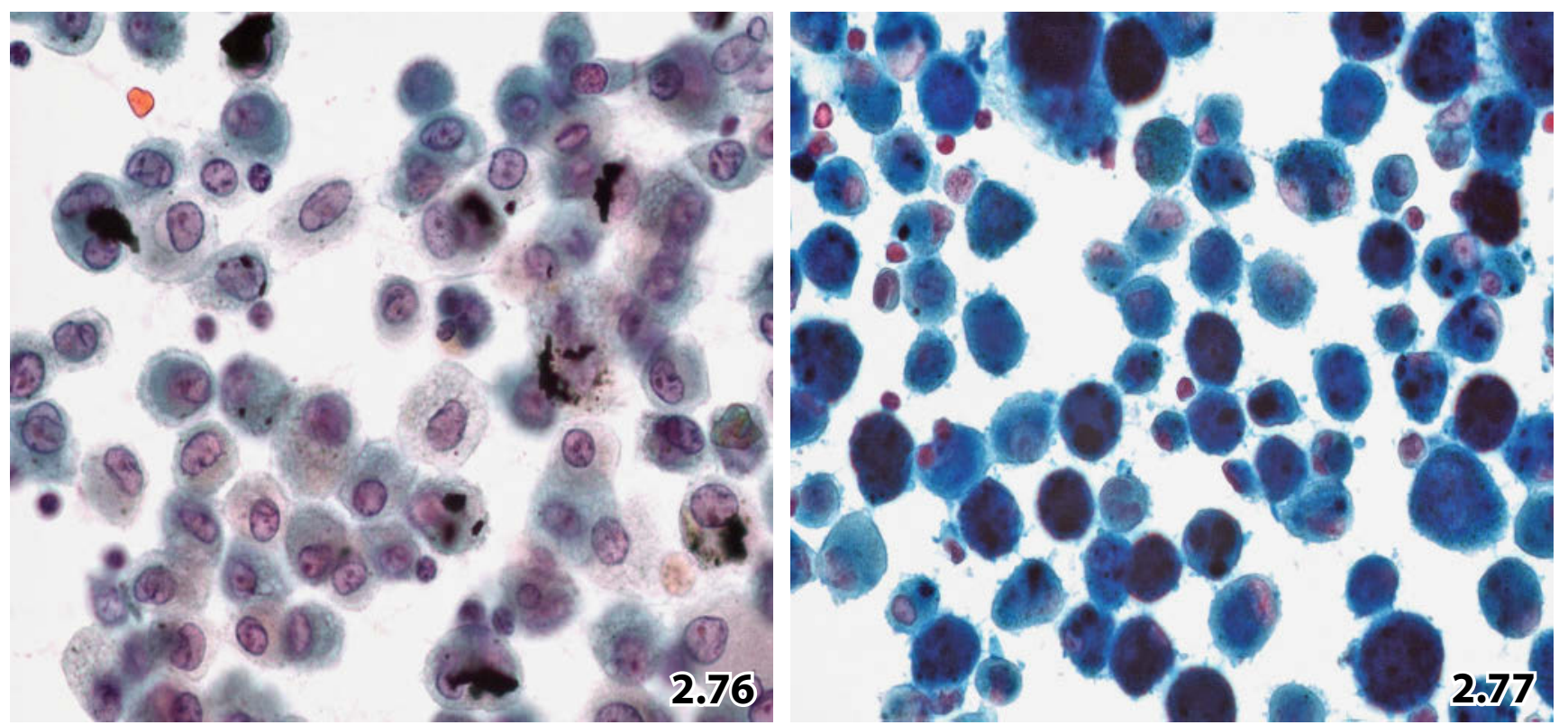

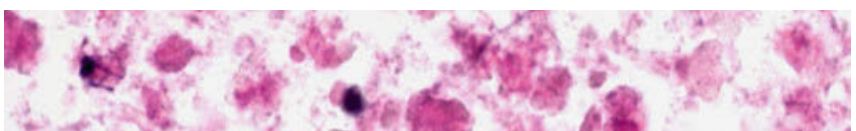

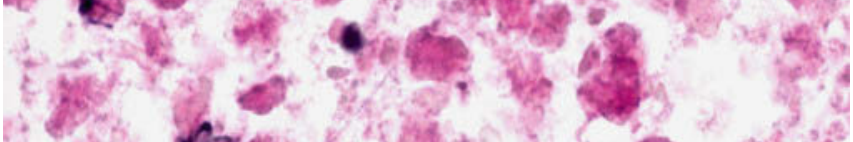

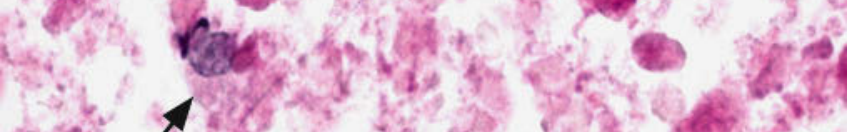

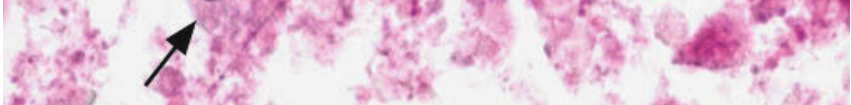

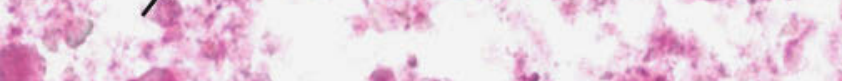

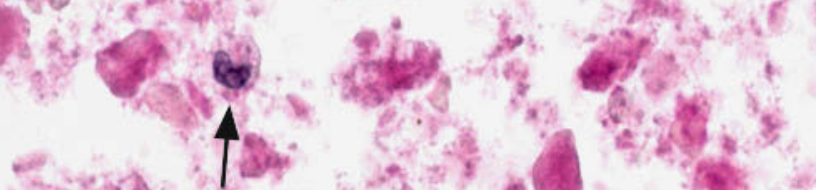
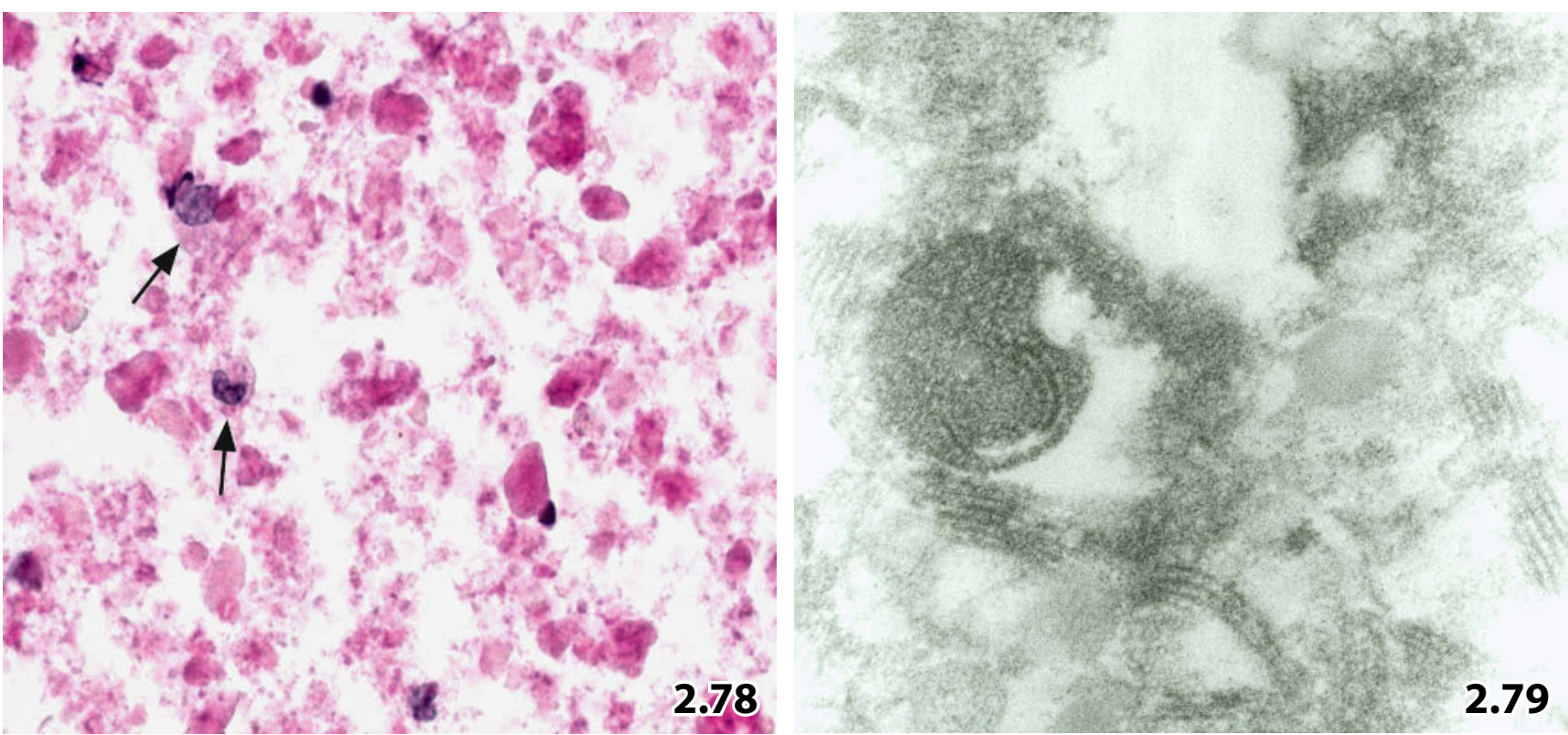
Fig. 2.80A, B Pneumocystis jirovecii.

Cytomorphologic appearance of the pathogen is demonstrated at low and high magnification from Pap-stained direct sediment smears. A Low magnification: Compact accumulation of pneumocysts presenting as a foamy mass with irregular outlines (arrow). The appearance is so characteristic that an accurate diagnosis can be established using conventional staining procedures. B High magnification shows sharply demarcated cysts, focal thickening of the cystic membranes, and grey-brown intracystic bodies (arrows).

\section{Fig. 2.81 Cryptococcus neoformans.}

Numerous intra- and extracellular yeast cells of varying size. Note the thick sharply demarcated capsule (arrow) (direct sediment smear, periodic-acid-Schiff stain, high magnification).

Fig. 2.82 Histoplasma capsulatum.

Accumulation of yeast cells in the cytoplasm of an activated multinucleated macrophage (direct sediment smear, Pap stain, high magnification).

Fig. 2.83 Cytomegalovirus.

A younger male patient suffering from AIDS presenting with cytomegalic inclusion disease in a BAL sample. Three affected epithelial cells are shown: two cells on the left exhibit the characteristic owl eye appearance; the cell at the right (arrow) seems to be in an earlier state of viral infestation (direct sediment smear, Pap stain, high magnification). 


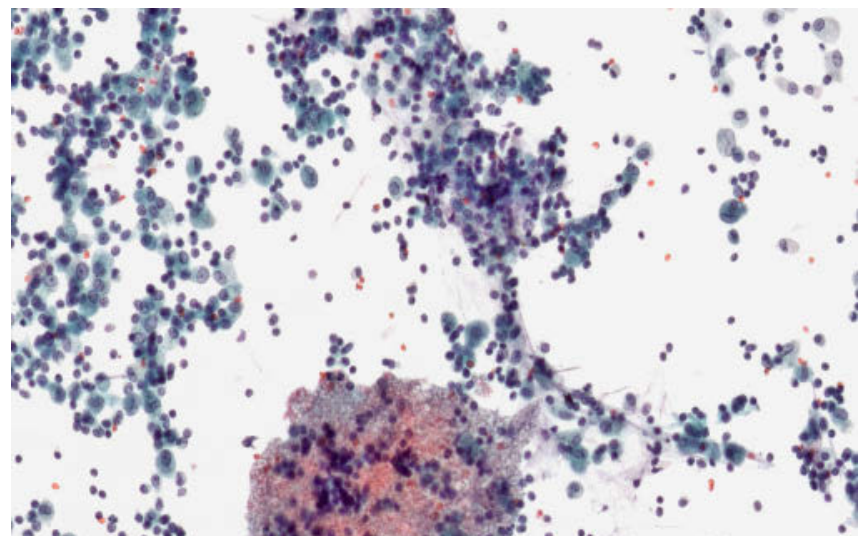

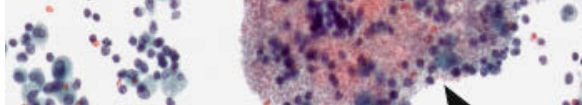

\$ै० \%. 月.
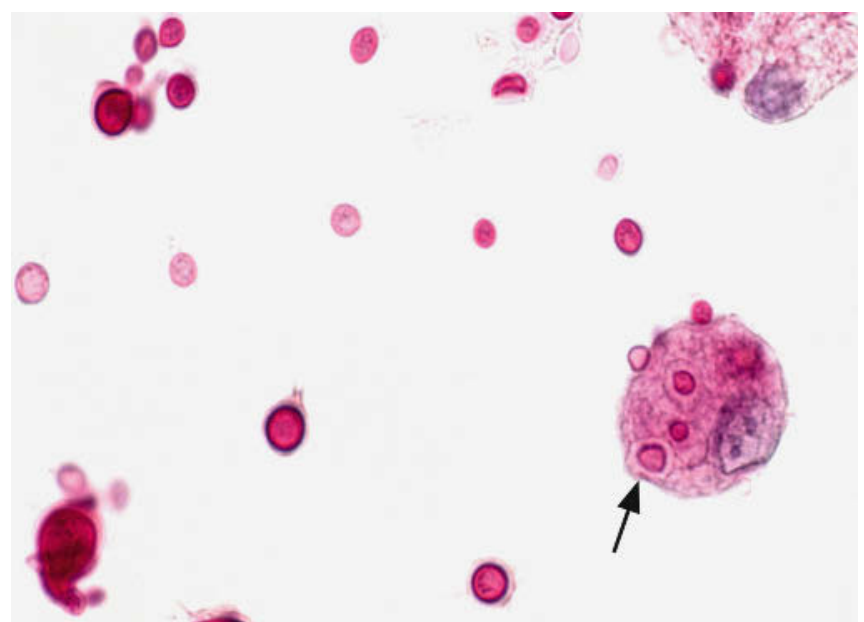

(3)

s

2.81
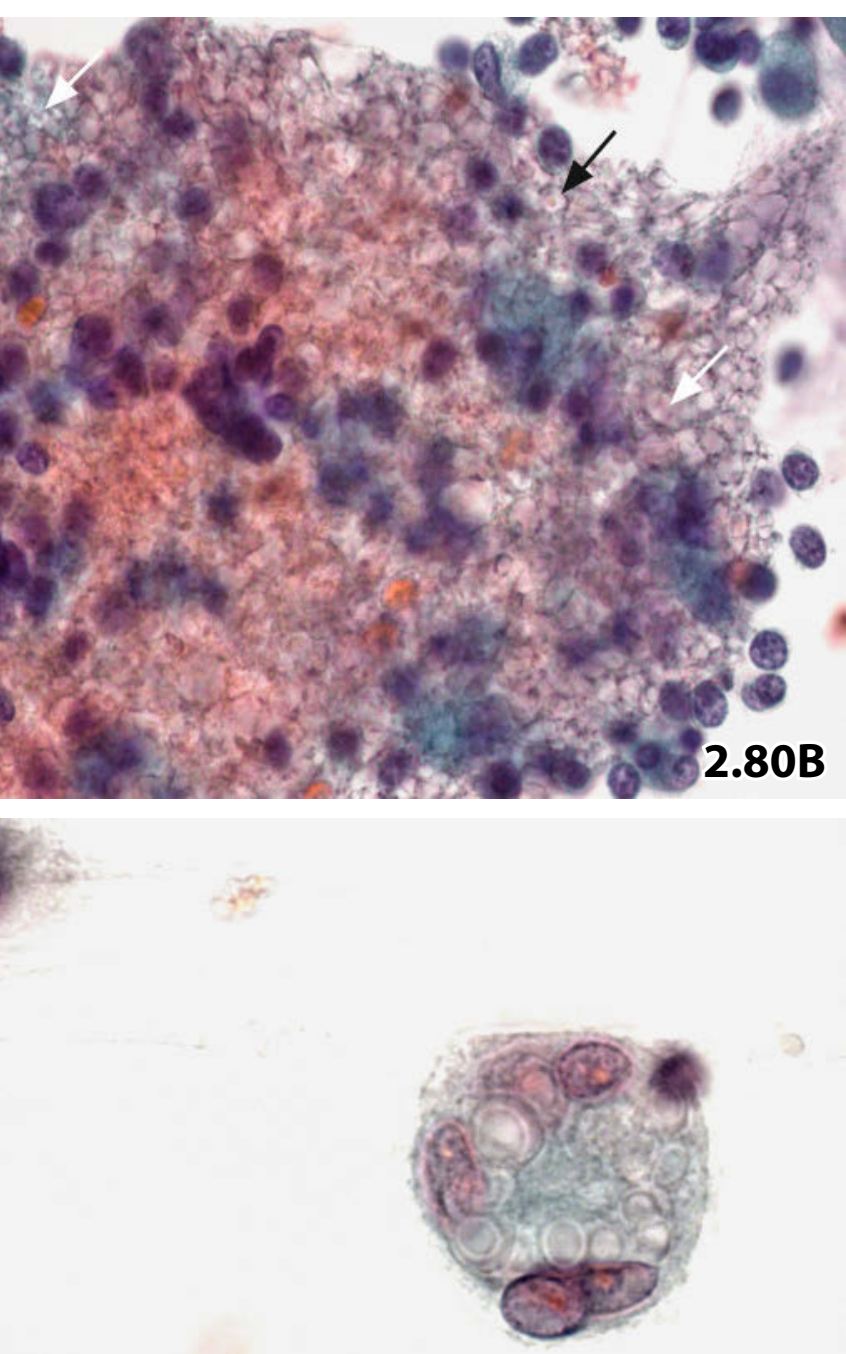

2.82

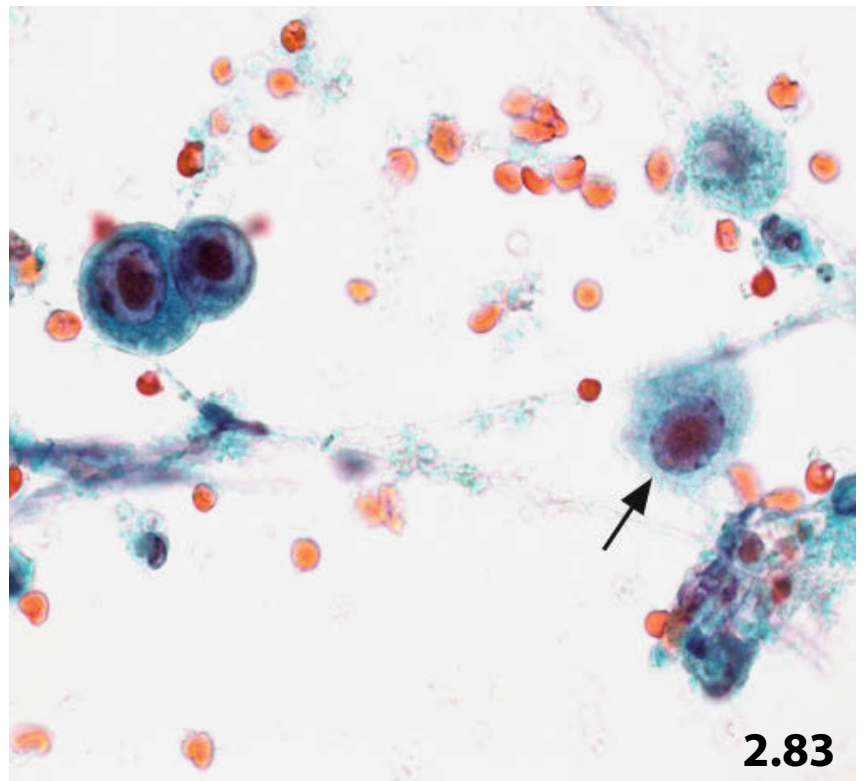


Fig. 2.84 Activated type II pneumocytes.

A 56-year-old man presenting with multiple infiltrates in the right lung. Direct smears from a BAL sediment show numerous small and medium-sized compact three-dimensional clusters of epithelial cells with minor atypias. The papilliform cluster shown displays acini-like formations and monomorphic cell appearance Pap stain, (high magnification).

Cytology: Cell changes are indeterminate between benign (hyperplastic type II pneumocytes) and malignant (bronchioloalveolar carcinoma).

Comment: Compare cell features with those of a bronchioloalveolar carcinoma presented in Fig. 2.85 for the distinct differences in nuclear texture and nuclear contour.

Final diagnosis was Chlamydia pneumonia.

\section{Fig. 2.85 Bronchioloalveolar carcinoma.}

A 36-year-old man presented with nodular infiltrates in both lungs. Direct smears were performed from the sediment of a BAL fluid (Pap stain).

Cytology and histologic diagnosis: Bronchioloalveolar carcinoma.

Note similarities and differences of the malignant tumor cells in comparison with hyperplastic type II pneumocytes as shown in Fig. 2.84 (same magnification).

Fig. 2.86 Pulmonary lymphangiosis carcinomatosa secondary to breast carcinoma

BAL in a 57-year-old woman with a history of breast carcinoma presenting with diffuse pulmonary infiltrates. Direct sediment smears reveal numerous loose clusters composed of malignant cells. Tumor cells exhibit distinct features of common type breast carcinoma: monomorphous cell population, eccentric nuclei, homogeneous cyanophilic cytoplasm, occasional lucid cytoplasmic inclusions, nuclear molding and cleaving, both finely granular and focally patternless chromatin (Pap stain, high magnification).

Cytologic diagnosis: Adenocarcinoma. The overall cell pattern in comparison with the previous histomorphology is consistent with metastatic breast carcinoma.

Comment: In cases with equivocal clinical history and absence of a preceding histologic/cytologic investigation, the differential diagnosis must also consider hyperplasia of type II histiocytes and bronchioloalveolar carcinoma. An appropriate immunopanel is helpful to solve the diagnostic problems.

\section{Fig. 2.87 Langerhans cell histiocytosis.}

BAL of a 38-year-old woman presenting with an uneventful history. Bronchoscopy revealed nonspecific inflammatory changes of the bronchial mucosa. Extremely cellular bronchoalveolar lavage fluids from the lung periphery showed a heterogeneous histiocytic population. Abnormal histiocytes exhibit multinucleation, nuclear cleaves and grooves, and vesicular chromatin (arrows). Positive immunostaining for S-100 and CD1 (immunocytochemistry not shown) classified the atypical cells as Langerhans cells accounting for $64 \%$ of the total number of histiocytic elements (direct sediment smear, MGG stain, high magnification). 


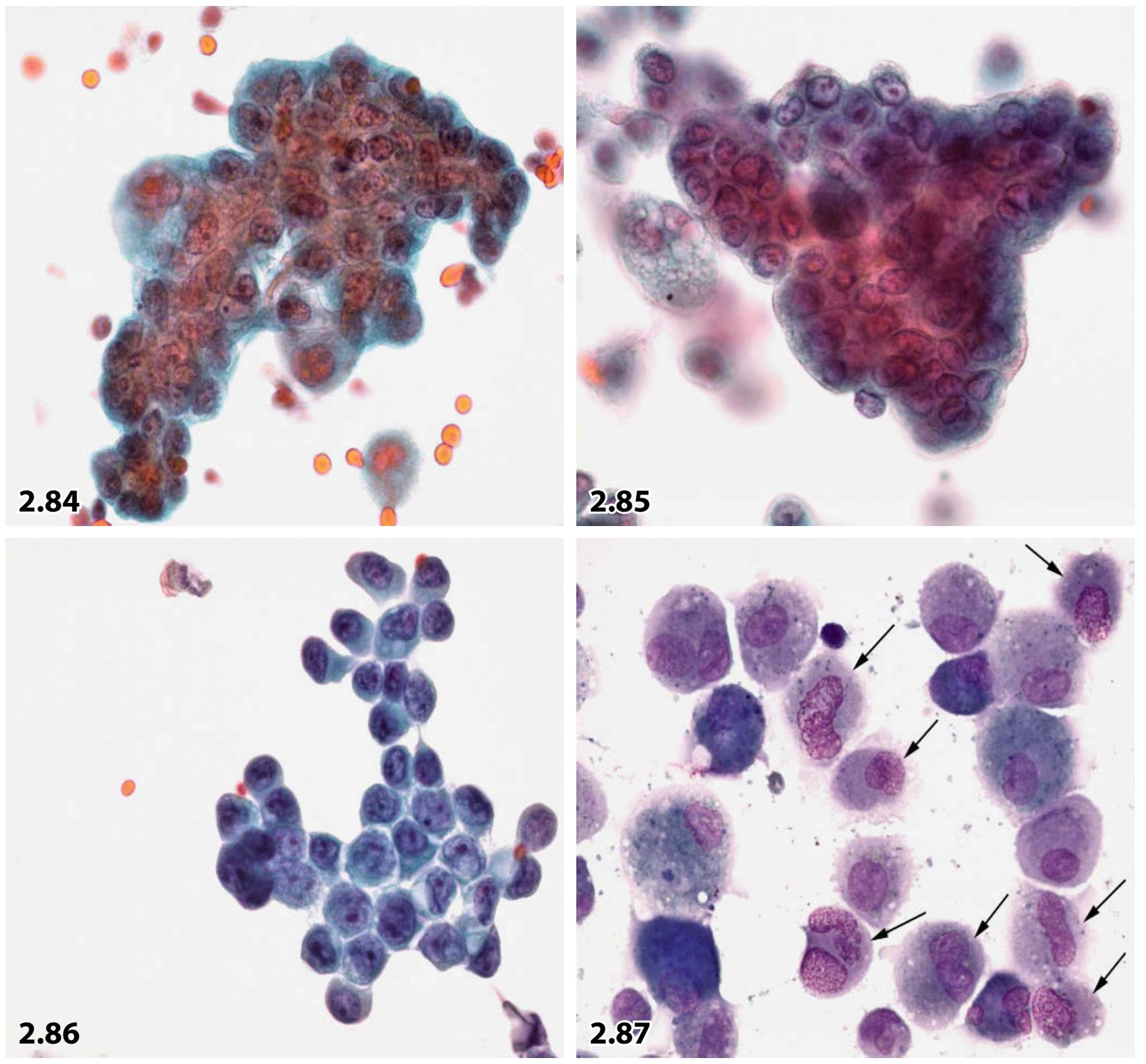




\section{Section 2.4 \\ Mediastinum}

Introduction

Non-tumorous and Neoplastic Mediastinal Disorders

Thymus Gland and its Diseases

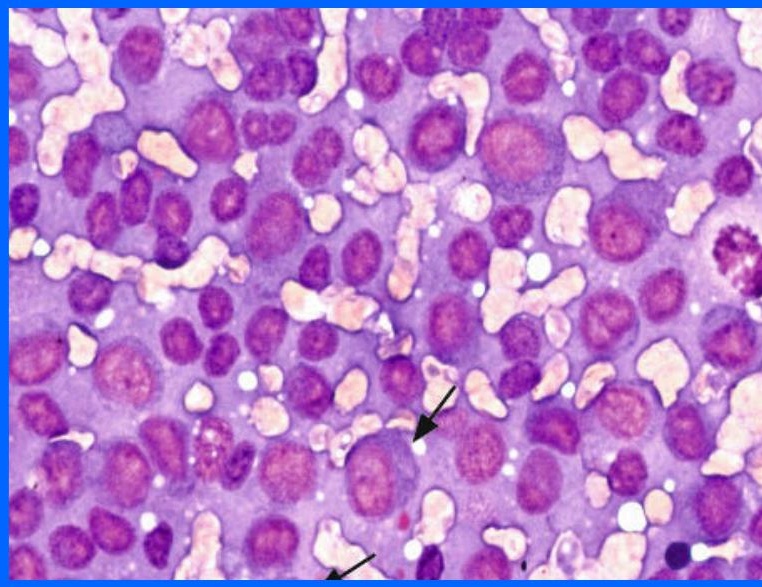

\subsubsection{Introduction}

\section{General Comments}

- The mediastinum is a part of the chest cavity that extends anteroposteriorly from the posterior surface of the sternum to the spine and sagittally from the thoracic aperture to the diaphragm. The most widely used scheme to divide the mediastinum uses four compartments: superior, anterior, middle, and posterior.

- The mediastinum is an area of great interest, because it is a site of numerous organs that can become involved in various pathologic disorders (thymus, lymph nodes, ganglia, soft tissue), apart from lesions spreading from organs that are located in the mediastinum or border this space (heart, esophagus, major vessels, vertebral column, and the membranes confining the heart and lungs).

- The development of new radiologic techniques such as computerized tomography, sonography, or endoscopic ultrasound allows the chest physician extensive use of invasive preoperative diagnostic procedures such as mediastinoscopy, limited thoracotomy, transthoracic fine-needle aspiration biopsy (FNAB), and endoscopic ultrasoundguided fine-needle aspiration (EUS-FNAB). Tumorous mediastinal lesions such as tumors of the thymus, lymph nodes, ganglia, soft tissue, and others have gained interest in recent years not only to surgical pathologists, but also, to a great extent, to cytopathologists.

- Metastases are the largest category of mediastinal neoplasms diagnosed by FNAB followed by primary mediastinal tumors. Metastases usually present minor cytodiagnostic difficulties and ancillary immunocytochemical studies are helpful in assessing primary tumor location. In contrast, many primary neoplasms such as malignant lymphoma, thymoma, and germ cell tumors implicitly call for additional analyses, in order to achieve a reliable cytologic diagnosis and subclassification, or surgical biopsies [80].

- An excellent review of the various entities of mediastinal lesions in FNABs has been published by Geisinger [28].

\subsubsection{Fine-Needle Aspiration Biopsy Techniques}

- Varied FNAB techniques have made the morphologic investigation of mediastinal masses not only possible, but also safe. Complications are rare including pneumothorax, hemorrhage, and hemoptysis. Pneumothorax has been reported as the most common complication [1, 34 . 81]. Image-guided FNAB is becoming increasingly accepted as a diagnostic tool and as a substitute for core biopsy. This method can prevent a substantial number of more invasive surgeries, for instance mediastinoscopy and open thoracotomy. Furthermore, FNAB has been shown to be an excellent tool in diagnosing mediastinal lesions in correlation with clinical history, imaging studies, laboratory features, and with excellent team work with interventional radiologists or chest physicians performing the needle aspirations [80].

- Diagnostic accuracy ranges from about $80 \%$ to $100 \%$ [10, $29,41,80]$. Diagnostic yield for tumors has been shown to be roughly equal in FNAB and punch biopsies, but his- 
topathologic examination of core-needle biopsies seems to be more accurate for tumor typing [11].

- Inadequate aspirates have been reported constituting a rate between 10 and $20 \%$ [29, 80]. Proximity of major vessels and deep-seated small lesions are major technical reasons for inadequate sampling, whereas necrosis and fibrosis are biological factors responsible for limited cellularity in aspirate smears. Bloody specimens are a third reason for inadequate cytological results.

- High specificity and sensitivity have been achieved when an experienced cytopathologist or cytotechnologist is on site to ensure the adequacy of the sample $[5,20]$. Immediate on-site cytologic interpretation is an additional factor that can improve diagnostic outcome [20,92], but this setting is very time-consuming for cytopathologists and impracticable in a majority of institutions.

- Ancillary tests such as cytochemical staining, immunocytochemistry, and molecular pathology are helpful in increasing the diagnostic accuracy of FNAB samples. Scant cellularity, poor preservation of cellular material, and blood-rich specimens are limiting factors in this respect. Special stains are particularly useful in the presence of inflammatory lesions in order to visualize organisms, such as bacteria (Gram), mycobacteria (Ziehl-Neelsen), and fungi (periodic acid-Schiff and Crocott-Gomori methenamine-silver stain). Immunocytochemical work-up of neoplastic mediastinal masses is essential in order to confirm and subclassify primary neoplasms, and to assess the primary origin of metastases [80]. FNAB may also provide material for microbiological tests (including culture) and molecular genetic analyses.

- Ancillary laboratory techniques including liquid-based cytology and cell block preparations [6] can be extremely helpful in certain diagnostic settings. At our institution, the liquid-based technique has recently been successfully implemented for endoscopic transbronchial FNAB of hilar, parabronchial, paratracheal, and mediastinal lymph nodes.

\subsection{Transthoracic FNAB $[6,29,80,81]$}

Most FNABs today are performed under radiologic guidance using computed tomography. Ultrasound can also be used to guide a fine needle into lesions located in the different compartments of the mediastinum. Masses located in the superior mediastinum may reliably be targeted by ultrasound-guided FNAB using retroclavicular and retrosternal needle passes. A fine needle attached to a syringe (best attached in a pistol-type holder) is passed through the chest wall into the lesion (references are indicated in Sect. 2.1.1.2.3, "FNAB Methods," p. 109).

\subsection{Transbronchial FNAB [85]}

Modern fiberoptic equipment enables the operator to visualize parabronchial-situated nodules molding the wall of the tracheobronchial tree. The needle is passed through the fiber- endoscope and precisely inserted through the bronchial or tracheal wall into enlarged parabronchial, hilar, and paratracheal lymph nodes.

\subsection{Endoscopic Ultrasound-Guided FNAB}

Endoscopic ultrasound-guided FNAB (EUS-FNAB) has proved to be a highly accurate diagnostic test for suspected tumorous lesions at various sites of the body, therefore avoiding numerous invasive surgical interventions [113]. Transesophageal and transbronchial EUS-FNABs are used with a high degree of sensitivity and specificity for staging of lung cancers and for primary diagnoses of mediastinal lesions. EUS-FNAB is a highly valuable method for diagnostic evaluation of lesions, especially when other modalities have failed $[21,42,53,68,106]$. The intervention is usually well tolerated [10].

Transbronchial EUS-FNAB allows the operator to visualize and evaluate small intramural/submucosal-situated lesions of the bronchi, and tumors within the lung parenchyma, as well as lymph nodes and abnormal findings located in the mediastinal space $[5,35,85]$.

Transesophageal EUS-FNAB has become an important tool for staging lung cancer at the time of diagnosis and for assessing diagnoses on otherwise undiagnosed pulmonary and mediastinal masses. Such lesions are usually located in the posterior areas of the mediastinum and in the upper lobes of the lung $[10,13,21,42,103,111]$.

\section{Caution}

The passing of the needle into the mediastinal lesion causes contamination of cells from the bronchial/ esophageal inner layers and from bronchial glands (Fig. 2.88).

Beware of erroneous diagnostic conclusions!

\subsubsection{Liquid-Based Cytology for FNAB Samples} [108]

At our institution, we prefer the use of liquid-based thinlayer technology (Cytospin, ThinPrep) for endoscopic image-guided FNAB of mediastinal disorders. The reasons for this procedure are the following:

- The entire amount of FNAB material can be preserved.

- The thin-layer method has proved to be a perfect procedure for clinicians who are not familiar with the proper preparation and fixation technique for the aspirated material, or when a cytotechnologist is not available on site during the intervention.

- In many circumstances, the liquid-based method is superior to conventional smears with regard to clear background, monolayer cell preparation, and cell preservation.

- An optimal preparation can be achieved for special investigations, in particular for immunocytochemistry, FISH, 
or static DNA cytometry (Figs. 2.108 and 2.112). In addition, the rinse from needle and syringe may be used for immunolabeled flow cytometry.

- Regardless of operator, hemolyzing fixatives (Cytolyt and others) have shown to be indispensable as initial transport medium for highly sanguineous FNAB material. Combined with thin-layer preparation, hemolyzing fixatives are a useful modality for blood-rich aspirates providing well-preserved cells and a clean background.

- In our experience, which is in agreement with the results reported in the literature, smear preparation and fixation is improved and artifacts are reduced using the thin-layer technique. However, morphologic features may be altered and cell interpretation may need modification. The most challenging morphologic changes compared with conventional smears are (Figs. 2.114 and 2.115):

O Cell aggregates may be crowded and tight.

O Cell shrinkage and disruption of the cytoplasm may be more pronounced.

O Nucleoli are more distinct.

$\bigcirc$ Background material such as mucin or detritus may be scant or completely lost.

Practically all recent reports in the literature indicate that liquid-based cytology is an accurate and feasible method in the FNAB investigation from lesions of various sites, comparable with conventional smear preparation (references are provided in Sect. 10.1.2.2, "Liquid-Based Cytology," p. 634, and elsewhere). The liquid-based technique has rarely been applied on FNAB samples for the diagnosis of thymic lesions [74].

\subsubsection{Mediastinal Compartments with Their Organs and Principal Lesions}

Dividing the mediastinum into four compartments is not only useful for clinical purposes, but also for pathologists, because many lesions are restricted to certain compartments and related to the individual organs:

\subsection{Superior Mediastinum}

- Thymus: cysts, thymoma, carcinoid, lymphoma.

- Thyroid: goiter and neoplasms, originating from ectopic tissue or primary thyroid lesions extending into the mediastinal space [88].

- Parathyroid glands: cysts, tumors.

- Lymph node: inflammatory disease, lymphoma, metastases.

- Generally: cysts, aneurysm.

\subsection{Anterior Mediastinum}

- Lesions of the superior mediastinum.

- Germ cell tumors.

- Paraganglioma.

- Mesenchymal tumors such as lipoma, angioma, and others.

\subsection{Middle Mediastinum}

- Heart and pericardium: cysts and tumors.

- Lung hilus: bronchogenic cyst.

- Hilar and broncho-pulmonary lymph nodes: inflammatory disease, lymphoma, metastases.

\subsection{Posterior Mediastinum}

- Neurogenic system, also sympathetic: schwannoma, ganglioneuroma/blastoma, neuroblastoma, paraganglioma, and others.

- Lymph nodes: inflammatory disease, lymphoma, metastases.

- Development defect: gastroenteric cysts.

- Esophagus: carcinoma and other lesions.

- Spinal column: osseous and chondroid tumors, lymphoma (plasmacytoma), hypostatic abscess, meningocele.

- Major vessels: aneurysm.

\subsubsection{Cytology of Nontumorous Mediastinal Disorders}

\subsubsection{Inflammatory Diseases}

\subsection{Acute Mediastinitis [82]}

Esophageal perforation is the most common cause for this uncommon but severe clinical condition frequently resulting from postoperative dehiscence of intrathoracic esophageal anastomoses. Perforation can also follow endoscopy, dilatation of the esophagus, trauma, ingestion of foreign bodies, irradiation, erosion of the esophageal wall by malignant tumors, etc. Mediastinitis may exceptionally result from lymphatic spread of infections located in tissues and organs adjacent to the mediastinum such as deep neck infections, lung abscess, subphrenic abscess, or vertebral osteomyelitis.

O Cytologic specimens contain abundant neutrophils and signs of abscess formation (degenerating neutrophils and debris). It is recommended to submit a portion of the aspirated material for microbiological studies.

\subsection{Chronic Mediastinitis [24, 50, 55, 90]}

Synonyms: Granulomatous mediastinitis, fibrous and sclerosing mediastinitis, and others.

Infectious and noninfectious diseases may lead to the development of a chronic mediastinal inflammatory process frequently associated with granulomatosis and fibrosis. Histoplasmosis and tuberculosis are the most common etiologic factors for granulomatous mediastinitis. A noninfectious etiology is assumed to be associated with sarcoidosis (Figs. 2.89 and 2.90), autoimmune diseases, drugs, trauma, cancer, and coexistent with similar fibrotic processes in the retroperitoneum, thyroid, orbita, and other 
parts of the body. Sclerosing mediastinitis is usually selflimiting.

\section{Microscopic features}

O The inflammatory process shows various morphologic patterns [24]. Cellular fibromyxoid tissue, leukocytes, and plasma cells mark the florid stage, whereas sclerosis with collagen and dystrophic calcification represents the final stage of the disorder.

O FNAB samples are likely to be hypocellular, comprising a few stromal cells and fragments of fibrotic tissue unless a florid inflammatory process provides characteristic elements of granulomatous tissue.

O Epithelioid cells and giant cells of the Langhans type raise suspicions of sarcoidosis, tuberculosis, or atypical mycobacteriosis. Additional caseating necrosis is a strong indication of mycobacterial infection. Detection of mycobacteria by Ziehl-Neelsen stain or microbiological studies supports the morphologic diagnosis [31].

\section{Differential Diagnosis}

- Granulomatous inflammation may be associated with malignant neoplasms such as germ cell neoplasia, Hodgkin lymphoma and non-Hodgkin lymphoma [94].

- Malignant neoplasms with a strong sclerotic component such as sarcoma, Hodgkin lymphoma of the nodular sclerosing type [23], or sclerosing non-Hodgkin lymphoma may simulate chronic sclerosing mediastinitis.

\subsubsection{Uncommon Mediastinal Deposits}

\subsection{Pronounced Anthracosis}

Pronounced anthracosis in mediastinal lymph nodes may induce unorthodox proliferative activity of histiocytes and enlargement of the lymph node. Aspirated material appears as a black stained mass.

O Microscopy: masses of extracellular anthracotic pigment is also included in the cytoplasm of macrophages as well as a few lymphocytes.

\subsection{Mediastinal Amyloidosis}

Amyloid deposits within the mediastinal space may give rise to reactive cell changes. Cellular atypias should not lead to a misdiagnosis of cancer [80]. Morphologic features and other attributes of amyloid are covered elsewhere in this book (Sect. 2.2.1.9.1, “Amyloid Tumor,” p. 136).

\subsubsection{Mediastinal Cysts}

Mediastinal cysts comprise $10-27 \%$ of all mediastinal tumorous disorders [50]. A variety of mediastinal cysts exist, which can be divided into two main categories:
1. Congenital cysts resulting from developmental anomalies of the foregut or related embryonal structures.

2. Acquired cysts including benign cyst-like lesions and secondary cystic changes in neoplastic disorders.

Transthoracic or endoscopically guided FNAB is an effective method for diagnosing cystic lesions [19, 32]. Their nature can be assessed or suspected in a number of cases as a result of the cytologic features in the aspirated cyst content.

\subsection{Congenital Cysts [19, 32, 87]}

Most of these cysts are spherical and usually unilocular, and show a strong variability in size, up to several centimeters.

\section{Cystic mature teratoma (Fig. 2.91)}

More information is available in Sect. 2.4.3.6.1, "Benign Teratoma," p. 213.

\section{Bronchogenic cyst}

Bronchogenic cysts result from abnormal branching of the tracheobronchial tree during embryonic development. They are the most common variety of all congenital cysts found in the mediastinum and occur at any age. Bronchogenic cysts are located in the anterior mediastinum but may be present elsewhere in the mediastinal space and also within the lung parenchyma.

The cyst fluid may be clear, turbid, or mucoid.

\section{Microscopic Features and Differential Diagnosis}

O Sediment smears contain ciliated columnar cells of the respiratory type and usually sheets of metaplastic squamous cells. A few detached ciliary tufts may be the only remnants of ciliated columnar cells [19] (Fig. 2.92).

O Other elements that are normally present in bronchial walls may be found as well such as cartilage, smooth muscles, and bronchial glands.

O Calcium deposits occasionally occur. Birefringent, needle-shaped crystals have been described in many cases $[43,44,91]$.

Esophageal cysts contain cellular elements equal to bronchogenic cysts, except cartilage tissue and chondrocytes.

\section{Esophageal cyst}

Esophageal cysts arise from noncoalescing vacuoles in the wall of the foregut during development of the esophagus. These cysts are most frequently found in children and young men.

\section{Microscopic Features and Differential diagnosis}

O Nonkeratinized stratified epithelium is most likely encountered, but varying amounts of ciliated columnar epithelial cells and ciliary tufts may be present as well. 
O Other elements as mentioned for bronchogenic cysts may also be encountered.

Distinction from bronchogenic cyst is difficult. However, cartilage is definitely no component in fluids of esophageal cysts.

\section{Gastroenteric cyst}

Gastroenteric cysts develop in the posterior mediastinum. They are usually associated with vertebral anomalies [87]. Gastroenteric cysts may be reported under various terms: gastric cyst, enterogenous cyst, foregut duplications, esophageal duplications, etc.

O The epithelial cells may be of the gastric type, intestinal type, or both, including mucin-secreting cells. Ciliated columnar cells and squamous cells are frequently observed.

\section{Pericardial and Mesothelial cyst}

Pericardial and mesothelial cysts result from developmental abnormalities of the pericardial or pleuroperitoneal coelom. They are typically located close to the pericardium and adjacent to the diaphragm, they are usually found in adult patients.

The cystic fluid is watery, clear, and frequently acellular.

O Mesothelial cells may occur, arranged in regular flattened sheets. The mesothelial cytoplasm is wide, nuclei are monomorphic with bland chromatin and smooth borders, and the N/C ratio is low. An inflammatory component is usually absent.

\section{Cysts containing pancreatic tissue}

These cystic lesions have been rarely reported [110]. Ectopic pancreatic tissue associated with cystic changes generally includes ducts, acini, and islets of Langerhans.

\section{Differential diagnosis}

Mediastinal teratoma containing pancreatic tissue and pancreatic pseudocysts extending into the mediastinum have to be taken into consideration.

Other congenital cystic disorders of the mediastinum that have to be included in differential diagnosis considerations are thymic cysts (described in Sect. 2.4.3.3, p. 209) and meningoceles.

\subsection{Acquired Cysts (Fig. 2.93) \\ Thoracic duct cyst}

Thoracic duct cysts are probably caused by degenerative changes or congenital harm of the thoracic duct wall followed by duct dilatation and aneurysm formation [50].

A macroscopically milky chylous fluid is a diagnostic key feature.

A few spindle-shaped or flattened endothelial cells and a variable number of mature lymphocytes may be present in smear preparations.

\section{Parasitic cysts}

Hydatid cysts are most common in the mediastinum are hydatid cysts. They are caused by the larval stage of the dog tapeworm. The cystic lesion appears unilocular and multilocular, characteristically with focal areas of calcification in the cyst wall.

Microscopic features, general comments, and cautions are given in several chapters of this book, e.g. Sect. 9.1.7.3, "Hydatid Cyst," p. 590.

\section{Neoplastic cyst}

Neoplastic cysts are frequent. Many mediastinal tumors are primarily cystic or have a cystic component: thymoma (see Sect. 2.4.3.4, p. 209), thymus lymphoma, teratogenous tumors, thyroid and parathyroidal tumors, nerve sheath tumors, and metastatic neoplasms (Fig. 2.94).

\section{Other cystic formations}

They can occur in the regressive course of hematomas and inflammatory process. Mediastinal pancreatic pseudocyst has been mentioned in the context of mediastinal cystic pancreatic tissue. Normal thymus in adults can show extensive cystic degeneration.

\section{Caution}

Contaminating cells from organs penetrated by the needle on its way into the cyst may cause erroneous typing of the cystic lesion (Fig. 2 .88)

\subsubsection{Thymus Gland and Its Diseases}

\subsubsection{Normal Thymus Gland [50]}

- The thymus is a pure epithelial organ during the first stages of its evolution. By the end of the second month of intrauterine life, the epithelial tissue becomes secondarily infiltrated by bone marrow-derived lymphocytes and mesenchymal elements.

- The thymus gland reaches the maximum weight during puberty followed by a gradual process of fatty involution. However, the organ never completely disappears but commonly becomes cystic.

- The thymus plays an important role for the immune system and produces several hormones. Primarily undifferentiated lymphocytes - migrated from bone marrow - acquire characteristics of $\mathrm{T}$ cells in close contact with thymic epithelium and its microenvironment. After migration to peripheral lymphoid organs the post-thymic precursor $\mathrm{T}$ cells finally acquire the characteristics of mature immunocompetent $\mathrm{T}$ cells. The process is triggered by thymic hormones.

- The thymus is located in the anterior mediastinum but small ectopic islands of thymic tissue are found throughout the mediastinal space and are extramediastinal as well. 
- The encapsulated organ consists of two lobes and is divided into lobules by fibrous strands. The peripheral portion of the thymic lobes is the cortex, it appears darker than the central area, which is called the medulla.

- Parathyroid tissue is commonly found in the anterior mediastinum adjacent to the thymus gland or surrounded by thymic parenchyma.

\section{Histology and Immunocytochemistry}

The cortex is almost entirely composed of lymphocytes. The lymphoid population is best analyzed by flow cytometric analysis, which predominantly demonstrates $\mathrm{T}$ cells coexpressing CD4 and CD8 and staining positive for the early Tcell markers CD1a and TdT. A few small lymphoid follicles and rare plasma cells represent the B-cell lymphoid population. A few scattered cortical epithelial cells are difficult to distinguish from large histiocytes.

The medulla (Fig. 2.95) chiefly contains epithelial cells occurring in small groups. Squamous differentiation and formation of keratin pearls (called Hassall corpuscles) are obvious. Lymphocytes of the medulla mainly represent the inducer phenotype T4. Myoid cells are also found.

\subsubsection{Thymic Hyperplasia (Fig. 2.96)}

\subsection{True Thymic Hyperplasia}

True thymic hyperplasia is characterized by an increase in the size and weight of the whole gland without changes in normal architecture and morphology for age. Common hyperplasia has to be separated from a true neoplastic disorder (thymoma). Massive benign enlargement of the thymus gland is rare. It has been described in children treated for malignancies and in conjunction with other pathological conditions [50].

\subsection{Reactive Lymphoid Hyperplasia}

Follicular hyperplasia is characterized by the presence of germinal centers in the medullary area of the thymus gland. Follicular hyperplasia of lymphocytes of the B phenotype is often associated with myasthenia gravis and various autoimmune disorders [30]. Morphologic features of follicular hyperplasia are provided in Sect. 15.2.2, "Common Reactive Lymphadenopathy," p. 926.

\subsubsection{Thymic Cysts [50] (Fig. 2.97)}

Thymic cysts are particular lesions. Most of them are probably congenital and derived from tubular remnants of the thymus anlage. Distention occurs by fluid accumulation or hemorrhage.

The cyst fluid is serous but may also be sanguineous.

O The background of the smears may contain inflammatory cells, erythrocytes, debris, calcium deposits, and particularly cholesterol crystals.
O If present, epithelial cells are cuboid, columnar, ciliated columnar, or squamous.

Differential diagnosis: Various types of congenital mediastinal cysts show a similar fluid cell pattern in comparison to thymic cysts (see Sect. 2.4.2.3.1, p. 207). Other cystic disorders should be considered as well such as cystic thymoma, cystic germ cell tumor,lymphangioma, and cystic lymphoma of the thymus gland.

\subsubsection{Thymoma}

In the past, the term "thymoma" has generally been applied to any type of tumor originating in the thymus gland: thymic neoplasms included tumors arising from thymic epithelium, neuroendocrine cells, germ cells, lymphoid cell populations, and various mesenchymal cell types, particularly adipose cells.

Today, the term "thymoma" is restricted to tumors originating from the thymic epithelial cells [50]; therefore, thymomas should be separated from other neoplasms that have their origin in the thymic gland such as carcinoid, germ cell tumors, and malignant lymphomas.

There have been several varied classifications of thymic tumors up to the end of the last century. Nowadays, the most widely used classing is the 2004 WHO histological typing system [102].

\subsection{Tumors of the Thymic Epithelium: Common Type Thymoma (Fig. 2.98) \\ General Comments}

- Thymoma is the most common primary tumor in the superior/anterior mediastinum and one of the most frequent tumors of the entire mediastinal space.

- Most tumors are observed in patients in the fifth and sixth decades of life. There is no predilection for sex, race, and geographic area [48].

- Thymoma can sporadically be found in unusual sites according to its particular embryologic development, descending through the neck into the mediastinum. Tumors may be located in the neck area [105], lung [60], pleura, and mediastinal areas other than the anterior compartment.

- A unique feature of the tumor is its association with paraneoplastic syndromes, and in particular myasthenia gravis.

- Thymomas may be roughly categorized into a noninvasive stage and invasive stage, whereas prognosis depends on the invasive status of the individual tumor. The vast majority of the thymomas are completely encapsulated and behave clinically benign. The 2004 WHO typing system classifies thymomas into five types according to the morphology and the atypical features of the tumor cells as well as the proportion of epithelial cells and lymphocytes. 
Invasiveness and prognosis of the thymomas were shown to correlate with this classification system. Other prognostic factors include the tumor stage, tumor size, and the presence of clinical symptoms. Surgery is the principal treatment for thymomas $[39,46,71]$.

- Extrathoracic metastases are rare; the most important sites include cervical lymph nodes and liver parenchyma [48].

\section{Histology}

- Most thymomas are well encapsulated, reaching a diameter of up to several centimeters. Calcification of the tumor capsule is uncommon but presumed to be a characteristic of thymomas. The tumors exhibit variable degrees of cyst formation as well as areas of hemorrhage and necrosis.

- Basically, thymomas are composed of a biphasic cell population, namely neoplastic epithelial cells and lymphocytes of the T-cell phenotype.

- Thymoma can be evaluated from two different perspectives:

1. Related to the relative proportions of epithelial cells and lymphocytes:

- In epithelial thymomas, the epithelial cell population predominates. Epithelial cells represent more than two-thirds of all cells.

- In lymphocytic thymomas, lymphocytes predominate.

- In mixed thymomas, the number of epithelial tumor cells and lymphocytes is almost equal.

2. Based on cortical and medullary differentiation of the epithelial cells:

- Cortical thymomas show epithelioid thymocytes. These are tumors having a more aggressive behavior belonging to the mixed thymoma variant [14].

- Medullary thymomas are composed of spindle epithelial cells.

- Mixed thymomas contain both cell types.

Epithelioid tumor cells show epithelial clustering, clearly distinguishing these tumor cells from histiocytes/mesenchymal cells. Spindle epithelial cells may mimic fibroblasts; their growth pattern is manifold such as whorls or bundles. Epithelial cells in benign thymomas may be very large and pleomorphic but lack clear signs of malignancy. Architectural features include rosettes, glandular and papillary structures, perivascular spaces, and Hassall corpuscles. Squamous epithelial cells and myoid cells may also be observed and glands may be lined by goblet cells or ciliated epithelium.

\section{Cytologic Features}

[4, 14, 28, 97, 98, 107] (Fig. 2.98)
A biphasic population of epithelial cells and lymphocytes in varying proportions is a key feature for the cytologic diagnosis of thymoma.

○ Epithelioid epithelial cells (Fig. 2.95B) are round to oval in shape and variable in size. The nuclei are bland in appearance, showing a smooth outline, pale chromatin, and distinct but small nucleoli. The nuclei may sometimes be crowded and cytoplasmic invaginations may be observed.

The cytoplasm is typically round or polygonal, varying from scant to moderate in size and has indistinct borders. It may be clear and delicate or densely structured and squamoid.

Identical architectural features, as seen in histologic sections, including Hassall corpuscles, may be detected (Fig. 2.95A)

O Spindle epithelial cells are commonly seen in fineneedle aspiration of thymomas, but predominance of this cell type is less common. The cells are arranged in loose groups or bundles. Both cytoplasm and nuclei are elongated. Regular nuclei show evenly distributed chromatin.

O Lymphoid cells vary in number and phenotype, depending of the thymoma type. Type A thymomas show only a few mature T-cell lymphocytes. The number of $\mathrm{T}$ cells and the fraction of immature $\mathrm{T}$ cells increase within the type B thymoma group. Activated lymphocytes show increased size, nuclear irregularities, and nucleoli. Plasma cells are extremely rare.

O Thymoma cells that have accumulated glycogen in their cytoplasm stand out as clear cells with abundant pale cytoplasm.

O Benign thymoma can exhibit distinctive atypias of the epithelial cells including pronounced cellular enlargement, cellular and nuclear pleomorphism, and large nucleoli. Unequivocal malignant cell features together with necrosis and high mitotic activity may suggest a diagnosis of thymic carcinoma.

o Calcification, fibrotic tissue fragments, and cystic degeneration with foam cells vary depending on the tumor subtype. No mitotic activity.

\section{Caution}

- Cytologic examination alone cannot reliably discriminate among the various subtypes of thymomas.

- Cytologic diagnosis of thymoma is challenging if a pronounced population of lymphocytes is obscuring the epithelial component.

- Cytologic features alone are not adequate to determine invasive growth of thymoma into surrounding structures. Absence of atypias and necrosis do not exclude an aggressive tumor behavior [14].

- Pronounced cytological atypias, necrosis, and mitoses raise suspicions of thymic carcinoma. 


\subsection{Tumors of the Thymic Epithelium:}

Invasive Thymoma (Figs. 2.99 and 2.100)

- Invasiveness of thymomas is invariably established by histologic examination of the periphery of the tumors, demonstrating invasion through the capsule and into surrounding tissues (vessels, nerves, pericardium, pleura, and lung).

- A considerable number of invasive thymomas goes along with a bland cytologic pattern. Such tumors rarely show metastases in distant organs.

- Neither cytological features nor histological classification and paraneoplastic clinical symptoms are reliable parameters for the biological behavior of an individual tumor. However, Baba and coauthors have emphasized cytological features as well as morphometric results that are useful in distinguishing between low-stage and high-stage thymomas [7].

\section{Microscopic Features}

O Microscopic patterns, in particular the characteristic biphasic cell population and cytologic features, are the same as described above [22,107]

$\circ$ Features that may suggest invasive growth (as compared to common thymoma type) are:

- Predominant epithelioid cell pattern.

- Nuclear enlargement.

- Pronounced nucleoli.

- Enhanced mitotic activity.

\section{Caution}

Presence of focal cellular atypias, cellular pleomorphism, and increased mitotic activity is of limited value for estimating invasive behavior and prognosis of thymomas by cytology $[14,84,107]$.

\subsection{Tumors of the Thymic Epithelium:}

\section{Thymic Carcinoma [33, 56]}

- Thymic neoplasms that exhibit unequivocal cytologic features of malignancy should be classified as thymic carcinoma. They have all the characteristics of malignant behavior, both histologically and clinically. Thymic carcinomas account for only a small group of the mediastinal neoplasms. A great number of morphologic variants have been reported [102], whereas squamous cell carcinoma has proved to be the most common entity among thymic carcinomas. The histologic and cytologic features of thymic carcinoma variants as listed below are indistinguishable from corresponding tumors arising in a variety of other organs throughout the body.

\section{Microscopic Features and Immunocytochemistry}

O General cytological and background features include pronounced cellular and nuclear pleomorphism, prominent nucleoli, numerous and bizarre mitotic figures, tumor necrosis, inflammatory infiltrate [7].
O We refer to other chapters of this book regarding the cytologic pattern of particular tumor types and ordinary differential diagnosis considerations:

- Squamous cell carcinoma (Fig. 2.101). Intercellular bridges and keratotic pearls are usually present (cytomorphology and others see Sect. 2.2.2.2, "Squamous Cell Carcinoma," p. 139). A combination of immunocytochemical staining for CD117(KIT) and CD5 indicates the thymic origin of the tumor and has been shown to be extremely helpful in distinguishing between thymic squamous cell carcinoma and metastatic squamous cell carcinoma [61].

- Lymphoepithelioma-like carcinoma (cytomorphology and other information are given in Sect. 8.7.3, "Lymphoepithelial Carcinoma," p. 568). Mediastinal seminoma/dysgerminoma may closely resemble this particular subtype of thymic carcinoma.

- Basaloid carcinoma [79] (cytomorphology and others see Sect. 16.2.7, "Basal Cell Carcinoma," p. 1029).

- Small-cell carcinoma (cytomorphology and others see Sect. 2.2.2.6, "Small-Cell Carcinoma," p. 144). Pure and mixed tumors (combined small-cell carcinoma) have been reported. Neuroendocrine features of thymic small-cell carcinoma have been confirmed by immunohistochemical studies for chromogranin and CD56 [101]. Differential diagnosis with metastatic small-cell carcinoma of the lung is very difficult if not impossible.

- Clear cell carcinoma (cytomorphology and others see Sect. 12.1.8.1.1, "Clear Cell Renal Cell Carcinoma," p. 739).

- Other high-grade thymic carcinomas include mucoepidermoid carcinoma, adenosquamous carcinoma, and carcinosarcoma

\subsection{Additional Analyses on Tumors of Thymic Epithelium \\ Immunocytochemistry [18, 99] (Figs. 2.99B-E)}

The thymocytic tumor cell exhibit a bilineage pattern of epithelial and lymphocytic antigens. On the one hand, they show varied epithelial markers such as EMA and different cytokeratins (e.g., AE1/AE3, Cam 5.2, CK5/6, CK7, CK14, CK19), and on the other hand CD20 or CD57.

The accompanying lymphocytes usually express an immature T-cell phenotype showing variable reactivity for several T-cell antigens (e.g., CD1a, CD3, CD5, CD4, CD8, CD99, TdT).

CD5 and CD117 have been reported to express positive immunoreactivity in a high percentage of thymic carcinoma cells in contrast to thymoma cells. Furthermore, CD205 and Foxn1 have been proposed as a sensitive and specific marker for benign and malignant thymoma. The sensitivity of CD205 seems to be lower than CD5 and CD117 for thymic carcinoma, and Foxn1 was found to be superior 
to CD5 and CD117 as a marker for thymic carcinomas [61, 66].

\section{Flow Cytometry}

Flow cytometric immunophenotyping of the lymphoid cell population may be helpful in preoperative diagnosis of thymomas, excluding benign thymic tissue and other types of thymic tumors [78]. CD4/CD8 coexpression on the lymphocytes in thymic tumors assessed by fluorescence-activated cell sorting analysis is an additional indicator for the diagnosis of thymoma [27, 28, 70, 114]. Furthermore, flow cytometric analysis on the lymphocytic population appears to be useful to determine the malignant potential of thymomas $[62,114]$.

Enzyme Immunoassay in Cystic Fluids

Elevated CA-125 content in the fluid obtained from a cystic mediastinal tumor may be helpful in classifying the lesion as thymoma [76].

\section{Differential Diagnosis [28, 80]}

The most frequent differential diagnoses of thymomas are listed next, together with immunocytochemical markers proved to be the most helpful:

- Thymomas with a dominant epithelioid component may be confused with

- Primary mediastinal neoplasms: germinomas, embryonal carcinoma (placental alkaline phosphatase + ), thymic carcinoid (neuroendocrine markers + ); admixture of a lymphoid cell population may occur, particularly with germ cell tumors (seminoma/dysgerminoma).

- Any metastatic carcinoma and melanoma (melanomatypical markers +) to the mediastinum. TTF-1 may be expressed immunocytochemically in pulmonary adenocarcinomas but not in thymoma cells [77].

- Thyroid papillary carcinoma (TTF-1 and thyroglobulin + ) if the nuclei of a thymoma exhibit pale chromatin, small nucleoli, nuclear crowding and cytoplasmic invaginations $[51,67]$.

- Thymomas composed of an epithelioid population of predominant small cells have to be differentiated from nonHodgkin lymphoma (CD45 +), small-cell carcinoma, and carcinoid of the lung (neuroendocrine markers + and TTF-1 +), and paraganglioma in adult patients (see Sect. 5.2.6.2, "Carotid Body Paraganglioma," p. 467).

Tumors of the small blue round cell tumor group, in particular neuroblastoma (see Sect. 12.1.10.2.2, "Wilms Tumor," p. 743) and malignant lymphoma should be considered in the pediatric patient group.

- Thymomas with intense admixture of lymphocytes to the epithelioid cell component may mimic lymphoma. Various adjuvant techniques are available on FNAB material to establish monoclonality of a malignant lymphoid cell population (see Sect. 3.2.3.2, "Malignant Lymphoma," p. 267, and Sect. 15.1.4, “Ancillary Techniques,” p. 910):
- Lymphocyte-rich thymoma that contains numerous transformed lymphoid elements of the B phenotype (benign lymphoblasts) may be mistaken for large-cell B-type non-Hodgkin lymphoma infiltrating the thymus gland $[25,115]$.

- A small-cell lymphoid infiltrate may simulate lymphoblastic non-Hodgkin lymphoma, which is a disease that affects predominantly children and young adults. The vast majority of these tumors are of T-cell lineage.

- Thymomas associated with a significant spindle cell component have a wide variety of benign and malignant counterparts [94]:

- Granulomatous inflammation and cellular fibrous tissue. Monocytes, histiocytes, and macrophages express CD68 +.

- Granulomatosis and cellular fibrous tissue may also occur as a reactive component or genuine proportion of epithelial and lymphoid neoplasias, e.g., Hodgkin lymphoma.

- Benign and malignant mesenchymal tumors such as sarcoma and nerve sheath tumors (cell line-typical mesenchymal immunmarkers).

- Spindle cell squamous carcinoma.

- Spindle cell melanoma, nonpigmented [8] (melanomatypical markers + ).

- Spindle cell carcinoid (neuroendocrine markers + ).

\section{Caution}

- Primaries in remote organs metastasizing to the thymic gland and mediastinum must be unambiguously excluded before assessing a diagnosis of primary thymic carcinoma by cytology.

- Remember germinoma (seminoma/dysgerminoma) as another potential mediastinal tumor entity with a biphasic appearance exhibiting epithelioid cells and lymphoid cells !

- Thymoma and thymic carcinoid [72] exhibit negative immunoreactivity for TTF-1.

- Thymomas presenting as a palpable tumor of the neck are easily mistaken as a primary disorder of the thyroid [54]. Immunocytochemically, TTF-1 [77] and thyroglobulin should reliably differentiate thymic tumors from benign and malignant thyroid tissue.

\subsubsection{Thymic Carcinoid (Figs. 2.102 and 2.103)}

- Thymic carcinoid is a rare tumor accounting for about $2 \%$ of all neoplasms of this organ. Carcinoid tumors are of neural crest origin but commonly develop in endodermal organs including the thymus gland, lung, and gastrointestinal tract. 
- The peak incidence of thymic carcinoids is in the fifth decade and is more frequent in male patients. Endocrine disorders are observed in about half of the patients afflicted with thymic carcinoid [50].

- In contrast to thymomas, thymic carcinoids do not present with an explicit encapsulation, they are frequently invasive to adjacent structures, and show frequent metastases to regional lymph nodes and distant organs. Thymic carcinoid has an overall poor prognosis [65]. Focal hemorrhage and necrosis, but not cystic degeneration, may be present.

- Thymic carcinoid is very rarely encountered in FNABs of the mediastinum.

\section{Microscopic Features [65, 83, 109]}

O Hallmarks: Cellular smears are composed of cell clusters and numerous single tumor cells. Cells have round to oval nuclei, finely granular chromatin, and a scant granular cytoplasm. Dispersed large-tumor cells are usually present showing abundant granular cytoplasm and macronucleoli. Occasionally, spindle-shaped tumor cells can be found.

O Predominance of spindle cells has been reported [47].

o Numerous small pyknotic tumor cells may mimic lymphocytes.

\section{Differential Diagnosis and Immunocytochemistry}

- Thymoma has been reported as the most frequent misdiagnosis in the presence of a carcinoid tumor of the thymus (Fig. 2.102). Cells of carcinoid tumors may share morphologic features with epithelioid cells of thymomas, but the frequent occurrence of pyknotic cells in carcinoids mimicking lymphocytes seems to be the main reason for misdiagnosis between carcinoid tumor and thymoma [83]. Immunocytochemical reactivity for neuroendocrine markers (synaptophysin, chromogranin, CD56) should help in the correct assignment of a thymic carcinoid tumor [101]; however, positivity for neuroendocrine markers is occasionally achieved in thymic carcinomas as well. Further immunostainings that may be helpful to distinguish thymoma from carcinoid tumor are p63 and CK5/6 (positive on thymoma and thymic carcinoma, negative on carcinoids) and CD5. CD5 yields a positive reaction in half of the thymic carcinomas and is suitable in distinguishing poorly differentiated carcinoids [83].

- Malignant lymphoma usually demonstrates a pattern composed of noncohesive cells with typical morphologic features. An immunocytochemical panel with antibodies directed against epithelial, leukocytic/lymphoid, and neuroendocrine markers provides a correct diagnosis.

- Adenocarcinomas represent characteristic cytomorphologic features including single cells, compact spherical and acinar clusters, large eccentric nuclei, prominent nucleoli, thinly dispersed chromatin, and usually a low N/C ratio. Certain monomorphic adenocarcinomas of the gra- nular cell type may provoke differential diagnosis problems, such as metastasis of renal cell carcinoma and thyroid carcinoma (among others).

- Small-cell carcinomas show characteristic cell clustering and cellular features on single cells (see Sect. 2.2.2.6, "Small-Cell Carcinoma," p. 144). However, the differential diagnosis between thymic carcinoid tumor and metastatic small-cell carcinoma can be difficult in individual cases from cytology alone (Fig. 2.103). Immunocytochemistry cannot distinguish between thymic carcinoid tumor and small-cell carcinoma of the thymus or between small-cell neuroendocrine carcinoma of the thymus and small cell carcinoma secondary to the mediastinum.

- Spindle cell tumors must be differentiated from thymic carcinoid with a pronounced spindle cell pattern (see also Sect. 2.4.3.4.4 “Additional Analyses," p. 211, and Sect. 2.4.4, "Neurogenic and Mesenchymal Tumors," p. 216).

\subsubsection{Germ Cell Tumors [17, 112]}

\section{General Comments}

- The mediastinum is the most common site of extragonadal germ cell tumors in adults: approximately $15 \%$ of all primary mediastinal tumors in adults are germ cell tumors.

- Twenty-five percent of all primary mediastinal tumors in the pediatric age group are germ cell tumors [64].

- Most germ cell tumors arise in the anterior mediastinum near the thymus gland.

- Most patients with mediastinal germ cell tumors are male and in the third decade of their life, except for mature teratomas (benign germ cell tumors) whose male:female ratio is about equal.

- The majority of all mediastinal germ cell tumors are benign teratomas. The prognosis for malignant nonseminomatous germ cell tumors is poor.

- Morphologically, primary mediastinal germ cell tumors are practically identical to their counterparts in the male and female gonads.

\section{Caution}

Mediastinal metastases from a primary germ cell tumor of the gonads must always be excluded by clinical and radiographic examination of the testes/ovaries and retroperitoneal lymph nodes, and the patient's history.

\subsection{Teratoma}

- Mature teratomas are predominantly cystic (Fig. 2.91). They are composed of tissue elements usually derived from all three germ layers.

- Immature teratomas occur extremely rarely in the mediastinum and are particularly characterized by the presence of immature squamous cells and mesenchymal cells. 
O Fine-needle aspiration usually contains cells of ectodermal origin (squamous cells, sebaceous cells, squamous epithelium detritus). Calcification and a granulomatous response to keratin including foreign body giant cells are common.

\subsection{Seminoma (Germinoma)}

[3, 15, 45, 58] (Fig. 12.38)

Seminoma in the mediastinum occurs nearly exclusively in men and is the most common malignant germ cell tumor at this site. Seminomas have a better prognosis compared to other malignant germ cell tumors of the mediastinum because they are highly sensitive to radiation therapy.

\section{Microscopic Features}

O Highly cellular smears are composed of a dual cell population. Large monomorphic tumor cells are obviously malignant with minor evidence of intercellular cohesion. They are interspersed with mature and reactive lymphocytes including mature plasma cells.

o Malignant cells show large vesicular, hyperchromatic nuclei with membrane irregularities and one or multiple prominent nucleoli.

O The cytoplasm is usually scant, comprising a well-defined border and intermittent double-contour and thickenings.

O Naked nuclei and necrosis are rather frequent. The latter effects a so-called tigroid background.

O The granulomatous tissue reaction including histiocytic multinucleated giant cells may be present.

\section{Caution}

Syncytiotrophoblast-like multinucleated giant cells of histiocytic origin should not mislead the cytopathologist to a diagnosis of choriocarcinoma. Syncytiotrophoblasts are immunocytochemically positive for $\beta$-human chorionic gonadotropin and giant cells of histiocytic origin exhibit CD68 antigen.

\section{Differential Diagnosis and Immunocytochemistry}

\section{$[15,28,45]$}

- Placental alkaline phosphatase (PLAP) is a reliable immunomarker for germinoma on cytological preparations (Fig. 12.38D).

- The dual cell component of seminoma may give the impression of thymoma as well as of undifferentiated largecell carcinomas metastatic to mediastinal lymph nodes. Thymoma cells generally exhibit a completely different morphology compared with seminoma cells, and their lymphoid component lacks plasma cells.

Immunocytochemistry: thymoma as well as metastatic carcinoma cells show positivity for cytokeratins, but antibodies against cytokeratins rarely stain seminomatous cells positive. PLAP is definitely not expressed in neoplastic thymoma and carcinoma cells.
- Non-Hodgkin lymphoma of the large-cell type is a major challenge in the differential diagnosis with seminoma, particularly in cases of lymphoma with a tendency to cellular cohesion. Large-cell lymphoma with a reactive hyperplastic population of T-lineage lymphocytes should not exhibit plasma cells.

In cytomorphologically equivocal cases, immunocytochemistry is of major help: large-cell lymphoma cells are usually positive for CD45 and in most cases for Bcell markers. Positive immunoreaction for leukocyte/lymphocytic markers is definitely absent in germinomatous cells.

\section{4.3.6.3 Embryonal Carcinoma, Yolk Sac Tumor, Choriocarcinoma [2, 15, 57, 58]}

These variants of germ cell tumors rarely arise in the mediastinum. Microscopic and immunocytochemical characteristics of these entities are provided in Sect. 12.3.7, "Germ Cell Tumors," p. 784, and Table 12.3.2, respectively (Figs. 2.104, $12.39,12.40)$.

\subsubsection{Benign and Malignant Lymphoid Disorders in Mediastinal Lymph Nodes and Thymus (see also Chap. 15, p. 905)}

\subsection{Angiofollicular Hyperplasia}

(Castleman Disease) (Fig. 15.38)

- Angiofollicular hyperplasia is a benign lesion that may develop at a single site (in particular in the mediastinum) or throughout the body.

- The lesion in the mediastinum usually presents as a large single mass and may resemble thymoma to a certain extent.

- Castleman disease occurs in lymphoid organs and involves hyperproliferation of $\mathrm{B}$ lymphocytes including plasma cells, vessels, and endothelial cells [12, 40, 63].

- The hyaline vascular variant of this lymphoid hyperplastic process is much more common compared to the plasma cell variant. The latter accounts for only about $10 \%$ of all cases.

\section{Microscopic Features and Differential Diagnosis}

O A polymorphous lymphoid population is encountered: predominantly small mature lymphocytes (B and $\mathrm{T}$ phenotype) as well as eosinophils, follicle center cells (including immunoblasts), and plasma cells.

O Furthermore, large atypical histiocytoid cells (follicular dendritic cells) are encountered, showing ill-defined cytoplasm and enlarged nuclei with a distinctly irregular outline or crumpled appearance, granular to coarse chromatin, and nucleoli $[49,52,100]$. These cells may be clustered and concentrically arranged, resembling Hassall thymoma corpuscles. Occurring in an isolated 
manner, they may cause confusion with Hodgkin or Reed-Sternberg cells. Immunocytochemical stains demonstrate no positivity for cytokeratins.

O The plasma cell type of angiofollicular hyperplasia may be characterized by sheets of plasma cells and many follicle center cells originating from large germinal centers. Plasmacytoma has to be excluded in this morphologic setting.

\subsection{Hodgkin Lymphoma}

[9, 28] (Figs. 2.105 and 2.106)

Hodgkin lymphoma may arise in the thymus or in mediastinal lymph nodes. The lesion most frequently affects young female patients.

\section{Histologic and Cytologic Features}

Hodgkin lymphoma may exhibit particular histological features characteristic for Hodgkin lymphoma at this site [50]:

1. Cystic changes occasionally occur, and in rare instances cysts predominate.

2. Areas of the lymphoid tumor tissue may be interspersed with hyperplastic remnants of the thymus gland (squamous epithelial cells, ciliated epithelium, Hassall corpuscles).

3. Most cases of mediastinal Hodgkin lymphoma are of the nodular sclerosing subtype (Fig. 2.106).

Cytology

O Cytological specimens are frequently sparsely cellular due to tumor sclerosis.

O The lymphoid cell population is polymorphous. The vast majority of cells are small lymphocytes intermingled with atypical lymphoid elements comprising enlarged irregular nuclei (wrinkled and molded), hyperchromasia, pronounced nucleoli, and indistinct cytoplasm. These atypical lymphoid cells may be difficult to separate from true mononuclear Hodgkin cells.

O Reed-Sternberg cells establish a definite diagnosis for Hodgkin lymphoma. However, the cells may occur extremely rarely and need to be carefully searched for. Typical Reed-Sternberg cells are huge and present with two large, mirror-image nuclei that contain redcolored, comma-shaped nucleoli. The chromatin is slightly hyperchromatic, finely granular, densely packed, and evenly distributed throughout the whole nucleus.

O Plasma cells, eosinophils, and histiocytes commonly occur together with the lymphoid population.

○ Epithelioid cell granulomatosis occasionally is marked.

\section{Differential Diagnosis and Immunocytochemistry}

- Hodgkin cells and Reed-Sternberg cells show pathognomonic immunopositivity for CD30, CD15, and PAX5.

- Malignant germ cell tumors and metastatic pleomorphic carcinoma are two neoplasms composed of huge tumor cells mimicking Hodgkin cells and Reed-Sternberg cells. Syncytiotrophoblasts from choriocarcinomatous components in germ cell tumors generally show multiple nuclei and are immunocytochemically positive for human chorionic gonadotropin. Carcinoma cells show positivity for cytokeratins and epithelial antigens.

\section{Caution}

- Cyst fluid from cystic degenerating Hodgkin lymphomas is usually clear and contains a nonspecific cell population. Distinguishing them from other cystic lesions of the mediastinum is difficult.

- Reed-Sternberg cells may be rare in aspirates from mediastinal Hodgkin lymphoma, they have to be searched for carefully in all cytologic smears.

- Furthermore, an overall pattern corresponding to an inflammatory infiltrate may indicate Hodgkin disease; but the finding is definitely not diagnostic if the specific HRS cells are absent.

- Aspirates from a mediastinal mass showing only a granulomatous component including a loose infiltrate of mixed and polymorphous lymphoid cells should always raise suspicions of Hodgkin lymphoma and call for advanced investigations.

\subsection{Non-Hodgkin Lymphomas}

\section{Lymphoblastic Lymphoma (Fig. 15.43)}

Cells of this high-grade malignant lymphoma usually exhibit the T-cell immunophenotype. Lymphoblastic lymphoma is the most common malignant lymphoma in children and young adults (particularly in males) and concomitantly a rather common cause of mediastinal mass in this age group [95]. A majority of the tumors arises in the thymus. Acute T-cell leukemia may occur during the course of the disease.

\section{Microscopic Features}

O Cellular smears are composed of monotonous-appearing lymphoblasts. The tumor cells are about twice the size of small benign lymphocytes.

O Hallmarks: Nuclei usually show characteristic indentations and grooves and a granular and powdery chromatin. Small blasts have inconspicuous nucleoli, whereas medium-sized blasts show variably prominent nucleoli. The cytoplasm displays a small but distinct rim.

0 The mitotic rate is high.

O Background necrosis and a focal starry-sky pattern may occasionally be pronounced.

○ Epithelial thymic fragments including residual Hassall corpuscles may be encountered in fine-needle aspirates, especially in lymphomas infiltrating the thymus [115].

\section{Differential Diagnosis}

Lymphocyte-rich thymoma could be misdiagnosed as lymphoblastic lymphoma. This is a challenging differential diag- 
nosis, particularly in cases where the tumor cells are intermingled with residual thymic epithelial components. But the typical appearance of the neoplastic lymphoblasts and the clinical features should provide enough evidence for a correct diagnosis.

\section{Large-Cell Non-Hodgkin Lymphoma} [89, 96] (Figs. 2.107 and 2.108)

Large-cell non-Hodgkin lymphoma of the mediastinum represents in most cases a distinct tumor entity arising from a native thymic B-cell population, unless mediastinal involvement is part of a systemic malignant lymphoid disorder. The primary mediastinal disorder occurs typically in a young adult patient group with a female preponderance [95] and suggests a more favorable course than that of diffuse large B-cell lymphoma [89].

\section{Microscopic Features [36, 37, 93]}

$\bigcirc$ The aspirates are usually highly cellular, composed of predominantly large atypical lymphocytes scattered throughout the smear; small cleaved atypical lymphocytes tend to be intermingled in a varying number.

$\bigcirc$ The nuclei are often cleaved and lobulated. Hyperlobulation may be pronounced.

O The chromatin is vesicular.

$\bigcirc$ The nucleoli are prominent and sporadically huge, occurring singly or multiply.

O The N/C ratio varies strongly within the same tumor. The cytoplasms often display basophilia using the May-Grünwald-Giemsa staining procedure and related staining methods.

O Fragments of sclerotic tissue and spindle mesenchymal cells are observed in cases associated with pronounced tumor sclerosis. Accordingly, the specimens tend to paucity of cells.

\section{Differential Diagnosis and Immunocytochemistry}

\section{$[28,93,115]$}

- Paucity of cells due to strong tumor sclerosis may:

- lead to a false-negative diagnosis.

- suspect spindle cell neoplasia such as soft tissue sarcoma, nerve sheath tumors, spindle-cell thymoma, spindle-cell melanoma. All these tumor entities express tissue-typical markers but not CD45.

- lead to erroneous interpretation of individual large lymphoid tumor cells as (1) large epithelial cells from a thymoma (immunocytochemistry of neoplastic thymic epithelium: see Sect. 2.4.3.4.4, p. 211), (2) undifferentiated carcinoma cells (CKs +), or (3) Hodgkin/ Reed-Sternberg cells (CD15, CD30, and PAX5 +).

- The immunoblastic-like variant of large-cell lymphoma can appear quite similar to Hodgkin lymphoma. However, the background of small lymphocytes is different when comparing the two entities. Hodgkin lymphoma yields much fewer large tumor cells on FNAB samples compared to large cell non-Hodgkin lymphoma.

- A pseudo-dual cell pattern composed of large and small malignant lymphoma cells may be misinterpreted as germinoma. However, the morphological features of small lymphoid cells and immunocytochemical reactivities are completely different between the two tumor entities: germinoma cells exhibit PLAP, large lymphoid tumor cells are positive for $\mathrm{CD} 45$.

- Cohesive cell grouping in specimens of non-Hodgkin lymphoma may be confused with thymic carcinoma or metastatic carcinoma (Fig. 2.107).

- Residual thymic epithelial tissue enmeshed in a malignant lymphoid cell population can lead to a false diagnosis of thymoma.

- Immunocytochemical and flow cytometric immunophenotyping have been shown to be helpful as an ancillary investigation supporting the diagnosis of malignant lymphoma. Cytogenetic studies are mandatory when morphologic and immunophenotyping results are not conclusive.

\section{Caution}

Cytomorphology and immunophenotyping are complemental investigations in order to distinguish between reactive lymphoid lesions and malignant lymphomas of the mediastinum. But the limitations of these two basic tests should always be remembered regarding:

- FNAB samples with limited cellularity.

- Partial tumor infiltration of a lymph node or of an organ with an important benign lymphoid proportion.

- Hodgkin lymphoma comprising a strong reactive lymphoid background together with a poor specific tumor cell fraction.

- Malignant lymphomas of the T-cell phenotype.

\subsubsection{Neurogenic Tumors and Mesenchymal Tumors}

- Neurogenic tumors are the most common neoplasias arising in the posterior mediastinum. Nerve sheath tumors and paragangliomas are more frequent in the adult patient group, whereas tumors of the sympathetic nervous system are frequently encountered in children.

- Any mesenchymal tumor may arise in the mediastinal soft tissue (Fig. 2.109). Only a few cases are on record concerning cytological investigation using fine needle aspirates. Benign mesenchymal lesions comprise, among others, lipomas, hemangiomas, and lymphangiomas [16]. Primary sarcomas are rare; however, a few case reports on FNAB of liposarcoma are available in the literature [28, $59,73,94]$. 
- A variety of information on diagnosis, differential diagnoses, and ancillary studies of the varied spindle cell lesions in FNAB samples are given in comprehensive publications by Geisinger [28], and Slagel and coauthors [94].

\subsubsection{Tumors of the Peripheral Nervous System} (Figs. 17.14-17.17)

The tumor group includes neurofibroma as well as benign and malignant schwannoma. The tumors are characterized by spindle-shaped cells; hence, the differential diagnosis includes a wide variety of benign and neoplastic conditions known to occur as primary or secondary tumors in the mediastinum. The morphologic features and immunocytochemical markers for schwannomas are reported in Sects. 12.3.4.3, "Schwannoma," p. 781, and 12.3.5.1.3, "Malignant Nerve Sheath Tumor," p. 783, respectively.

\subsubsection{Paraganglioma (Figs. 5.73 and 12.28)}

Paraganglia are clusters of neuroendocrine cells associated with the sympathetic and parasympathetic nervous system. They are located throughout the body at various sites. Tumors arising from these cells are referred to as paraganglioma, pheochromocytoma, carotid body tumor, and others. Adrenal medulla is one of the major locations of this neoplasm. Cytomorphology and differential diagnosis challenges of pheochromocytoma (Fig. 12.28) and carotid body paraganglioma (Fig. 5.73) are highlighted in Sects. 12.2.3.3.1, p. 769, and 5.2.6.2, p. 467, of this book, and in a recent study by Varma and coauthors [104].

\subsubsection{Tumors of the Sympathetic Nervous System}

The tumors are derived from non-chromaffin cells and include neuroblastoma, ganglioneuroblastoma (Fig. 2.110), and ganglioneuroma (Fig. 2.111). The three tumor entities together with differential diagnosis considerations are described in Sects. 12.2.3.3.2, p. 769, and 12.1.10.2.2, "Wilms Tumor," p. 743, respectively.

\subsubsection{Miscellaneous Lesions}

\subsubsection{Thymolipoma}

Thymolipoma usually appears as a large anterior mediastinal mass with a predilection in adolescents and young adults. The histogenesis of this benign disorder is not yet clear; it may possibly be caused by a precedent thymic hyperplasia.

$O$ FNAB specimens contain normal thymic cells, tissue fragments of epithelial (including Hassall corpuscles) and lymphatic origin, and mature adipose tissue.

The lesions must be distinguished from true lipomatous tumors [86].

\subsubsection{Thyroid and Parathyroid Tissue (Fig. 2.94)}

Thyroid and parathyroid tissue may be found in the superior/ anterior mediastinum as a primary ectopic lesion, a lesion extending from the cervical area into the mediastinal space, or a metastatic neoplasm. Goiters [88], thyroid cysts, parathyroid cyst [75], and parathyroid neoplasms [69] are among the most frequently diagnosed disorders on FNAB samples.

\subsubsection{Metastases to the Thymus and Mediastinum (Figs. 2.112-2.115)}

The thymus gland, mediastinal lymph nodes, and the mediastinal space can be affected by metastatic cancer. Metastases are the most common intrathoracic/extrapulmonary lesions diagnosed by FNAB. Tumor dissemination may occur by lymphogenic and hematogenic spreading, or by direct extension from adjacent structures and organs. Thymic and mediastinal metastasis is an indicator for generalized malignant disease. The most common source of mediastinal metastases is the lung, particularly small-cell carcinoma [28]. Breast, thyroid, head and neck tumors, malignant melanoma, and others are additional sources.

\section{Caution}

Trivial solid ectopic epithelial tissue should not be misinterpreted as metastasis in FNAB samples. 


\subsubsection{Further Reading}

1. Adler OB, Rosenberger A, Peleg H. Fine-needle aspiration biopsy of mediastinal masses: evaluation of 136 experiences. AJR 1983;140:893-896.

2. Afroz N, Khan N, Chana RS. Cytodiagnosis of yolk sac tumor. Indian J Pediatr 2004;71:939-942.

3. Akhtar M, Ali MA, Hug M, Bakry M. Fine-needle aspiration biopsy of seminoma and dysgerminoma: cytologic, histologic, and electron microscopic correlations. Diagn Cytopathol 1990;6:99105.

4. Ali SZ, Erozan YS. Thymoma. Cytopathologic features and differential diagnosis on fine needle aspiration. Acta Cytol 1998;42:845854.

5. Alsharif M, Andrade RS, Stelow EB, et al. Endobronchial ultrasound-guided (EBUS) transbronchial fine needle aspiration (FNA): The University of Minnesota initial experience. Cancer(Cancer Cytopathol) 2007; Suppl 111:408-409.

6. Assaad MW, Pantanowitz L, Otis CN. Diagnostic accuracy of image-guided percutaneous fine needle aspiration biopsy of the mediastinum. Diagn Cytopathol 2007;35:705-709.

7. Baba M, Nomoto Y, Iyoda A, et al. Cytomorphologic features characteristic of tumor stages of thymomas. Oncol Rep 2001;8:11391143.

8. Bavi P, Shet T, Gujral S. Malignant melanoma of mediastinum misdiagnosed as a spindle cell thymoma in a fine needle aspirate: a case report. Acta Cytol 2005;49:424-426.

9. Bergh NP, Gatzinsky P, Larsson S, et al. Tumors of the thymus and thymic region: II Clinicopathological studies on Hodgkin's disease of the thymus. Ann Thorac Surg 1978;25:99-106.

10. Binek J, Abraham D, Borovicka J , Spieler P, et al. Endosonographic guided fine needle aspiration (EUS-FNA) in mediastinal and abdominal lesions: accuracy and patients tolerance. Gut 2004;53 (Suppl VI):A42.

11. Boecking A, Klose KC, Kyll HJ, Hauptmann S. Cytologic versus histologic evaluation of needle biopsy of the lung, hilum and mediastinum: sensitivity, specificity and typing accuracy. Acta Cytol 1995;39:463-471.

12. Castleman B, Iverson L, Menendez VP. Localized mediastinal lymph node hyperplasia resembling thymoma. Cancer 1956;9: 822-30.

13. Catalano MF, Rosenblatt ML, Chak A, et al. Endoscopic ultrasound-guided fine needle aspiration in the diagnosis of mediastinal masses of unknown origin. Am J Gastroenterol 2002;97:25592565.

14. Chhieng DC, Rose D, Ludwig ME, Zakowski MF. Cytology of thymomas: emphasis on morphology and correlation with histologic subtypes. Cancer 2000;25:90:24-32.

15. Chhieng DC, Lin O, Moran CA, et al. Fine-needle aspiration biopsy of nonteratomatous germ cell tumors of the mediastinum. Am J Clin Pathol 2002;118:418-424.

16. Coffing B, Gutmann EJ. Lymphangioma of the posterior mediastinum in an adult: diagnosis via cytopathologist-assisted fine-needle aspiration biopsy with cell block. Diagn Cytopathol 2005;33:412415.

17. Dehner LP. Germ cell tumors of the mediastinum. Semin Diagn Pathol 1990;7:266-284.

18. Dorfman DM, Shahsafaei A, Chan JK. Thymic carcinomas, but not thymomas and carcinomas of other sites, show CD5 immunoreactivity. Am J Surg Pathol 1997;21:936-940.

19. Eloubeidi MA, Cohn M, Cerfolio RJ, et al. Endoscopic ultrasoundguided fine-needle aspiration in the diagnosis of foregut duplication cysts: the value of demonstrating detached ciliary tufts in cyst fluid. Cancer 2004;102:253-258.

20. Emery SC, Savides TJ, Behling CA. Utility of immediate evaluation of endoscopic ultrasound-guided transesophageal fine needle aspiration of mediastinal lymph nodes. Acta Cytol 2004;48:630634.
21. Fernandez-Esparrach G, Gines A, Belda J, et al. Transesophageal ultrasound-guided fine needle aspiration improves mediastinal staging in patients with non-small cell lung cancer and normal mediastinum on computed tomography. Lung Cancer 2006;54:35-40.

22. Finley JL, Silverman JF, Strausbauch PH, et al. Malignant thymic neoplasms: diagnosis by fine-needle aspiration biopsy with histologic, immunocytochemical, and ultrastructural confirmation. Diagn Cytopathol 1986;2:118-125.

23. Flannery MT, Espino M, Altus P, et al. Hodgkin's disease masquerading as sclerosing mediastinitis. South Med J 1994;87:921-923.

24. Flieder DB, Suster S, Moran CA. Idiopathic fibroinflammatory (fibrosing/sclerosing) lesions of the mediastinum: a study of 30 cases with emphasis on morphologic heterogeneity. Mod Pathol 1999;12:257-264.

25. Friedman HD, Hutchison RE, Kohman LJ, Powers CN. Thymoma mimicking lymphoblastic lymphoma: a pitfall in fine-needle aspiration biopsy interpretation. Diagn Cytopathol 1996;14:165-169.

26. Fujii Y, Okumura M, Yamamoto S. Flow cytometric study of lymphocytes associated with thymoma and other thymic tumors. J Surg Res 1999;82:312-318.

27. Geisinger KR. Differential diagnostic considerations and potential pitfalls in fine-needle aspiration biopsies of the mediastinum. Diagn Cytopathol 1995;13:436-442.

28. Gatzimos KR, Moriarty AT, Pingleton JM, Mc Closkey DW. Diagnosis of metastatic thymoma using flow cytometry. Pathobiology 1992;60:168-172.

29. Goel D, Prayaga AK, Sundaram Challa, et al. Utility of fine needle aspiration cytology in mediastinal lesions. A clinicopathologic study of 161 cases from a single institution. Acta Cytol 2008;52:404411.

30. Goldstein G, Abbot A, Mackay IR. An electron microscopic study of the human thymus: Normal appearances and findings in myasthenia gravis and systemic lupus erythematosus. J Pathol 1968;95:211-215.

31. Gulati M, Venkataramu NK, Gupta S, et al. Ultrasound guided fine needle aspiration biopsy in mediastinal tuberculosis. Int $\mathrm{J}$ Tuberc Lung Dis 2000;4:1164-1168.

32. Hall DA, Pu RT, Pang Y. Diagnosis of foregut and tailgut cysts by endosonographically guided fine-needle aspiration. Diagn Cytopathol 2007;35:43-46.

33. Hartmann CA, Roth C, Minck C, Niedobitek G. Thymic carcinoma. Report of five cases and review of the literature. J Cancer Res Clin Oncol 1990;116:69-82.

34. Herman SJ, Holub RV, Weisbrod GL, et al. Anterior mediastinal masses: Utility of transthoracic needle biopsy. Radiology 1991;180:167-170.

35. Herth FJ, Eberhardt R, Vilmann P, et al. Real-time endobronchial ultrasound guided transbronchial needle aspiration for sampling mediastinal lymph nodes. Thorax 2006;61:795-798.

36. Hoda RS, Picklesimer L, Green KM, Self S. Fine-needle aspiration of a primary mediastinal large B-cell lymphoma: a case report with cytologic, histologic, and flow cytometric considerations. Diagn Cytopathol 2005;32:370-373.

37. Hughes JH, Katz RL, Fonseca GA, Cabanillas FF. Fine-needle aspiration cytology of mediastinal non-Hodgkin's nonlymphoblastic lymphoma. Cancer 1998;84:26-35.

38. Inoue $\mathrm{M}$, Starostik P, Zettl A, et al. Correlating genetic aberrations with World Health Organization-defined histology and stage across the spectrum of thymomas. Cancer Res 2003;63:3708-3715.

39. Johnson S, Eng TY, Giaccone G, Thomas CR Jr. Thymoma: update for the new millennium. Oncologist 2001;6:239-246.

40. Kardziev B, Hotzel B, Jachmann M. The angiofollicular lymph node hyperplasia Castleman - casuistic and review of the literature. Pneumologie 2006;60:229-234.

41. Kramer H, Sanders J, Post WJ, et al. Analysis of cytological specimens from mediastinal lesions obtained by endoscopic ultrasoundguided fine-needle aspiration. Cancer(Cancer Cytopathol) 2006;108:206-211. 
42. Kramer H, van Putten JW, Post WJ, et al. Oesophageal endoscopic ultrasound with fine needle aspiration improves and simplifies the staging of lung cancer. Thorax 2004;59:596-601.

43. Kuhlman JE, Fishman EK, Wang KP, et al. Mediastinal cysts: diagnosis by CT and needle aspiration. Am J Roentgenol 1988;150:7578.

44. Kumar PV, Ashraf MJ, Safaei A, et al. Fine needle aspiration diagnosis of bronchogenic cysts. Acta Cytol 2001;45:656-658.

45. Kwon MS. Aspiration cytology of mediastinal seminoma: report of a case with emphasis on the diagnostic role of aspiration cytology, cell block and immunocytochemistry. Acta Cytol 2005;49:669672.

46. Lara PN Jr. Malignant thymoma: current status and future directions. Cancer Treat Rev 2000;26:127-131.

47. Levine GD, Rosai J. A spindle cell variant of thymic carcinoid. A clinical, histologic and fine structural study with emphasis on its distinction from spindle cell thymoma. Arch Pathol 1976;100:293300.

48. Lewis JE, Wick MR, Scheithauer BW, et al. Thymoma: A clinicopathologic review. Cancer 1987;60:2727-2743.

49. Mallik MK, Kapila K, Das DK, et al. Cytomorphology of hyalinevascular Castleman's disease: a diagnostic challenge. Cytopathology 2007;18:168-174.

50. Marchevsky AM, Kaneko M. Surgical Pathology of the Mediastinum. Raven Press, New York 1984.

51. Matsuura B, Tokunaga H, Miyake T, et al. A case of malignant thymoma mimicking thyroid carcinoma: a pitfall in fine-needle aspiration. Endocr J 2004;51:237-241.

52. Meyer L, Gibbons D, Ashfaq R, et al. Fine-needle aspiration findings in Castleman's disease. Diagn Cytopathol 1999;21:57-60.

53. Micames CG, McCrory DC, Pavey DA, et al. Endoscopic ultrasound-guided fine-needle aspiration for non-small cell lung cancer staging: A systematic review and metaanalysis. Chest 2007;131:539548.

54. Milde P, Sidawy MK. Thymoma presenting as a palpable thyroid nodule: a pitfall in fine needle aspiration (FNA) of the neck. Cytopathology 1999;10:415-419.

55. Mole TM, Glover J, Sheppard MN. Sclerosing mediastinitis: a report on 18 cases. Thorax 1995;50:280-283.

56. Moran CA, Suster S. Thymic carcinoma: current concepts and histologic features. Hematol Oncol Clin North Am 2008;22:393-407.

57. Moran CA, Suster S, Koss MN. Primary germ cell tumors of the mediastinum: III. Yolk sac tumor, embryonal carcinoma, choriocarcinoma, and combined nonteratomatous germ cell tumors of the mediastinum - a clinicopathologic and immunohistochemical study of 64 cases. Cancer 1997;80:699-707.

58. Motoyama T, Yamamoto O, Iwamoto H, Watanabe H. Fine needle aspiration cytology of primary mediastinal germ cell tumors. Acta Cytol 1995;39:725-732.

59. Munjal K, Pancholi V, Rege J, et al. Fine needle aspiration cytology in mediastinal myxoid liposarcoma: a case report. Acta Cytol 2007;51:456-458.

60. Myers PO, Kritikos N, Bongiovanni M, et al. Primary intrapulmonary thymoma: a systematic review. Eur J Surg Oncol 2007;33:11371141.

61. Nakagawa K, Matsuno Y, Kunitoh H, et al. Immunohistochemical KIT (CD117) expression in thymic epithelial tumors. Chest 2005;128:140-144.

62. Nakajima J, Takamoto S, Oka T, et al. Flow cytometric analysis of lymphoid cells in thymic epithelial neoplasms. Eur J Cardiothorac Surg 2000;18:287-292.

63. Newlon JL, Couch M, Brennan J. Castleman's disease: three case reports and a review of the literature. Ear Nose Throat $\mathbf{J}$ 2007;86:414-418.

64. Nichols CR. Mediastinal germ cell tumors: Clinical features and biological correlates. Chest 1991;99:472-479.
65. Nichols GL Jr., Hopkins III MB, Geisinger KR. Thymic carcinoid. Report of a case with diagnosis by fine needle aspiration biopsy. Acta Cytol 1997;41:1839-1844.

66. Nonaka D, Henley JD, Chiriboga L, Yee H. Diagnostic utility of thymic epithelial markers CD205 (DEC205) and Foxn1 in thymic epithelial neoplasms. Am J Surg Pathol 2007;31:1038-1044.

67. Oertel YC. Thymoma mimicking thyroid papillary carcinoma: another pitfall in fine-needle aspiration. Diagn Cytopathol 1997;17:6163.

68. Ogita S, Robbins DH, Blum RH, Harris LJ. Endoscopic ultrasound fine-needle aspiration in the staging of non-small-cell lung cancer. Oncology(Williston Park) 2006;20:1419-1425.

69. Okazaki M, Matsumoto H, Tomioka H, et al. A case of mediastinal parathyroid adenoma diagnosed by transtracheal needle aspiration. Nihon Kyobu Shikkan Gakkai Zasshi 1994;32:1104-1108.

70. Okumura M, Fujii Y, Miyoshi S, et al. Three-color flow cytometric study on lymphocytes derived from thymic diseases. J Surg Res 2001;101:130-137.

71. Okumura M, Shiono H, Minami M, et al. Clinical and pathological aspects of thymic epithelial tumors. Gen Thorac Cardiovasc Surg 2008;56:10-16.

72. Oliveira AM, Tazelaar HD, Myers JL, et al. Thyroid transcription factor- distinguishes metastatic pulmonary from well-differentiated neuroendocrine tumors of other sites. Am J Surg Pathol 2001;25:815-819.

73. Pant I, Kaur G, Joshi SC, Khalid IA. Myxoid liposarcoma of the breast in a 25-year-old female as a diagnostic pitfall in fine needle aspiration cytology: report of a rare case. Diagn Cytopathol 2008;36:674-677.

74. Pantidou A, Kiziridou A, Antoniadis T, et al. Mediastinum thymoma diagnosed by FNA and ThinPrep technique: a case report. Diagn Cytopathol 2006;34:37-40.

75. Petri N, Holten I. Parathyroid cyst: Report of a case in the mediastinum. J Laryngol Otol 1990;104:56-57.

76. Pinto MM, Dovgan D, Kaye AD, Chinniah A. Fine needle aspiration for diagnosing a thymoma producing CA-125. A case report. Acta Cytol 1993;37:929-932.

77. Pomplun S, Wotherspoon AC, Shah G, et al. Immunohistochemical markers in the differentiation of thymic and pulmonary neoplasms. Histopathology 2002;40:152-158.

78. Ponder TB, Collins BT, Bee CS, et al. Diagnosis of cervical thymoma by fine needle aspiration biopsy with flow cytometry. A case report. Acta Cytol 2002;46:1129-1132.

79. Posligua L, Ylagan L. Fine-needle aspiration cytology of thymic basaloid carcinoma: case studies and review of the literature. Diagn Cytopathol 2006;34:358-366.

80. Powers CN, Silverman JF, Geisinger KR, Frable WJ. Fine-needle aspiration biopsy of the mediastinum. A multi-institutional analysis. Am J Clin Pathol 1996;105:168-173.

81. Priola AM, Priola SM, Cataldi A, et al. CT-guided percutaneous transthoracic biopsy in the diagnosis of mediastinal masses: evaluation of 73 procedures. Radiol Med(Torino) 2008;113:3-15.

82. Ragusa M, Avenia N, Fedeli C, et al. Acute mediastinitis: clinical features and review of a case load. Chir Ital 2003;55:519-524.

83. Renshaw AA, Haja JC, Neal MH, et al. Distinguishing carcinoid tumor of the mediastinum from thymoma. Correlating cytologic features and performance in the College of American Pathologists Interlaboratory Comparison Program in Nongynecologic Cytopathology. Arch Pathol Lab Med 2006;130:1612-1615.

84. Riazmontazer N, Bedayat C, Izadi B. Epithelial cytologic atypia in fine needle aspirate of an invasive thymoma. A case report. Acta Cytol 1992;36:387-390.

85. Rintoul RC, Skwarski KM, Murchison JT, et al. Endobronchial and endoscopic ultrasound-guided real-time fine-needle aspiration for mediastinal staging. Eur Respir J 2005;25:416-421. 
86. Romero-Guadarrama MB, Duran-Padilla MA, Cruz-Ortiz H, et al. Diagnosis of thymolipoma with fine needle aspiration biopsy. Report of a case initially misdiagnosed as liposarcoma. Acta Cytol 2004;48:441-446.

87. Salyer DC, Salyer WR, Eggleston JC. Benign developmental cysts of the mediastinum. Arch Pathol Lab Med 1977;101:136139.

88. Sanders LE, Rossi RL, Shahian DM, et al. Mediastinal goiters: The need for an aggressive approach. Arch Surg 1992;127:609613.

89. Savage KJ. Primary mediastinal large B-cell lymphoma. Oncologist 2006;11:488-495.

90. Schowengerdt CG, Suyemoto R, Main FB. Granulomatous and fibrous mediastinitis: A review and analysis of 180 cases. J Thorac Cardiovasc Surg 1969;57:365-379.

91. Schwartz AR, Fishman EK, Wang KP. Diagnosis and treatment of a bronchogenic cyst using transbronchial needle aspiration. Tho$\operatorname{rax} 1986 ; 41: 326-327$.

92. Silverman JF, Finley JL, O'Brien KF, et al. Diagnostic accuracy and role of immediate interpretation of fine-needle aspiration biopsy specimens from various sites. Acta Cytol 1989;33:791-796.

93. Silverman JF, Raab SS, Park HK. Fine-needle aspiration cytology of primary large-cell lymphoma of the mediastinum: cytomorphologic findings with potential pitfalls in diagnosis. Diagn Cytopathol 1993;9:209-214

94. Slagel DD, Powers CN, Melaragno MJ, et al. Spindle cell lesions of the mediastinum: Diagnosis by fine-needle aspiration biopsy. Diagn Cytopathol 1997;17:167-176.

95. Strickler JG, Kurtin PJ. Mediastinal lymphoma. Semin Diagn Pathol 1991;8:2-13

96. Suster S. Primary large-cell lymphomas of the mediastinum. Semin Diagn Pathol 1999;16:51-64.

97. Tangthangtham A, Chonmaitri I, Subhannachart P, Tungsagunwattana S. Fine needle aspiration cytology of thymoma. J Med Assoc Thai 1999;82:1226-1229.

98. Tao LC, Pearson FG, Cooper JD, et al. Cytopathology of thymoma. Acta Cytol 1984;28:165-170.

99. Tateyama H, Eimoto T, Tada T, et al. Immunoreactivity of new CD5 antibody with normal epithelium and malignant tumors including thymic carcinoma. Am J Clin Pathol 1999;111:235-240.

100. Taylor GB, Smeeton IW. Cytologic demonstration of "dysplastic" follicular dendritic cells in a case of hyaline-vascular Castleman's disease. Diagn Cytopathol 2000;22:230-234.

101. Tiffet O, Nicholson AG, Ladas G, et al. A clinicopathologic study of 12 neuroendocrine tumors arising in the thymus. Chest 2004;125:2368-2369.
102. Travis WD, Brambilla E, Muller-Hermelink HK, Harris CC. (Eds.): World Health Organization Classification of Tumours. Pathology and Genetics of Tumours of the Lung, Pleura, Thymus and Heart. IARC Press: Lyon 2004.

103. van Beek FT, Maas KW, Timmer R, et al. Oesophageal endoscopic ultrasound with fine-needle aspiration biopsy in the staging of non-small-cell lung carcinoma; results from 43 patients. Ned Tijdschr Geneeskd 2006;150:144-150.

104. Varma K, Jain S, Mandal S. Cytomorphologic spectrum in paraganglioma. Acta Cytol 2008;52:549-556.

105. Vengrove MA, Schimmel M, Atkinson BF, et al. Invasive cervical thymoma masquerading as a solitary thyroid nodule: Report of a case studied by fine needle aspiration. Acta Cytol 1991;35:431433.

106. Vilmann P, Puri R. The complete "medical" mediastinoscopy (EUS-FNA + EBUS-TBNA). Minerva Med 2007;98:331-338.

107. Wakely PE Jr. Fine needle aspiration in the diagnosis of thymic epithelial neoplasms. Hematol Oncol Clin North Am 2008;22:433442.

108. Wallace WA, Monaghan HM, Salter DM, et al. Endobronchial ultrasound-guided fine-needle aspiration and liquid-based thinlayer cytology. J Clin Pathol 2007;60:388-391.

109. Wang DY, Kuo SH, Chang DB, et al. Fine needle aspiration cytology of thymic carcinoid tumor. Acta Cytol 1995;39:423-427.

110. Wang W, Li K, Qin W, et al. Ectopic pancreas in mediastinum: report of 2 cases and review of the literature. J Thorac Imaging 2007;22:256-258

111. Wiersema MJ, Kochman ML, Cramer HM, Wiersema LM. Preoperative staging of non-small cell lung cancer: transesophageal US-guided fine-needle aspiration biopsy of mediastinal lymph nodes. Radiology 1994;190:239-242.

112. Yang CJ, Cheng MS, Chou SH, et al. Primary germ cell tumors of the mediastinum: 10 years of experience in a tertiary teaching hospital. Kaohsiung J Med Sci 2005;21:395-400.

113. Yasufuku K, Chiyo M, Koh E, et al. Endobronchial ultrasoundguided transbronchial needle aspiration for staging of lung cancer. Lung Cancer 2005;50:347-354.

114. Yokoyama T, Tanahashi M,Tateyama H, et al. Flow-cytometric diagnosis of thymoma using needle biopsy specimens. Surg Today 2003;33:163-168.

115. Yu GH, Salhany KE, Gokaslan ST, et al. Thymic epithelial cells as a diagnostic pitfall in the fine-needle aspiration diagnosis of primary mediastinal lymphoma. Diagn Cytopathol 1997;16:460465. 
Fig. 2.88 Contaminant glandular cells from the needle track.

A 73-year-old woman with a history of both Hodgkin lymphoma and breast carcinoma presented with enlarged mediastinal lymph nodes. Ultrasound-guided transtracheal FNAB of a mediastinal lymph node yielded single cells and clusters from a seromucinous tracheal gland (direct smear, Pap stain, high magnification). There were no malignant cells present.

Erroneous interpretation of benign but activated tracheal/bronchial gland cells may lead to a false diagnosis of carcinoma, such as the clear cell variant, oncocytic variant, or mucoepidermoid variant.

\section{Figs. 2.89 and 2.90 Sarcoidosis.}

Transtracheal FNAB in two patients presenting with enlarged mediastinal lymph nodes. The cytologic samples provided a diagnosis of a granulomatous inflammatory disorder consistent with sarcoidosis.

Fig. 2.89A, B (case \#1) Sarcoidosis in a conventional smear. Cytologic appearance in a direct aspirate smear is demonstrated (Pap stain). A Lower magnification shows a large fragment of granulomatous tissue composed of histiocytes, epithelioid cells, and lymphocytes. Isolated epithelioid cells (bottom) and mucosal goblet cells (arrows) are encountered as well. B High magnification focuses on an asteroid body enclosed in a giant cell of the Langhans type.

Fig. 2.90 (case \#2) Sarcoidosis in a liquid-based specimen. Liquid-based preparation (ThinPrep) of a fine-needle aspirate exhibiting identical morphologic characteristics of an epithelioid granulomatous fragment compared to the conventional smear (Pap stain, higher magnification). 

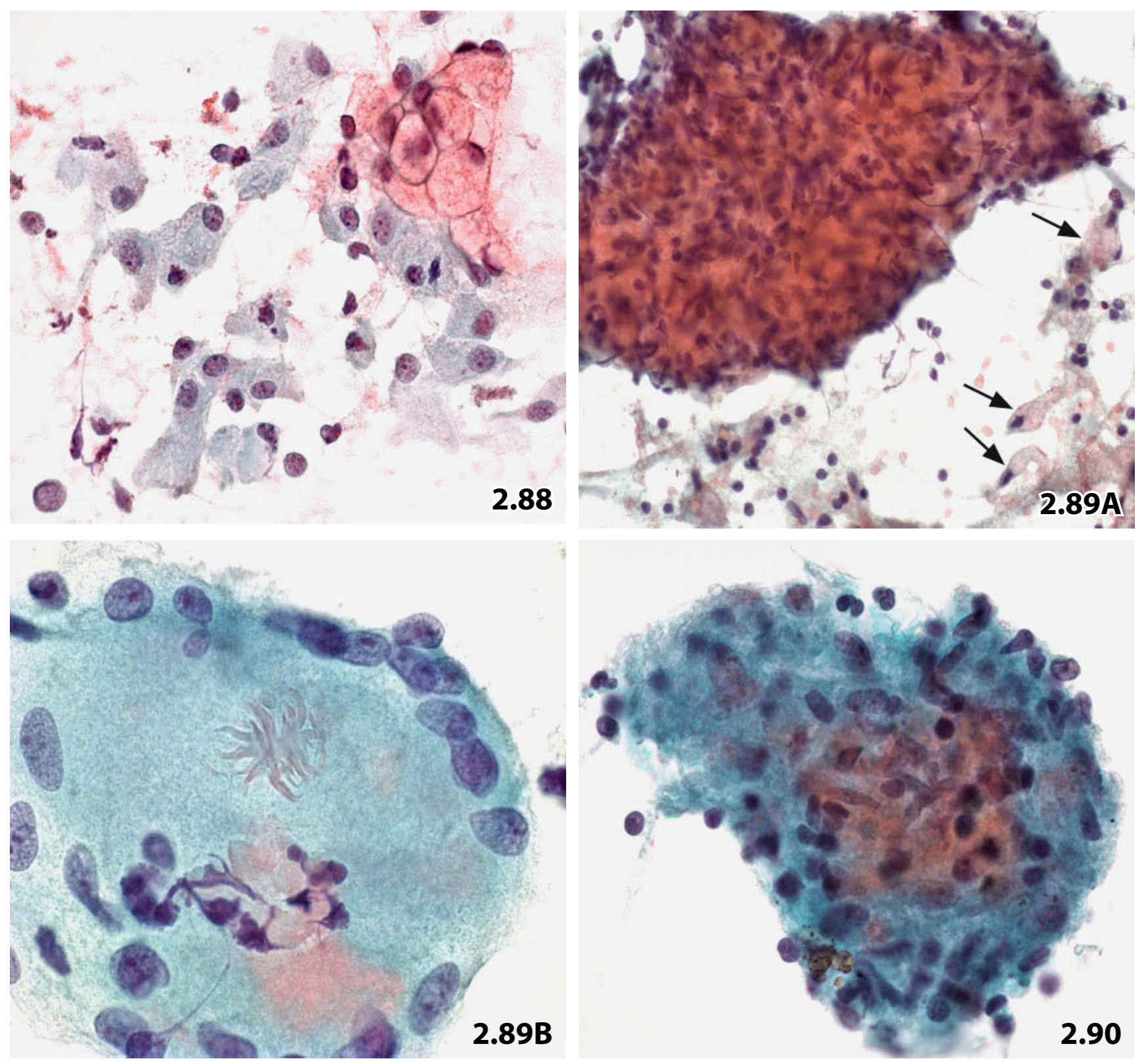
Fig. 2.91 Cystic mature teratoma.

CT-guided transthoracic FNAB of a mediastinal mass in an 11-year-old girl. The aspirated fluid originated from an inflammatory cystic lesion containing a few degenerating keratinized squamous cells (arrows) (direct sediment smear, Pap stain, low magnification).

Cytology: A descriptive diagnosis was made. A more specific diagnosis was not possible.

Tissue diagnosis (excision of the cystic mass): Cystic mature teratoma.

\section{Fig. 2.92 Bronchogenic cyst.}

Transbronchial FNAB of a tumorous lesion located in the posterior mediastinum of a 66-yearold man. Fine-needle aspirate reveals proteinaceous cystic background, well preserved and degenerating columnar cells of the respiratory type, detached ciliary tufts (incompletely focused; arrows), and a few degenerating squamous cells (direct sediment smear, Pap stain, lower magnification).

Tentative cytologic diagnosis: Bronchogenic cyst (confirmed by histology).

Fig. 2.93 Cystic lesion of unclear origin.

Transtracheal FNAB of a mediastinal cystic lesion in a 62-year-old man. Image studies provided no further information. Cyst fluid containing hemosiderophages (arrow) and benign lymphocytes sporadically exhibiting reactive changes (arrowhead). Absence of epithelial cells (direct sediment smear, Pap stain, higher magnification).

Tentative cytologic diagnosis: Cyst content from a nonspecific cystic lesion.

Comment: Lymphocytosis may suspect thoracic duct cyst, but reactive lymphocytes and macrophages do not necessarily support this diagnosis.

Tissue diagnosis (surgical excision of the mediastinal cyst): Benign epithelial cyst.

Caution: reactive lymphoid cells should not lead to an erroneous diagnosis of malignant lymphoma.

\section{Fig. 2.94 Cystic changes in a mediastinal goiter.}

Transthoracic FNAB of a tumor located in the anterior/superior mediastinum of a 48-year-old man. Low magnification shows the classical appearance of a cystic goiter: thyroidal parenchymatous tissue containing small follicles and a background with hemosiderophages (arrows) and colloid masses (direct smear, Pap stain). 


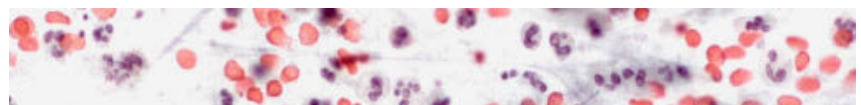
in 00 o.

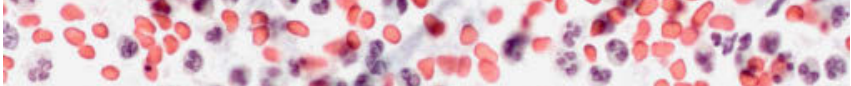

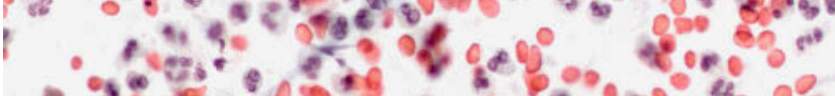

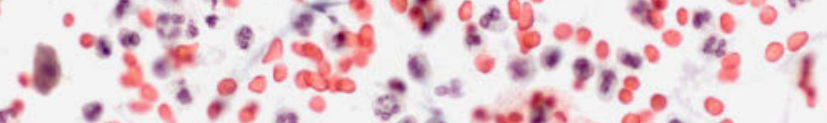

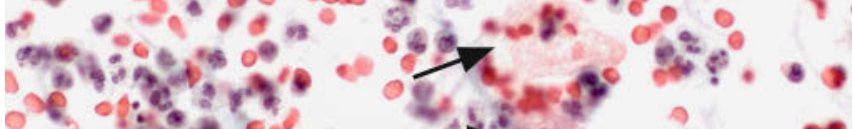
P.

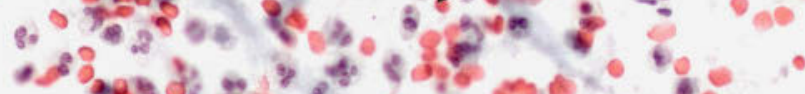

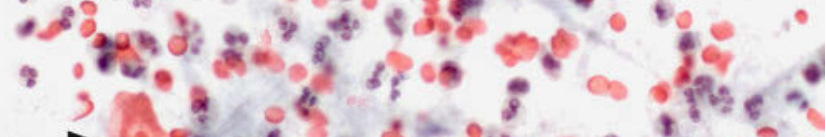

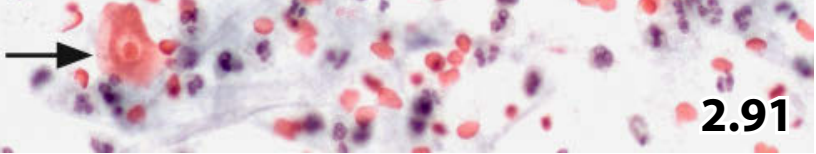
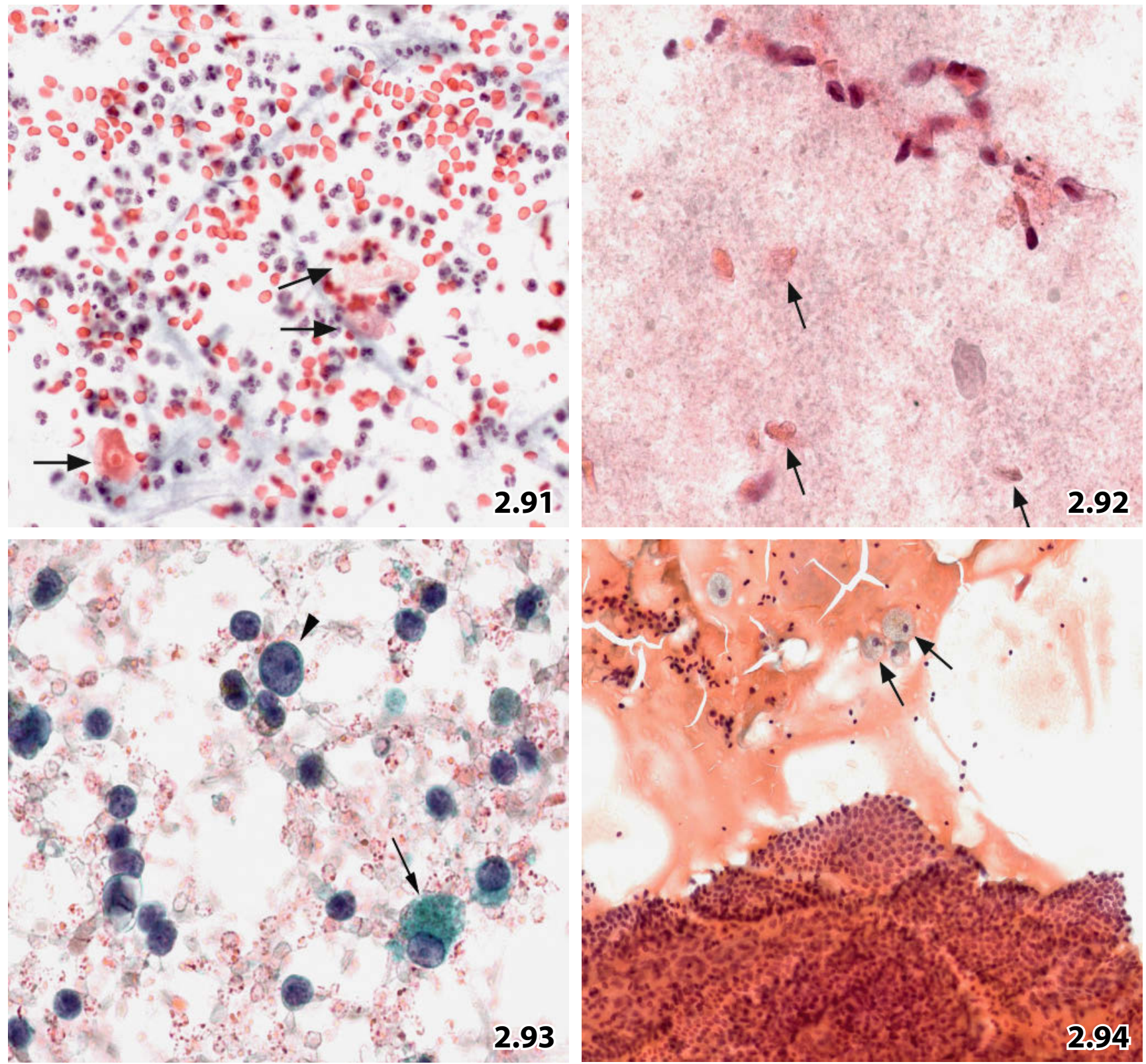
Fig. 2.95A, B Normal thymic gland

Scraping from the medullary zone of the cut surface of a normal thymic gland (Pap stain). A A keratin pearl, so-called Hassall corpuscle is embedded in a lymphoid cell population (high magnification). B Sparsely dispersed and grouped (not in view) epithelial thymocytes; note single thymocytes exhibiting prominent nucleoli and a foamy cytoplasm of variable size (arrows) (lower magnification).

\section{Fig. 2.96A, B Thymic hyperplasia.}

Image-guided (CT) FNAB of a retrosternal tumorous lesion in a 35-year-old man. Direct smears were stained with the Papanicolaou method.

Initial cytologic diagnosis in combination with clinical information was thymic hyperplasia. Tissue diagnosis (subsequent surgical biopsy): Thymus hyperplasia.

A Numerous epithelial cells (arrows) intermingled with lymphocytes (high magnification). B Epithelial thymocytes are highlighted by positive immunostaining for pancytokeratin (Lu5). Negative-staining lymphocytes are seen in the background (note their faint nuclear pseudopositivity) (Pap-prestained specimen).

\section{Fig. 2.97 Thymic cyst.}

Transthoracic FNAB of a voluminous cystic lesion $(10 \mathrm{~cm})$ in the anterior/superior mediastinum of a 5-year-old boy. Sediment preparations from the fluid revealed a sanguineous cystic background together with squamoid cells (arrows and asterisk), lymphocytes, and histiocytes (Pap stain, low magnification).

Cytology suggested a thymic cyst.

Histology: The cytologic diagnosis was confirmed by subsequent histologic examination of the excised tumor mass.

\section{Fig. 2.98 Common type thymoma.}

A 55-year-old man presented with a lesion in the anterior mediastinum; clinical and radiological findings suggested metastatic manifestation of a lung cancer. Image-guided transthoracic FNAB revealed a biphasic pattern comprising lymphocytes (showing deep-staining nuclei) and epithelial cells. The latter exhibit irregularly outlined nuclei, usually blurred nucleoli, and cytoplasmic bodies that are highly variable in size (direct smear, MGG stain, higher magnification). Epithelial thymocytes stained immunocytochemically positive for pancytokeratin Lu-5 (not shown).

Cytologic diagnosis: Thymoma.

Tissue diagnosis (tumor excision): Cortical thymoma. 

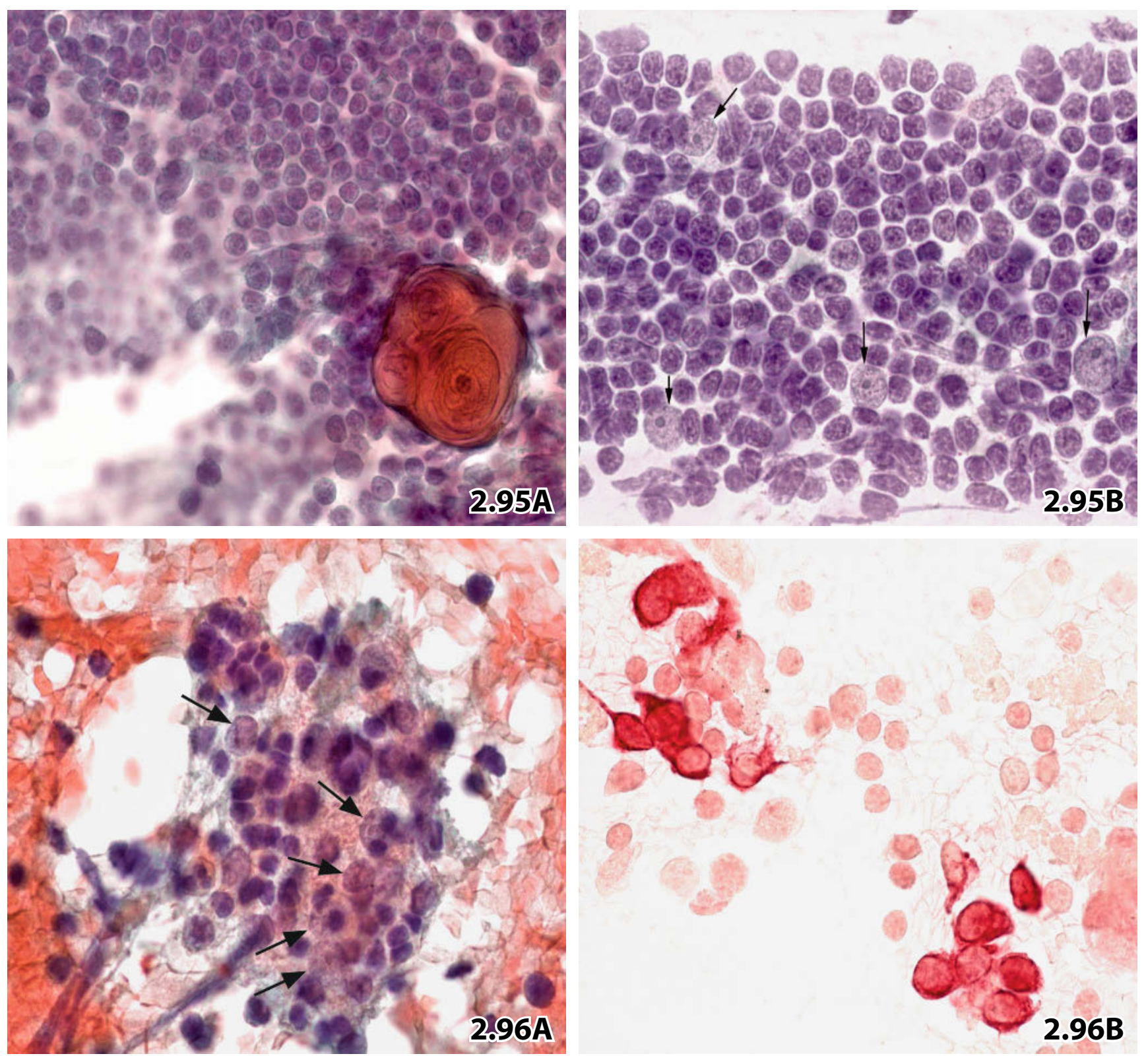

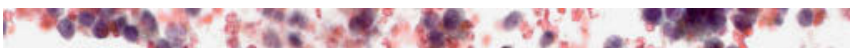

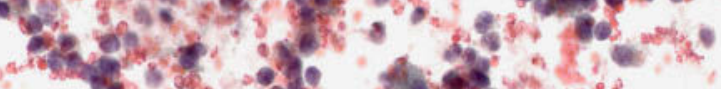
160 of

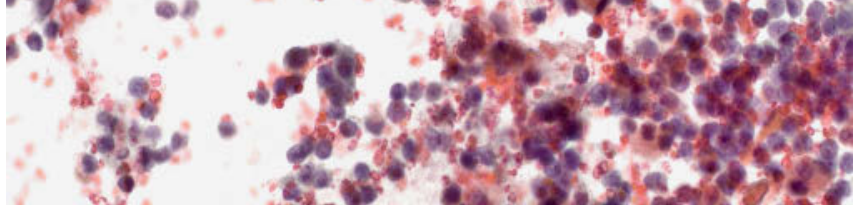

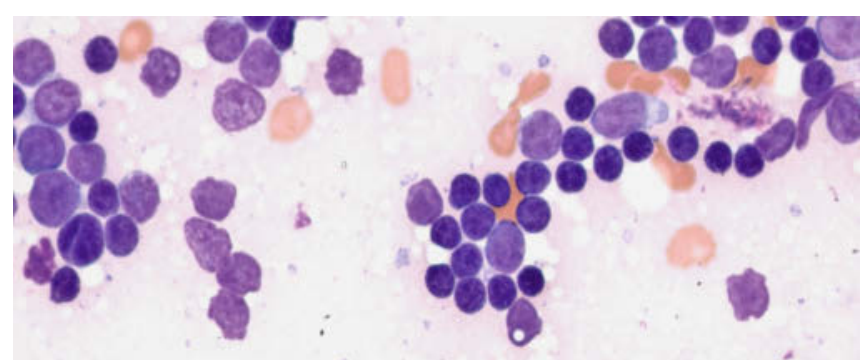

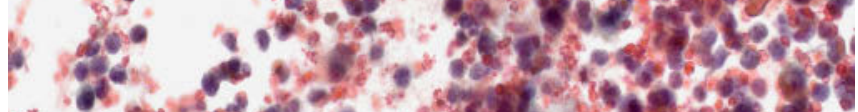
gis.

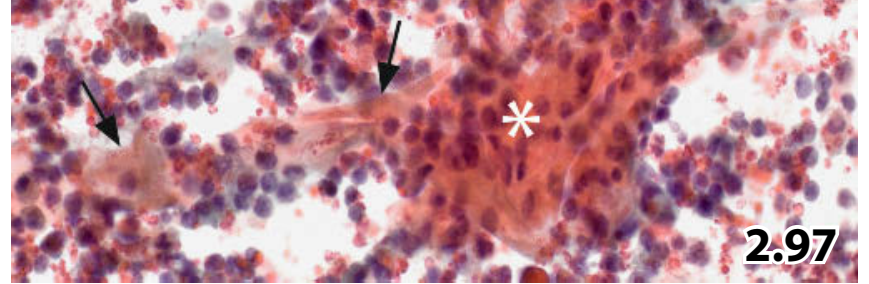

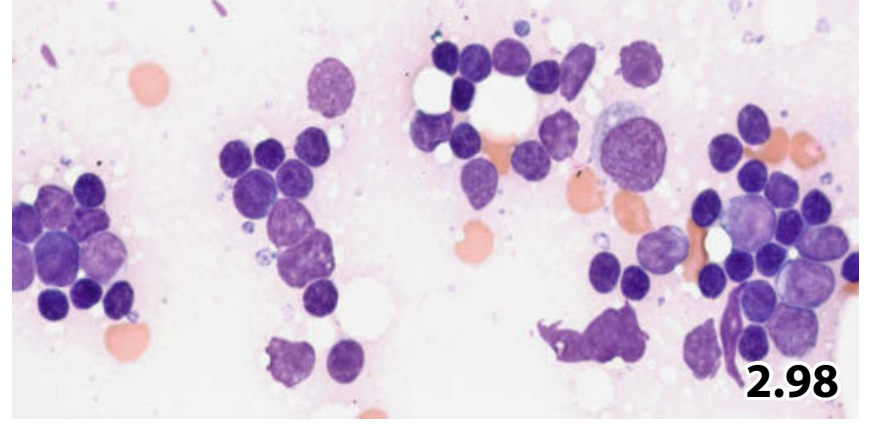


Figs. 2.99 and 2.100 Invasive thymoma.

Two examples refer to cytomorphologic and immunocytochemical features of invasive thymoma.

Fig. 2.99A-E (case \#1) A 71-year-old woman presented with a solid tumor mass in the anterior mediastinal compartment. Endoscopic transtracheal FNAB was performed. Direct smears were Pap-stained. All immunostains were performed using Pap-prestained smears.

Tentative cytologic diagnosis: Morphology and immunocytochemical results suggest invasive thymoma.

Tissue diagnosis (tumor excision): Invasive epithelial thymoma rich in lymphocytes (type B1-2).

A High magnification discloses a predominant epithelioid pattern consistent with epithelial thymocytes. A few lymphoid cells are also present. The irregularly grouped epithelial cells show mild nuclear atypias with varied size, irregular contours, and coarse chromatin. B Epithelioid cells demonstrate strong immunopositivity for pancytokeratin, MNF-116. C Epithelioid cells occasionally showing positivity for CD20. D Note immunoreactivity of the lymphocytes for $\mathrm{CD} 3$, in contrast to negative staining of the epithelial cells (arrows) and histiocytes. E Nuclear immunopositivity for MIB-1 of the thymocytes, indicating high proliferation index. 

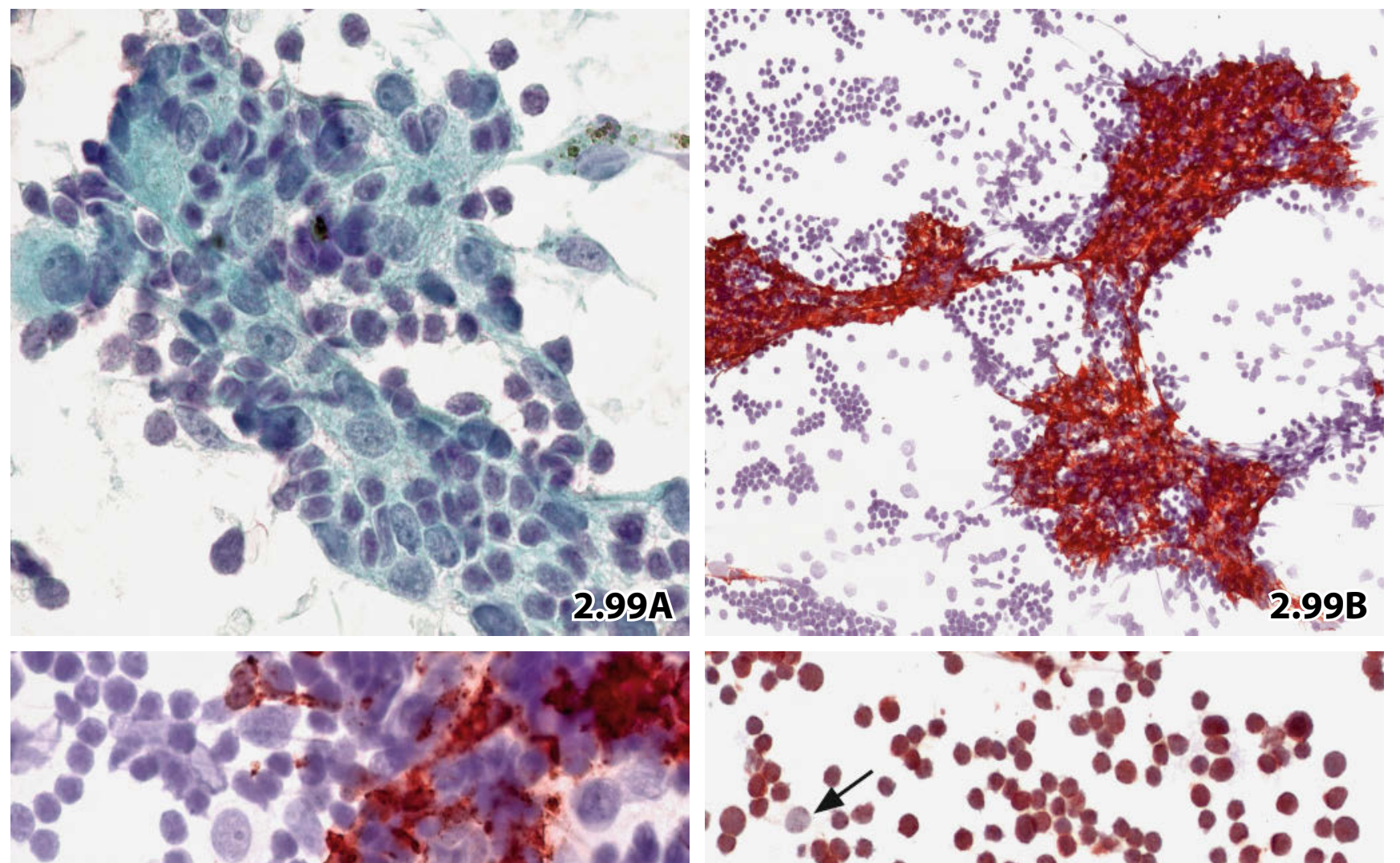

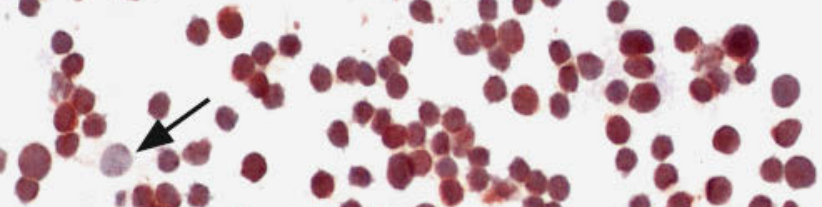
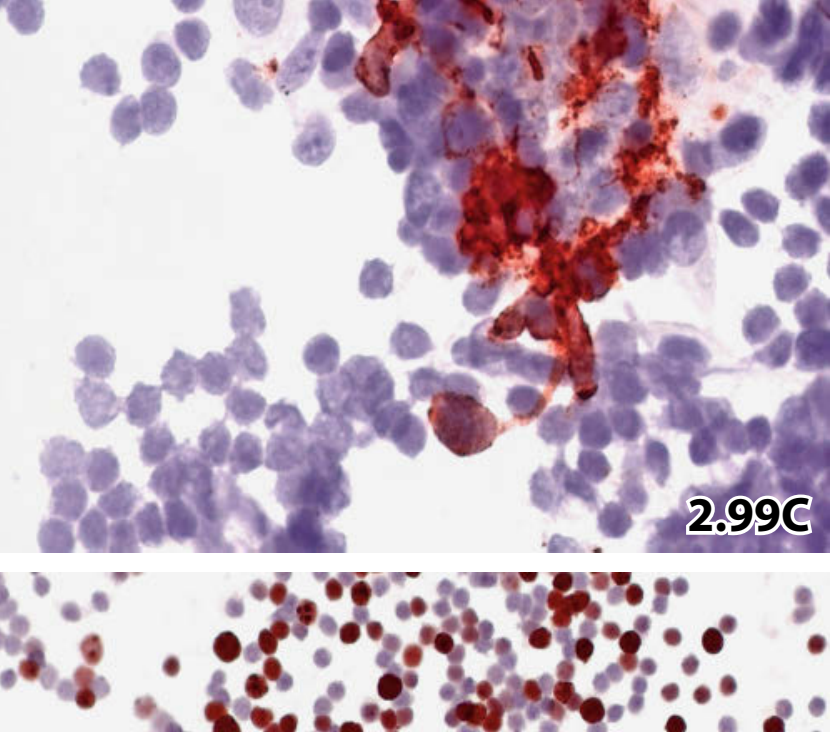

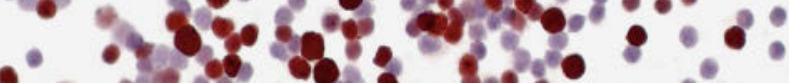

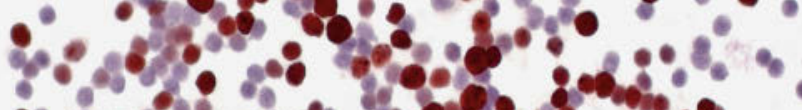

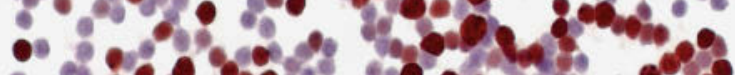

$100^{\circ}$

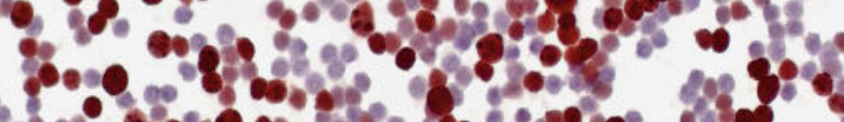

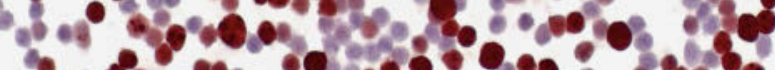

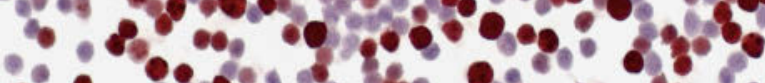

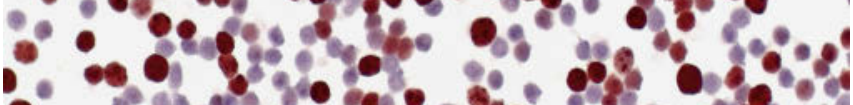

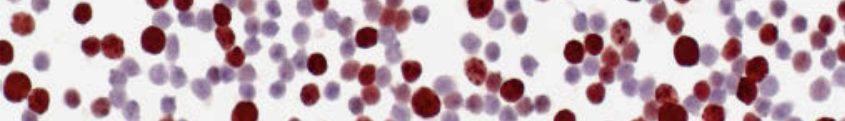

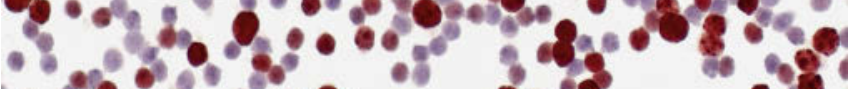
28\% $2.09 \mathrm{E}$ 
Fig. 2.100A, B (case \#2) Another example of invasive thymoma: CT-guided transthoracic FNAB of a mediastinal mass in a 58-year-old woman. Direct smears were Pap-stained.

Cytologic diagnosis: Epithelial spindle-cell thymoma.

Tissue diagnosis: Invasive epithelial thymoma.

A Low magnification reveals bundles and compact clusters of epithelioid thymocytes. The cells of this case exhibit mainly elongated and spindle-shaped cytoplasm. B High magnification: nuclear features are virtually identical compared to those depicted in A. 


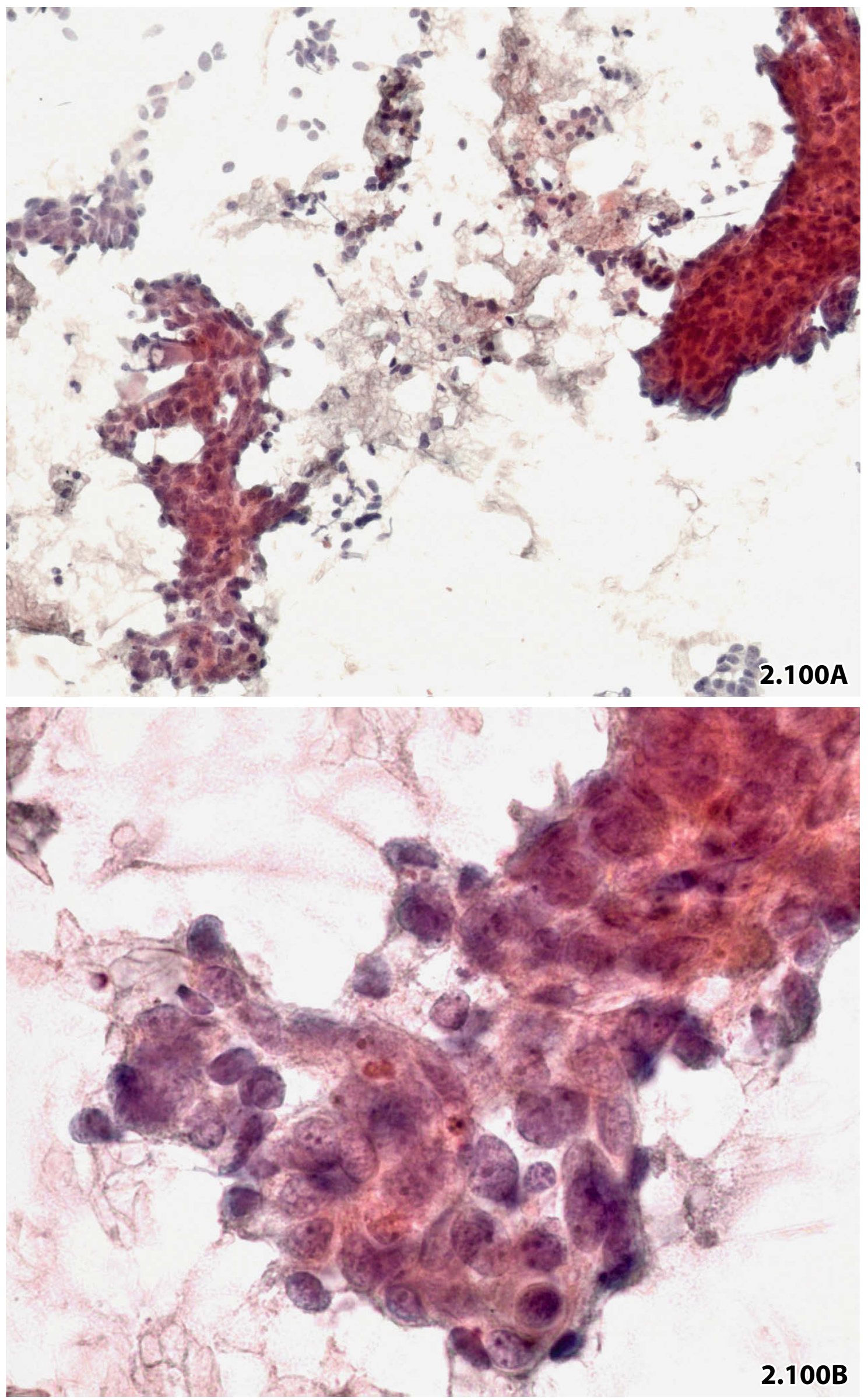


Fig. 2.101 Thymic carcinoma: squamous cell variant.

A 49-year-old man presented with a retrosternal tumor mass (anterior/superior mediastinum) associated with pleural and pericardial effusion. Image-guided transthoracic FNAB was performed. Direct smears were stained using the Papanicolaou procedure. Lower magnification reveals clusters composed of malignant spindle cells together with degenerating keratinized squamous cells in the background (right). Tumor cell nuclei showing dense and thinly dispersed chromatin may indicate thymic cell origin.

Cytology and histology suggested squamous cell carcinoma of thymic origin, a secondary squamoid neoplasia to the mediastinum could not be excluded.

Final diagnosis: Thymic squamous cell carcinoma.

Fig. 2.102 and 2.103 Thymic carcinoid.

Two different patients underwent image-guided transthoracic fine needle aspiration biopsy of a thymic carcinoid. Cytomorphology and diagnostic challenge are discussed.

Fig. 2.102 (case \#1) Dissociated atypical cells exhibiting distinct variation in nuclear and cytoplasmic size (direct smear, MGG stain, high magnification).

Cytology as a first-line diagnostic procedure established a diagnosis of epithelial thymoma, which turned out to be wrong. Absence of lymphocytes, pronounced variation of cell size, occasional plasmacytoid cell appearance (arrows), conspicuous granularity of the cytoplasm, frequent absence of nucleoli, and minor cellular clustering indicate endocrine origin of the neoplastic cells.

Tissue diagnosis (extirpation of the tumor): Thymic carcinoid tumor.

Fig. 2.103 (case \#2) The current case of thymic carcinoid mimics the cytoarchitecture of an undifferentiated small-cell carcinoma (e.g., single-file cell arrangement and dense cell clustering; left). However, the tumor cell sheet (arrow) displays the characteristic features of a neuroendocrine tumors: eccentrically located nuclei, relatively bland nuclear texture, and granular cytoplasm (direct smear, Pap stain, lower magnification).

Cytologic and subsequent histologic diagnosis: Thymic carcinoid.

Fig. 2.104 Embryonal carcinoma.

A 26-year-old man presenting with a voluminous mediastinal mass and nodular lesions in the liver. Transthoracic FNAB reveals the characteristic cumulative cell pattern of embryonal carcinoma: syncytial arrangement of pleomorphic neoplastic cells, abundant cytoplasms showing indistinct borders, variable N/C ratio, and varying nuclear size and shape. The chromatin tends to be coarse and clumped. Occasional prominent nucleoli. Multinucleation is frequent (direct smear, Pap stain, lower magnification). Immunocytochemistry revealed strong expression of pancytokeratin-Lu-5 (not shown).

Cytologic diagnosis: Undifferentiated pleomorphic carcinoma, most likely embryonal carcinoma.

Final diagnosis (extended pneumonectomy including tumor mass and imaging results): Undifferentiated embryonal carcinoma of the mediastinum infiltrating into the right lung, secondary liver tumors.

Fig. 2.105 Hodgkin lymphoma: mixed cellularity.

A 21-year-old man presented with a tumor mass in the anterior superior mediastinal space. Direct smears from a CT-guided transthoracic FNAB disclosed the classical cytologic pattern of mixed cellular variant Hodgkin lymphoma. Note the mixed cellular background (lymphocytes, neutrophils, eosinophils, histiocytes), Reed-Sternberg cells, and Hodgkin cells (MGG stain, lower magnification).

Fig. 2.106 Hodgkin lymphoma: nodular sclerosis.

A 26-year-old woman presented with a mediastinal-parasternal tumor mass with evidence of sternal bone and rib erosion. Image-guided transthoracic FNAB was performed. A direct smear of the paucicellular aspirate was prepared and Pap-stained. Microscopy revealed sporadic HRS cells (one Reed-Sternberg cell is depicted) together with scarce inflammatory background (low magnification). The smear with a paucity of cells may indicate a lesion comprising a high proportion of fibrosclerotic tissue.

Tentative cytologic diagnosis: Malignant lesion comprising giant cells, most likely Hodgkin lymphoma. The FNA specimen is too paucicellular to provide a conclusive diagnosis.

Tissue diagnosis: Hodgkin lymphoma, nodular sclerosis, G1. 

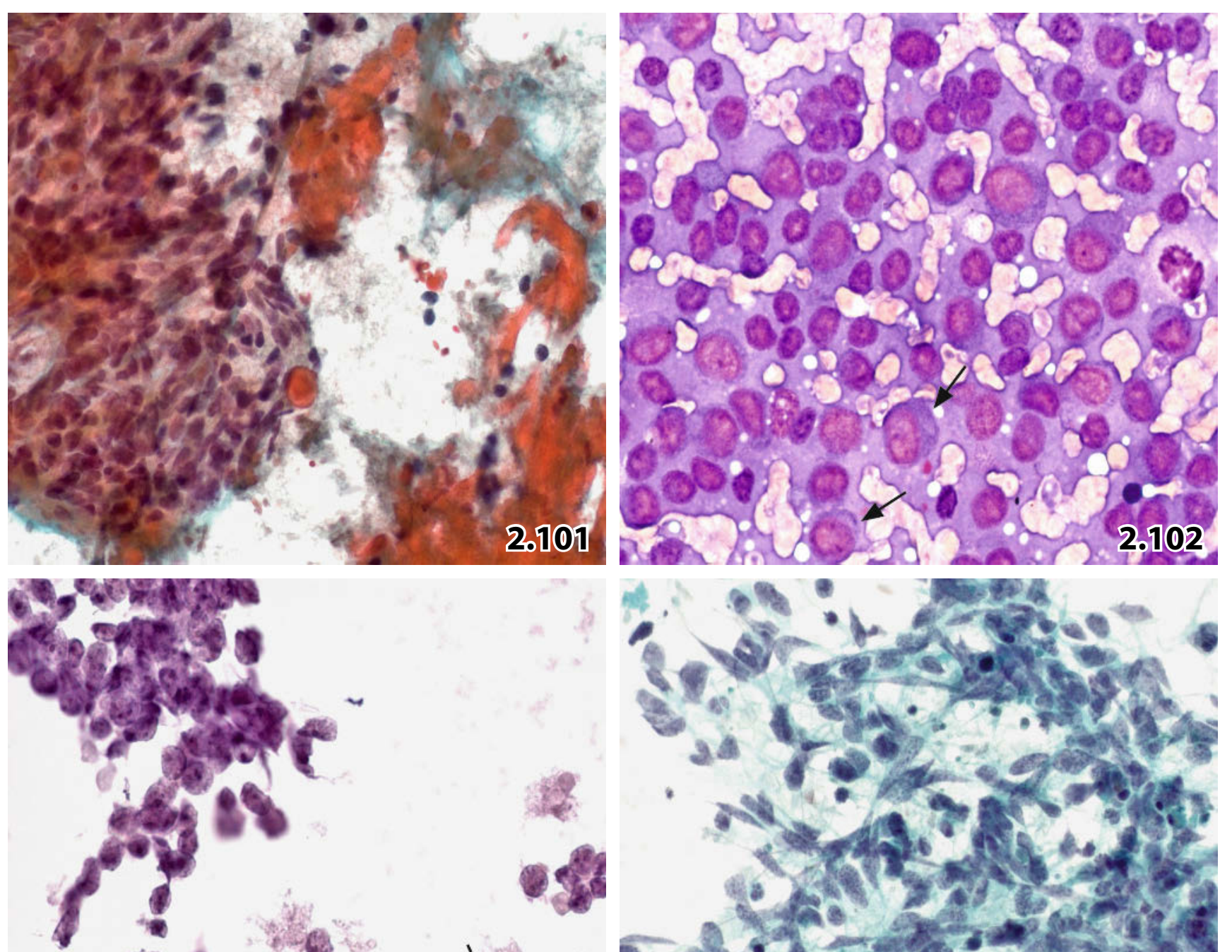

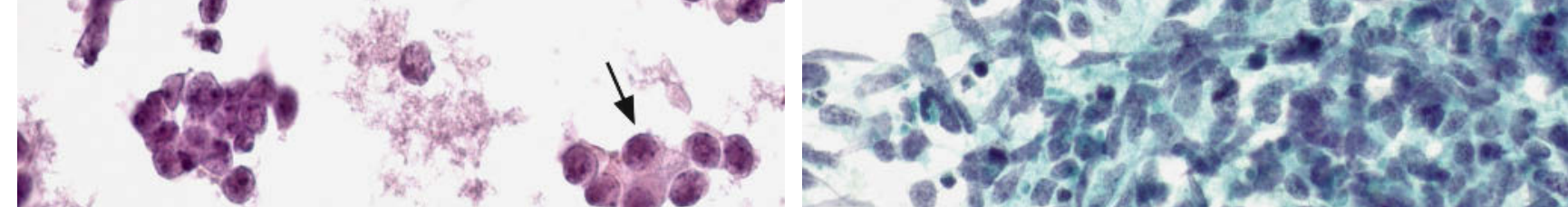

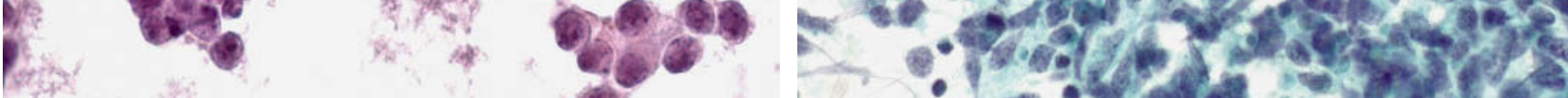

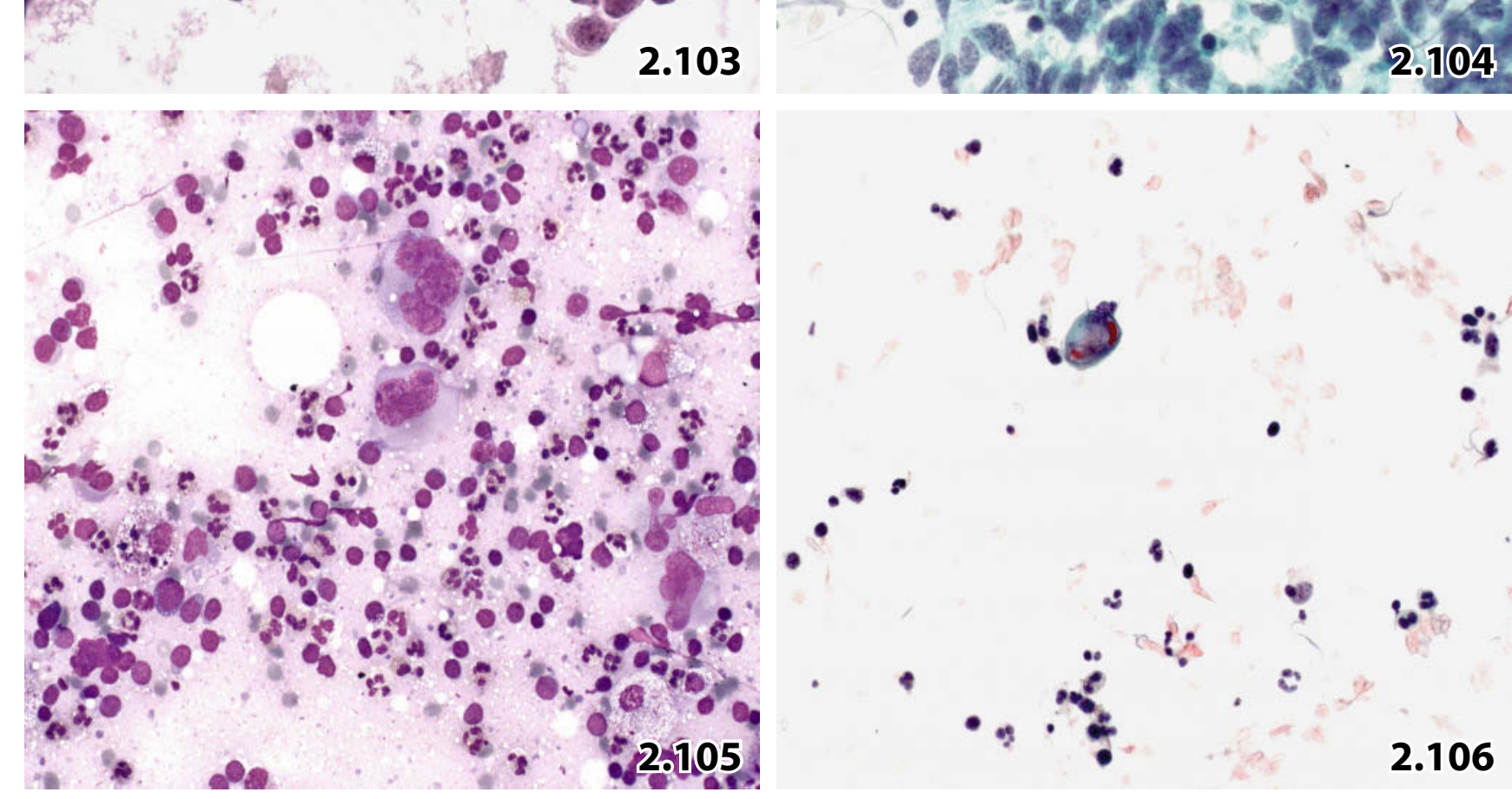




\section{Fig. 2.107 Mediastinal large-cell non-Hodgkin lymphoma.}

Transthoracic FNAB of a mediastinal tumor in a young woman. Direct smears revealed small and large malignant cells sometimes arranged in compact clusters (Pap stain, higher magnification).

Cytology: Differential diagnostic considerations included high-grade malignant lymphoma, poorly differentiated carcinoma, and invasive thymoma (immunocytochemical analyses were not performed for technical reasons).

Histologic diagnosis (surgical biopsy): Highly malignant sclerosing large-cell mediastinal lymphoma of the B-cell phenotype.

\section{Fig. 2.108A, B High-grade follicular non-Hodgkin lymphoma of the mediastinum.}

A transtracheal FNAB was performed in an elderly woman presenting with a mediastinal mass. Imaging and clinical data suggested metastatic lung carcinoma. The sanguineous but paucicellular aspirate was processed by the liquid-based ThinPrep method.

Initial diagnosis by cytology: High-grade non-Hodgkin lymphoma.

Tissue diagnosis: Follicular lymphoma, G2/G3a.

A ThinPrep specimen contains blood and few large individual cells of atypical blast type (Pap stain, lower magnification). B CD45 immunostaining confirmed lymphoid origin of the large atypical cells (ThinPrep preparation, low magnification).

\section{Fig. 2.109 Synovial sarcoma of the mediastinum.}

A 29-year-old man presented with a mediastinal tumor. Transbronchial aspirates were performed, direct smears were Pap-stained. Highly cellular smears revealed a uniform population of medium-sized tumor cells appearing solitary and in compact clusters (lower magnification).

Cytology: The overall cell pattern caused diagnostic dilemma; a tentative cytologic diagnosis of epithelial thymoma was established.

Tissue diagnosis including immunohistochemical investigations: mediastinal synovial sarcoma.

\section{Figs. 2.110 and 2.111 Ganglioneuroblastoma and ganglioneuroma.}

Two tumors of the sympathetic nervous system are demonstrated. Both lesions occurred in young patients ' posterior mediastinum. Image-guided transthoracic FNABs were performed in order to reach an initial morphologic result. Direct smears were Pap-stained.

Fig. 2.110 (case \#1) A 17-year-old woman presented with a tumor in the posterior mediastinum.

Cytologic diagnosis: Ganglioneuroblastoma.

Comment: Aspirates revealed a heterogeneous cellular population consistent with ganglioneuroblastoma (higher magnification):

- Irregularly clustered small cells exhibiting small cytoplasmic rims (bottom) represent neuroblasts.

- Medium-sized cells with eccentric nuclei (arrows) represent differentiating neuroblasts.

- Mature ganglion cells are readily identified by their large nucleoli, and abundant cytoplasm with vague processes (arrowheads).

Tissue diagnosis (extirpation of the tumor): Ganglioneuroma associated with ganglioneuroblastoma.

Fig.2.111 (case \#2) The second patient was a 16-year-old woman.

Cytologic specimens showed mature ganglion cells (lower left) enclosed in bundles of nerve fibers (low magnification).

Cytologic and subsequent histologic diagnosis: Ganglioneuroma. 


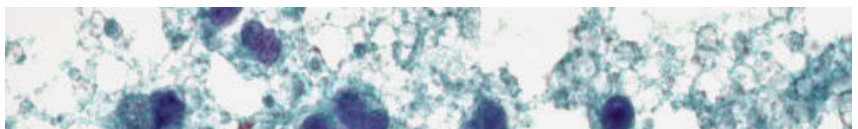

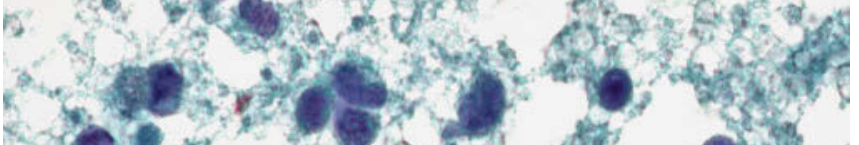

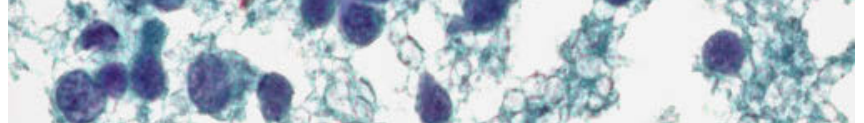

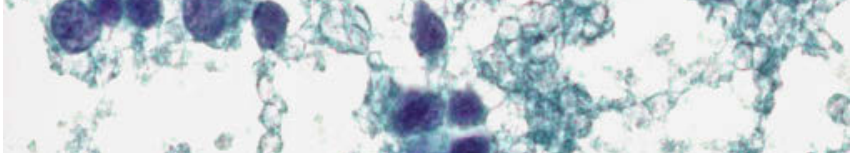

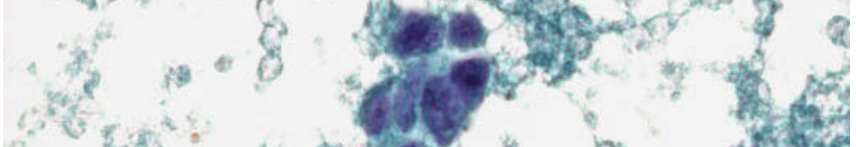

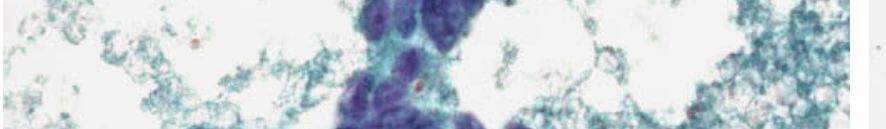

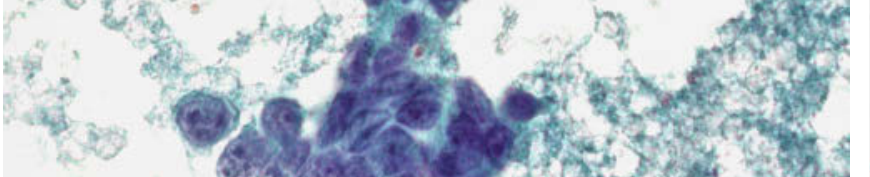

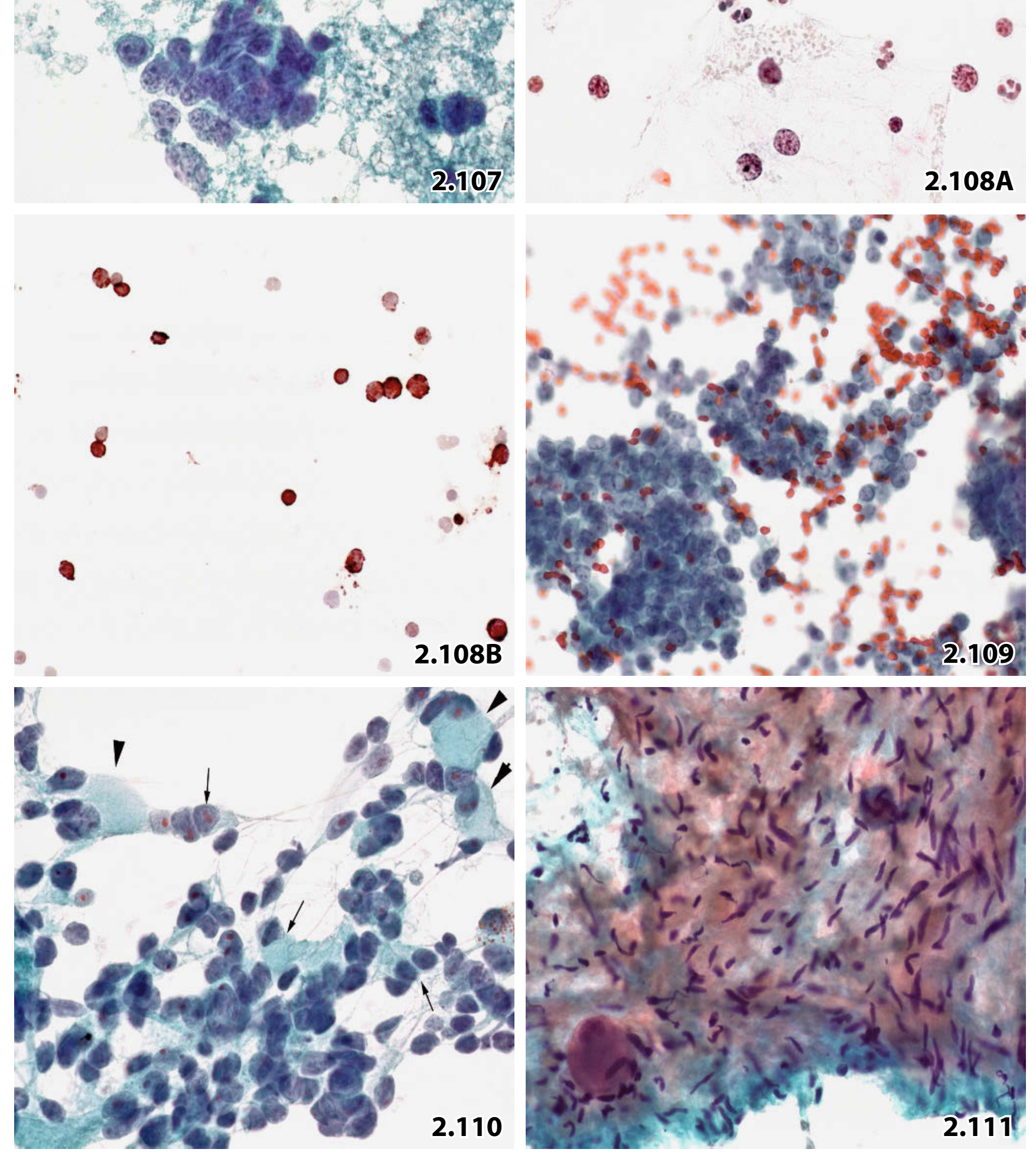


Fig. 2.112A-C Mediastinal metastasis of uncertain clinical assessment.

A transtracheal aspirate from an enlarged mediastinal lymph node in a 74-year-old woman was processed using the cytospin technique.

Cytologic and immunocytochemical diagnosis: Metastatic ovarian carcinoma, serous type (confirmed by postmortem examination).

A Thin-layer specimens contained numerous cells of a poorly differentiated non-small-cell carcinoma (Pap stain, high magnification). B A panel of selected immunocytochemical markers established the aforementioned conclusive diagnosis: strong immunopositivity for CK7. C Positive immunoreaction for CK5/6. Negative immunoreaction for CK20 is not shown.

\section{Fig. 2.113 Transitional cell carcinoma.}

A 63-year-old man with a history of bladder cancer presented with enlarged mediastinal lymph nodes. The sanguineous transtracheal mediastinal aspirates were transferred to a hemolyzing fixative (Cytolyt) and subsequently processed using the cytospin technique. Tumor cells exhibiting polymorphic deep-staining nuclei and squamoid cytoplasm were strong indicators for transitional cell carcinoma (Pap stain, high magnification).

Cytologic diagnosis: Metastatic transitional cell carcinoma. Neither surgical intervention nor histologic examinations were performed.

\section{Fig. 2.114 Small-cell carcinoma of lung.}

A 66-year-old man presented with a nonspecific lung disorder and enlarged mediastinal lymph nodes. The sanguineous transbronchial mediastinal aspirate was transferred to a hemolyzing fixative (Cytolyt) and subsequently processed by cytospin technique.

Liquid-based cytology exhibits characteristic cell arrangement (short single-file rows, arrows), dense granular chromatin, and necrosis, indicating small-cell carcinoma (Pap stain, higher magnification).

Simultaneous bronchial brushing yielded the same diagnosis. No tissue examination.

\section{Fig. 2.115 Adenocarcinoma of lung.}

A 69-year-old man presented with a lung tumor and enlarged paratracheal lymph nodes. Transtracheal aspirates of the lymph nodes were processed using the the cytospin technique. Cytologic findings: Rather monomorphic malignant cells showing large foamy cytoplasm, evenly distributed granular chromatin, and prominent nucleoli. Background with histiocytes and trachea lining epithelial cells (Pap stain, high magnification).

Cytologic and synchronous histologic diagnosis (bronchial biopsy): Poorly differentiated mucinous adenocarcinoma.

Note the cellular shrinking associated with deeply stained nuclei in Figs. 2.112A, 2.114, 2.115. This is an artifact resulting from the liquid-based processing. 


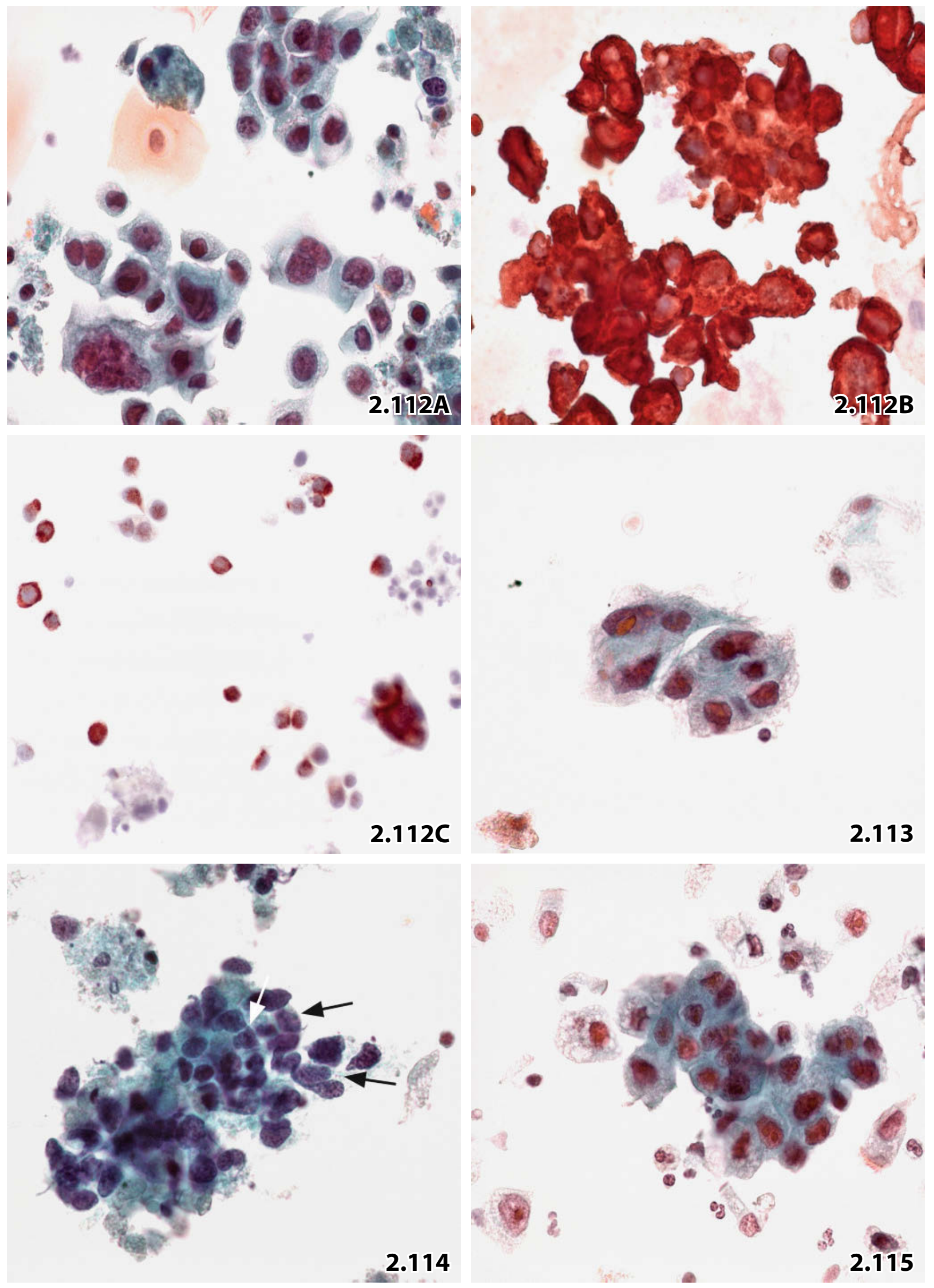

